UNIVERSIDADE DE BRASÍLIA

FACULDADE DE TECNOLOGIA

DEPARTAMENTO DE ENGENHARIA ELÉTRICA

\title{
UMA CONTRIBUIÇÃO PARA O ESTUDO DO DESEQUILÍBRIO DE TENSÃO NOS SISTEMAS ELÉTRICOS DE POTÊNCIA
}

\author{
MARCOS GARCIA DA SILVA PINTO
}

ORIENTADOR: ANÉSIO DE LELES FERREIRA FILHO

PROJETO FINAL DE GRADUAÇÃO EM ENGENHARIA ELÉTRICA

PUBLICAÇÃO: ENE - 1/2006

BRASÍLIA/DF: AGOSTO - 2006 
UNIVERSIDADE DE BRASÍLIA

FACULDADE DE TECNOLOGIA

DEPARTAMENTO DE ENGENHARIA ELÉTRICA

UMA CONTRIBUIÇÃO PARA O ESTUDO DO DESEQUILÍBRIO DE TENSÃO NOS SISTEMAS ELÉTRICOS DE POTÊNCIA.

MARCOS GARCIA DA SILVA PINTO

RELATÓRIO DE PROJETO FINAL SUBMETIDO AO DEPARTAMENTO DE ENGENHARIA ELÉTRICA DA FACULDADE DE TECNOLOGIA DA UNIVERSIDADE DE BRASÍLIA COMO PARTE DOS REQUISÍTOS NECESSÁRIOS PARA A OBTENÇÃO DO GRAU DE ENGENHEIRO ELETRICISTA.

APROVADO POR:

Prof. Anésio de Leles Ferreira Filho, (ENE-UnB)

(Orientador)

Prof. Mauro Moura Severino, (ENE-UnB)

(Examinador Interno)

Prof. Ivan Marques de Toledo Camargo, (ENE-UnB)

(Examinador Interno)

BRASÍLIA/DF, 04 DE AGOSTO DE 2006 


\section{FICHA CATALOGRÁFICA}

PINTO, MARCOS GARCIA DA SILVA

Uma Contribuição para o Estudo do Desequilíbrio de Tensão no Sistema Elétrico de Potência [Distrito Federal] 2006.

xiii, 196p., 210 x 297 mm (ENE/FT/UnB, Engenheiro, Engenharia Elétrica, 2006).

Projeto Final de Graduação - Universidade de Brasília. Faculdade de Tecnologia.

Departamento de Engenharia Elétrica.

$\begin{array}{ll}\text { 1. Desequilíbrio de Tensão } & \text { 2. Quantificação }\end{array}$

$\begin{array}{ll}\text { 3. Qualificação } & \text { 4. Fator K }\end{array}$

$\begin{array}{ll}\text { I. ENE/FT/UnB II. Título (série) } & \text { InB }\end{array}$

\section{REFERÊNCIA BIBLIOGRÁFICA}

GARCIA, M. P. (2006). Uma Contribuição para o Estudo do Desequilíbrio de Tensão nos Sistemas Elétricos de Potência. Projeto Final de Graduação em Engenharia Elétrica, Publicação ENE-1/06, Departamento de Engenharia Elétrica, Universidade de Brasília, Brasília, DF, 198p.

\section{CESSÃO DE DIREITOS}

AUTOR: Marcos Garcia da Silva Pinto. ORIENTADOR: Anésio de Leles Ferreira Filho TÍTULO: Uma Contribuição para o Estudo do Desequilíbrio de Tensão nos Sistemas Elétricos de Potência.

GRAU: Engenheiro $\quad$ ANO: 2006

É concedida à Universidade de Brasília permissão para reproduzir cópias deste relatório de projeto final de graduação e para emprestar ou vender tais cópias somente para propósitos acadêmicos e científicos. $\mathrm{O}$ autor e o orientador reservam outros direitos de publicação e nenhuma parte desse relatório de projeto final de graduação pode ser reproduzida sem autorização por escrito do autor e do orientador.

Marcos Garcia da S. Pinto (AUTOR)

Anésio de Leles Ferreira Filho (ORIENTADOR) 
DEDICATÓRIA

À minha mãe, Eneida. 


\section{AGRADECIMENTOS}

A Deus. "Porque Dele e por meio Dele e para Ele são todas as coisas". Rm.11:36.

Ao meu pai Almir, que tanto amo. À minha mãe por ser meu exemplo e minha motivação. Pelo seu amor e dedicação em prol da minha vida. Aos meus irmãos, Ernani e Mariana, que são parte da razão pela qual me dispus a cumprir essa missão.

Ao Professor Anésio de Leles, cuja orientação diferenciada me permitiu ter o gosto pela academia. Pela sua dedicação à nossa pesquisa e pelas oportunidades oferecidas. Pela amizade e compreensão.

Ao Professor Marco de Oliveira por estar sempre disposto a ajudar e a propiciar o necessário para o bom curso da pesquisa. Pelas oportunidades concedidas.

Ao Professor Mauro Moura. Certamente um dos profissionais mais coerentes que já conheci. Pela qualidade de seus ensinamentos.

Ao engenheiro Dr. Fritz Walter Mohn pelo muito que com ele aprendi.

Ao Professor Assis pelo apoio, sempre que necessário.

Aos Professores Damasceno e Ivan pelas matérias ministradas que trouxeram a base dos estudos de Sistemas de Potência.

Aos amigos de graduação com quem vivi momentos inesquecíveis. Ao amigo Thompson Rolim, parceiro de muitas batalhas. 


\section{SUMÁRIO}

\section{Capítulo 1 - INTRODUÇÃO}

1.1 Aspectos Gerais .1

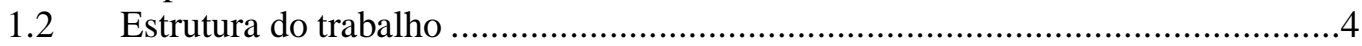

\section{Capítulo 2 - A QUALIDADE DA ENERGIA E SEUS PRINCIPAIS DISTÚRBIOS}

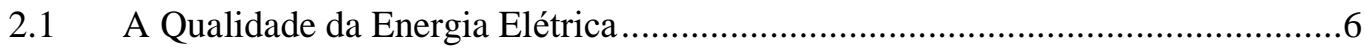

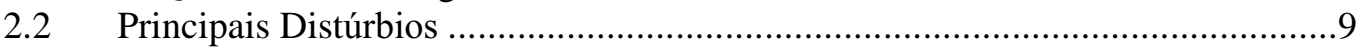

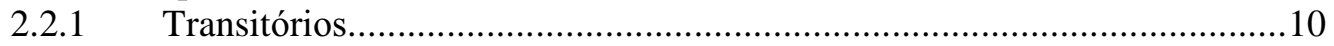

2.2.2 Variação de Tensão de Curta Duração (VTCD).........................................11

2.2.3 Variação de Tensão de Longa Duração (VTLD) ..........................................12

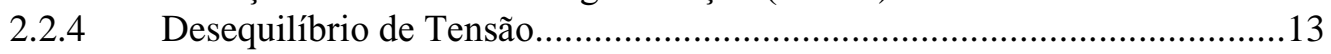

2.2.5 Distorções da Forma de Onda ............................................................13

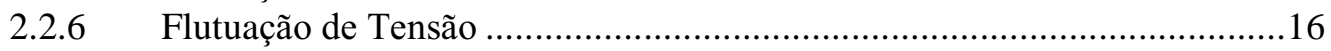

2.2.7 Variação de Freqüência...........................................................................16

\section{Capítulo 3 - DESEQUILÍBRIO DE TENSÃO}

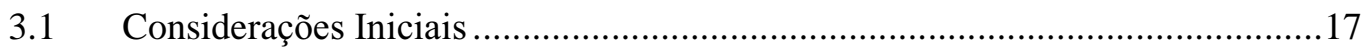

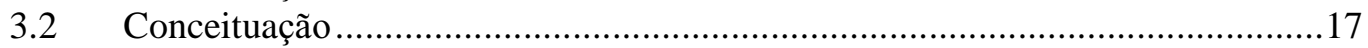

3.3 Métodos de Cálculo do Desequilíbrio de Tensão..............................................18

3.3.1 Método 1 - Componentes Simétricas........................................................19

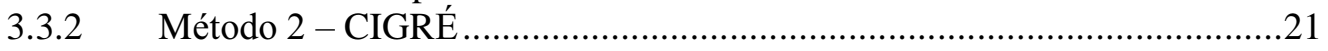

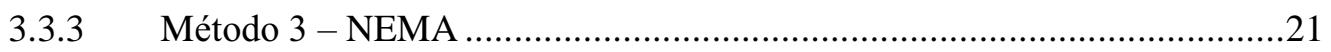

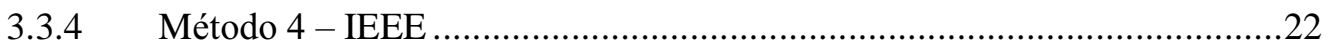

3.4 Principais Causas dos Desequilíbrios de Tensão .............................................22

3.5 Principais Efeitos dos Desequilíbrios de Tensão ….........................................24

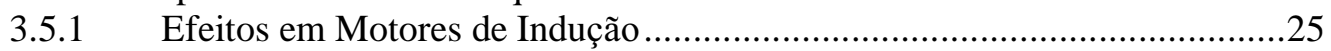

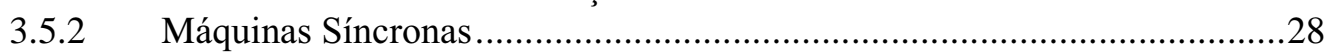

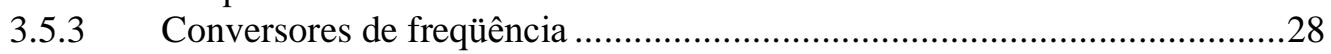

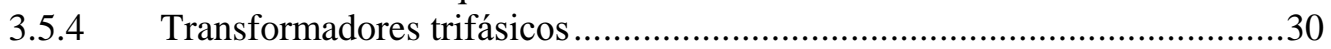

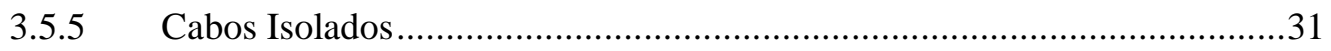

3.5.6 Relés de Proteção Microprocessados............................................................33

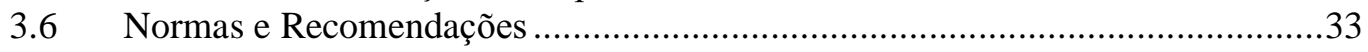

3.6.1 IEC - International Electrotechnical Commission .....................................35

3.6.2 CENELEC - European Committee for Electrotechnical Standardization..35

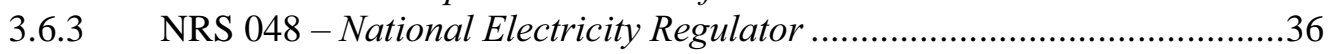

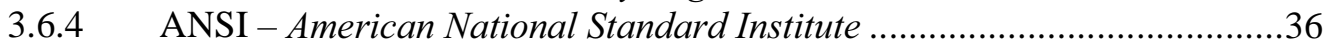

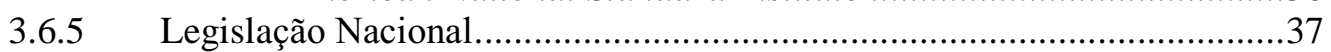

3.6.5.1 Procedimentos de Rede - Submódulo 2.2 ................................................38

3.6.5.2 PRODIST - Procedimentos de Rede - Módulo 8 ......................................39

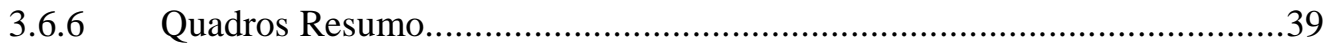




\section{Capítulo 4 - FERRAMENTA COMPUTACIONAL}

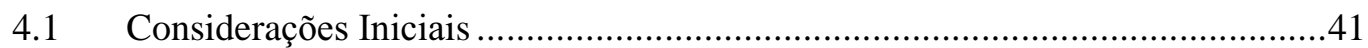

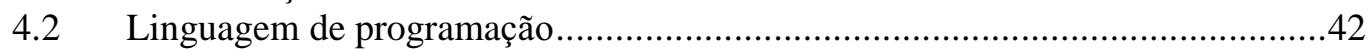

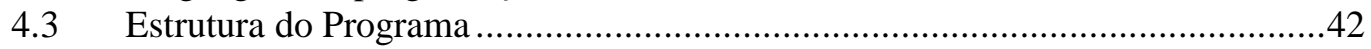

4.4 Conceitos estatísticos presentes na ferramenta computacional...........................44

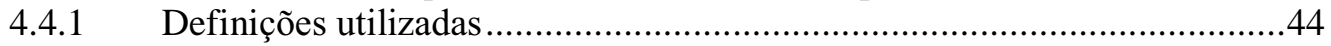

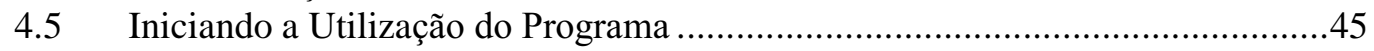

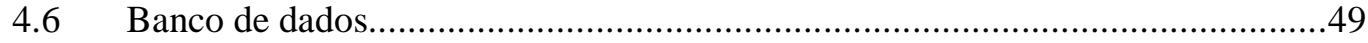

4.7 Apresentação da Ferramenta neste Trabalho ....................................................51

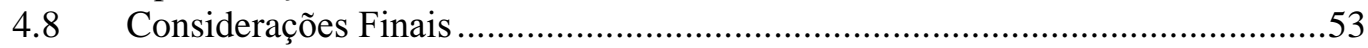

\section{Capítulo 5 - QUANTIFICAÇÃO DO DESEQUILÍBRIO DE TENSÃO - CÁLCULO DO FATOR K E COMPARAÇÃO ENTRE MÉTODOS}

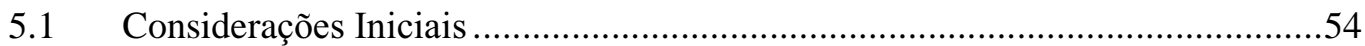

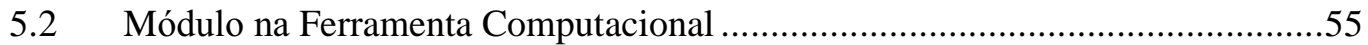

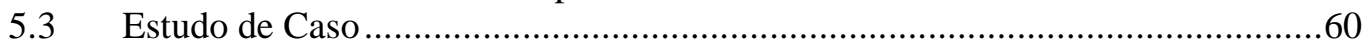

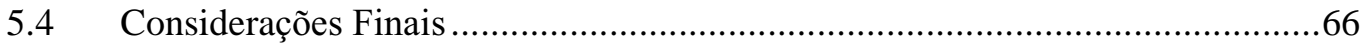

\section{Capítulo 6 - SENSIBILIDADE DO FATOR DE DESEQUILÍBRIO DE TENSÃO ÀS VARIAÇÕES NOS ÂNGULOS E MAGNITUDES DAS TENSÕES}

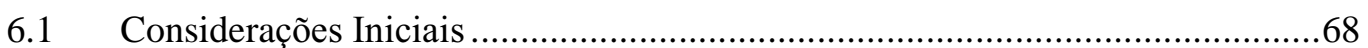

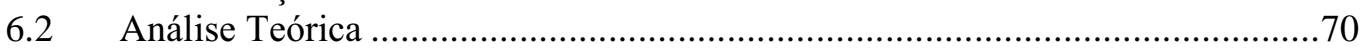

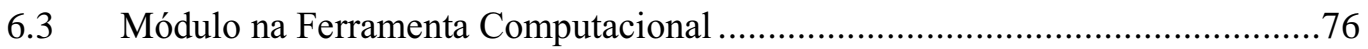

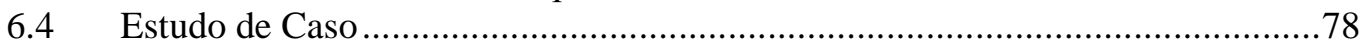

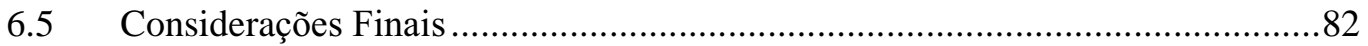

\section{Capítulo 7 - ANÁLISE DOS FASORES}

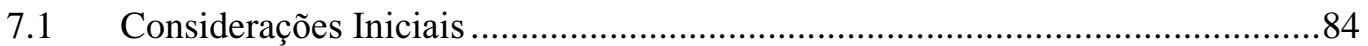

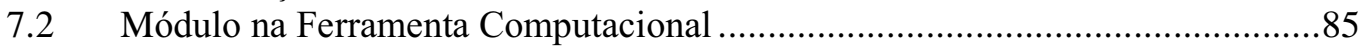

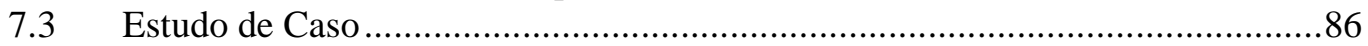

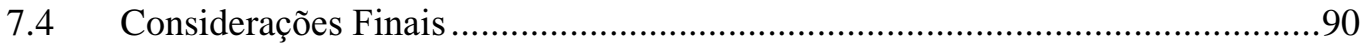

\section{Capítulo 8 - SIMILARIDADE ENTRE DIAS E ENTRE PERÍODOS DO DIA}

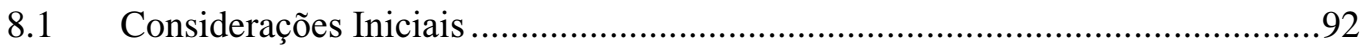

8.2 Módulo na Ferramenta Computacional para Similaridade entre Dias .................92

8.3 Módulo na Ferramenta Computacional para Similaridade entre Períodos ...........93

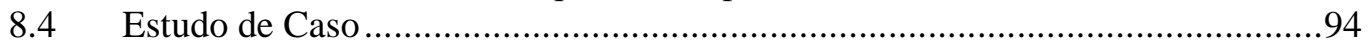

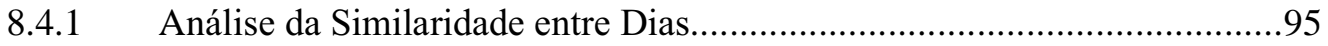

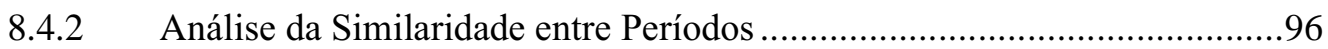

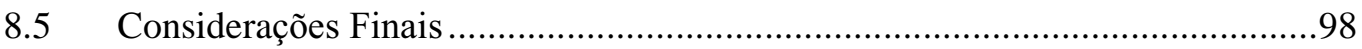




\section{Capítulo 9 - ANÁLISE DA DISTRIBUIÇÃO NO TEMPO DOS NÍVEIS DE DESEQUILÍBRIO DE TENSÃO}

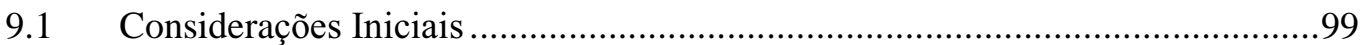

9.2 Módulo na Ferramenta Computacional ……...................................................99

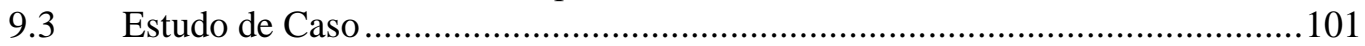

9.3.1 Análise considerando-se o valor de média quadrática como referência....102

9.3.2 Análise considerando-se o valor de P95\% como referência ......................105

9.3.3 Análise considerando-se o valor de P99\% como referência .....................109

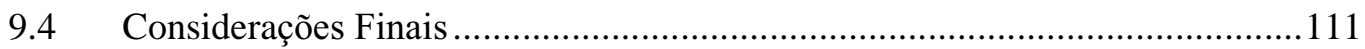

\section{Capítulo 10 - ANÁLISE DA CARGA}

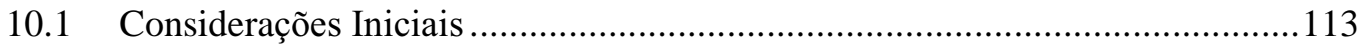

10.2 Módulo na Ferramenta Computacional ........................................................113

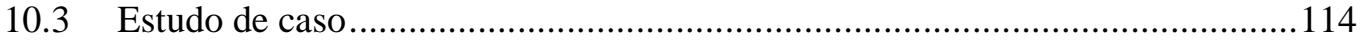

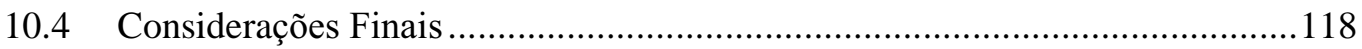

\section{Capítulo 11 - ANÁLISE DA FREQUÊNCIA DE AQUISIÇÃO DOS DADOS}

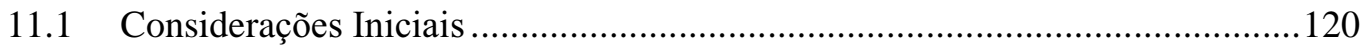

11.2 Módulo na Ferramenta Computacional …….................................................121

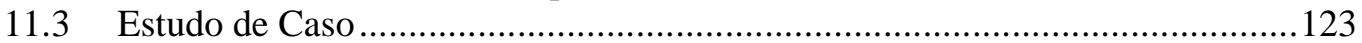

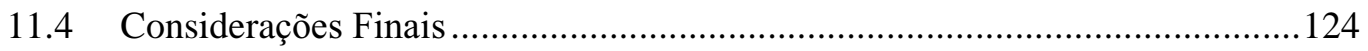

\section{Capítulo 12 - QUALIFICAÇÃO DO DESEQUILÍBRIO}

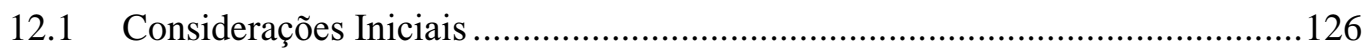

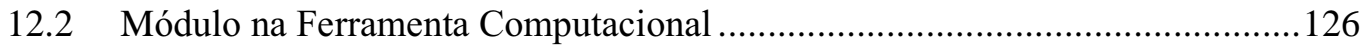

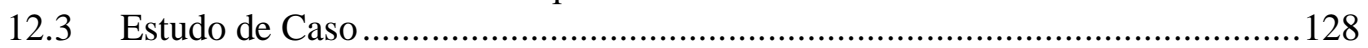

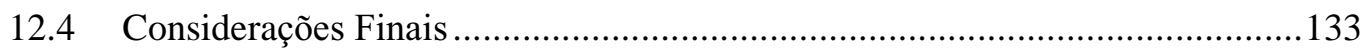

\section{Capítulo 13 - CONCLUSÕES GERAIS}

13.1 Conclusões Gerais

\section{APENDICES}

A - SBQEE - Seminário Brasileiro sobre a Qualidade da Energia Elétrica, 21 a 24 de Agosto de 2005. "Ferramenta Computacional para Quantificação e Qualificação dos Desequilíbrios de Tensão". 
B - T\&D - Transmission and Distribution Conference and Exposition Latin America, 15 a 18 de Agosto de 2005, Caracas, Venezuela, 2006. "A Computational Tool to Analyze, Quantify and Classifying Voltage Imbalance in Electrical Power Systems". 150

C $-2^{\circ}$ Congresso de Iniciação Científica do DF e XI Congresso de Iniciação Científica da UnB, 23 a 26 de Agosto de 2005. Resumo - "Quantificação e Qualificação dos Desequilíbrios de Tensão". $3^{\circ}$ Congresso de Iniciação Científica do DF e XII Congresso de Iniciação Científica da UnB, 12 a 15 de Setembro de 2006. Resumo - "Monitoramento dos Desequilíbrios de Tensão em Cargas com Perfil Comercial".

D - CIDEL - International Congress on Electricity Distribution, de 27 a 29 de novembro de 2006, Buenos Aires, Argentina. "Análise da Sensibilidade do Desequilibrio de Tensão frente a Variações nos Ángulos e Magnitudes das Tensões".

E - SEPOPE - X Simpósio de Especialistas em Planejamento da Operação e Expansão Elétrica, 21 a 25 de maio de 2006, Florianópolis, Brasil. "Análise dos Desequilíbrios de Tensão no Sistema ELETRONORTE Subestações em $230 \mathrm{kV}$ "

F - CIDEL - International Congress on Electricity Distribution, de 27 a 29 de novembro de 2006, Buenos Aires, Argentina. "Monitoramento dos Desequilíbrios de Tensão em Cargas com Perfil Industrial"..... 182

G - ICHQP - International Conference on Harmonics and Quality of Power, 1 a 5 de Outubro de 2006, Cascais, Portugal. "Comparative Analysis Among Indexes Related to Quantifying Voltage Imbalance". 190 


\section{LISTA DE TABELAS}

Tabela 2.1 - Principais distúrbios que afetam a qualidade da energia...............................9

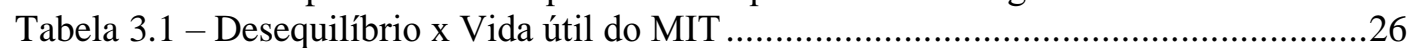

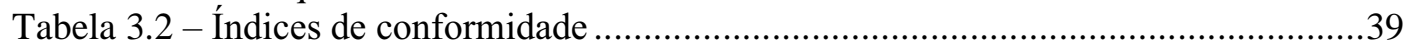

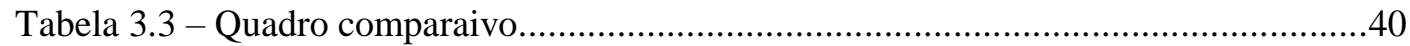

Tabela 4.1 - Características do Banco de Dados..................................................................53

Tabela 5.1 - Estatísticas dos valores de desequilíbrio (Componentes Simétricas) .............61

Tabela 5.2 - Estatísticas dos valores de desequilíbrio pelos 4 métodos .............................62

Tabela 5.3 - Diferenças entre métodos em valores absolutos de K (Ref.: Comp. Sim.)....65

Tabela 5.4 - Diferenças entre métodos em porcentagem (Ref.: Componentes Simétricas) 65

Tabela 6.1- Alguns valores encontrados nas simulações da Fig. 6.3 ….............................72

Tabela 6.2 - Alguns valores encontrados nas simulações da Fig. 6.6 ................................75

Tabela 6.3 - Estatística das análises individuais das magnitudes e ângulos.......................79

Tabela 6.4 - Estatísticas das análises individuais das fases .............................................82

Tabela 7.1 - Estatísticas dos valores das magnitudes das tensões de fase..........................86

Tabela 7.2 - Estatísticas dos valores das magnitudes das tensões de fase.........................87

Tabela 7.3 - Estatísticas das magnitudes das componentes simétricas ..............................89

Tabela 8.1 - Estatísticas dos valores de desequilíbrio para os sete dias............................95

Tabela 8.2 - Estatísticas dos valores de desequilíbrio para o dia $04 / 06 \ldots \ldots \ldots \ldots \ldots \ldots \ldots \ldots \ldots \ldots . . . . .97$

Tabela 9.1 - Resultados das análise considerando todos os índices................................102

Tabela 10.1 - Estatísticas das correntes de linha..........................................................115

Tabela 10.2 - Estatísticas das tensões de linha ............................................................117

Tabela 10.3 - Estatísticas das potências ativa, reativa e aparente....................................117

Tabela 11.1 - Estatísticas dos valores de fator K para cada freqüência de aquisição ........123

Tabela 12.1 - Metodologia da norma/recomendação e resultados da comparação com o valor limite. 


\section{LISTA DE FIGURAS}

Figura 2.1 - crescimento do uso de cargas eletrônicas nos EUA …................................... Figura 2.2 - Custos associados a interrupções com duração de até um minuto (EUA) ........8

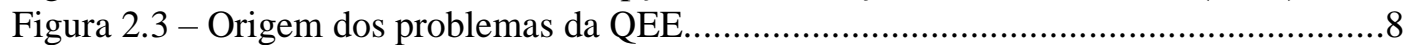

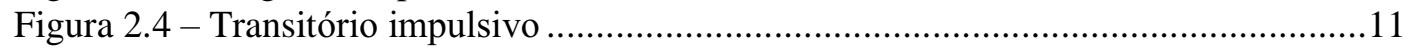

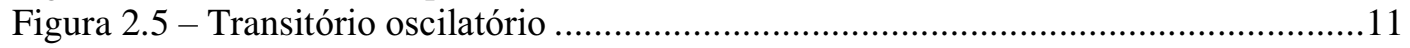

Figura 2.6 - Variação de Tensão de Curta Duração .........................................................12

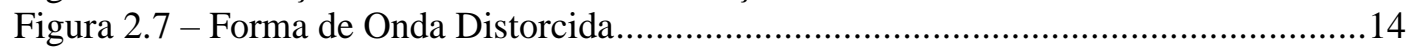

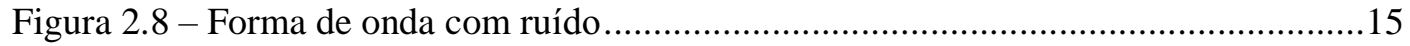

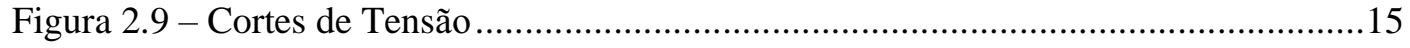

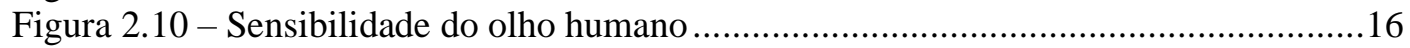

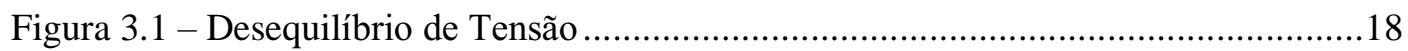

Figura 3.2 - Diagrama fasorial das componentes simétricas de um sistema trifásico.........19

Figura 3.3 - Custos Adicionais Anuais de Um Sistema Industrial de Pequeno Porte.........25

Figura 3.4 - Elevação da temperatura em função do desequilíbrio de tensão e corrente ....27

Figura 3.5 - Expectativa de vida em função da temperatura dos enrolamentos .................27

Figura 3.6 - Elevação das perdas em função do desequilíbrio de tensão ..............................28

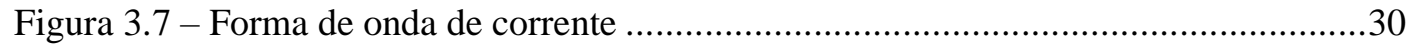

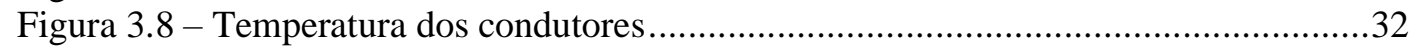

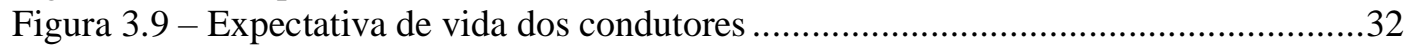

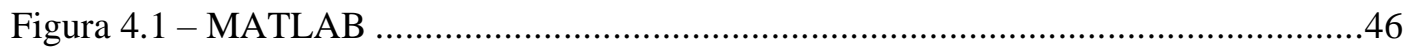

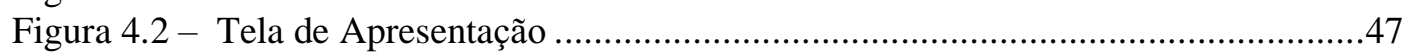

Figura 4.3 - Tela de descrição dos tópicos de análise ....................................................4

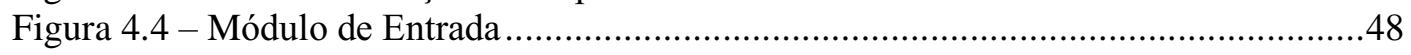

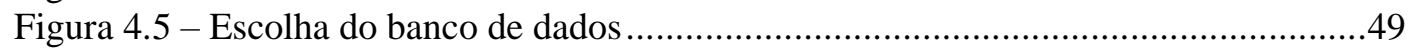

Figura 4.6 - Mensagem confirmando a leitura dos dados pelo aplicativo.........................49

Figura 4.7 - Planilha contendo dados de medição ............................................................51

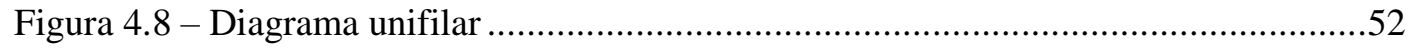

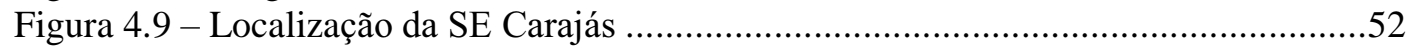

Figura 5.1 - Módulo de Quantificação do Desequilíbrio......................................................55

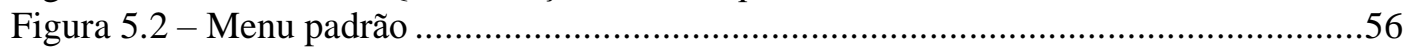

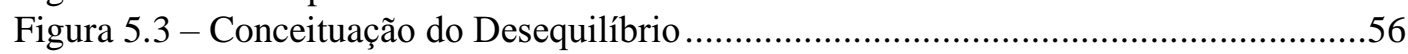

Figura 5.4- Quantificação do Desequilíbrio - Análise Gráfica ........................................57

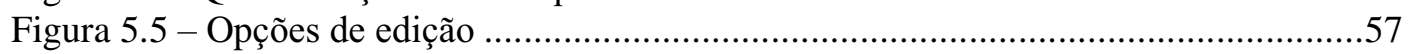

Figura 5.6 - Submódulo de Comparação entre Métodos....................................................58

Figura 5.7 - Cálculo das Diferenças entre Métodos .......................................................60

Figura 5.8 - Estatísticas dos valores de desequilíbrio (Componentes Simétricas) .............61

Figura 5.9 - Fator K versus período de medição.................................................................62

Figura 5.10 - Estatísticas dos valores de desequilíbrio pelos 4 métodos ...........................63

Figura 5.11 - Fator K versus período de medição, a partir dos 4 métodos ..........................63

Figura 5.12 - Fator K versus período de medição, a partir dos 4 métodos (dia 09/06) .......64

Figura 5.13 - Diferenças entre métodos (Ref.: Componentes Simétricas) .........................65

Figura 5.14 - Diferenças entre métodos em porcentagem (Ref.: Componentes Sim.) ........66 
Figura 6.1 - Desequilíbrio considerando variação na magnitude de uma fase

Figura 6.2 - Desequilíbrio considerando variação no ângulo de uma fase.........................71

Figura 6.3 - Desequilíbrio considerando variação conjunta na amplitude e no ângulo de uma fase

Figura 6.4 - Desequilíbrio considerando variação na magnitude de duas fases ..................74

Figura 6.5 - Desequilíbrio considerando variação na magnitude de duas fases ...................74

Figura 6.6 - Desequilíbrio considerando variação conjunta na amplitude e no ângulo de duas fases

Figura 6.7 - Tela do módulo na ferramenta computacional ........................................77

Figura 6.8 - Desequilíbrio considerando apenas os valores de amplitude medidos e ângulos ideais.

Figura 6.9 - Desequilíbrio considerando apenas os valores de ângulo medidos e amplitudes

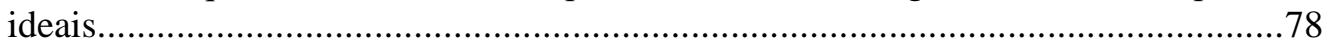

Figura 6.10 - Zoom do gráfico do K considerando os valores medidos dos ângulos ..........80

Figura 6.11 - Desequilíbrio considerando os valores medidos da fase A (ângulo e

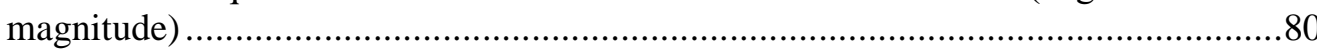

Figura 6.12 - Desequilíbrio considerando os valores medidos da fase B (ângulo e magnitude)

Figura 6.13 - Desequilíbrio considerando os valores medidos da fase C (ângulo e magnitude)

Figura 6.14 - Estatísticas dos desequilíbrios individuais por cada fase ............................81

Figura 7.1 - Tela do módulo na ferramenta computacional ............................................85

Figura 7.2 - Estatísticas dos valores das magnitudes das tensões de fase .........................86

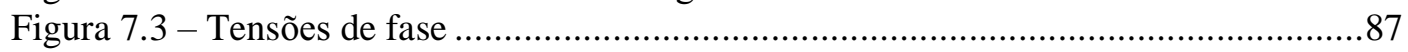

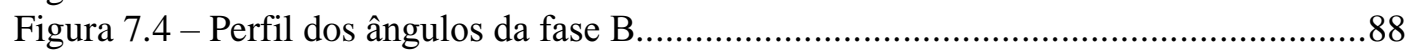

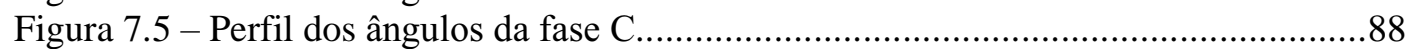

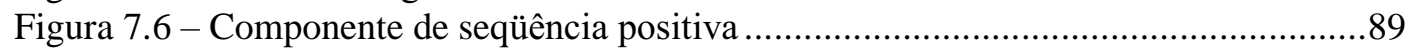

Figura 7.7 - Componente de seqüência negativa ..........................................................90

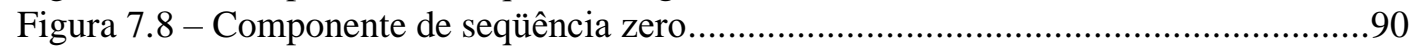

Figura 8.1 - Tela do módulo da ferramenta computacional ............................................93

Figura 8.2 - Tela do módulo da ferramenta computacional ...............................................94

Figura 8.3 - Perfis do desequilíbrio durante os dias de medição ......................................95

Figura 8.4 - Estatísticas dos valores de desequilíbrio para os sete dias ..............................96

Figura 8.5 - Similaridade entre períodos do dia 04/06 _................................................97

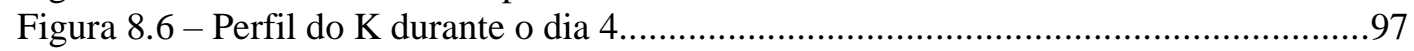

Figura 9.1 - Tela do módulo da ferramenta computacional ............................................101

Figura 9.2 - Valores com $\mathrm{K} \geq 0,2808 \%$ versus tempo total de medição em minutos ..........103

Figura 9.3 - Intervalos ininterruptos de tempo com valores com C\% …..........................103

Figura 9.4 - Intervalos ininterruptos de tempo com valores de $K<0,2808$.......................104

Figura 9.5 - Probabilidades de ocorrência dos intervalos ininterruptos de tempo com

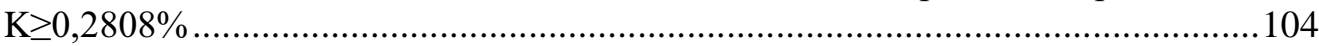

Figura 9.6 - Probabilidades de ocorrência dos intervalos ininterruptos de tempo com

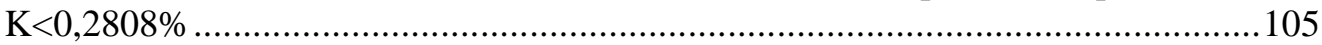

Figura 9.7 - Valores com $\mathrm{K} \geq 0,3807 \%$ versus tempo total de medição em minutos .........106

Figura 9.8 - Intervalos ininterruptos de tempo com valores com $\mathrm{K} \geq 0,3807 \%$..................106

Figura 9.9 - Intervalos ininterruptos de tempo com valores de $K<0,3807$.....................107 
Figura 9.10 - Probabilidades de ocorrência dos intervalos ininterruptos de tempo com

$\mathrm{K} \geq 0,3807 \%$

Figura 9.11 - Probabilidades de ocorrência dos intervalos ininterruptos de tempo com

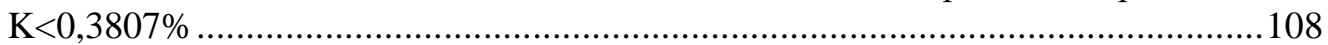

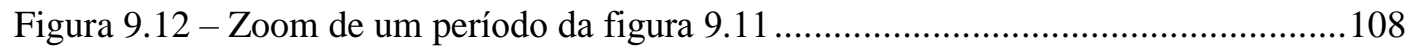

Figura 9.13 - Valores com $\mathrm{K} \geq 0,4029 \%$ versus tempo total de medição em minutos .......109

Figura 9.14 - Intervalos ininterruptos de tempo com valores com $\mathrm{K} \geq 0,4029 \%$...............109

Figura 9.15 - Intervalos ininterruptos de tempo com valores de $K<0,4029$....................110

Figura 9.16 - Probabilidades de ocorrência dos intervalos ininterruptos de tempo com

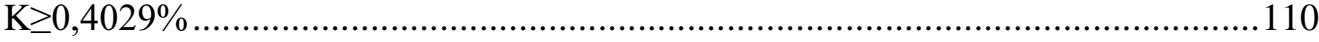

Figura 9.17 - Probabilidades de ocorrência dos intervalos ininterruptos de tempo com

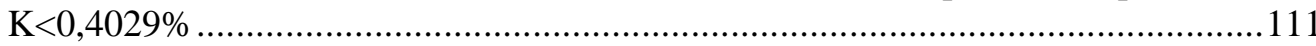

Figura 10.1 - Tela do módulo da ferramenta computacional .........................................114

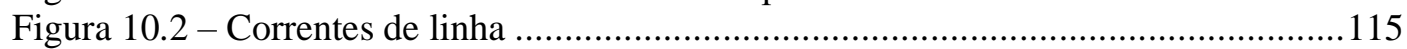

Figura 10.3 - Estatísticas das correntes de linha ........................................................116

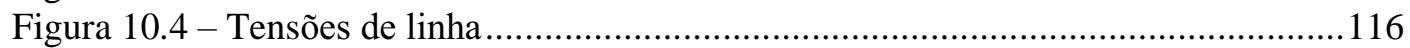

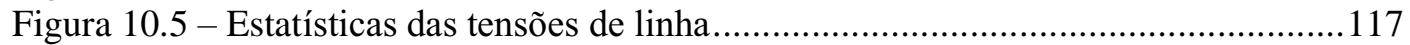

Figura 10.6 - Potências ativa, reativa e aparente .........................................................118

Figura 11.1 - Tela do módulo da ferramenta computacional .........................................122

Figura 11.2 - Estatísticas dos valores de fator K para cada freqüência de aquisição .........123

Figura 11.3 - Perfil do desequilíbrio para diferentes freqüências de aquisição..................124

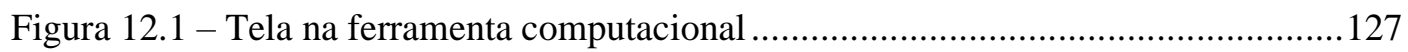

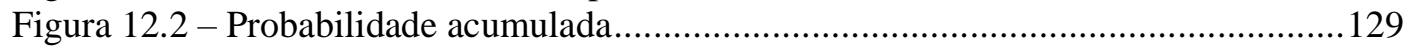

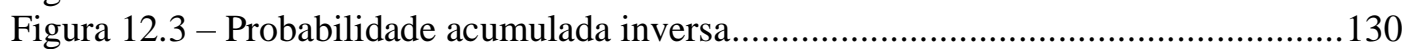

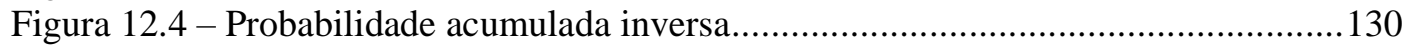

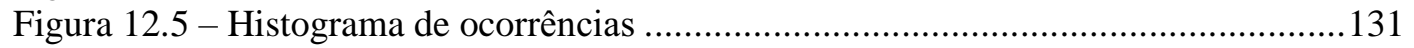

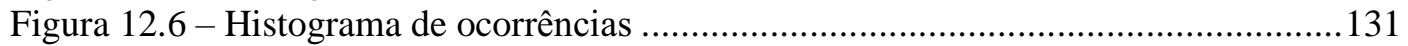

Figura 12.7 - Probabilidade acumulada e histograma de ocorrências normalizado...........132

Figura 12.8 - Distribuição de probabilidade .................................................................132 


\section{Capítulo 1}

\section{Introdução}

\subsection{Aspectos Gerais}

O setor elétrico brasileiro congrega particularidades que o distingue de qualquer outro no mundo. Sua dimensão e suas características de diversidade geográfica e econômica, somadas à crescente necessidade de expansão para atendimento da demanda, fizeram com que este sempre experimentasse desafios vultosos para gestão eficiente de sua infraestrutura.

Historicamente, a questão energética brasileira vem enfrentando problemas que tiveram início na crise do petróleo na década de 70 e na crise fiscal que se abateu sobre o Estado no final dos anos 80. Paralelamente, o que se via era a incapacidade do modelo estatal em investir o mínimo necessário para inserir as empresas de energia em um cenário apto a suprir as emergentes necessidades de fornecimento energético, o que tornava os riscos de déficits de energia iminentes. Tal fato impulsionou o setor a ser alvo de profundas reformas de reestruturação, cujo início data de meados dos anos 90 e que se estendem até o dia de hoje (PIRES, 2000).

Com as reformas setoriais ocorrendo juntamente com a privatização dos ativos federais e estaduais, e com a criação da Agência Nacional de Energia Elétrica (ANEEL), começou-se a desenhar o novo quadro de políticas regulatórias nacionais. As mesmas se apoiaram, dentre outros, na introdução da competição nos setores de geração e comercialização de energia elétrica, com incentivo de redução de custos e aumento dos lucros das concessionárias, tornando possível a prática de tarifas módicas. Nascia um mercado altamente competitivo, onde a qualidade no fornecimento da energia passou a exprimir lucratividade e garantia de clientes (GBIRARD et al., 2002). 
Adicionalmente, em um passado recente (2001), o Brasil experimentou a maior crise de abastecimento de eletricidade de sua história. Neste momento, foram propostas medidas de racionalização e conservação da energia, onde destaca-se o PROCEL (Programa Nacional de Conservação de Energia Elétrica). O consumo de energia apresentou redução superior a $20 \%$ em algumas regiões do país, e grande parte desta redução foi devida à introdução de cargas com tecnologias mais econômicas e eficientes (JANNUZZI, 2003). Tal fato foi possível graças aos avanços da eletrônica de potência, a qual trouxe um maior conforto aos usuários, melhoria da confiabilidade, rendimento, comando e controle dos processos comerciais e industriais, etc., sob diminuição dos gastos.

Assim, a crescente utilização da eletrônica e os incentivos governamentais advindos da crise, culminaram na proliferação do uso de cargas com processamento eletrônico da energia, as denominadas cargas especiais. Essas solicitam correntes não-senoidais, levando à perda da qualidade das redes elétricas, com o surgimento de vários distúrbios no sistema. Constata-se, ainda, que essas mesmas cargas que conduzem à maior produtividade, economia e eficiência e, ao mesmo tempo, deterioram a rede, são as que demandam maior qualidade da tensão de suprimento, agravando ainda mais o quadro enunciado.

É neste contexto, de novos paradigmas institucional/regulamental e de transição tecnológica das cargas, que se consolidava a eminente necessidade do estudo da Qualidade da Energia Elétrica (QEE).

Grandes esforços têm sido enveredados pelos agentes de operação, geração, transmissão, distribuição e consumidores no sentido de se acharem meios para lidar com os novos aspectos de fornecimento. Os equipamentos utilizados no sistema elétrico tornaram-se mais sensíveis e as empresas de energia não estavam preparadas para lidar com as pressões dos consumidores, advindas da manifestação dos, outrora negligenciados, distúrbios em suas cargas (RAMOS, 2000a).

Dentre os fenômenos que caracterizam a perda da QEE está o desequilíbrio de tensão. Contudo, os efeitos dos desequilíbrios não são facilmente reconhecidos por grande parte dos técnicos, sejam concessionários ou consumidores, fazendo com que os problemas na tensão de suprimento sejam rapidamente atribuídos a outros distúrbios relacionados com 
qualidade da energia, como harmônicos e afundamentos. Não obstante, vale ressaltar que, em muitas situações, os mesmos não configuram foco de preocupação.

Sabe-se, porém, que o desequilíbrio de tensão pode trazer conseqüências danosas ao sistema elétrico e a uma larga gama de tipos de cargas, como motores e transformadores trifásicos, levando a prejuízos volumosos para os diversos agentes do setor. Deste modo, atualmente, com vistas ao entendimento e à mitigação de seus efeitos, este fenômeno tem merecido preocupação acentuada entre os profissionais da área, e em fóruns técnicos que tratam do assunto em âmbito mundial.

Como subsídio a essa discussão, este trabalho apresenta uma ferramenta computacional para análise, quantificação e qualificação do desequilíbrio de tensão. A partir de sua utilização, os bancos de dados oriundos de diversas medições podem ser caracterizados, analisados e interpretados segundo diversas normas e recomendações. Tem-se à disposição uma série de análises contendo gráficos, valores estatísticos e índices, com os quais podese traçar diagnósticos dos locais em estudo, quanto ao comportamento e os níveis dos desequilíbrios de tensão.

Neste particular, esse estudo mostra-se de fundamental relevância, tendo considerado que suas aplicações vão ao encontro das emergentes, e cada vez mais exigentes, necessidades de todos os profissionais, concessionárias, universidades e demais interessados no estudo e monitoramento da qualidade da energia elétrica, especialmente dos desequilíbrios de tensão.

Vale ressaltar que a ferramenta computacional já vem sendo discutida em seminários e congressos específicos sobre a QEE, tendo seu desenvolvimento iniciado em pesquisas de iniciação científica em setembro de 2004. Os Apêndices A, B e C trazem alguns resultados obtidos. 


\subsection{Estrutura do trabalho}

No Capítulo 2, são feitas as caracterizações e definições da Qualidade da Energia e de seus principais distúrbios.

O Capítulo 3 é destinado à conceituação do desequilíbrio de tensão, suas principais causas e efeitos. São expostos os métodos de cálculo do desequilíbrio e é realizada uma explanação das principais normas e recomendações que tratam desse fenômeno.

No Capítulo 4, é apresentada a ferramenta computacional. É dada uma explicação de como utilizar o aplicativo e são efetuadas sínteses dos seus módulos de análise. Ao final, tem-se uma descrição do local que será objeto de estudo neste trabalho, nos capítulos subseqüentes.

Dirigido à quantificação do desequilíbrio de tensão, o Capítulo 5 mostra o módulo da ferramenta computacional criado para este fim. Nele, o fator de desequilíbrio é calculado a partir de vários métodos e é feita uma comparação entre seus resultados. Como nos próximos capítulos de análise, encerra-se com um estudo de caso.

O Capítulo 6 é voltado para, a partir da utilização do módulo correspondente no aplicativo computacional, verificar a sensibilidade do desequilíbrio de tensão frente às variações nos ângulos e magnitudes dos fasores de tensão.

No Capítulo 7, tem-se uma investigação do comportamento das magnitudes e ângulos das tensões advindos de medições, com vistas ao seu entendimento. Conjuntamente, são analisadas as componentes simétricas, relacionando-as com a condição em que se encontram os fasores.

No Capítulo 8, são feitas análises que buscam saber da existência ou não de similaridade entre os dias de medição e entre os períodos do dia, em relação aos valores de desequilíbrio constatados.

O Capítulo 9 apresenta uma análise temporal e probabilística da distribuição dos valores de desequilíbrios de tensão ao longo do período de monitoração. 
No Capítulo 10, é exibido o módulo do aplicativo computacional para avaliação dos valores de tensão, corrente e potência.

No Capítulo 11, é feita uma avaliação comparativa das freqüências de aquisição dos dados.

No Capítulo 12, é mostrado o módulo da ferramenta computacional que possibilita a apreciação dos dados obtidos em medições com os limites impostos pelas diversas normas e recomendações.

O Capítulo 13 traz as conclusões finais deste trabalho. 


\section{Capítulo 2}

\section{A Qualidade da Energia Elétrica e seus Principais Distúrbios}

\subsection{A Qualidade da Energia Elétrica}

O termo "qualidade" sempre foi aplicado em muitas áreas da sociedade e seu significado vem apresentando variações ao longo da história, sob os diversos pontos de vista de quem o analisa. Nos últimos anos, observa-se, de um modo geral, um novo sentido de consciência e informação a respeito dos direitos dos consumidores por produtos que se destacam pelos seus diferenciais qualitativos. Nesta conjuntura, os processos de discussão sobre os critérios e metodologias a serem adotados pelos produtores e/ou fornecedores dos serviços são dinamicamente revisados, a fim de se atender às expectativas de seus compradores.

No que tange à Qualidade da Energia Elétrica (QEE), cumpre enfatizar que seus conceitos também não são novos e sempre foram objeto de estudo no setor energético, principalmente a partir dos anos 80. No Brasil, nos anos de 1978 e 1980, foram criadas portarias onde já se falava em "serviço adequado" e "condições técnicas e qualidade do serviço de energia elétrica". A atenção, porém, era dada somente aos aspectos de continuidade do fornecimento (qualidade do serviço) e variações de tensão em regime permanente (RAMOS, 2000a; OLIVEIRA, J.C., 2000a).

Ultimamente, a substituição tecnológica das cargas e o novo contexto de mercado da energia, onde se tem a entrada do capital privado e a livre escolha de fornecimento de energia por parte dos grandes consumidores, trouxeram um novo horizonte de desafios. $\mathrm{O}$ aumento da sensibilidade das cargas dos consumidores os tornaram mais exigentes e levaram o entendimento da "qualidade" ao patamar de suportabilidade dos seus equipamentos. Os aspectos de conformidade (qualidade do produto) passaram a ser primordiais, onde o que está em jogo é o bom funcionamento dos equipamentos elétricos 
dos consumidores, a partir do serviço adequado de fornecimento de energia pelas empresas concessionárias.

Neste trabalho, o suprimento de qualidade é definido como "aquele que garanta, a custos viáveis, o funcionamento de equipamentos elétricos de consumidores" (BRONZEADO, 2004). Deste modo, espera-se a "operação contínua com tensões senoidais puras, equilibradas, de amplitude e freqüência constantes" (RAMOS, 2000a). Os problemas relacionados com a qualidade da energia são, então, oriundos de desvios na tensão, na corrente ou na freqüência que conduzam à falha ou má operação de um equipamento do consumidor (DUNGAN et al., 1996).

Os problemas relacionados com a QEE acumulam prejuízos em todo mundo, com conseqüências vertiginosas. De acordo com o EPRI (Electric Power Research Institute), estes prejuízos chegam a mais de 120 bilhões de euros por ano, só nos Estados Unidos (AFONSO, 2004). As Figuras 2.1 e 2.2 mostram o crescimento do uso de cargas eletrônicas (não-lineares) nos EUA e os custos associados a interrupções com duração de até um minuto, para alguns setores econômicos nos EUA (OLESKOVICZ, 2004).

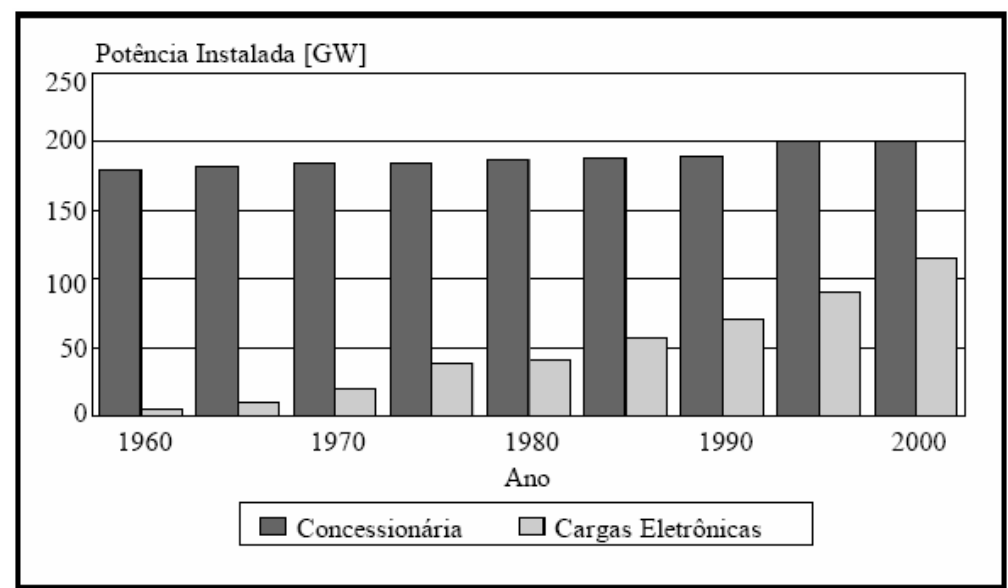

Figura 2.1 - crescimento do uso de cargas eletrônicas nos EUA 


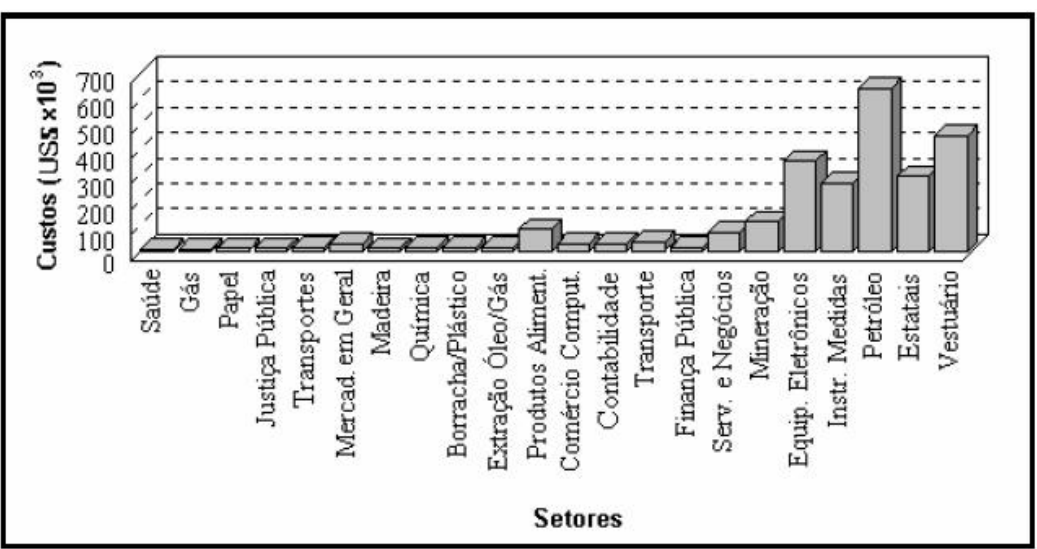

Figura 2.2 - Custos associados a interrupções com duração de até um minuto (EUA)

Neste sentido, o estudo da QEE tem assumido importância de destaque, recebendo a atenção de todos os agentes do setor elétrico, incluindo os centros de pesquisa e universidades. Observa-se a necessidade premente da definição de indicadores e índices de referência que venham a refletir corretamente a realidade de desempenho da rede, sob mérito de se considerar as questões econômicas concernentes à operação.

Nos dias de hoje, porém, quando da discussão das responsabilidades a respeito da QEE, ainda são observados pontos de vista diferentes a respeito da origem dos distúrbios, dificultando a solução eficaz dos problemas advindos dos fenômenos que afetam a qualidade da energia. A Figura 2.3 ilustra a origem dos distúrbios sob os pontos de vista da concessionária e do consumidor.
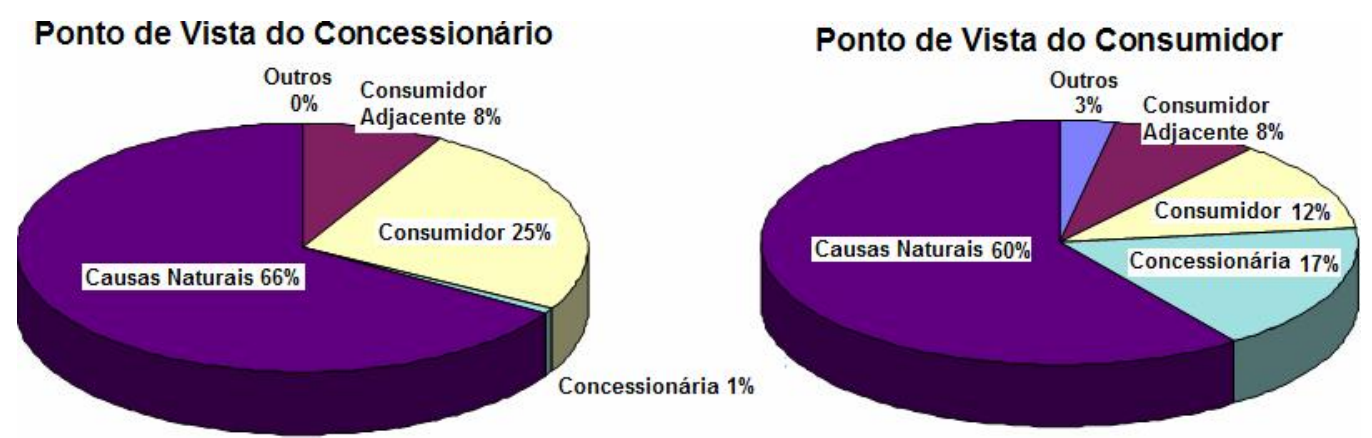

Figura 2.3 - Origem dos problemas da QEE (OLIVEIRA, J. C., 2005)

Entretanto, considerando que a qualidade do fornecimento da energia tem relação direta com o tipo de carga conectada aos barramentos do sistema, a questão da QEE deve ser enxergada como sendo de responsabilidade dividida entre todas as partes envolvidas, sejam 
elas, quem produz, transmite, distribui e consome a energia elétrica (BRONZEADO, 2004).

\subsection{Principais Distúrbios}

Os distúrbios que afetam a QEE constituem um universo de fenômenos. Estes podem ser agrupados de acordo com a sua duração típica, amplitude, conteúdo espectral, etc. A seguir, é posta à apreciação a Tabela 2.1, com os principais distúrbios considerados no estudo da QEE, juntamente com algumas de suas características. Em seguida, é feita uma síntese desses fenômenos, em que são citados suas principais causas e efeitos, abordando as definições mais usadas nos dias de hoje (OLIVEIRA, M.A., 2002; SILVEIRA, 2002; DELMONT, 2003; CARVALHO, 1997; MEHL, 2004).

Tabela 2.1 - Principais distúrbios que afetam a qualidade da energia (OLIVEIRA, M.A., 2002)

\begin{tabular}{|l|c|c|}
\hline \multicolumn{1}{|c|}{ CATEGORIAS } & DURAÇÃO & AMPLITUDE \\
\hline Transitórios & & \\
\hline Impulsivos & $50 \mathrm{~ns}-1 \mathrm{~ms}$ & \\
\hline Oscilatórios & & $0-8 \mathrm{pu}-50 \mathrm{~ms}$ \\
\hline Variações de curta duração & 0,5 ciclo $-1 \mathrm{~min}$ & $<0,1 \mathrm{pu}$ \\
\hline Interrupção transitória & 0,5 ciclo $-1 \mathrm{~min}$ & $0,1-0,9 \mathrm{pu}$ \\
\hline Afundamento de tensão & 0,5 ciclo $-1 \mathrm{~min}$ & $1,1-1,8 \mathrm{pu}$ \\
\hline Elevação de tensão & & \\
\hline Variações de longa duração & $>1$ min & $0,0 \mathrm{pu}$ \\
\hline Interrupção sustentada & $>1$ min & $0,8-0,9 \mathrm{pu}$ \\
\hline Subtensão & $>1$ min & $1,1-1,2 \mathrm{pu}$ \\
\hline Sobretensão & Reg. permanente & $0,02-0,05 \mathrm{pu}$ \\
\hline Desequilíbrios & & \\
\hline Distorção de forma de onda & Reg. permanente & $0-0,2 \mathrm{pu}$ \\
\hline Harmônicas & Reg. permanente & $0-0,02 \mathrm{pu}$ \\
\hline Interharmônicas & Reg. permanente & $0-0,01 \mathrm{pu}$ \\
\hline Ruído & Reg. permanente & $0-0,01 \mathrm{pu}$ \\
\hline Nível CC & Intermitente & $0,001-0,07 \mathrm{pu}$ \\
\hline Flutuação de tensão & $<10 \mathrm{~s}$ & \\
\hline Variação de freqüência & \multicolumn{2}{|c|}{} \\
\hline
\end{tabular}




\subsubsection{Transitórios}

São eventos de natureza momentânea, com alterações muito rápidas da tensão e duração de subciclos. Apesar de terem curta duração, podem acarretar conseqüências significativas, haja vista que os equipamentos conectados ao sistema estarão submetidos a grandes solicitações de tensão e/ou corrente.

As principais causas dos transitórios são cargas com operação intermitente, chaveamento de bancos de capacitores, faltas envolvendo a terra e operação de dispositivos de semicondutores

Os transitórios são usualmente divididos em transitórios impulsivos e transitórios oscilatórios:

Os transitórios impulsivos são conhecidos pela alteração súbita na forma de onda, normalmente com polaridade unidirecional. São causados, em muitos casos, pelas descargas atmosféricas. Por esse motivo, esses transitórios também são conhecidos como transitórios atmosféricos. Em função das altas freqüências, os componentes resistivos do sistema tendem a atenuar rapidamente esse fenômeno, fazendo com que este atinja principalmente as cargas mais próximas ao seu causador. Seu principal efeito está associado à degradação ou falha da isolação de equipamentos com fontes eletrônicas. Os transitórios impulsivos podem ainda excitar a freqüência natural do sistema, levando ao surgimento dos transitórios oscilatórios. A Figura 2.4 mostra o comportamento do transitório impulsivo.

Transitórios oscilatórios consistem em rápidas alterações na tensão e/ou corrente, onde a polaridade do valor instantâneo da forma de onda alterna muito rapidamente. São caracterizados pelo seu conteúdo espectral e são subdividos em transitórios oscilatórios de baixa, média e alta freqüência, de acordo com os tipos de eventos que os geram. Energização de capacitores e transformadores são algumas das causas mais comuns. Podem causar queima ou dano em equipamentos eletro-eletrônicos. A Figura 2.5 ilustra o comportamento deste transitório. 


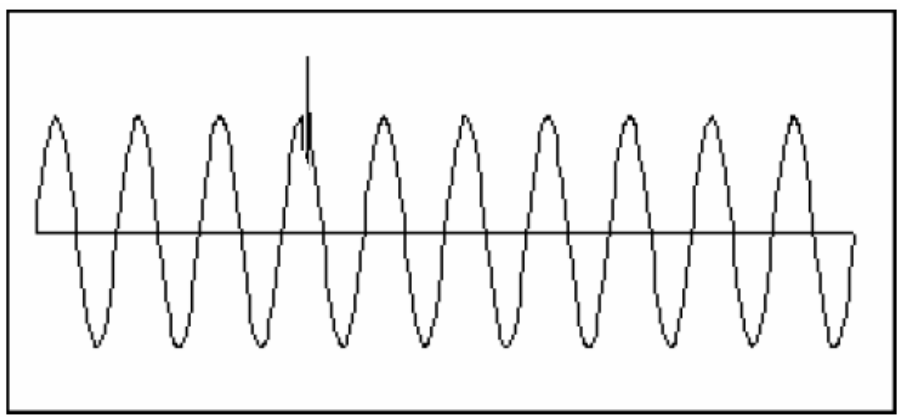

Figura 2.4 - Transitório impulsivo (CARVALHO, 1997)

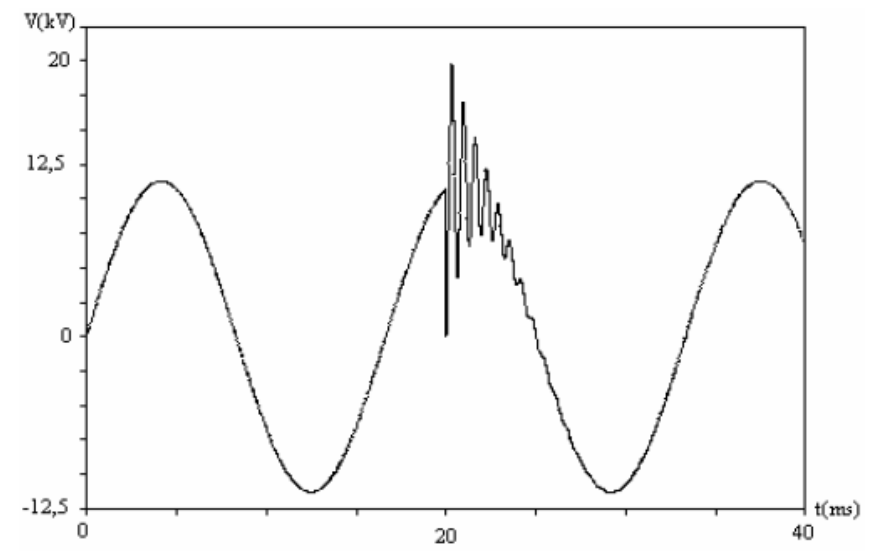

Figura 2.5 - Transitório oscilatório (DELMONT, 2003)

\subsubsection{Variação de Tensão de Curta Duração (VTCD)}

São variações no valor da tensão com duração inferior a um minuto. Em geral, são causadas por curtos-circuitos no sistema, operação de cargas com elevada corrente de partida e perda intermitente de conexões. Podem ocorrer de três formas distintas, dependendo da localização da falta e das condições operacionais do sistema: interrupções, afundamentos ou depressão de tensão, elevação ou saltos de tensão.

As interrupções ocorrem quando o valor da tensão atinge valores menores que $10 \%$ da nominal, em um período de 0,5 ciclos a 1 (um) minuto. Quase sempre levam ao desligamento ou mau funcionamento de eletro-eletrônicos.

Afundamentos de tensão ( $\operatorname{sag}$ ) é a condição na qual ocorre a redução no valor da tensão entre 10 e $90 \%$ do valor nominal, em um período de 0,5 ciclos a 1 (um) minuto. São causados por entradas de cargas, partidas de grandes motores e faltas, dentre outros fatores. 
Quando é devido a uma falta, ocorre no período compreendido entre o início da falta e atuação da proteção. Como conseqüência, pode levar à parada de processos produtivos.

Nas elevações de tensão (swell), a tensão fica acima de $110 \%$ da nominal, tipicamente entre 1,1 e 1,8 pu, em um período de 0,5 ciclos a 1 (um) minuto. Entre suas principais causas pode-se citar a entrada de bancos de capacitores, saída de um grande bloco de cargas e falta fase-terra. Podem ocasionar má operação e perda de isolação de em equipamentos eletrônicos.

A Figura 2.6 traz, em pu, exemplos de interrupção de tensão, afundamento e elevação de tensão.

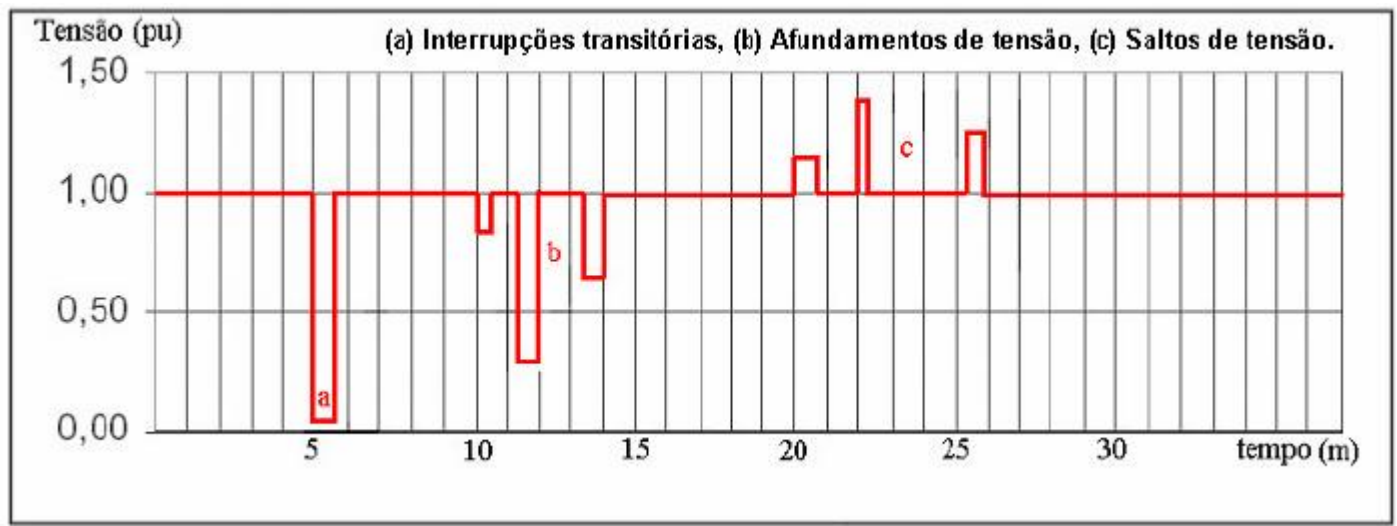

Figura 2.6 - Variação de Tensão de Curta Duração (XAVIER, 2005)

\subsubsection{Variação de Tensão de Longa Duração (VTLD)}

Também conhecidas como variações sustentadas de tensão, se distinguem das VTCD por serem alterações na tensão com duração superior a 1 (um) minuto, sendo consideradas como eventos em regime permanente. Geralmente é causada pela manobra de grandes blocos de cargas e elementos para compensação de reativos. De forma análoga ao item precedente, podem se manifestar em sobretensões, subtensões e interrupções sustentadas.

As sobretensões são elevações na tensão eficaz acima de $110 \%$ do valor nominal, por um período superior a 1 (um) minuto. São advindos de desligamentos de grandes blocos de cargas e energização de bancos de capacitores. 
Subtensões ocorrem quando da redução no valor da tensão para valores inferiores a $90 \%$ do padrão nominal, por um período superior a 1 (um) minuto. Suas causas são os casos inversos dos citados para sobretensões, além de sobrecarga nos circuitos, dentre outras.

Interrupções sustentadas se verificam com a redução para zero da tensão eficaz por um período superior a 1 (um) minuto, requerendo a intervenção manual do operador para restabelecimento do funcionamento do sistema.

\subsubsection{Desequilíbrio de Tensão}

Por se tratar do assunto principal do trabalho, esse tópico será apresentado minuciosamente no capítulo seguinte.

\subsubsection{Distorções da Forma de Onda}

Constitui o desvio, em regime permanente, da forma de onda de tensão ou corrente de sua forma senoidal pura. Os principais tipos são listados como harmônicos, inter-harmônicos, ruídos, nível CC e corte (notch).

Harmônicos são tensões ou correntes que possuem freqüência igual a um múltiplo inteiro da freqüência nominal de operação do sistema. São provenientes dos processos com cargas de características não-lineares. Seus efeitos incluem sobreaquecimentos, má operação e redução de vida útil de equipamentos. É comumente medida pela DHT, Distorção Harmônica Total, representada pela porcentagem em relação à tensão ou corrente nominal. A figura 2.7 ilustra uma onda de tensão com componentes harmônicas de $3^{\mathrm{a}}$ e $5^{\mathrm{a}}$ ordens (ondas em 180 e $300 \mathrm{~Hz}$, respectivamente). 


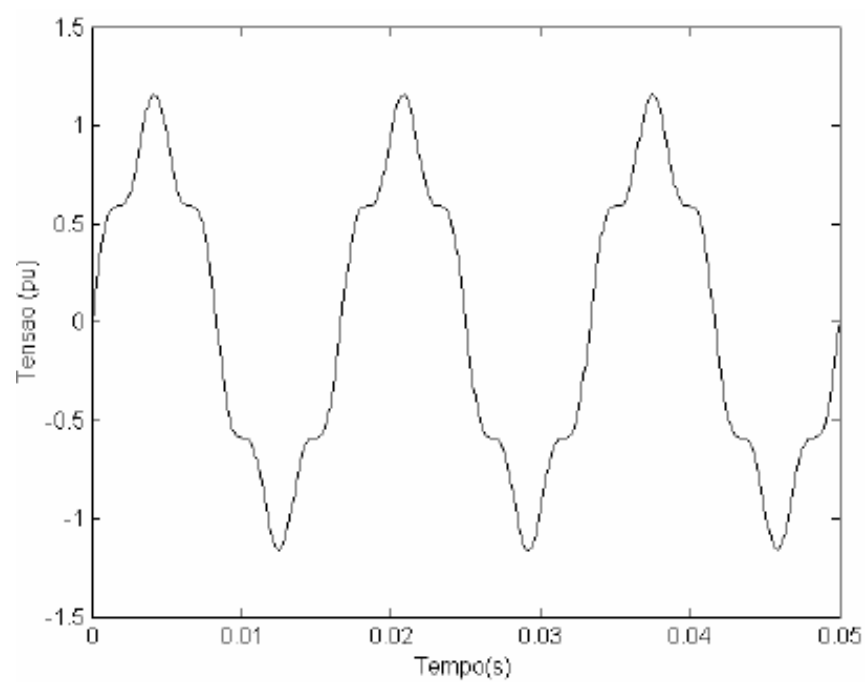

Figura 2.7 - Forma de Onda Distorcida (DELMONT, 2003)

Inter-harmônicos são tensões ou correntes que possuem freqüência igual a um múltiplo não-inteiro da freqüência nominal de operação do sistema. São causados majoritariamente por conversores estáticos de potência, conversores, motores de indução e equipamentos a arco.

Os ruídos são sinais com largo conteúdo espectral inferior em freqüências menores que $200 \mathrm{kHz}$, superpostos ao sinal de tensão ou corrente do sistema. São decorrentes de instalações inadequadas de componentes no sistema, operações defeituosas de equipamentos, cargas com retificadores de estado sólido, equipamentos a arco e fontes chaveadas. Podem causar problemas em controladores programáveis e microcomputadores.

A Figura 2.8 apresenta uma forma de onda de tensão senoidal com a presença de ruídos. 


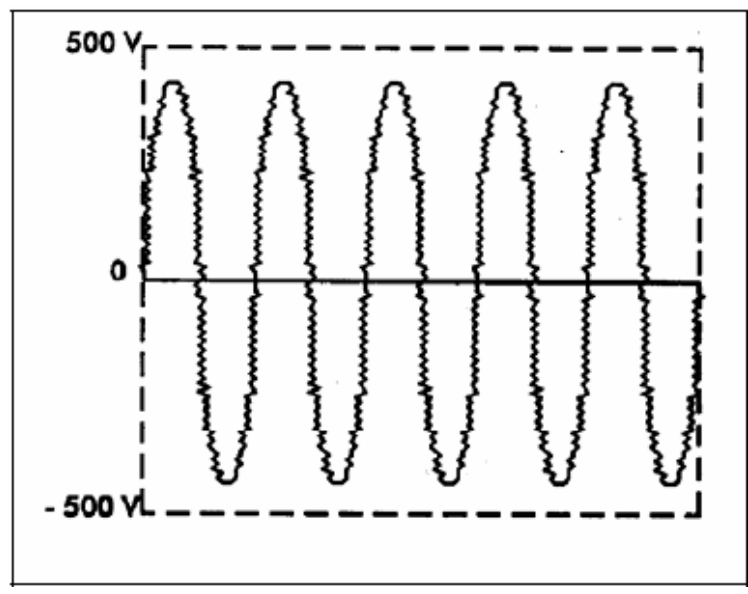

Figura 2.8 - Forma de onda com ruído (MEHL, 2004)

O desvio no nível CC é a presença de tensão ou corrente $\mathrm{CC}$ em um sistema elétrico CA. Podem ser resultado da utilização de retificadores de meia onda e distúrbios geomagnéticos. Leva à saturação de transformadores, corrosão de eletrodos de aterramento e stress adicional da isolação.

Os cortes de tensão (notch) são descontinuidades periódicas no valor instantâneo da tensão. Surgem durante a normal operação de dispositivos da eletrônica de potência, como conversores trifásicos, durante a comutação de corrente entre as fases.

A Figura 2.9 exemplifica uma onda onde ocorrem cortes de tensão.

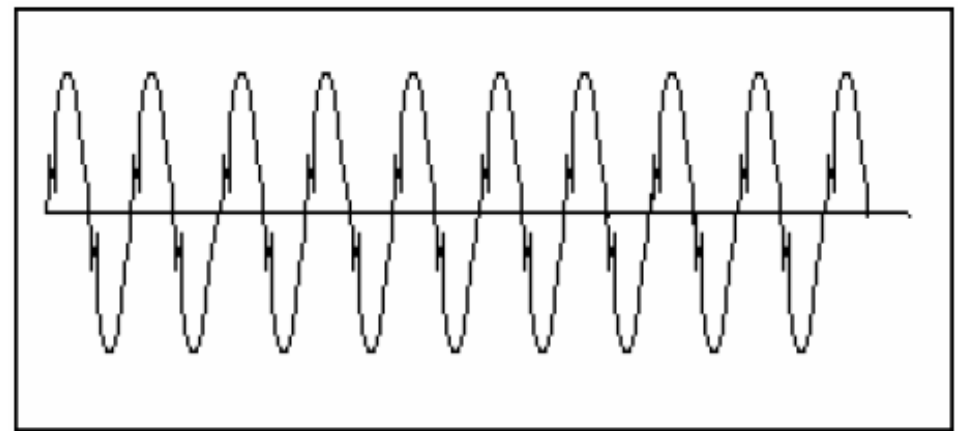

Figura 2.9 - Cortes de Tensão (CARVALHO, 1997) 


\subsubsection{Flutuação de Tensão}

É um fenômeno eletromagnético que provoca alterações sistemáticas na tensão, podendo ser uma flutuação aleatória, repetitiva ou esporádica, não excedendo os limites entre 0,95 e 1,05 pu de tensão. Cargas com solicitação variável da magnitude da corrente são fontes em potencial deste distúrbio. É constatada visualmente a partir das variações do fluxo luminoso em algumas lâmpadas, constituindo o efeito da cintilação luminosa (flicker). A freqüência de operação das cargas com ciclo variável produz uma modulação da magnitude da tensão da rede entre 0 e $30 \mathrm{~Hz}$. Nesta banda de freqüência, algumas pessoas apresentam bastante sensibilidade às variações das emissões luminosas. A máxima sensibilidade do olho humano é em aproximadamente $10 \mathrm{~Hz}$. A Figura 2.10 traça a sensibilidade do olho humano em função da freqüência.

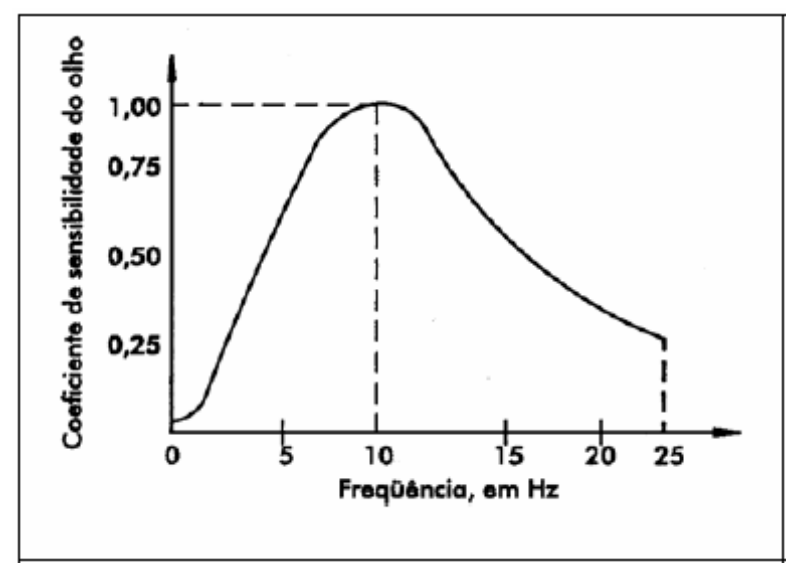

Figura 2.10 - Sensibilidade do olho humano (MEHL, 2004)

\subsubsection{Variação de Freqüência}

São desvios no valor da freqüência fundamental do sistema. São decorrentes do desbalanço entre a geração de energia e o consumo da carga, possuindo duração e magnitude reduzidos na maioria dos casos, dependendo da velocidade de resposta do sistema à variações de potência. Normalmente estão relacionados à ocorrência de faltas no sistema de transmissão e desconexão de grandes blocos de cargas ou de geradores. 


\section{Capítulo 3}

\section{Desequilíbrio de Tensão}

\subsection{Considerações Iniciais}

Neste capítulo são abordados os tópicos concernentes ao entendimento dos desequilíbrios de tensão. Inicialmente, é feita a definição do presente fenômeno e são expostos os métodos de cálculo do fator de desequilíbrio. Em seguida é feita uma listagem das principais causas deste distúrbio no sistema e uma abordagem quanto aos seus efeitos em alguns equipamentos que normalmente encontram-se conectados à rede elétrica. Ao final, é feita uma síntese das principais normas e recomendações que se manifestam a respeito desse tema.

\subsection{Conceituação}

Um sistema elétrico trifásico equilibrado é constituído por tensões iguais em módulo e defasadas entre si de $120^{\circ}$ elétricos.

$$
\begin{aligned}
& \bar{V}_{a}=V_{m} \angle 0^{\circ} \\
& \bar{V}_{b}=V_{m} \angle-120^{\circ} \\
& \bar{V}_{c}=V_{m} \angle 120^{\circ}
\end{aligned}
$$

Deste modo, define-se desequilíbrio de tensão como a condição na qual os fasores de tensão apresentam magnitudes diferentes entre si, defasagem angular diferente de $120^{\circ} \mathrm{ou}$ estas duas situações simultaneamente.

A Figura 3.1 traz uma ilustração das ondas de tensão com o sistema em desequilíbrio, onde é destacada a alteração no módulo de uma fase (a) e no ângulo (b). 


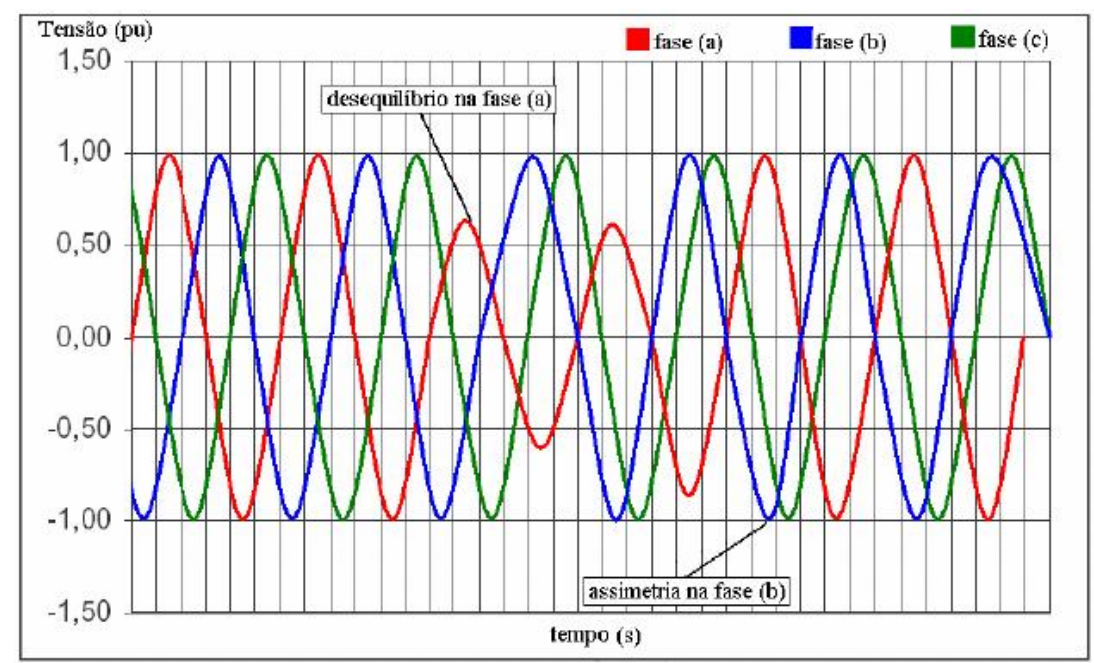

Figura 3.1 - Desequilíbrio de Tensão (XAVIER, 2005)

Os métodos comumente utilizados para a quantificação do desequilíbrio serão detalhadamente discutidos no próximo capítulo.

\subsection{Métodos de Cálculo do Desequilíbrio de Tensão}

Hoje, na literatura, podem ser encontrados vários métodos de cálculo para obtenção do fator de desequilíbrio de tensão. Diante do fato de os ângulos das tensões não serem usualmente disponibilizados por um grande número de medidores, métodos alternativos foram criados a fim de possibilitar a determinação do fator de desequilíbrio - Fator K. Tais metodologias fazem uso apenas das magnitudes das tensões trifásicas. Adicionalmente, os instrumentos de medição possuem limitação de memória para registro de dados, incentivando, em alguns casos específicos, a opção por um dos métodos que utilizam apenas as magnitudes dos fasores de tensão.

Nesta seção serão descritos 4 (quatro) métodos de cálculo. O primeiro utiliza as magnitudes e os ângulos das tensões, e os demais ocupam-se somente com as magnitudes das tensões de linha para a obtenção do fator K. Vale ressaltar que, nos capítulos adjacentes será ilustrada uma ferramenta computacional que permitirá, dentre outros itens, efetuar uma análise comparativa entre os métodos, o que possibilitará avaliar as discrepâncias oriundas do uso dessas expressões alternativas. 


\subsubsection{Método 1 - Componentes Simétricas}

O método das Componentes Simétricas é alicerçado nos estudos de C. L. FORTESCUE que data do ano de 1918. O Teorema de Fortescue diz:

"Qualquer grupo desequilibrado de $n$ fasores associados, do mesmo tipo, pode ser resolvido em $\mathrm{n}$ grupos de fasores equilibrados, denominados componentes simétricas dos fasores originais".

Assim, um sistema trifásico desequilibrado, com seqüência de fases $a, b, c$, pode ser decomposto em três sistemas simétricos e equilibrados (DAMASCENO, 1995):

- Um sistema trifásico equilibrado de fasores, na mesma seqüência de fases do sistema desequilibrado original, denominado sistema de seqüência positiva (ou sistema de seqüência direta).

- Um sistema trifásico equilibrado de fasores, na seqüência de fases inversa ao sistema de fases do sistema desequilibrado original, denominado sistema de seqüência negativa (ou sistema de seqüência inversa).

- Um sistema trifásico de fasores paralelos, denominado sistema de seqüência zero.

A Figura 3.2 mostra o diagrama fasorial das componentes simétricas de um sistema trifásico desequilibrado.
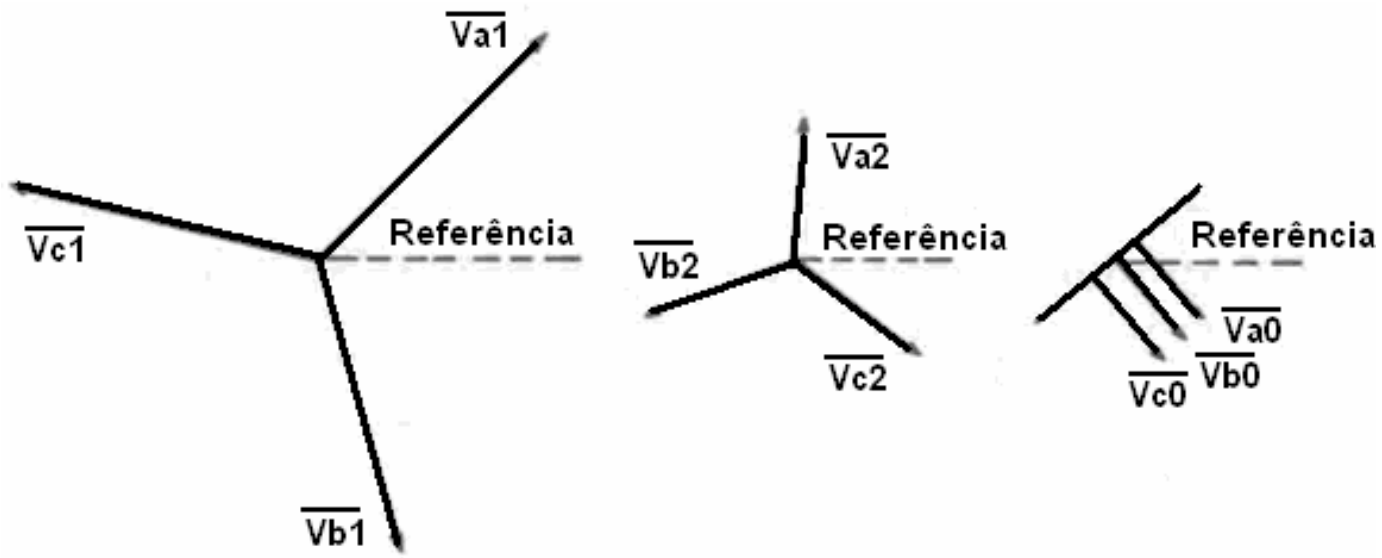

Figura 3.2 - Diagrama fasorial das componentes simétricas de um sistema trifásico 
Onde,

$\mathrm{V}_{1} \rightarrow$ Módulo da tensão de seqüência positiva;

$\mathrm{V}_{2} \rightarrow$ Módulo da tensão de seqüência negativa;

$\mathrm{V}_{0} \rightarrow$ Módulo da tensão de seqüência zero.

A determinação analítica das componentes simétricas se dá a partir da chamada Matriz de Fortescue.

$$
\left[\begin{array}{l}
\bar{V}_{a} \\
\bar{V}_{b} \\
\bar{V}_{c}
\end{array}\right]=\left[\begin{array}{ccc}
1 & 1 & 1 \\
1 & a^{2} & a \\
1 & a & a^{2}
\end{array}\right]\left[\begin{array}{l}
\bar{V}_{0} \\
\bar{V}_{1} \\
\bar{V}_{2}
\end{array}\right]
$$

Sendo,

$\mathrm{a} \rightarrow$ Operador rotacional, cujo módulo é um e o ângulo é $120^{\circ}$.

Deste modo, define-se o fator de desequilíbrio de tensão (fator $\mathrm{K}$ ) como sendo a relação entre os módulos das componentes de seqüência negativa e positiva, em porcentagem da última.

$$
K \%=\frac{V_{2}}{V_{1}} \times 100
$$

Dentre os métodos de quantificação, este é o que melhor representa o grau de desequilíbrio (Oliveira, J. C., 2000a). Isto porque esse é o único método que leva em conta tanto a magnitude como os ângulos das tensões. Além disso, a presença da componente de seqüência negativa está intimamente ligada aos efeitos de mau funcionamento e interferências em diversos equipamentos conectados ao sistema. 


\subsubsection{Método 2-CIGRÉ}

O CIGRÉ (Congress Internationale des Grand Réseaux Électriques a Haute Tension) traz um método que correlaciona as tensões de linha, formando uma expressão para a medida do fator de desequilíbrio.

$$
K \%=\sqrt{\frac{1-\sqrt{3-6 \beta}}{1+\sqrt{3-6 \beta}}} \times 100
$$

Onde,

$$
\beta=\frac{\left|V_{a b}\right|^{4}+\left|V_{b c}\right|^{4}+\left|V_{c a}\right|^{4}}{\left(\left|V_{a b}\right|^{2}+\left|V_{b c}\right|^{2}+\left|V_{c a}\right|^{2}\right)^{2}}
$$

$V_{a b}, V_{b c}, V_{c a} \rightarrow$ Módulo das tensões trifásicas.

\subsubsection{Método 3 - NEMA}

Uma metodologia alternativa bastante utilizada em todo mundo para a medida do grau de desequilíbrio provém da norma NEMA, "National Electrical Manufacturers Association", MG1-14.34. Esta define o fator K como a relação entre o máximo desvio das tensões em relação à tensão média, tendo como referência as tensões de linha.

$$
K \%=\frac{\Delta V}{V_{m}} \times 100
$$

Onde,

$\Delta \mathrm{V} \rightarrow$ Máximo desvio das tensões de linha em relação ao valor médio;

$\mathrm{V}_{\mathrm{m}} \rightarrow$ Média aritmética dos módulos das tensões trifásicas. 


\subsubsection{Método 4 - IEEE}

Um outro procedimento para a determinação do fator de desequilíbrio de tensão é sugerido pelo IEEE (Institute of Electrical and Electronics Engineers). Este recomenda que o $\mathrm{K}$ pode ser obtido por meio de uma expressão que exprime a maior diferença entre as tensões medidas e o somatório das mesmas.

$$
K \%=\frac{3(V m a ́ x-V \min )}{V_{a b}+V_{b c}+V_{c a}} \times 100
$$

Onde,

Vmáx $\rightarrow$ Maior valor dentre os módulos das tensões trifásicas;

Vmín $\rightarrow$ Menor valor dentre os módulos das tensões trifásicas;

$V_{a b}, V_{b c}, V_{c a} \rightarrow$ Módulo das tensões trifásicas.

\subsection{Principais Causas dos Desequilíbrios de Tensão}

As origens do desequilíbrio de tensão são associadas a alterações no padrão nominal das tensões trifásicas, trazidas por diversos componentes que formam os sistemas de transmissão, distribuição, transformação e a interação do sistema com as cargas.

Dentre as principais causas de desequilíbrios destacam-se (WANG et al., 2000; JOUANNE et al, 2001; LEE et al., 1997):

- Distribuição desigual de cargas monofásicas entre as fases;

Hoje, quando da elaboração de projetos de sistemas de distribuição e de instalações elétricas, busca-se distribuir uniformemente as cargas monofásicas entre as fases. Sabese, porém, que a utilização destas cargas no sistema ocorre de maneira randômica, em função das constantes entradas e saídas de cargas nos grandes sistemas de distribuição. Tal fato faz com que, mesmo que se consiga distribuir as cargas de maneira igual, as solicitações das cargas ocorram diferentemente em cada fase, em cada instante. Assim, 
as quedas de tensão provocadas serão diferentes nas três fases, levando à constatação de desequilíbrios no ponto de acoplamento comum do sistema.

- Sistemas de distribuição com grandes demandas monofásicas;

Alimentação de ferrovias e grandes veículos de tração monofásicos são alguns exemplos.

- Cargas trifásicas desequilibradas;

- Alimentação de processos industriais que utilizam fornos de indução e/ou fornos a arco;

- Linhas de distribuição muito longas;

Destaca-se o caso das linhas que alimentam sistemas rurais, onde a alimentação é usualmente monofásica.

- Transposição incompleta ou assimétrica das linhas de transmissão;

Quando ocorre a má transposição das linhas de transmissão ao longo do percurso, os espaçamentos dos condutores não são iguais. Neste caso, o fluxo concatenado e a indutância de cada fase diferem, levando à indução de tensões indesejadas e, conseqüentemente, ao desequilíbrio. Como as impedâncias de linhas e cabos são amplamente dependentes da geometria do circuito, observa-se assimetrias nas impedâncias destes.

- Assimetria nas impedâncias dos enrolamentos de transformadores e/ou máquinas rotativas;

Esta situação decorre tanto de processo de construção inadequado quanto de falhas de isolação e perdas de espiras nas fases. Nos casos extremos, ocorre a abertura de enrolamentos em bancos trifásicos de transformadores.

- Motores com rotor desalinhado e/ou estator assimétrico;

- Mau contato e alta impedância de conexões; 
- Bancos de capacitores com fusíveis queimados;

- Utilização de compensadores de reativo, como o STATCOM (Static Compensator), SVC (Static VAr Compensator) e outros.

Nesta situação pode ocorrer compensação desigual de reativos nas fases, verificando-se níveis diferentes de tensão nas mesmas.

- Distorção harmônica em níveis desiguais entre as fases;

- Interrupções, afundamentos, elevações, transitórios, etc.

\subsection{Principais Efeitos dos Desequilíbrios de Tensão}

Nos últimos anos, o número de grandes cargas monofásicas, incluindo trens elétricos e cargas a tração, tem aumentado significantemente. Isso resulta no aumento gradativo dos desequilíbrios nos sistemas de distribuição, o que requer equipamentos cada vez mais robustos e tolerantes a tal fenômeno (BERGERON, 1989).

O desequilíbrio de tensão traz efeitos danosos ao sistema elétrico e a uma grande quantidade de cargas. Neste sentido, os estudos destes efeitos têm crescido consideravelmente nos últimos anos. De uma forma geral, seus problemas estão associados com sobreaquecimento, falha e má operação dos dispositivos de proteção, solicitação indevida do isolamento e a diminuição da vida útil, além da possibilidade de circulação de correntes de seqüência zero, mesmo em situação de carga equilibrada.

Os efeitos dos desequilíbrios são intensificados à medida que um pequeno desequilíbrio de tensão pode levar a um de desequilíbrio de corrente de maneira não-proporcional, com conseqüências incomensuráveis. O desequilíbrio de corrente chega a ser 6 (seis) a 10 (dez) vezes maior que o desequilíbrio de tensão, aumentando as perdas elétricas em linhas e cabos (JOUANNE et al, 2001).

Um outro efeito relevante desse fenômeno diz respeito ao fato de que o sistema pode se tornar menos estável, haja vista a diminuição da capacidade de responder a solicitações de transferência de cargas. O desequilíbrio de tensão modifica as características de 
funcionamento das máquinas elétricas, alterando o consumo das potências ativa e reativa, podendo afetar seriamente a estabilidade transitória do sistema (LEE et al, 1997).

Os gráficos da Figura 3.3 ilustram os prejuízos com os efeitos dos desequilíbrios de tensão em um sistema industrial típico de pequeno porte. A situação 1 é em condições ideais de tensão de alimentação. Na situação 2 o sistema opera com $10 \%$ de desequilíbrio (OLIVEIRA, J. C., 2005).

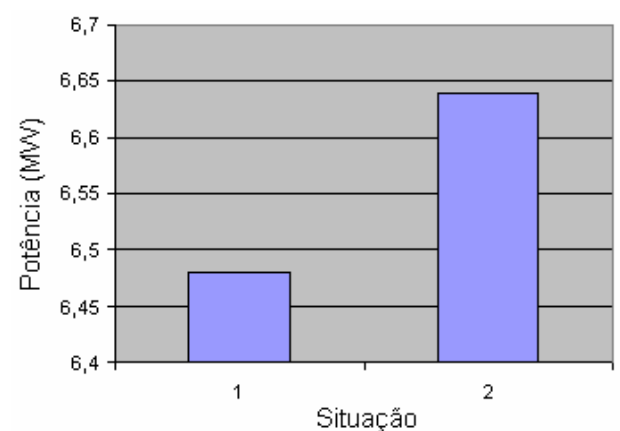

(a)

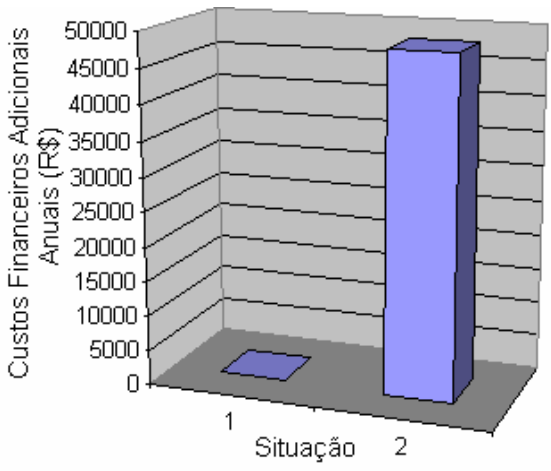

(b)

Figura 3.3 - Custos Adicionais Anuais de Um Sistema Industrial de Pequeno Porte

(a) Potência; (b) Custos Adicionais

Observa-se que, quando o sistema encontra-se desequilibrado, ocorre um aumento da potência consumida pela industria com o conseqüente prejuízo de aproximadamente $\mathrm{R} \$$ $50.000,00$ por ano.

A seguir são discriminados os efeitos do desequilíbrio em alguns equipamentos.

\subsubsection{Efeitos em Motores de Indução}

Os motores de indução são largamente utilizados em sistemas industriais, comerciais e residenciais. Estudos preliminares apontam que os Estados Unidos têm prejuízos de 1,8 bilhões de dólares por ano com os efeitos dos desequilíbrios de tensão associados a distorções harmônicas na vida útil de motores de indução (EMANUEL et al., 2002). 
Estudos de efeitos de desequilíbrio em motores de indução trifásicos (MIT) são encontrados desde 1954, onde foram apresentados resultados da diminuição da eficiência dos motores quando em desequilíbrio (WILLIAMS, 1954). Em 1959, os efeitos no aumento da temperatura do MIT começaram a ser conhecidos, os quais levam a uma redução da vida útil do motor (GAFFORF, 1959). Nas últimas décadas, os esforços têm se concentrado no estudo de métodos de proteção dos motores de indução aos desequilíbrios.

Na condição de desequilíbrio, surge a tensão de componente de seqüência negativa, que gera a circulação de corrente de seqüência negativa, responsável por gerar um conjugado nas máquinas contrário ao desejado. Normalmente, as correntes de seqüência zero não circulam na alimentação de linha dos motores, dado que os mesmos são geralmente conectados em delta ou estrela isolada.

A operação de motores com tensões desequilibradas leva à redução da velocidade de rotação no sentido de interesse, pulsações de velocidade e torque, aumento no ruído dos motores, aumento das perdas e da temperatura dos enrolamentos, diminuição da eficiência e da vida útil. É estimado que $2 \%$ de desequilíbrio requer um motor $5 \%$ maior para poder operar com carga nominal e que sob 3\% de desequilíbrio seria necessário o aumento em $12 \%$ da potência do motor (JOUANNE et al., 2001).

A Tabela 3.1 apresenta resultados de ensaios que relacionaram a redução da vida útil de motores com a operação destes sob vários níveis de desequilíbrio de tensão.

Tabela 3.1 - Desequilíbrio x Vida útil do MIT (OLIVEIRA, D., 2001)

\begin{tabular}{|c|c|}
\hline Desequilíbrio (K\%) & Redução da vida útil (\%) \\
\hline 2 & 4 \\
\hline 5 & 32 \\
\hline 10 & 80,1 \\
\hline 15 & 97 \\
\hline
\end{tabular}

Nota-se da Tabela 3.1 que com $5 \%$ de desequilíbrio a expectativa de vida do motor é praticamente três vezes menor.

As elevações de temperatura típicas de motor de indução em função dos valores de desequilíbrios de tensão e corrente podem ser vistos a seguir, na Figura 3.4. 


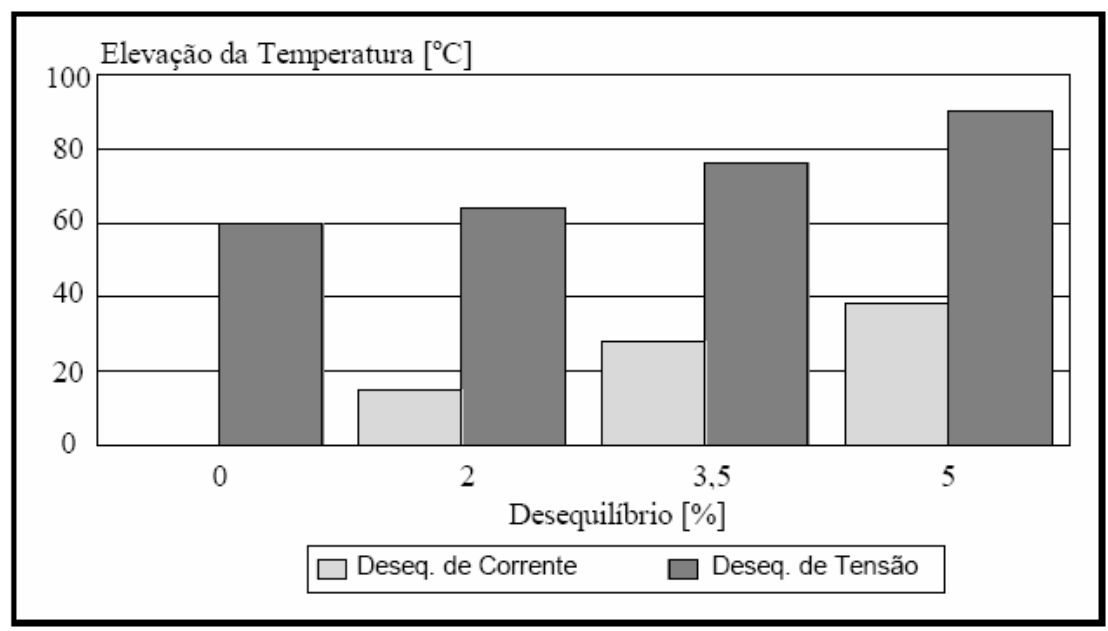

Figura 3.4 - Elevação da temperatura em função do desequilíbrio de tensão e corrente (OLESKOVICZ, 2004)

Observa-se na Figura 3.4 um aumento de cerca de $15^{\circ} \mathrm{C} \operatorname{com} 3,5 \%$ de desequilíbrio de tensão e aproximadamente $30^{\circ} \mathrm{C}$ com $5 \%$. Como conseqüência destes aumentos da temperatura dos enrolamentos, tem-se a redução da vida útil dos motores. A Figura 3.5 ilustra esse fato, para diferentes classes de isolamento de motores.

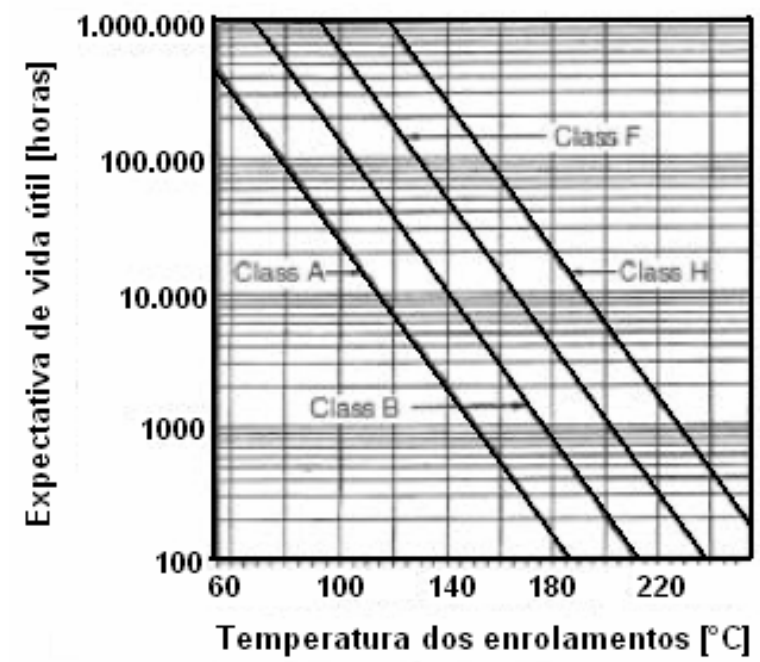

Figura 3.5 - Expectativa de vida em função da temperatura dos enrolamentos (PQC, 2002)

Na Figura 3.5, a escala logarítmica no eixo das coordenadas explicita a severidade dos danos trazidos. 
Percentualmente, a elevação das perdas em um MIT submetido a ensaios de desequilíbrios pode ser percebida por meio da Figura 3.6.

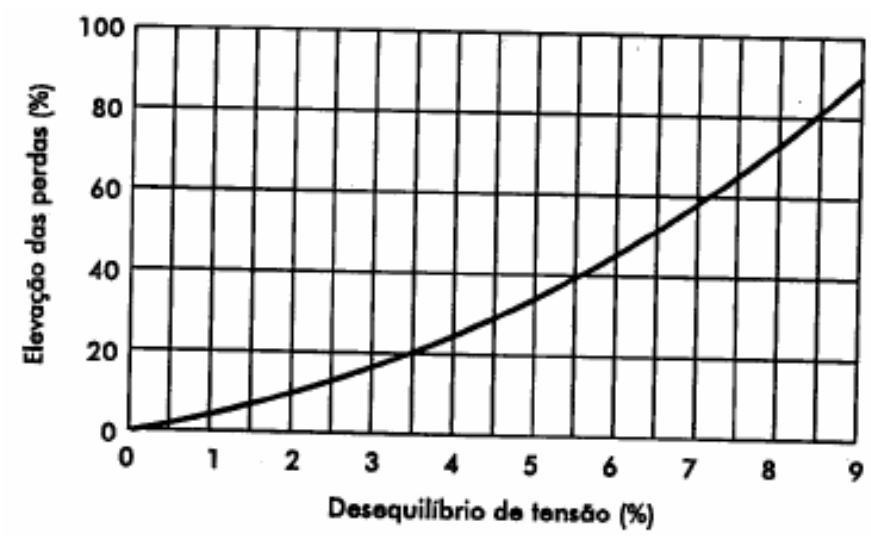

Figura 3.6 - Elevação das perdas em função do desequilíbrio de tensão (MEHL, 2004)

Verifica-se, na Figura 3.6, um aumento de $10 \%$ nas perdas para um valor de $2 \%$ de desequilíbrio e cerca de $60 \%$ para um fator de $7 \%$ de desequilíbrio.

\subsubsection{Máquinas Síncronas}

Em uma máquina síncrona, assim como nos motores de indução, os desequilíbrios de tensão conduzem ao aparecimento de correntes de seqüência negativa através do estator, que produzem um torque contrário ao sentido de rotação do rotor.

As correntes induzidas no ferro do rotor e nos enrolamentos de campo e de amortecimento aumentam as perdas no rotor (principalmente no enrolamento de amortecimento, o qual possui a menor impedância). Ademais, estas correntes distorcem o campo magnético induzido, deformando o perfil da forma de onda de tensão gerada (OLESKOVICZ, 2004).

\subsubsection{Conversores de freqüiência}

Os conversores, advindos do desenvolvimento da eletrônica de potência, têm seu uso cada vez mais ampliado em aplicações diversas no sistema elétrico, onde ressalta-se a operação de motores com velocidade variável. Os conversores contêm diodos retificadores e 
capacitores para converter a tensão $\mathrm{CA}$ em uma tensão $\mathrm{CC}$ com baixo ripple, além de inversores com modulação por largura de pulso (PWM) que fazem a conversão da tensão de novo para AC.

Como se sabe, este conjunto drena da rede de alimentação uma corrente não-senoidal, fazendo circular correntes harmônicas em ordens características de cada tipo de conversor (harmônicos característicos). Em um sistema equilibrado, as correntes harmônicas características podem ser determinadas pela expressão:

$$
h=k q \pm 1
$$

onde,

$$
\begin{aligned}
& h=\text { ordem harmônica; } \\
& k=1,2,3 \ldots ; \\
& q=\text { número de pulsos do retificador; }
\end{aligned}
$$

Um retificador de 6 pulsos, por exemplo, deve apresentar correntes harmônicas de ordem $5^{\mathrm{a}}, 7^{\mathrm{a}}, 11^{\mathrm{a}}, 13^{\mathrm{a}}, 17^{\mathrm{a}}$, etc.

Contudo, quando alimentado por um sistema desequilibrado, temos o aparecimento de correntes de seqüência zero $\left(3^{\mathrm{a}}, 9^{\mathrm{a}}\right.$, etc), levando à circulação de correntes harmônicas de ordens não-características. Nestes casos, o sistema não foi projetado para operar sob as novas condições de distorção harmônica, levando ao mau funcionamento dos equipamentos e a prejuízos inesperados, incluindo possíveis problemas de ressonâncias não previstas.

Em ensaios realizados em um conversor de $80 \mathrm{kVA}, 460 \mathrm{~V}$, retificador de 6 pulsos, observou-se que, em alimentação puramente senoidal, o conversor apresentou DHTi (Distorção Harmônica Total de Corrente - com relação à componente fundamental) de $79,4 \%$, sendo apenas $2,3 \%$ de $3^{\text {a }}$ harmônica (por se tratar de um harmônico não característico). Com um desequilíbrio de 0,3\%, tem-se 118,6\% de DHTi com 19,2\% de $3^{\text {a }}$ harmônica. Já com desequilíbrio de 3,75\%, apresenta-se 116,2\% de DHTi onde 83,7\% são de harmônicos de $3^{a}$ ordem (JOUANNE et al., 2001). A partir da constatação deste 
fenômeno são necessários estudos do novo espectro harmônico das correntes e, na maioria dos casos, instalação de filtros harmônicos (mais uma vez a questão da ressonância merece destaque, haja vista a modificação das impedâncias do sistema).

Observam-se, ainda, mudanças nas características das formas de onda de corrente nos conversores, que podem, por exemplo, passar a apresentar um pulso em vez de dois quando em condições de desequilíbrio. Este fenômeno pode gerar correntes excessivas em uma ou duas das fases, levando ao acionamento do sistema de proteção. A vida útil dos capacitores é reduzida e muitas vezes faz-se necessário a troca dos mesmos por outros maiores.

A Figura 3.7 traz as formas de onda da corrente de um retificador com o sistema equilibrado, com $5 \%$ e com $15 \%$ de desequilíbrio, respectivamente.

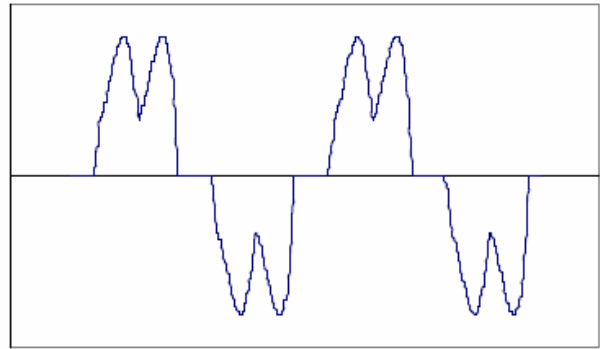

(a)

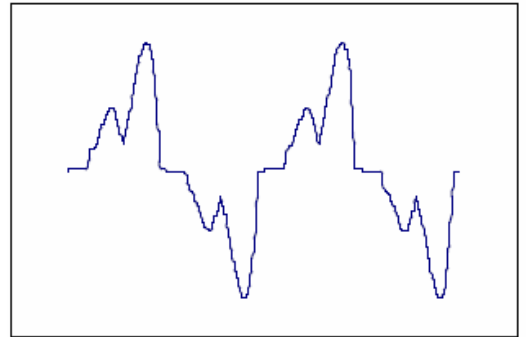

(b)

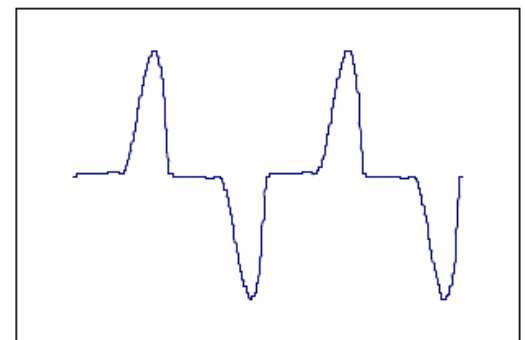

(c)

Figura 3.7 - Forma de onda de corrente (a) sistema equilibrado; (b) 5\% de desequilíbrio;

(c) $15 \%$ de desequilíbrio (PQC, 2002)

\subsubsection{Transformadores trifásicos}

Os transformadores de potência são amplamente utilizados nos sistemas de transmissão e distribuição. Grandes quantidades de cargas são alimentadas pelos sistemas de energia por 
meio destes elementos, justificando a importância da garantia do bom funcionamento dos mesmos.

Os fatores que, em grande parte das vezes, são responsáveis pela degradação dos transformadores trifásicos de potência são o calor, umidade, acidez e vibrações mecânicas excessivas (OLIVEIRA, D., 2001). A presença de desequilíbrios de tensão provoca o surgimento de correntes de seqüência negativa e de desequilíbrios de corrente nos enrolamentos. Estas correntes, por sua vez, são responsáveis pelo sobreaquecimento, aumento das perdas, maior solicitação do isolamento e a conseqüente diminuição da vida útil do transformador.

\subsubsection{Cabos Isolados}

O desequilíbrio de tensão em cabos faz com que haja o desbalanço de corrente entre os condutores das fases. Dependendo da maneira com que as fases do sistema estejam desequilibradas, o condutor de uma fase pode estar conduzindo corrente maior que a sua capacidade nominal, enquanto outro trabalha com folga de carga.

As Figuras 3.8 e 3.9 mostram, para um sistema equilibrado e para uma dada condição de desequilíbrio, a temperatura dos condutores das três fases e a expectativa de vida destes cabos. Admite-se que este circuito alimenta cargas puramente resistivas e com valor igual ao nominal (OLIVEIRA, D., 2001). 


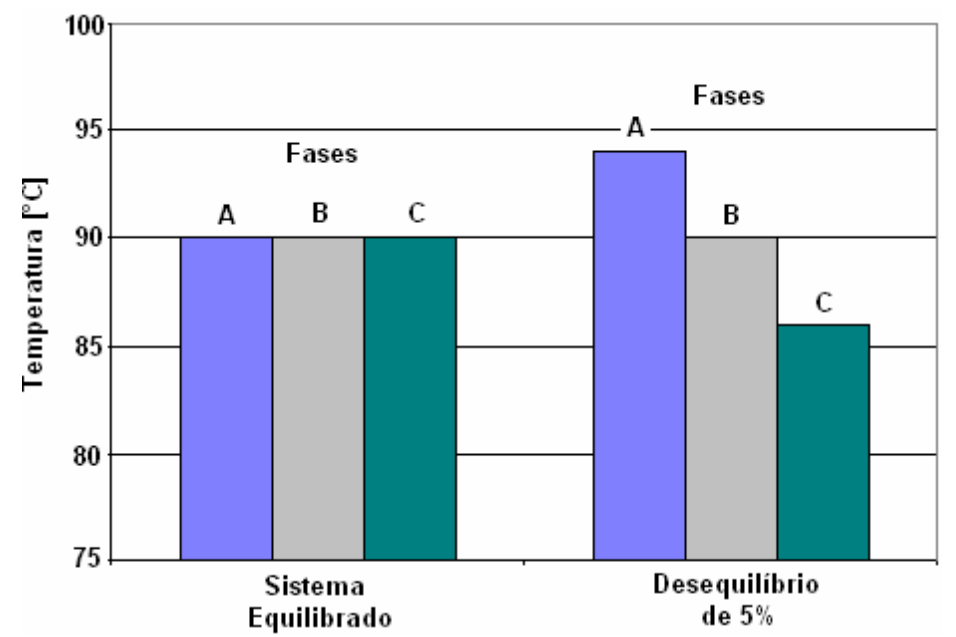

Figura 3.8 - Temperatura dos condutores

Note-se na Figura 3.8 que a fase A foi a mais solicitada e seu condutor apresenta uma temperatura maior que a nominal, enquanto a fase $\mathrm{C}$ foi percorrida por corrente menor que a nominal. A fase B foi mantida com tensão nominal e não sofreu mudança de temperatura.

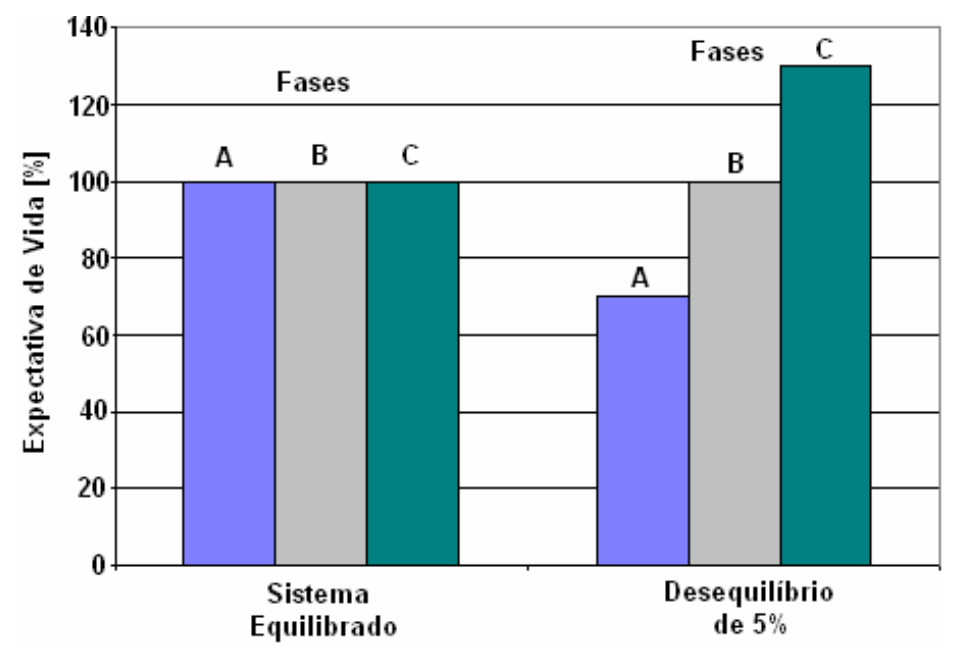

Figura 3.9 - Expectativa de vida dos condutores

Como o esperado, a Figura 3.9 representa um reflexo da situação descrita para o gráfico anterior, onde a expectativa de vida na fase A é reduzida, em decorrência da elevação da temperatura. Como na fase $\mathrm{C}$ a temperatura é menor que a nominal, sua vida útil é aumentada. 


\subsubsection{Relés de Proteção Microprocessados}

Atualmente, os sistemas de proteção vêm se relacionando cada vez mais com os fenômenos da qualidade da energia. Isso porque as características de operação dos relés de proteção trazem informações e influenciam na forma que alguns dos distúrbios se manifestam. Os problemas da QEE afetam o funcionamento dos relés e podem levar os mesmos a trabalharem próximos dos limites neles ajustados.

No que tange aos desequilíbrios de tensão, os mesmos podem mascarar uma condição de falta para os relés, desde que os níveis de desequilíbrio sejam suficientemente elevados comparados com os valores ajustados nos relés. Assim, a função de desequilíbrio do relé deve ser ajustada considerando valores mínimos de desequilíbrio que já se sabe estar presente no sistema, evitando desligamentos desnecessários. Quando isso não é possível, é preciso desabilitar a função de desequilíbrio dos relés (BALZI, 2005).

\subsection{Normas e Recomendações}

Atualmente, percebe-se a interação de diversos agentes no setor elétrico. Estão presentes empresas geradoras, distribuidoras, comercializadoras privadas, produtores independentes, consumidores livres, além das empresas de transmissão, do operador e do regulador/fiscalizador. O ambiente de competitividade está consolidado e os aspectos concernentes à operação com qualidade tornaram-se exigência. Neste ínterim, são necessárias a definição e apuração de indicadores e índices de referência capazes de refletir corretamente a degradação da QEE, cobrindo os inúmeros aspectos envolvidos no seu contexto, e que tenham um bom nível de consenso entre os agentes atuantes (DECKMANN, 2000).

Face à inquestionável complexidade de se solucionar esta questão, percebe-se que a concepção e implantação de alguns índices e indicadores acabam por não satisfazer a premissa de quantificar e qualificar os efeitos dos fenômenos sobre as cargas/processos dos consumidores, fugindo ao seu objetivo principal.

Adicionalmente, a questão dos protocolos de medição, de onde são definidas as estratégias de medição dos fenômenos e que resultam na formação do banco de dados que 
caracterizam um determinado local, ainda é objeto de estudos inconclusos. Desta forma, não se tem a definição cabal de uma metodologia de medições para os distúrbios da qualidade da energia, refletindo no questionamento da validação dos indicadores hoje analisados.

Os atributos essenciais dos indicadores compreendem (RAMOS, 2000b):

- Os indicadores devem ser transparentes, de fácil compreensão e implementação;

- Ter correlação com a sensibilidade das cargas e estabelecer relações de causaefeito;

- Serem diferenciados por região, se necessário, a depender das particularidades da topologia dos sistemas elétricos regionais;

- Permitirem harmonização entre a transmissão e a distribuição e possibilitarem clara alocação de responsabilidade entre agentes;

- Serem obtidos a partir dos parâmetros estatísticos dos componentes do sistema;

- Serem mensuráveis a partir dos dados históricos da operação, permitindo comparações entre valores previstos por cálculo e os valores medidos;

- Atenderem às necessidades dos consumidores e dos órgãos reguladores em termos de quantificação e qualificação do desempenho do sistema.

Em meio a este desafio denodado, existem diversas normas e recomendações internacionais que tratam dos fenômenos da QEE, especialmente procedentes dos grupos de trabalho europeus e americanos. Nos dias de hoje, a Agência Nacional de Energia Elétrica (ANEEL) e o Operador Nacional do Sistema (ONS), em parceria com universidades, centros de pesquisa, fabricantes de equipamentos e consumidores traçam os documentos que formarão a normalização brasileira dos fenômenos vinculados com a qualidade da energia elétrica.

A seguir, será apresentada uma síntese das principais normas e recomendações que versam sobre o desequilíbrio de tensão. 


\subsubsection{IEC - International Electrotechnical Commission}

As recomendações IEC constituem-se nos fundamentos da grande maioria das normas. É comum se encontrar uma correlação entre os critérios adotados na presente recomendação e o praticado em diversas outras recomendações e normas ao redor do mundo.

O objetivo da IEC é promover a cooperação internacional em questões relativas a normas/recomendações/orientações dos setores elétrico e eletrônico. Tal órgão publica documentos para o uso internacional, tais como normas, relatórios técnicos e manuais.

A IEC 1000-2-2 - "Electromagnetic Compatibility (EMC), Part 2, Section 2: Compatibility levels for low-frequency conducted disturbances and signaling in public low-voltage power supply systems", First Edition, 1990-5, apresenta conceitos relacionados com os desequilíbrios de tensão. No que se refere aos desequilíbrios, os documentos IEC oferecem, apenas uma orientação quantitativa dos limites recomendados. Sugere-se um nível máximo de $2 \%$ de seqüência negativa em relação à componente de seqüência positiva para sistemas de baixa tensão. Eventualmente, como em casos de curtos-circuitos, pode-se alcançar valores maiores a esse, durante períodos limitados.

A IEC não faz referência aos protocolos de medição específicos para desequilíbrios.

\subsubsection{CENELEC - European Committee for Electrotechnical Standardization}

A norma do CENELEC EN50160 - "Voltage Caracteristics of Eletricity Supplied by Public Distribution Systems", de novembro de 1994, estabelece os procedimentos comuns a serem empregados no contexto europeu. Está relacionada com as características de qualidade da tensão em níveis de baixa e média tensão, a serem analisadas no ponto de acoplamento com o consumidor.

A CENELEC estabelece que, em condições normais de suprimento, durante o período de sete dias consecutivos, apenas 5\% dos valores RMS da componente de seqüência negativa podem ultrapassar $2 \%$ da componente de seqüência positiva. As medições devem possuir pontos a cada dez minutos. Caso os consumidores sejam monofásicos ou bifásicos, admitese desequilíbrios de até 3\% (OLIVEIRA, J.C.; 2000a, 2000b). 
Esta norma não se aplica à operação após uma falta e/ou através de arranjo de suprimento temporário, como processos de manutenção, construção ou perda de alimentação, além de outras condições excepcionais.

A fundamentação para a metodologia adotada na medição não é clara na norma. A EN50160 não faz referência aos locais de medição nem à quantidade de pontos a serem monitorados.

\subsubsection{NRS 048 - National Electricity Regulator}

A norma sul-americana, NRS 048, compõe um documento atual que aborda vários aspectos estabelecidos por outras normas conhecidas mundialmente. Foi elaborada por representantes da "South African Electricity Supply Industry" e foi aprovada em novembro de 1996. Esta norma foi fundamentada em diretrizes estabelecidas pela IEC e pela CENELEC, além de relatórios e dados locais disponíveis.

Os métodos de cálculo do desequilíbrio adotados são o das componentes simétricas e o do CIGRÉ. O valor limite de desequilíbrio é de $2 \%$, a menos das localidades onde há predominância de consumidores monofásicos ou bifásicos. Para estes locais o limite é de 3\% (Oliveira, J.C.; 2000a, 2000b).

O período de medição deve ser de uma semana, tendo dados disponíveis a cada 10 minutos, observando-se o tratamento estatístico para as amostras. Os valores que devem ser comparados com os limites estabelecidos são os maiores valores dentre aqueles medidos diariamente.

Não há menção sobre a fundamentação do protocolo de medições para o item de conformidade de desequilíbrios.

\subsubsection{ANSI - American National Standard Institute}

A norma ANSI - C84.1 - 1995, complementa a bibliografia americana apresentando diretivas sobre a questão do desequilíbrio de tensão, estabelecendo valores nominais de tensão e tolerâncias operacionais para sistemas de 100 V a 230 V em 60 Hz. 
De acordo com a presente norma, o desequilíbrio deve ser quantificado por meio da expressão fornecida pelo NEMA. Recomenda que os sistemas de suprimento elétrico devem ser projetados e operados de forma que o desequilíbrio não ultrapasse $3 \%$, sob condições a vazio (Oliveira, J.C.; 2000a; 2000b).

Não apresenta em seu conteúdo, qualquer abordagem quanto aos protocolos de medição.

\subsubsection{Legislação Nacional}

No Brasil, os primeiros passos voltados a assegurar "um serviço adequado de fornecimento de energia elétrica" deram-se através do então regulador DNAEE, o qual emitiu as Portarias 046 e 047 de abril de 1978 e a Portaria 031 de 1980.

Grupos de trabalho no GCOI e GCPS (Grupo Coordenador para Operação Interligada/Grupo Coordenador de Planejamento dos Sistemas Elétricos) iniciaram estudos visando propor uma metodologia de medição e limites que passariam a ser adotados no gerenciamento e controle dos distúrbios da qualidade da energia. Em 1993, fazendo uso da larga experiência já adquirida por grupos de trabalho internacionais e de algumas empresas brasileiras, foi elaborado o documento "Critérios e Procedimentos para o Atendimento a Consumidores com Cargas Especiais", de autoria do GCOI e GCPS. Em novembro de 1997 este documento foi complementado pelo "Procedimentos de Medição para Aferição da Qualidade da Onda de Tensão ao Aspecto de Conformidade (Distorção Harmônica, Flutuação e Desequilíbrio de Tensão)". Nestes documentos foram definidas diretrizes que se referem à avaliação e o controle das perturbações causadas por cargas não-lineares, intermitentes ou desequilibradas (Oliveira, J. C., 2000a).

Em 26 de Agosto de 1998 foi criado o ONS (Operador Nacional do Sistema) responsável pela coordenação e controle da operação das instalações de geração e transmissão de energia elétrica no Sistema Interligado Nacional (SIN), sob a fiscalização e regulação da Agência Nacional de Energia Elétrica (ANEEL).

O ONS possui os Procedimentos de Rede, que são documentos elaborados com a participação dos Agentes e homologados pela ANEEL, os quais estabelecem os procedimentos e os requisitos técnicos para o planejamento, a implantação, o uso e a 
operação do SIN e as responsabilidades do ONS e de todos os demais agentes de operação (ONS, 2006).

O Módulo 2 dos Procedimentos de Rede trata dos "Requisitos Mínimos para Instalações e Gerenciamento de Indicadores de Desempenho da Rede Básica e de seus Componentes". Em 2002 foi autorizada a utilização, em caráter provisório, do submódulo 2.2 que traz os "Padrões de Desempenho da Rede Básica".

A ANEEL, por sua vez, está em processo de elaboração dos Procedimentos de Distribuição (PRODIST). São documentos na forma de regulamentações, normatizações e padronizações que têm como objetivo possibilitar a conexão elétrica aos sistemas de distribuição por usuários, garantindo que os indicadores de desempenho ou de qualidade de serviço sejam atingidos de forma clara e transparente (ANEEL, 2006). O Módulo 8 do PRODIST intitula-se "Qualidade da Energia Elétrica” (ANEEL, 2005).

\subsubsection{Procedimentos de Rede - Submódulo 2.2}

Estabelece que o cálculo do indicador $\mathrm{K}$ deve ser feito a partir do método das Componentes Simétricas e que o limite global é de 2\% de desequilíbrio. Quando da determinação do valor a ser comparado com tal limite deve-se:

1) identificar qual é o valor com probabilidade de $95 \%$ de não ser excedido (P95\%) calculado considerando 1 dia, para 7 dias de análise.

2) o valor indicador corresponde ao maior dentre os sete adquiridos anteriormente, em base diária.

"Caso as tensões de seqüência negativa variem de forma intermitente e repetitiva, é permitido que os limites especificados sejam ultrapassados em até o dobro", considerando o P95\% de todo o banco de dados (ONS, 2002).

Entretanto, não é clara a determinação das características "intermitente e repetitiva". Observa-se, porém, que o uso do P95\% de todo o banco pode conduzir a um patamar bem diferente do obtido a partir do procedimento padrão supracitado. 


\subsubsection{PRODIST - Procedimentos de Rede - Módulo 8}

Este permite que o desequilíbrio de tensão seja calculado tanto pelo método das componentes simétricas como pelo método do CIGRÉ. O limite global nos barramentos da rede de distribuição deve ser menor ou igual a $2 \%$.

O período de medição deve ser de uma semana, possuindo 144 amostras diárias de dados a cada 10 minutos. O procedimento para obtenção do valor representativo é o mesmo recomendado pelo submódulo 2.2. Ao final do intervalo semanal de monitorações tem-se 7 valores correspondentes aos P95\% de cada dia. Dentre esses, será selecionado o maior valor.

\subsubsection{Quadros Resumo}

Apresentam-se, na Tabela 3.2, os índices de conformidade retirados das normas e recomendações utilizadas ao redor do mundo para o controle da Qualidade da Energia Elétrica, com relação aos desequilíbrios de tensão (fator K).

Tabela 3.2 - Índices de conformidade

\begin{tabular}{|c|c|}
\hline Recomendação / Norma & Limite \\
\hline Procedimentos de Rede & $2 \%$ \\
\hline PRODIST & $2 \%$ \\
\hline IEC & $2 \%$ \\
\hline CENELEC & $2 \%$ \\
\hline NRS-48 & $2 \%$ \\
\hline ANSI & $3 \%$ \\
\hline
\end{tabular}

A CENELEC e a NRS-048 permitem, em algumas áreas onde parte dos consumidores são monofásicos ou bifásicos, que o índice de conformidade seja igual a 3\%. Verifica-se que a maioria das normas limita em $2 \%$ o desequilíbrio de tensão. Isto mostra que os índices de conformidade convergem para este valor.

A Tabela 3.3 traz um quadro comparativo das expressões utilizadas para se calcular o fator $\mathrm{K}$ de desequilíbrio, em função das normas e recomendações supramencionadas. 
Tabela 3.3 - Quadro comparaivo

\begin{tabular}{|c|c|}
\hline Normas/Recomendações & Expressões \\
\hline IEC & $K \%=\frac{V_{2}}{V_{1}} \times 100$ \\
\hline CENELEC & $K \%=\frac{V_{2}}{V_{1}} \times 100$ \\
\hline NRS 048 & $\begin{array}{c}K \%=\frac{V_{2}}{V_{1}} \times 100 \text { ou } K \%=\sqrt{\frac{1-\sqrt{3-6 \beta}}{1+\sqrt{3-6 \beta}}} \times 100, \text { onde } \\
\beta=\frac{\left|V_{a b}\right|^{4}+\left|V_{b c}\right|^{4}+\left|V_{c a}\right|^{4}}{\left(\left|V_{a b}\right|^{2}+\left|V_{b c}\right|^{2}+\left|V_{c a}\right|^{2}\right)^{2}}\end{array}$ \\
\hline ANSI & $K \%=\frac{\Delta V}{V_{m}} \times 100$ \\
\hline *IEEE & $K \%=\frac{3(V m a ́ x-V \min )}{V_{a b}+V_{b c}+V_{c a}} \times 100$ \\
\hline PRODIST & $\begin{array}{c}K \%=\frac{V_{2}}{V_{1}} \times 100 \text { ou } K \%=\sqrt{\frac{1-\sqrt{3-6 \beta}}{1+\sqrt{3-6 \beta}}} \times 100, \text { onde } \\
\beta=\frac{\left|V_{a b}\right|^{4}+\left|V_{b c}\right|^{4}+\left|V_{c a}\right|^{4}}{\left(\left|V_{a b}\right|^{2}+\left|V_{b c}\right|^{2}+\left|V_{c a}\right|^{2}\right)^{2}}\end{array}$ \\
\hline $\begin{array}{l}\text { Procedimentos de Rede } \\
\text { Submódulo } 2.2\end{array}$ & $K \%=\frac{V_{2}}{V_{1}} \times 100$ \\
\hline
\end{tabular}

* Apesar do IEEE não fazer menção aos procedimentos de medição e a valores limites, o mesmo apresenta uma expressão de cálculo do fator K. 


\section{Capítulo 4}

\section{Ferramenta Computacional}

\subsection{Considerações Iniciais}

Nos últimos anos, observa-se uma demanda veemente por estudos relacionados ao desequilíbrio de tensão. Paralelamente, normas e recomendações internacionais estabelecem limites para o referido fenômeno, reforçando a importância desta temática. Em outra frente, há de se reconhecer que inúmeros instrumentos de medição capazes de armazenar os dados segundo as exigências das normas estão à disposição no mercado. Todavia, no que diz respeito ao tratamento e análise das amostras, segue incipiente o número de ferramentas voltadas a este fim.

Assim sendo, neste capítulo é apresentada uma ferramenta computacional destinada à análise, quantificação e qualificação dos desequilíbrios de tensão. Seu uso pode se dar por parte das concessionárias, consumidores e fabricantes de equipamentos, dentre outros, possibilitando uma investigação objetiva, clara e conclusiva a respeito da situação em que se encontra o local monitorado.

Com atenção especial para a parte de interface gráfica, o software foi desenvolvido para que os dados possam ser analisados e interpretados, sem que as informações sejam perdidas com o acúmulo das amostras. A partir da utilização de um ferramental estatístico e do uso intenso de gráficos, o programa permitirá ao usuário avaliar o comportamento e os patamares dos desequilíbrios apresentados, de posse dos bancos de dados advindos de qualquer ambiente do sistema de potência. 


\subsection{Linguagem de programação}

O aplicativo foi construído a partir da linguagem de programação do MATLAB 6.5. Os comandos do MATLAB são muito próximos da forma como são escritas as expressões algébricas, tornando mais simples o seu uso. Além disso, pacotes para cálculos específicos podem ser incorporados às rotinas por ele pré-definidas em sua vasta biblioteca de funções matemáticas. O MATLAB é um software de alta performance voltado para o cálculo numérico, cujo elemento básico de informação é a matriz. É uma linguagem apropriada ao desenvolvimento de aplicativos de cunho técnico, onde os detalhes avançados de programação podem ser dispensados, a fim de se obterem resultados metodológicos com maior velocidade.

Como auxílio para utilização do MATLAB 6.5, tem-se o documento referenciado em (GARCIA, Marcos P.; ROLIM, Thompson S., 2005a).

Para instalação do MATLAB 6.5, é recomendado um microcomputador com configuração mínima equivalente a um PC Pentium III - $1.0 \mathrm{GHz}$ com 128 MB de memória RAM.

\subsection{Estrutura do Programa}

O aplicativo foi dividido em um módulo de entrada e ainda 9 outros totalmente independentes e ao mesmo tempo complementares. A seguir, são caracterizados, de forma sucinta, cada um dos módulos que compõem a estrutura geral da ferramenta.

- Módulo de entrada: Corresponde à etapa de inicialização do aplicativo, onde é feita a leitura do banco de dados e a apresentação de suas principais características. São elas: nome do banco de dados, freqüência de aquisição, data e hora do início e do término da medição, número de minutos, horas e dias de medição. Vale citar que estas características são lidas automaticamente do arquivo do banco de dados.

- Quantificação do Desequilíbrio: Neste tópico é realizado o cálculo do fator K. Inicialmente, o usuário opta por um dos 4 métodos de cálculo. As estatísticas são então calculadas, e em seguida, os gráficos de $\mathrm{K} \%$ são disponibilizados. Como submódulos 
apresenta-se a "Análise Comparativa entre Métodos" e o "Cálculo das Diferenças entre Métodos".

- Freqüência de Aquisição: Permite a comparação de dados registrados em medições com freqüência de aquisição distintas - 1, 5, 10, 15, 30, e 60 minutos, quantificando o erro cometido nessas amostragens pré-estabelecidas, com vistas a concluir a respeito da descaracterização ou não dos dados.

- $\quad$ Similaridade entre Dias: Busca saber da existência ou não de similaridade entre os dias, almejando-se a determinação de um período mínimo de medição, diminuindo o volume de dados necessários para medição e processamento.

- Similaridade entre Períodos: Realiza uma comparação entre períodos de um mesmo dia, a fim de saber a respeito da existência ou não de similaridade entre esses períodos. Sendo assim, sua utilização se justifica pelos mesmos motivos do módulo precedente, objetivando a determinação de um período de medição representativo aos demais.

- Sensibilidade à Variações nos Ângulos e Magnitudes das Tensões: É destinado à investigação da parcela do desequilíbrio que é proveniente das variações nos módulos e ângulos das tensões, por meio de análise em separado das suas contribuições. Deseja-se, ainda, conhecer qual das três fases contribui mais para os níveis de desequilíbrio apresentados.

- Análise de Fasores: Possibilita estudar o comportamento e as estatísticas das principais grandezas do banco de dados referentes ao desequilíbrio. São elas: magnitudes e ângulos das tensões, e componentes simétricas (seqüências positiva, negativa e zero).

- Análise da Carga: Esta etapa presta-se, principalmente, como um auxílio quando da busca das causas dos desequilíbrios constatados nas análises anteriores. São disponibilizados os gráficos de tensão de linha e de fase, corrente de linha e de fase, potência ativa, reativa e aparente. É possível observar o comportamento dessas grandezas ao longo do período de medição e concluir, por exemplo, a respeito da uniformidade ou não na distribuição da carga entre as fases. 
- Distribuição no Tempo: O objetivo principal deste item é apresentar uma metodologia auxiliar de avaliação que possibilita a análise da distribuição no tempo dos diversos patamares de desequilíbrio de tensão. A partir dos resultados gerados, é possível concluir quanto à representatividade dos índices P95\%, P99\% e a média quadrática dos fatores $\mathrm{K}$, quando das suas utilizações em representação aos demais valores medidos. Adicionalmente, caberá aos fabricantes, de posse dos limites de suportabilidade de cada um dos seus equipamentos frente aos desequilíbrios, entender se o seu equipamento suporta ou não os níveis apresentados, em função do tempo de exposição.

- Qualificação do Desequilíbrio: Possibilita a apreciação dos dados com relação aos limites impostos pelas principais normas e recomendações que versam sobre o assunto.

\subsection{Conceitos estatísticos presentes na ferramenta computacional}

Em todos os módulos de análise são disponibilizadas estatísticas das grandezas em avaliação, a saber, valores máximos, mínimos, médias aritméticas e quadráticas, desvio padrão, e valores de $\mathrm{P} 95 \%$ e $\mathrm{P} 99 \%$.

\subsubsection{Definições utilizadas}

1. Máximo: Representa o valor máximo de um vetor de dados numéricos;

2. Mínimo: Valor mínimo de um vetor de dados numéricos;

3. Média aritmética: A média aritmética $(\mu)$ de um conjunto de $\mathrm{N}$ elementos, $x_{1}, x_{2}, \ldots, x_{N}$, é definida como a soma dos valores do grupo de dados dividida pelo número de elementos.

$$
\mu=\frac{x_{1}+x_{2}+\ldots+x_{N}}{N}
$$


4. Média quadrática: A média quadrática de um conjunto de $\mathrm{N}$ elementos, $x_{1}, x_{2}, \ldots, x_{N}$, é definida como a razão entre a raiz quadrada da soma dos quadrados dos valores do grupo de dados e a raiz quadrada do número de elementos.

$$
\varphi=\sqrt{\frac{\sum_{i=1}^{N}\left(x_{i}\right)^{2}}{N}}
$$

5. Desvio-padrão: $\mathrm{O}$ desvio padrão de $\mathrm{N}$ variáveis aleatórias, $x_{1}, x_{2}, \ldots, x_{N}$ é definido conforme a equação abaixo:

$$
\sigma=\sqrt{\frac{\sum_{i=1}^{N}\left(x_{i}-\mu\right)^{2}}{N}}
$$

6. $\mathbf{P 9 5} \%$ : Indica, para um conjunto de dados, o valor com probabilidade de $95 \%$ de não ser excedido.

7. P99\%: Indica, para um conjunto de dados, o valor com probabilidade de $99 \%$ de não ser excedido.

\subsection{Iniciando a Utilização do Programa}

Após a correta instalação do MATLAB 6.5, clica-se no ícone referente na área de trabalho, e a janela da Figura 4.1 será aberta. 


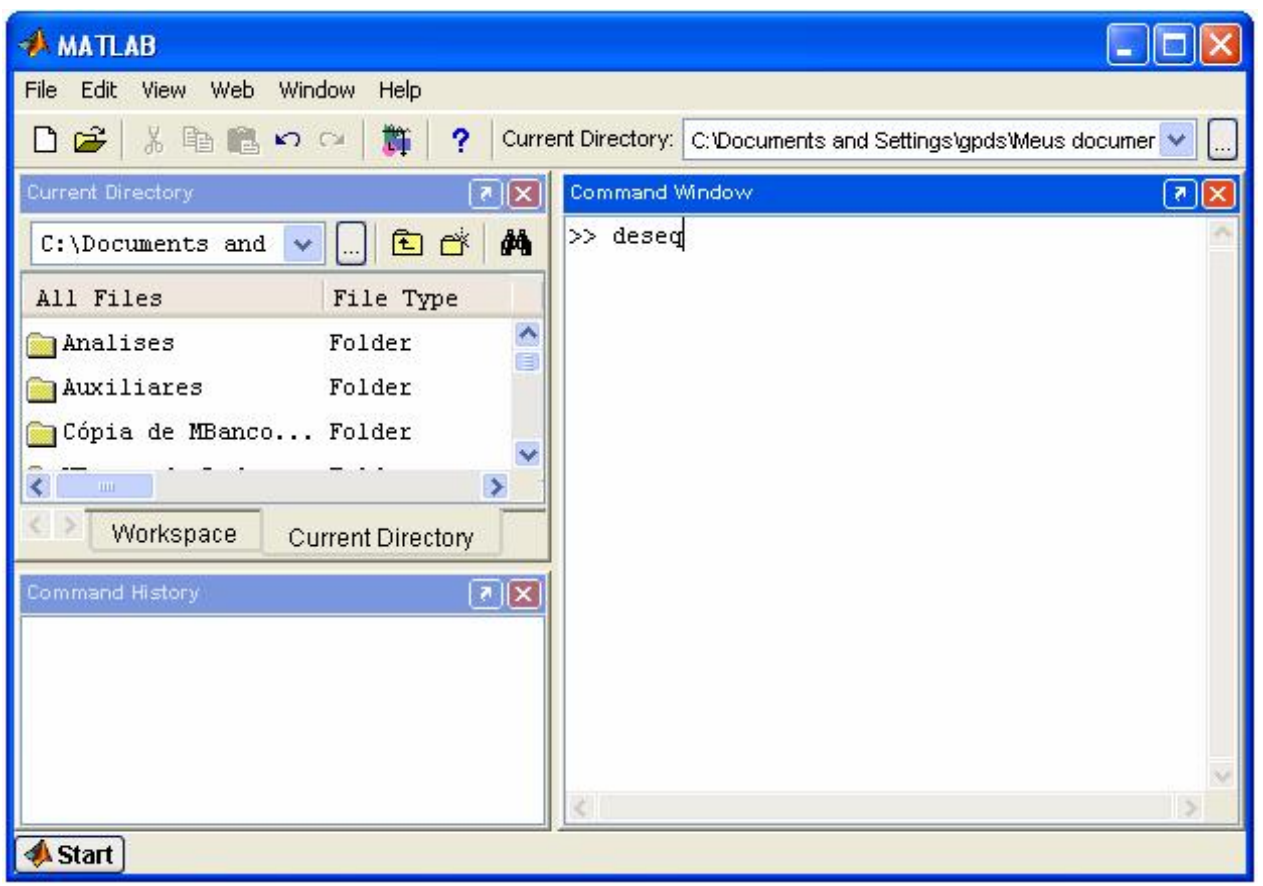

Figura 4.1 - MATLAB

Certificando-se de que a pasta contendo os arquivos do programa computacional está no Diretório Corrente (Current Directory), o usuário pode iniciar o aplicativo. Digitando-se "deseq" na janela de comandos (Command Window), como na Figura 4.1, é aberta a tela de apresentação, conforme Figura 4.2. 


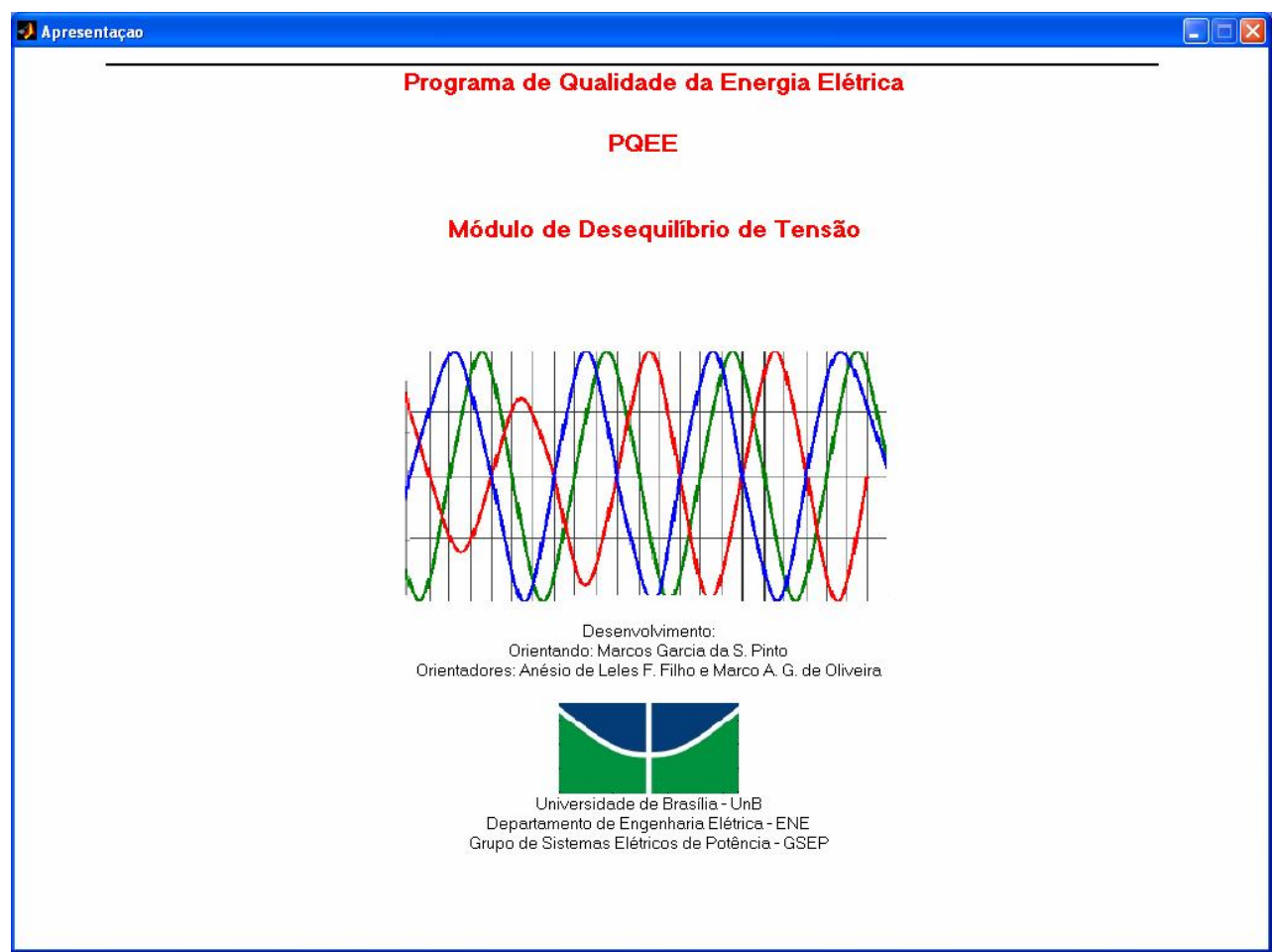

Figura 4.2 - Tela de Apresentação

Após 6 segundos, esta janela fecha e abre-se a tela do software que descreve os tópicos de análise da ferramenta, como mostrado na Figura 4.3.

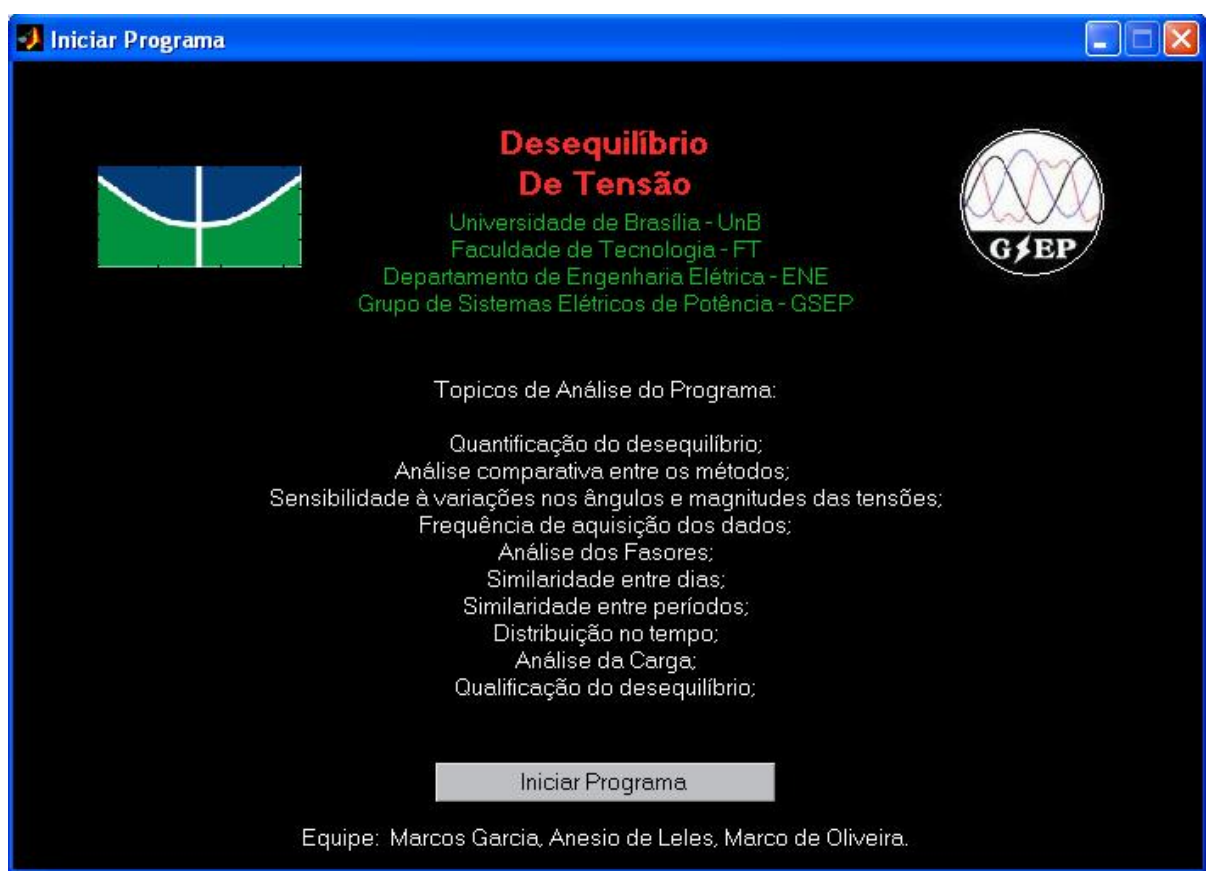

Figura 4.3 - Tela de descrição dos tópicos de análise 
A partir deste ponto, o usuário pode clicar em "Iniciar Programa", abrindo-se a janela referente ao Módulo de Entrada. A Figura 4.4 ilustra essa tela.

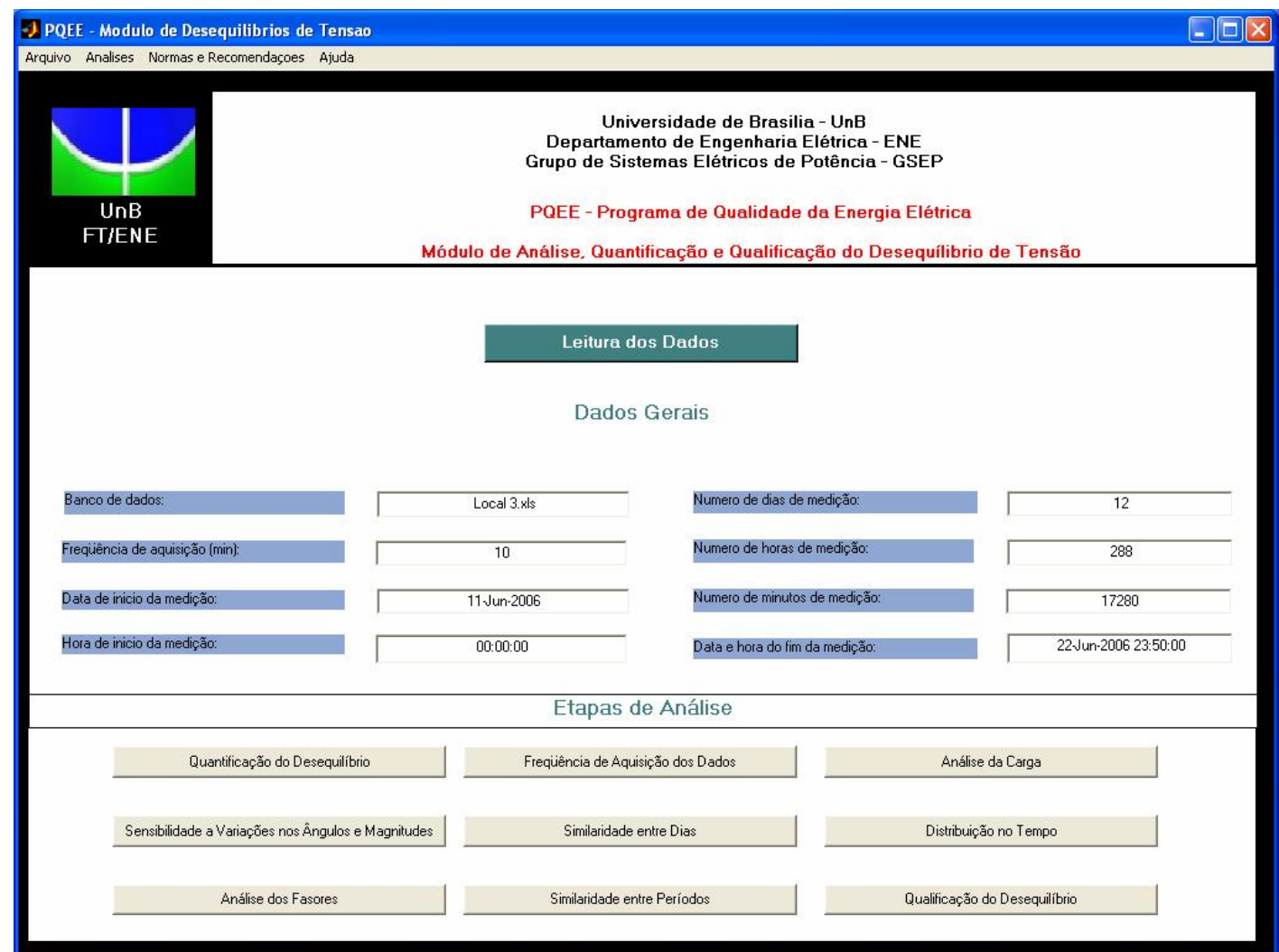

Figura 4.4 - Módulo de Entrada

A próxima etapa consiste em carregar o banco de dados. Isso é feito clicando-se em "Leitura dos Dados". O usuário deve, então, escolher o arquivo contendo os dados do local que deseja analisar, selecionando-o conforme Figura 4.5. 


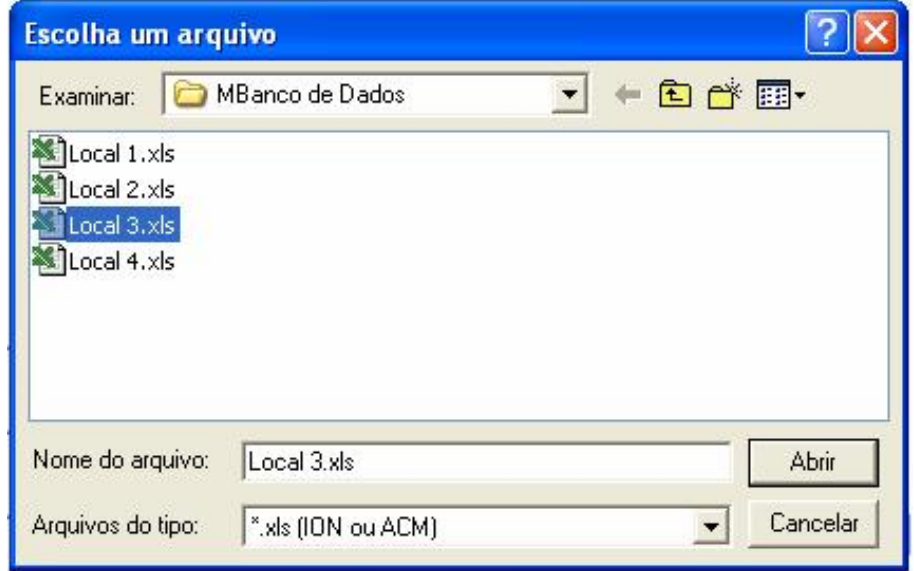

Figura 4.5 - Escolha do banco de dados

O programa lê o arquivo e a seguinte mensagem é exibida (Figura 4.6):

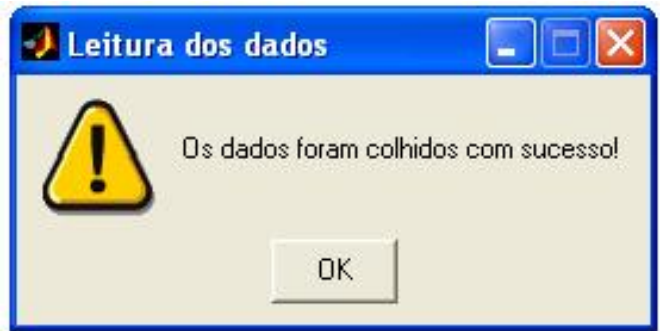

Figura 4.6 - Mensagem confirmando a leitura dos dados pelo aplicativo

Neste instante, são escritas, automaticamente, todas as características do banco de dados escolhido. O usuário pode, a qualquer momento, carregar outro banco de dados que se deseje, bastando seguir o mesmo procedimento.

\subsection{Banco de dados}

Para o caso dos desequilíbrios de tensão, os sinais monitorados devem ser tratados no domínio do tempo. Os aparelhos de medição devem ser baseados em tecnologia com microprocessadores e capacidades de processamento e armazenamento compatíveis com os requisitos impostos pelos protocolos de medição das normas/recomendações que se deseje atender (ANEEL, 2005). 
$\mathrm{Na}$ Universidade de Brasília, utiliza-se, dentre outros equipamentos, o medidor ION ("Integrated Objects Network") fabricado pela Power Measurement. Trata-se de um aparelho de aquisição de dados com uma linguagem de programação orientada a objetos, embutida com diversas funções lógicas, matemáticas e trigonométricas. As leituras de registros podem ser disponibilizadas em tempo real e gravadas em intervalos de tempo definidos. É possível o registro de mais de 600 tipos de grandezas diferentes (GARCIA, Marcos P.; ROLIM, Thompson S., 2005b).

As grandezas que devem ser medidas para o correto funcionamento do aplicativo são:

- $\quad$ Magnitude das tensões de linha;

- $\quad$ Tensões de fase, magnitude e ângulo;

- $\quad$ Componente de seqüência positiva, magnitude e ângulo;

- $\quad$ Componente de seqüência negativa, magnitude e ângulo;

- $\quad$ Componente de seqüência zero, magnitude e ângulo;

- $\quad$ Magnitude das correntes de linha*;

- $\quad$ Magnitude das correntes de fase*;

- $\quad$ Potências aparente, ativa e reativa*.

*Medidas opcionais para complementação da análise. São utilizadas no módulo de "Análise da Carga".

O banco de dados a ser lido pelo programa computacional deve estar, impreterivelmente, em formato de planilha Excell (.xls). Um exemplo de formato padrão de arquivo gerado pelo ION é o mostrado na Figura 4.7. 


\begin{tabular}{|c|c|c|c|c|c|c|}
\hline \multicolumn{5}{|c|}{ Microsoft Excel - Local 4.xls } & & $-\square \times$ \\
\hline \multirow{3}{*}{\multicolumn{7}{|c|}{ 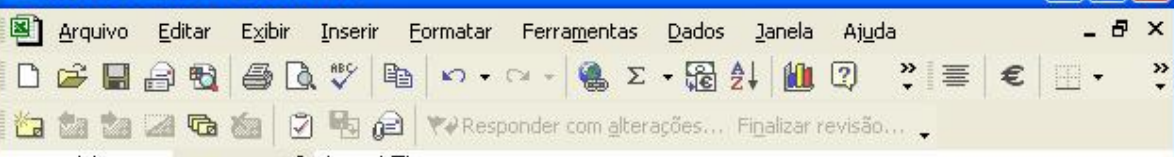 }} \\
\hline & & & & & & \\
\hline & & & & & & \\
\hline \multicolumn{7}{|c|}{ A1 $\quad-\quad f_{x}$ Local Time } \\
\hline & \multirow{2}{*}{\begin{tabular}{|c|} 
C \\
VzeroSegMg
\end{tabular}} & $\frac{D}{2}$ & E & $F$ & \\
\hline 1 & Local Time & & VzeroSeqFase & VposSeqMg & \multirow{2}{*}{\multicolumn{2}{|c|}{ VposSeqFase VI }} \\
\hline 2 & \multirow{2}{*}{$\begin{array}{l}2006 \text {-jun-04 00:00:00,000" } \\
\text { 2006-jun-04 00:10:00,000 }\end{array}$} & \multirow{2}{*}{$\begin{array}{l}71,01313019 \\
7057802582\end{array}$} & 51,58787537 & \multirow{2}{*}{132179,4219} & & \\
\hline & & & & & \multicolumn{2}{|l|}{0,00943002} \\
\hline & $2006-j u n-0400: 20: 00,000$ & 71,39920807 & 51,57102585 & 132717,2813 & \multicolumn{2}{|l|}{0,009115401} \\
\hline & 2006-jun-04 00:30:00,000 & \multirow{2}{*}{$\begin{array}{l}70,90740967 \\
7126725006\end{array}$} & 51,11325455 & 132577,0625 & \multicolumn{2}{|l|}{0,010757949} \\
\hline & 2006 -jun-04 00:40:00,000 & & 50,73899078 & \multirow{2}{*}{$\begin{array}{l}132511,2344 \\
1324517188\end{array}$} & 0,012927447 & \\
\hline & 2006-jun-04 00:50:00,000 & $\begin{array}{l}71,26 / 25000 \\
70,96369171\end{array}$ & & & & \\
\hline & 2006-jun-04 01:00:00,000 & 69,98594666 & 49,52218628 & 13217 & 0,018846067 & \\
\hline & 2006-jun-04 01:10:00,000 & 70,04496002 & 49,45760345 & 132221,4219 & 0,018046312 & \\
\hline & 2006-jun-04 01:20:00,000 & 70,961799 & & & & \\
\hline & 2006-jun-04 01:30:00,000 & 71,796051 & 83316 & 132135,6406 & 0,015611474 & \\
\hline & 2006-jun-04 01:40:00,000 & 72,17754364 & 52,34635162 & 131991,0938 & 0,019453878 & \\
\hline & 2006-jun-04 01:50:00,000 & 72,07857513 & 52,84557343 & 131829,4688 & 0,018685523 & \\
\hline & 2006-jun-04 02:00:00,000 & 72,94554901 & 53,29150772 & & 0,019176664 & \\
\hline & 2006-jun-04 02:10:00,000 & 72,87355804 & 53,61291885 & 130960,3281 & 0,018167838 & \\
\hline & 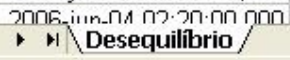 & $72 \pi 369873$ & 5A 3195.1त5 & $13 \Pi 30 \cap 585 a$ & & .15 \\
\hline Pront & & & & & Núm & \\
\hline
\end{tabular}

Figura 4.7 - Planilha contendo dados de medição

Note que na primeira coluna do arquivo estão as informações de ano, data e hora dos valores registrados.

\subsection{Apresentação da Ferramenta neste Trabalho}

Nos capítulos subseqüentes os módulos da ferramenta computacional serão detalhadamente apresentados. Será destinado um capítulo para cada módulo. Primeiramente são expostas suas respectivas telas e funções de análise, e em seguida são feitos estudos de caso que mostram suas aplicações.

Os dados utilizados são procedentes da subestação "SE Carajás" da Eletronorte - Centrais Elétricas do Norte do Brasil. Essa subestação alimenta a mineradora Serra do Sossego (MSS) que é uma empresa de mineração de cobre, com exploração e aproveitamento de jazidas minerais no município de Canaã dos Carajás/PA. Sua alimentação segue da UHE de Tucuruí por meio da SE Marabá, em 230 kV.

O diagrama unifilar do sistema junto a SE monitorada é ilustrado na Figura 4.8. 


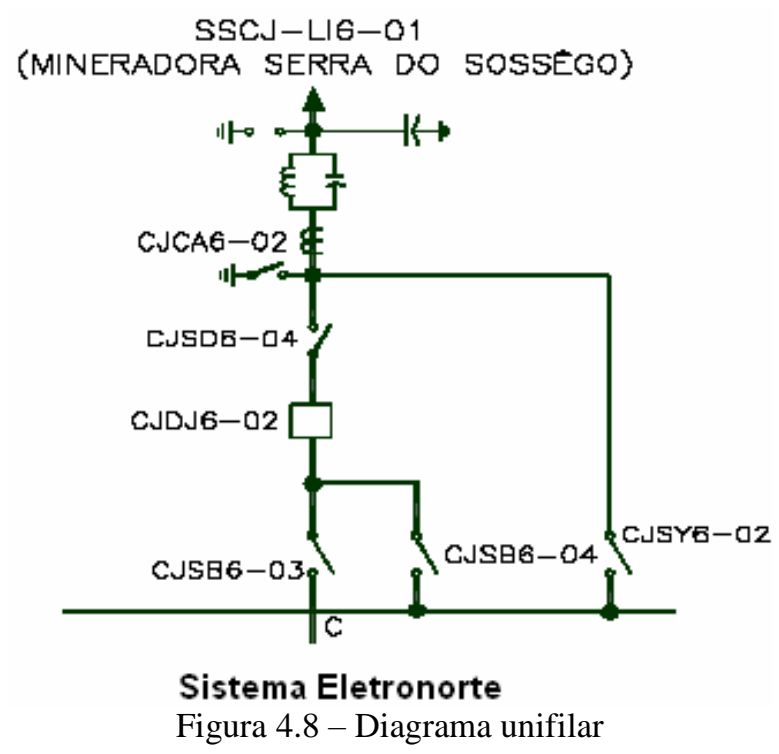

Sua localização é indicada na Figura 4.9.

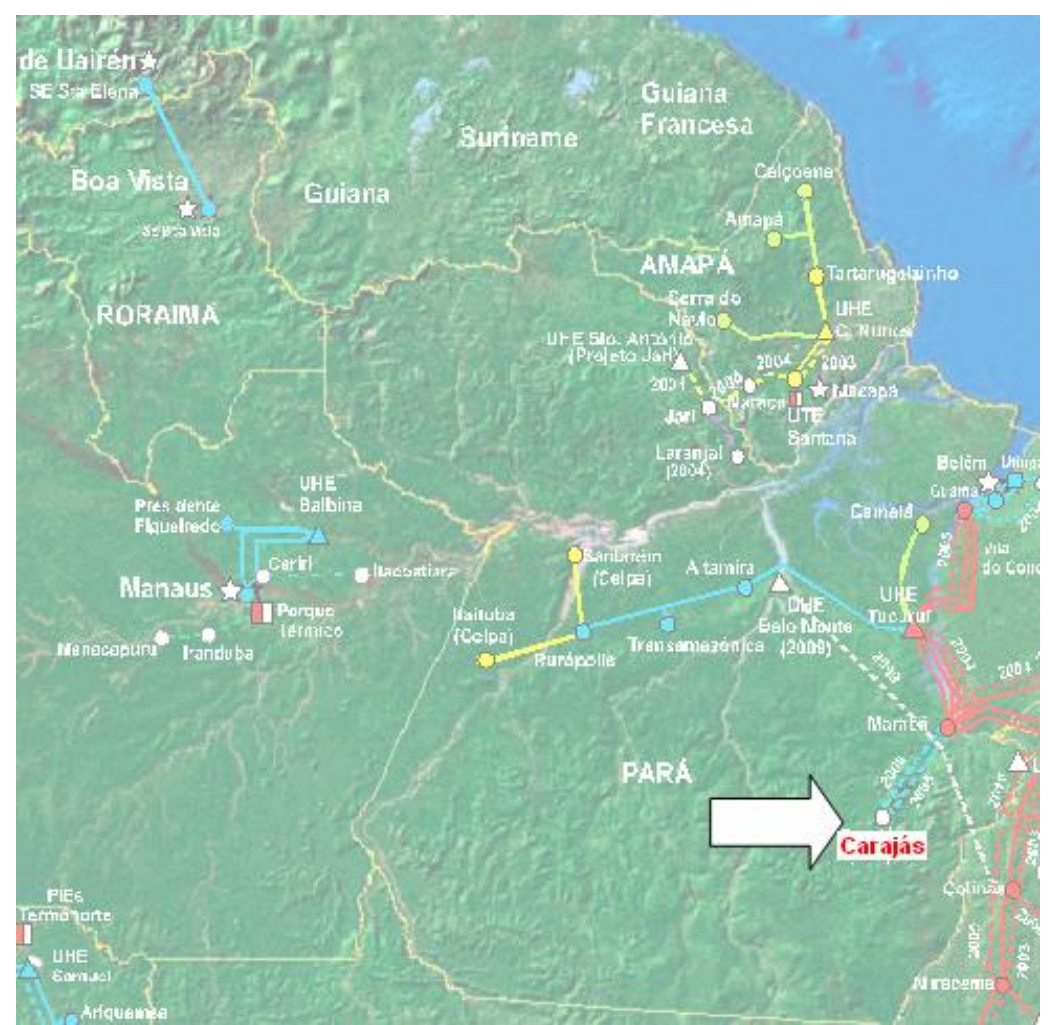

Figura 4.9 - Localização da SE Carajás

As medições foram realizadas no período de uma semana, de 4 de junho de 2006 (domingo) ao dia 10 de junho de 2006 (sábado), com dados integralizados a cada 10 
minutos. Ao se fazer a leitura dos dados pelo programa, as características do banco de dados fornecidas no módulo de entrada são mostradas na Tabela 4.1.

Tabela 4.1 - Características do Banco de Dados

\begin{tabular}{|c|c|}
\hline Banco de Dados & Carajás \\
\hline Data de Início da Medição & 04-Junho-2006 \\
\hline Hora de Início da Medição & $00: 00 \mathrm{~h}$ \\
\hline Data do Fim da Medição & 10-Junho-2006 \\
\hline Hora do Fim da Medição & $00: 00 \mathrm{~h}$ \\
\hline Freqüência de Aquisição (minutos) & 10 \\
\hline Número de Horas de Medição & 168 \\
\hline Número de Minutos de Medição & 10080 \\
\hline Número de Dias de Medição & 7 \\
\hline
\end{tabular}

\subsection{Considerações Finais}

Neste capítulo o programa computacional foi apresentado. Foram citadas suas principais características, sua estrutura e sua plataforma de funcionamento. Nos capítulos seguintes cada um dos módulos do aplicativo será apresentado, de sorte que a convicção da proficiência das metodologias propostas para a quantificação e qualificação dos desequilíbrios de tensão será formada, paulatinamente, ao longo deste trabalho. 


\section{Capítulo 5}

\section{Quantificação do Desequilíbrio de Tensão - Cálculo do Fator K e Comparação entre Métodos}

\subsection{Considerações Iniciais}

No presente capítulo é apresentado o módulo da ferramenta computacional destinado ao cálculo do desequilíbrio de tensão. São disponibilizadas as estatísticas dos níveis de desequilíbrio obtidos a partir de quatro métodos, a saber, Componentes Simétricas, CIGRÉ, NEMA e IEEE. Tem-se, ainda, nesta etapa do programa, a possibilidade de se traçar gráficos do perfil do K e o gráfico de barras de suas estatísticas.

Como recurso adicional, visando respaldar a escolha de um método de cálculo para um dado local, tem-se um submódulo de "Comparação entre os Métodos". Nele, pode-se comparar as estatísticas oriundas de cada método e plotar, conjuntamente, os gráficos ponto a ponto e de barras dos resultados encontrados. Por fim, é feita uma análise a fim de mensurar a diferença entre os métodos, fazendo-se uso, dentre outros índices, do "Coeficiente de Semelhança", que será definido mais adiante no texto.

Vale lembrar que apenas o método das Componentes Simétricas considera os ângulos e as magnitudes das tensões em sua expressão. Os demais contemplam apenas as magnitudes das tensões de linha, conduzindo a valores diferentes de fator K. Dependendo das características do banco de dados, o desvio entre os resultados obtidos pelos quatro diferentes métodos pode ser bastante relevante, haja vista a possibilidade de alterações significativas nos ângulos das tensões. 


\subsection{Módulo na Ferramenta Computacional}

A Figura 5.1 mostra a tela inicial deste módulo. Neste e em todos os capítulos posteriores destinados à apresentarão dos módulos, os dados referentes ao banco de dados da SE Carajás serão investigados minuciosamente ao fim de cada capítulo, em seções denominadas "Estudo de Caso".

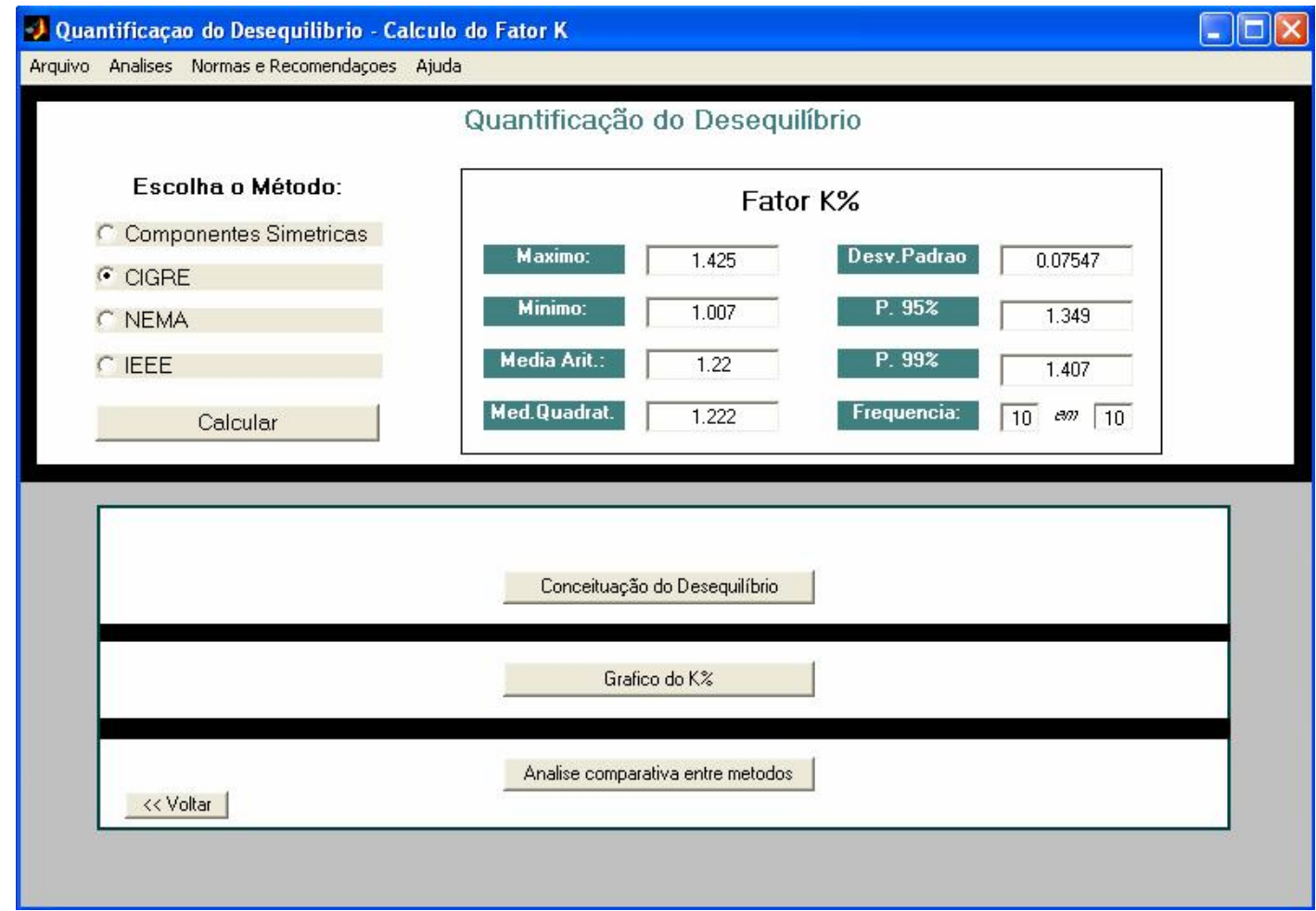

Figura 5.1 - Módulo de Quantificação do Desequilíbrio

Para agilizar a construção de relatórios e a análise dos dados dos locais monitorados, a ferramenta computacional permite que, tanto os valores estatísticos, como todos os valores de desequilíbrio calculados, sejam exportados. A Figura 5.2 ilustra a parte do menu que dispõem essa opção. Os formatos disponíveis são o de documento (.doc), planilha (.xls) e ASCII (.txt). O usuário deve escolher o formato e o local onde o arquivo deverá ser salvo. 


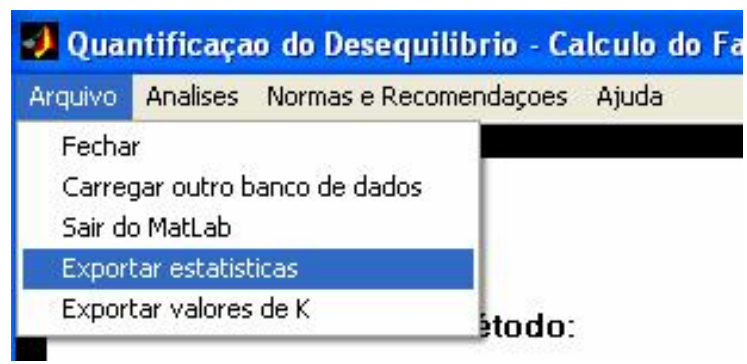

Figura 5.2 - Menu padrão

Além disso, como menu padrão, pode-se carregar um outro banco de dados e ter acesso a um resumo das principais normas e recomendações.

Considerando ainda a Figura 5.1, obtém-se, ao se clicar no botão "Conceituação do Desequilíbrio", um arquivo contendo a definição para desequilíbrio adotada neste trabalho e as expressões utilizadas por cada método de quantificação (Figura 5.3).

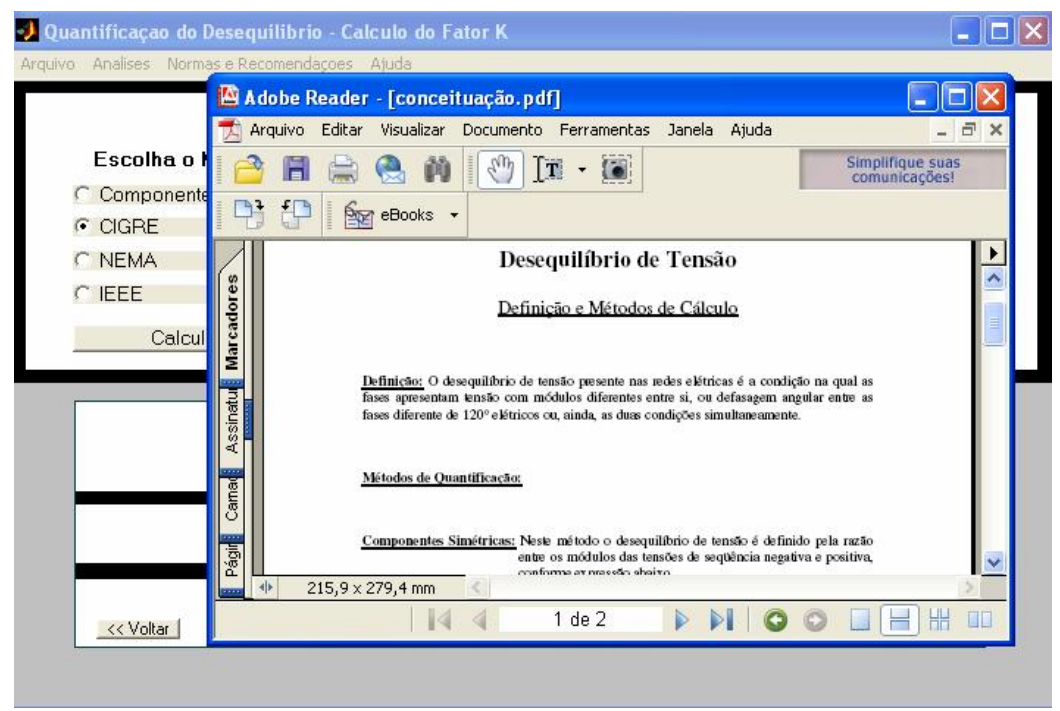

Figura 5.3 - Conceituação do Desequilíbrio

No submódulo "Gráfico do K\%" (Figura 6.1) é feita a análise gráfica do desequilíbrio, utilizando-se o método escolhido no módulo principal de quantificação. $\mathrm{O}$ usuário pode selecionar os dias que deseja analisar, e as estatísticas são novamente calculadas para o período estabelecido. A Figura 5.4 traz a tela referente a esta etapa e a Figura 5.5 mostra as opções de edição dos gráficos. 


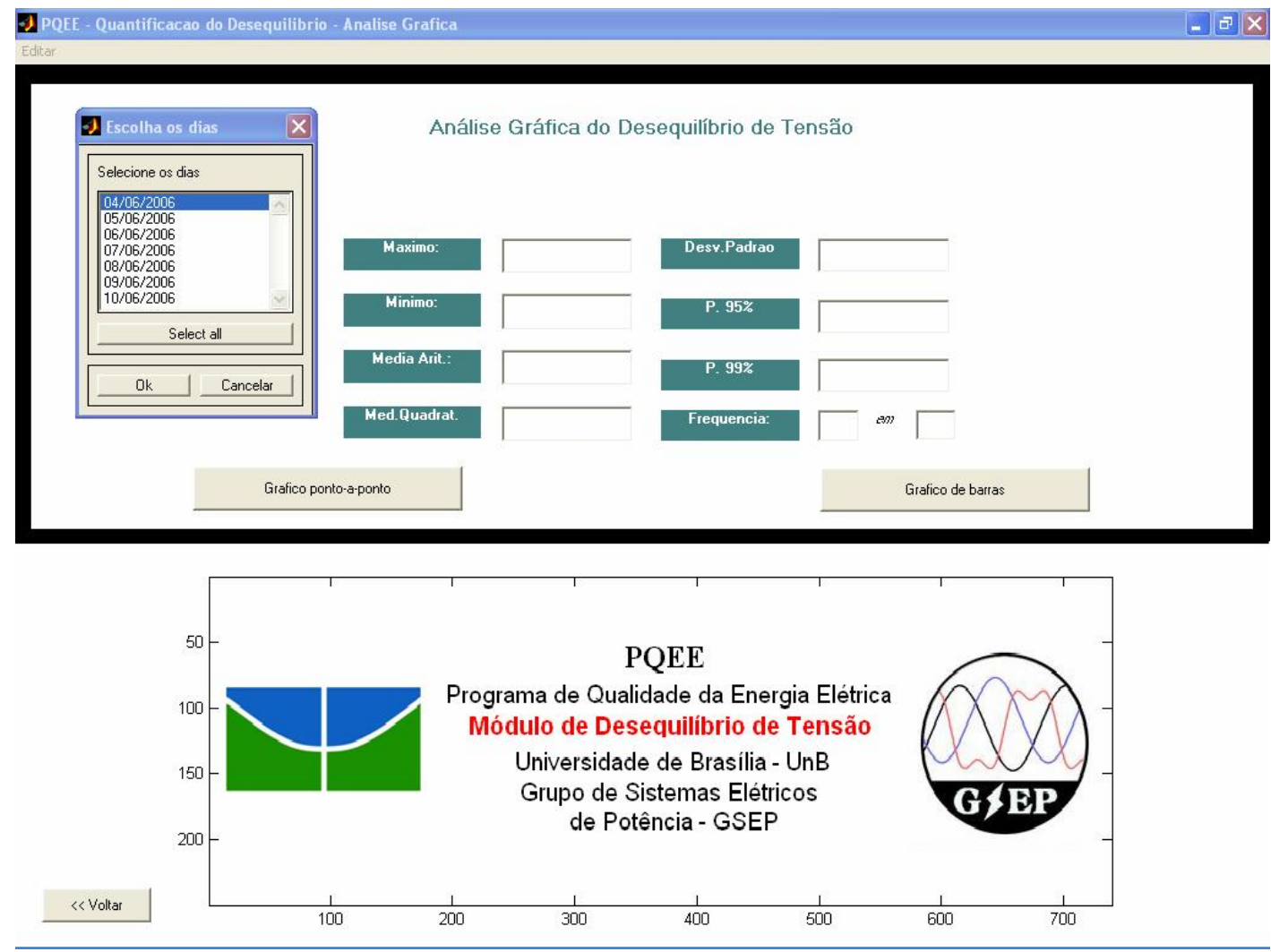

Figura 5.4- Quantificação do Desequilíbrio - Análise Gráfica

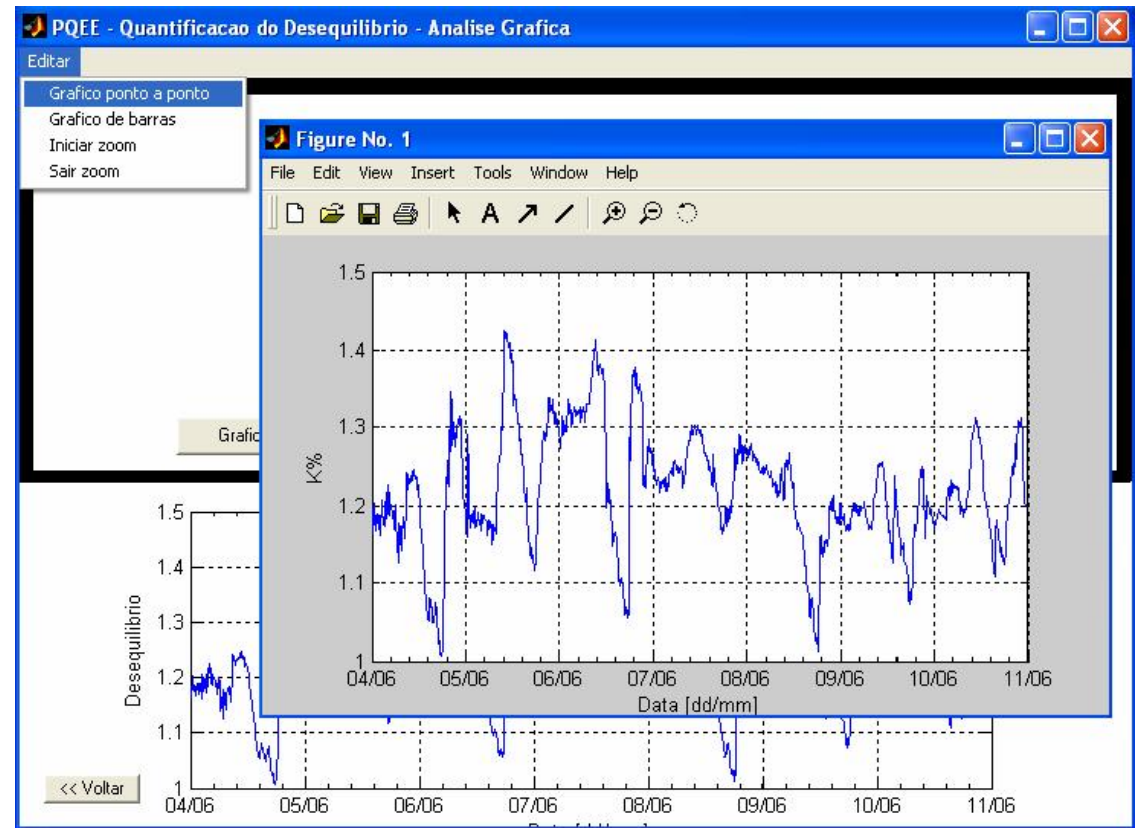

Figura 5.5 - Opções de edição 
As opções de edição estão disponíveis em todos os módulos de análise da ferramenta computacional.

A Figura 5.6 ilustra o submódulo de "Análise Comparativa entre Métodos”. É possível comparar os valores das estatísticas provenientes de cada método, bem como fazer análises gráficas.

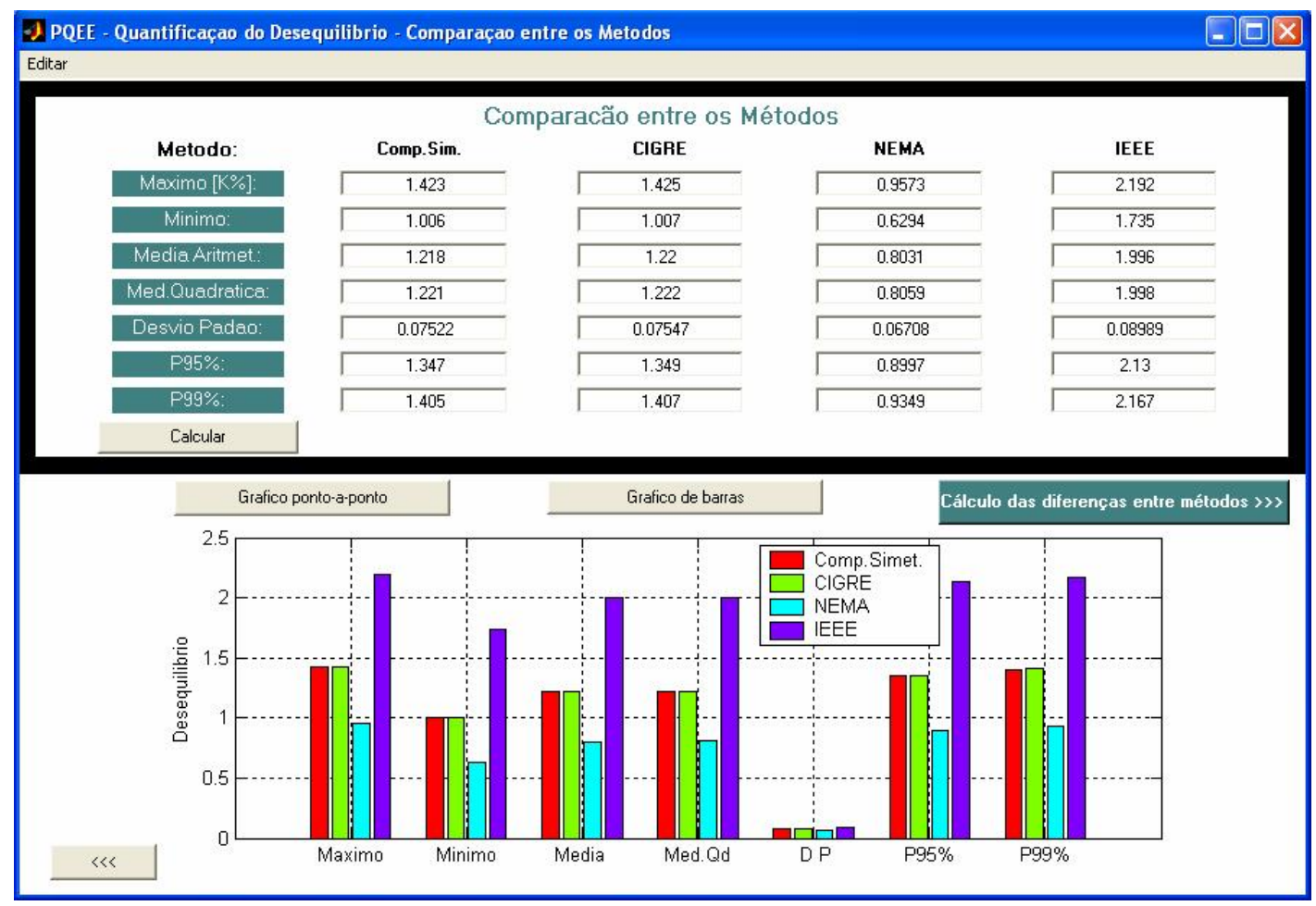

Figura 5.6 - Submódulo de Comparação entre Métodos

A partir desta tela, pode-se acessar a análise da Figura 5.7, que objetiva a verificação do grau de semelhança entre os métodos, para o banco de dados analisado.

A metodologia consiste em:

1. Escolhe-se um método como referência;

2. Para cada instante, calcula-se a diferença entre os valores calculados por cada um dos outros três métodos e o método de referência. As estatísticas do vetor formado por essas diferenças são fornecidas em valores absolutos de $\mathrm{K}$ ou em porcentagem da referência. A escolha cabe ao usuário. 
3. É disponibilizado, também, o Coeficiente de Semelhança, calculado a partir da expressão abaixo:

$$
\xi=1-\sqrt{\frac{\sum_{i=1}^{n}\left(\overline{x_{i}}-x_{i}\right)^{2}}{\sum_{i=1}^{n}\left(\overline{x_{i}}\right)^{2}}} \times 100 \%
$$

onde,

$\xi=$ Coeficiente de Semelhança;

$n=$ número de elementos do vetor;

$i=1,2,3, \ldots, n$;

$\bar{x}=$ vetor do método de referência;

$x=$ vetor de valores de $\mathrm{K}$ do método que está sendo comparado.

O uso deste parâmetro é fundamentado na Distância Euclidiana entre vetores, que pode ser utilizada como uma medida de dissimilaridade. A adaptação feita para formação da expressão acima faz com que, quando $\xi$ é igual a $100 \%$, o mesmo represente a igualdade total entre os vetores. Deste modo, $\xi$ é aqui definido como Coeficiente de Semelhança. A Figura 5.7 apresenta a tela contendo este índice. 


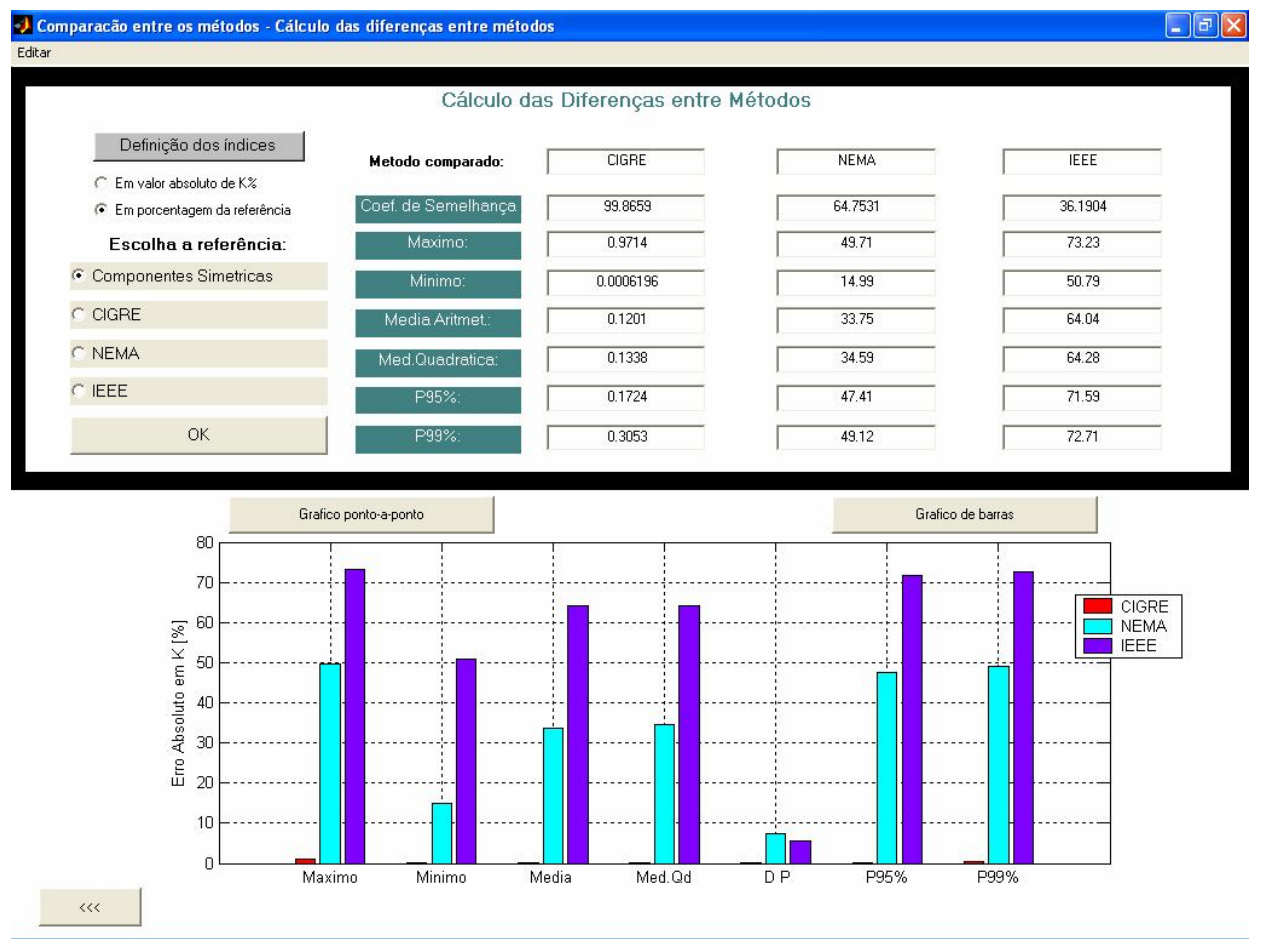

Figura 5.7 - Cálculo das Diferenças entre Métodos

Antes de começar a análise da Figura 5.7, o usuário pode ainda clicar em "Definição dos índices", tendo acesso às expressões utilizadas nesta etapa.

\subsection{Estudo de Caso}

Neste tópico serão apresentados resultados de um estudo de quantificação do desequilíbrio de tensão dos dados da SE Carajás, a partir da utilização da ferramenta computacional.

Inicialmente, serão ilustrados os resultados numéricos das estatísticas dos valores de desequilíbrio medidos em todo o período. Em seguida, são expostos os gráficos do fator $\mathrm{K}$ versus tempo de medição, com vistas ao atendimento dos objetivos almejados.

A Tabela 5.1 traz os resultados obtidos considerando o método das componentes simétricas. Esses valores são também plotados no gráfico da Figura 5.8. 
Tabela 5.1 - Estatísticas dos valores de desequilíbrio (Componentes Simétricas)

\begin{tabular}{|c|c|}
\hline Estatísticas & $\mathrm{K} \%$ \\
\hline Máximo & 0,4159 \\
\hline Mínimo & 0,02939 \\
\hline Média Aritmética & 0,2652 \\
\hline Média Quadrática & 0,2808 \\
\hline Desvio Padrão & 0,09222 \\
\hline P95\% & 0,3807 \\
\hline P99\% & 0,4029 \\
\hline
\end{tabular}

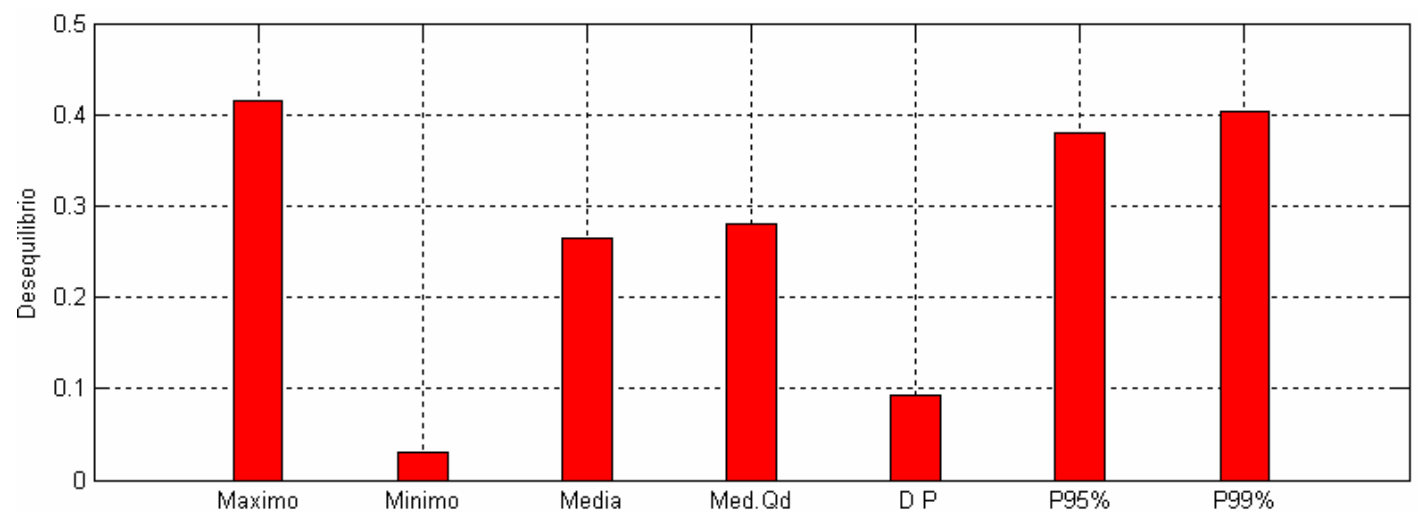

Figura 5.8 - Estatísticas dos valores de desequilíbrio (Componentes Simétricas)

Em uma análise preliminar das estatísticas, nota-se que os níveis de desequilíbrio estiveram dentro dos limites comumente utilizados pelas normas e recomendações, como ilustrados na Tabela 3.2. Nota-se pequenos valores de desvio padrão, sobretudo se comparados com medições em consumidores de baixa tensão, onde a variação da carga com o tempo é mais evidente.

A Figura 5.9 apresenta o gráfico com o comportamento do fator $\mathrm{K}$ durante todos os dias em estudo. Os dias 4 e 10 correspondem a dias de final de semana. 


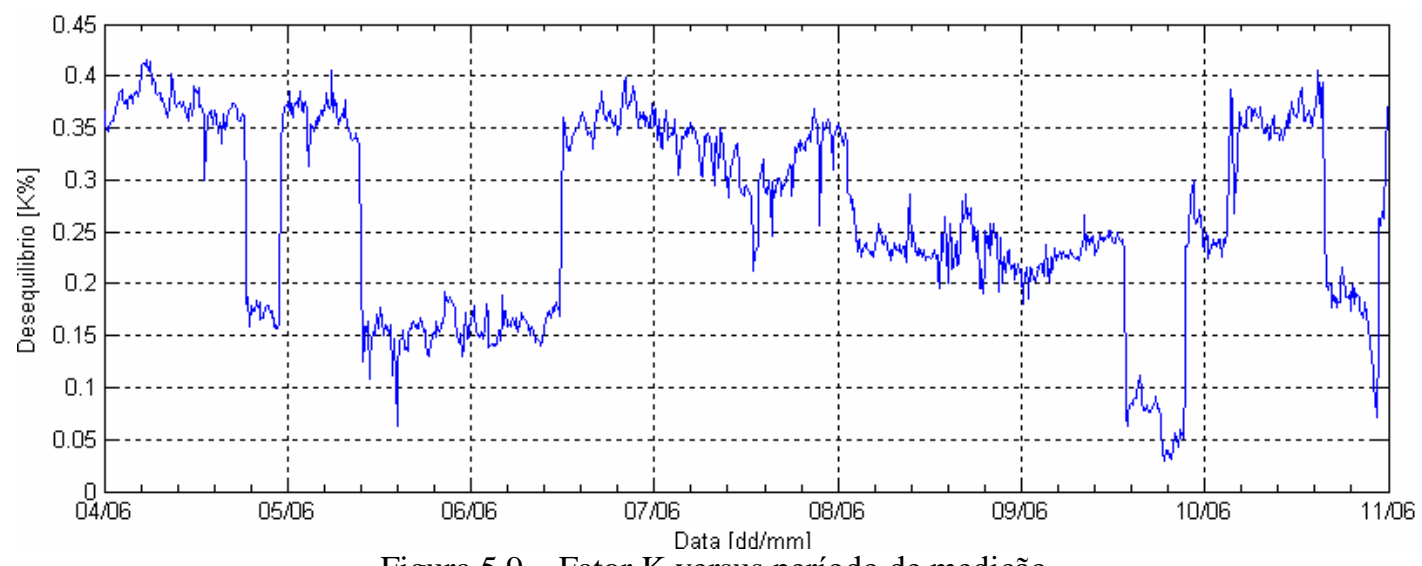

Figura 5.9 - Fator K versus período de medição

Nota-se um perfil desuniforme durante o período monitorado. A comparação entre os patamares apresentados em cada dia será feita no Capítulo 8.

A seguir são fornecidos os resultados do cálculo do $\mathrm{K}$ quando da utilização dos quatro métodos de quantificação. A Tabela 5.2 e a Figura 5.10 mostram as estatísticas.

Tabela 5.2 - Estatísticas dos valores de desequilíbrio pelos 4 métodos

\begin{tabular}{|c|c|c|c|c|}
\hline $\begin{array}{c}\text { Estatísticas } \\
{[\text { K\% }]}\end{array}$ & $\begin{array}{c}\text { Componentes } \\
\text { Simétricas }\end{array}$ & CIGRÉ & NEMA & IEEE \\
\hline Máximo & 0,4159 & 0,4124 & 0,3055 & 0,6839 \\
\hline Mínimo & 0,2939 & 0,01001 & 0,009554 & 0,01692 \\
\hline Média Arit. & 0,2652 & 0,2591 & 0,1898 & 0,4324 \\
\hline Média Quad. & 0,2808 & 0,2755 & 0,2008 & 0,4603 \\
\hline Desvio Padrão & 0,09222 & 0,0937 & 0,06573 & 0,1579 \\
\hline P95\% & 0,3807 & 0,3761 & 0,2807 & 0,6284 \\
\hline P99\% & 0,4029 & 0,3993 & 0,2931 & 0,6697 \\
\hline
\end{tabular}




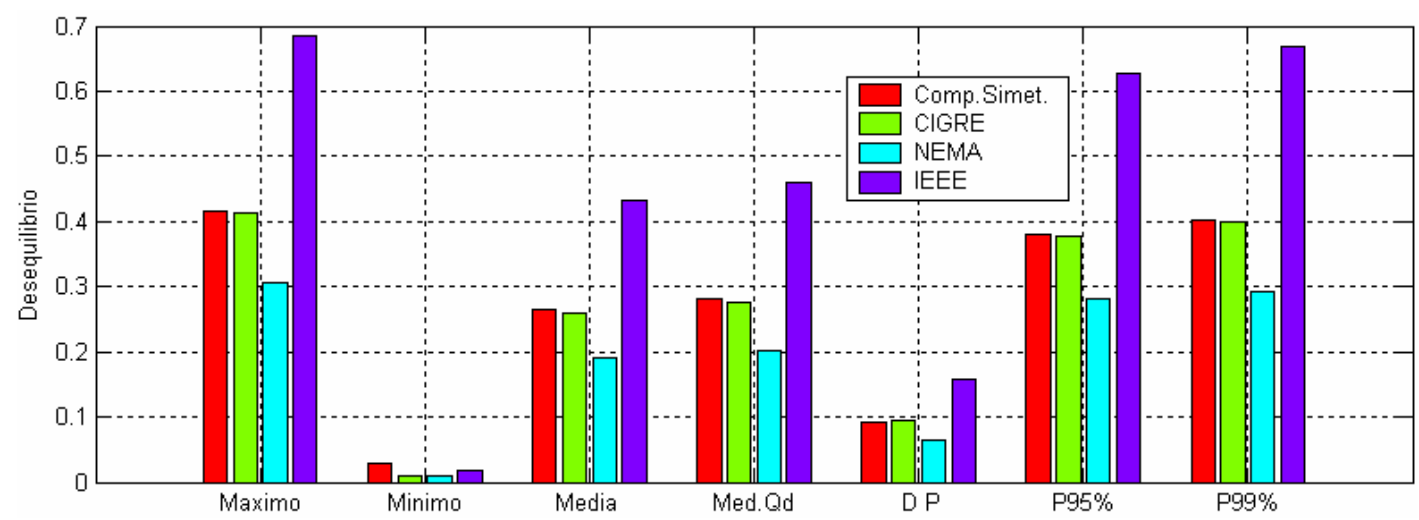

Figura 5.10 - Estatísticas dos valores de desequilíbrio pelos 4 métodos

Dos resultados obtidos, fica explícito que os dados obtidos pelos métodos divergem de maneira significativa. $\mathrm{O}$ fator $\mathrm{K}$ calculado a partir do NEMA possui os menores valores. $\mathrm{O}$ IEEE apresenta os índices mais elevados. Já o método CIGRÉ forneceu patamares muito semelhantes aos das Componentes Simétricas.

A Figura 5.11 esclarece de uma forma mais nítida essa comparação.

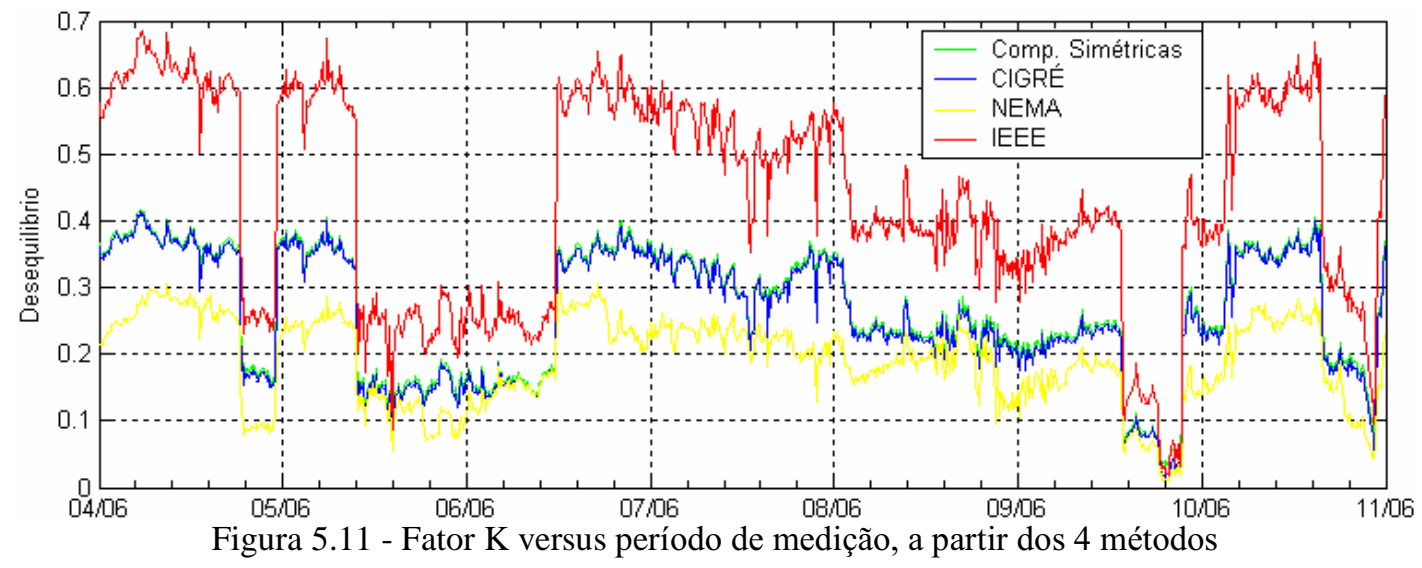

Observa-se, a partir da Figura 5.11, que em quase todo o intervalo de medição, os valores adquiridos pelo método do Cigré e das Componentes Simétricas se superpõem.

Entretanto, é importante destacar que, em alguns momentos, ocorre dos três métodos que consideram apenas as magnitudes das tensões de linha apresentarem valores inferiores aos correspondentes das Componentes Simétricas. Note-se, na Tabela 5.2, que o valor mínimo 
do método das Componentes Simétricas foi maior que o mínimo do IEEE, apesar do inverso ter sido evidenciado para as demais estatísticas. Com isto, tem-se para o método do IEEE a maior taxa de variação, culminando no maior desvio padrão.

Na Figura 5.11 é possível identificar, no dia 9, o instante em que o método das Componentes Simétricas esteve com os maiores valores de K. Tal situação é esperada em casos onde ocorram desequilíbrios provenientes de alterações nos ângulos, os quais não são imediatamente contabilizados pelos métodos alternativos.

A Figura 5.12 traz um “zoom” do dia em discussão.

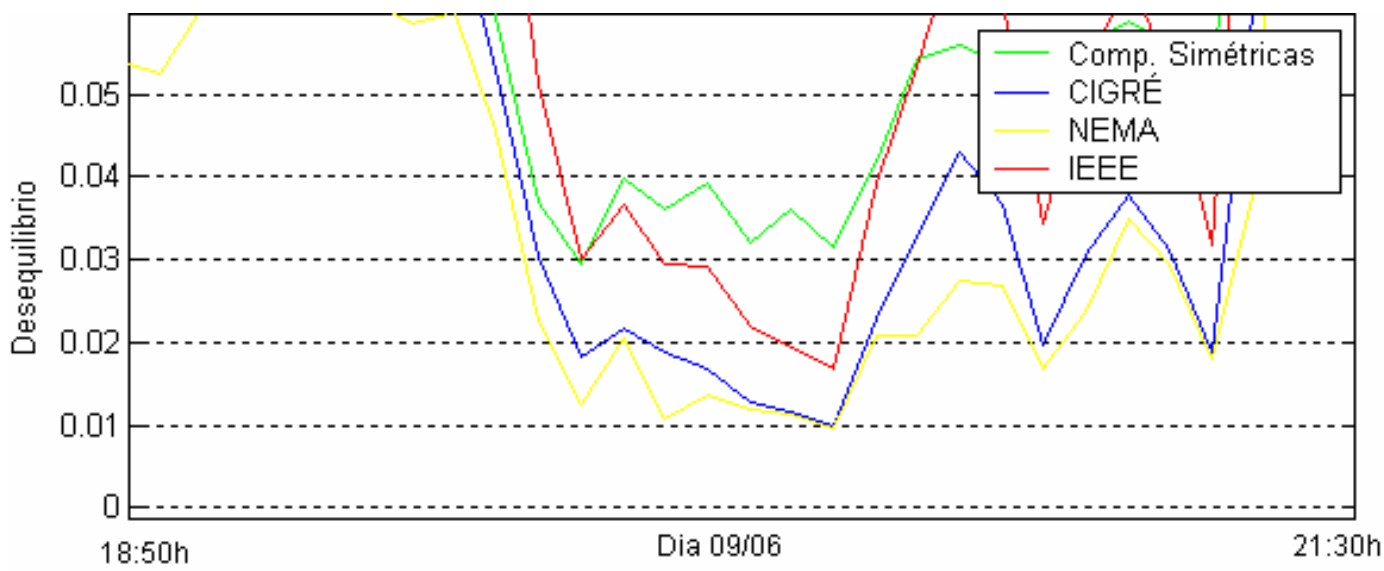

Figura 5.12 - Fator K versus período de medição, a partir dos 4 métodos (dia 09/06)

Observa-se que, em todo o período estudado, este comportamento só ocorreu no intervalo em destaque na Figura 5.12.

A seguir, são mensuradas as diferenças dos resultados fornecidos pelos métodos. Tomando-se como base o método das Componentes Simétricas, a Tabela 5.3 mostra as estatísticas do vetor que representa a diferença, em valor absoluto de $\mathrm{K} \%$, entre cada um dos 3 métodos e a referida referência. É calculado, também, o Coeficiente de Semelhança $(\xi)$. 
Tabela 5.3 - Diferenças entre métodos em valores absolutos de K (Ref.: Comp. Simétricas)

\begin{tabular}{|c|c|c|c|}
\hline Índice & CIGRÉ & NEMA & IEEE \\
\hline Coef. de Semelhança [\%] & 97,4686 & 69,7295 & 35,925 \\
\hline Máximo & 0,04767 & 0,1762 & 0,2785 \\
\hline Mínimo & 0,0002834 & 0,00221 & 0,0006939 \\
\hline Média Arit. & 0,006097 & 0,07545 & 0,1674 \\
\hline Média Quad. & 0,007108 & 0,085 & 0,1799 \\
\hline P95\% & 0,0105 & 0,1363 & 0,2541 \\
\hline P99\% & 0,02252 & 0,1493 & 0,2662 \\
\hline
\end{tabular}

Mais uma vez fica evidente que o método CIGRÉ é o que mais se aproxima do método de referência. O Coeficiente de Semelhança obtido foi de mais de 97\%. A maior diferença registrada foi de $0,2785 \%$, advinda do IEEE. Esse valor foi bem acima do máximo desvio considerando os métodos CIGRÉ e NEMA.

Os valores da Tabela 6.3 são repetidos na Figura 5.13.

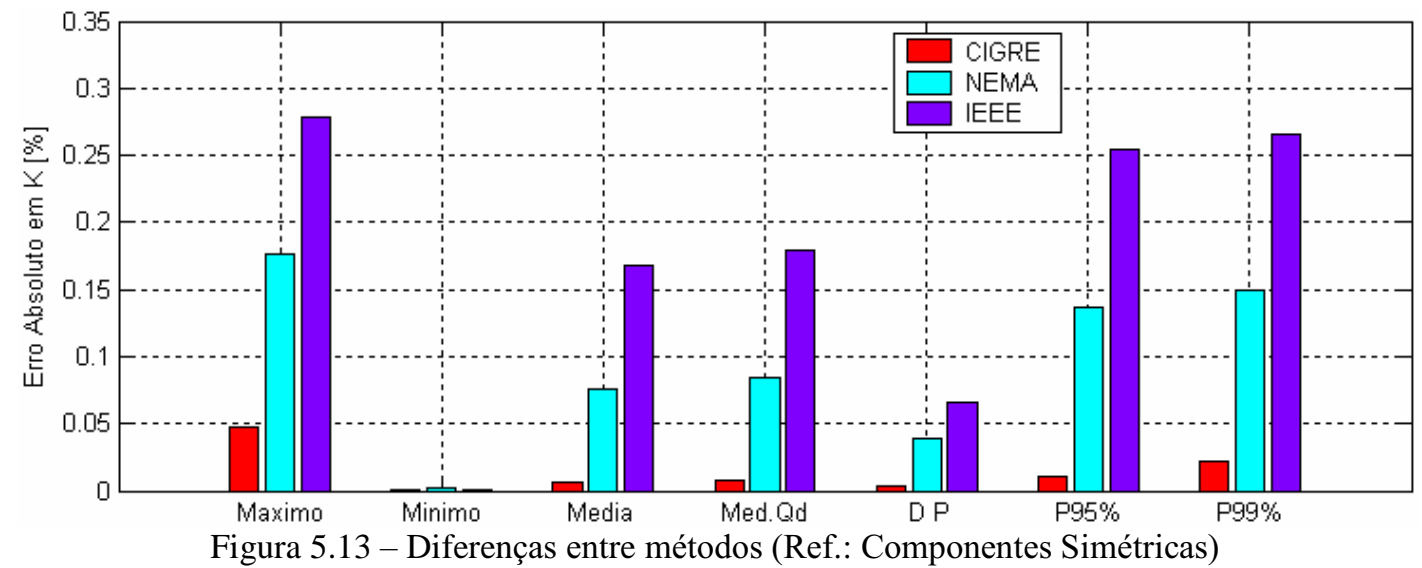

Essas mesmas estatísticas são agora calculadas em porcentagem dos valores do método das Componentes Simétricas. A Tabela 5.4 apresenta os resultados.

Tabela 5.4 - Diferenças entre métodos em porcentagem (Ref.: Componentes Simétricas)

\begin{tabular}{|c|c|c|c|}
\hline Índices [\%] & CIGRÉ & NEMA & IEEE \\
\hline Coef. de Semelhança & 97.4686 & 69.7295 & 35.925 \\
\hline Máximo & 68.24 & 70.02 & 72.06 \\
\hline Mínimo & 0.08271 & 1.43 & 1.547 \\
\hline Média Arit. & 3.384 & 28.01 & 61.55 \\
\hline Média Quad. & 7.22 & 30.42 & 62.23 \\
\hline P95\% & 6.135 & 48.77 & 69.54 \\
\hline P99\% & 44.94 & 57.75 & 70.43 \\
\hline
\end{tabular}


Observa-se que, em porcentagem, os erros oriundos dos três métodos tiveram valores máximos muito próximos (da ordem de 70\%). Porém, O IEEE apresentou, em média, diferenças de até $62 \%$ com relação ao método das Componentes Simétricas.

Constata-se, ainda, que o P95\% do vetor das diferenças considerando o método CIGRÉ foi de apenas $6,135 \%$. Significa dizer que, em $95 \%$ do tempo de medição, os valores de K calculados pelo CIGRÉ e pelas Componentes Simétricas atingiram erro máximo entre si de $6,135 \%$.

A Figura 5.14 traz o gráfico das diferenças, em porcentagem, de cada método com relação às Componentes Simétricas.

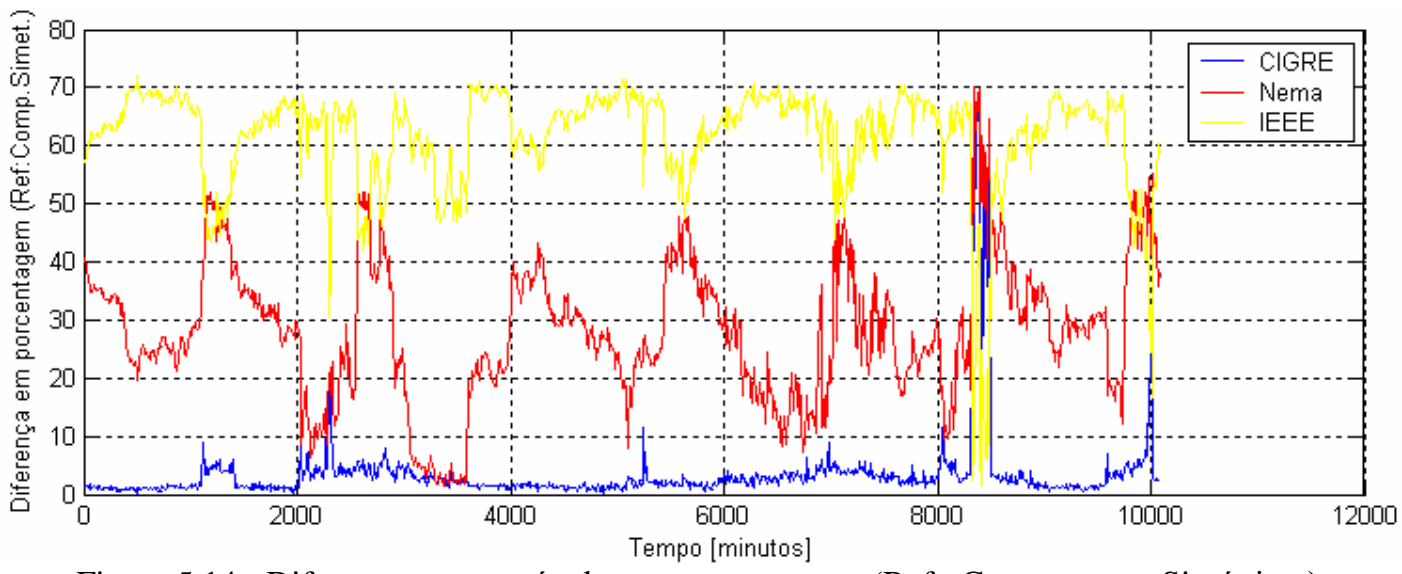

Figura 5.14 - Diferenças entre métodos em porcentagem (Ref.: Componentes Simétricas)

Ao observar o comportamento da curva referente ao CIGRÉ, fica clara a razão da grande diferença entre o valor máximo e o P95\% (minuto 8400, aproximadamente).

\subsection{Considerações Finais}

Neste capítulo foi apresentado, inicialmente, o módulo da ferramenta computacional dedicado ao cálculo do desequilíbrio de tensão. Foram também mostrados os submódulos de "Comparação entre Métodos" e "Cálculo das Diferenças entre Métodos". Suas utilizações mostraram-se de grande valia aos interessados na quantificação do desequilíbrio de tensão. As análises comparativas dos métodos norteiam o usuário quando da possibilidade de obter resultados satisfatórios sem a necessidade de se medir os ângulos. 
A partir do estudo de caso foi possível verificar que os métodos fornecem resultados significativamente diferentes. No caso estudado, a diferença chegou a $70 \%$. O método IEEE conduziu, na maior parte do tempo, aos maiores valores de desequilíbrio. Já o fator $\mathrm{K}$ calculado a partir do NEMA possui os menores valores. Das análises executadas, concluise que o método CIGRÉ é o que oferece patamares mais próximos aos das Componentes Simétricas. Deste modo, este é o método mais recomendado para a quantificação do desequilíbrio de tensão, na ausência de medições dos valores dos ângulos das tensões. 


\section{Capítulo 6}

\section{Sensibilidade do Fator de Desequilíbrio de Tensão às Variações nos Ângulos e Magnitudes das Tensões}

\subsection{Considerações Iniciais}

A maioria das recomendações e normas que tratam do desequilíbrio de tensão ao redor do mundo trazem limites para o fator K. Sabe-se, porém, que existem várias situações de desequilíbrio entre as fases que levam a um mesmo valor do fator $\mathrm{K}$, fato este não considerado nas referidas normas e recomendações.

Entretanto, os impactos na eficiência, nas perdas, no fator de potência e na temperatura dos elementos do sistema se dão de maneira distinta para cada condição de desequilíbrio em que se encontram os fasores de tensão. Deste modo, a situação exata do sistema com relação aos desequilíbrios não é mensurada corretamente apenas com o valor do fator de desequilíbrio de tensão.

Isoladamente, os desequilíbrios de tensão podem ser oriundos de:

1) Perda total de uma fase;

2) Perda total de duas fases;

3) Uma fase com tensão abaixo da nominal;

4) Duas fases com tensão abaixo da nominal;

5) Três fases com tensão abaixo da nominal;

6) Uma fase com tensão acima da nominal;

7) Duas fases com tensão acima da nominal; 
8) Três fases com tensão acima da nominal;

9) Um ângulo entre fases diferente de $120^{\circ}$;

10) Dois ângulos entre fases diferentes de $120^{\circ}$;

Estudos mostraram que, para um mesmo valor do fator $\mathrm{K}$, a eficiência de motores de indução é crescente na ordem das condições enumeradas a seguir: $05-04-03-10-09$ 06 - 07 - 08. Em alguns casos, a eficiência do motor operando em desequilíbrio é maior, inclusive, que no caso do sistema equilibrado.

As perdas, a solicitação da isolação e a temperatura nos enrolamentos do motor também variam de acordo com a forma que estiverem os fasores. Curiosamente, as maiores temperaturas ocorrem com tensões desequilibradas com valores abaixo da nominal (LEE et al, 1997).

Adicionalmente, saber o nível de desequilíbrio em uma instalação não é suficiente para sugerir os procedimentos necessários para correção do problema. Isso porque o valor de $\mathrm{K}$ não traz informações sobre de que maneira os fasores de tensão encontram-se desequilibrados.

O exposto comprova a necessidade de se conhecer a real condição de desequilíbrio do sistema, não bastando saber o valor do fator K. O sistema e grande parte das cargas respondem diferentemente às formas com que as tensões estão desequilibradas, mesmo que com o mesmo valor do K. Ademais, o conhecimento das condições dos fasores de tensão permite que sejam tomadas medidas de mitigação dos problemas de maneira mais precisa.

Ressalta-se que, os desequilíbrios no sistema não ocorrem de forma segregada como apresentado. Em geral, as condições supranumeradas estão inter-relaciondas, tornando ainda mais difícil a tarefa de se conhecer a situação dos fasores. Ao mesmo tempo em que uma fase apresenta tensão inferior à nominal, uma outra fase pode apresentar tensão elevada e, ainda, pode existir um ângulo entre fases diferente de $120^{\circ}$.

Este estudo, em particular, visa apresentar uma metodologia preliminar de análise da sensibilidade do desequilíbrio frente às variações nas magnitudes e ângulos dos fasores de tensão. Busca-se identificar a parcela do desequilíbrio que é proveniente das alterações nos 
módulos e ângulos das tensões, por meio de análise em separado das suas contribuições. Tenciona-se conhecer qual das três fases contribui mais para os níveis de desequilíbrio apresentados e, ainda, verificar qual fator influencia mais os níveis de desequilíbrio detectados, a saber, o valor de ângulo ou da magnitude.

Primeiramente é realizada uma análise teórica do comportamento do fator $\mathrm{K}$ em função da variação, em separado, dos ângulos e das magnitudes das tensões. Em seguida, será apresentado o módulo da ferramenta computacional destinado a este tipo de análise.

\subsection{Análise Teórica}

Neste estudo, a situação ideal é considerada com valores das tensões fase-neutro em $220 \mathrm{~V}$ e defasagem angular entre fases de $120^{\circ}$ elétricos.

Primeiramente, na Figura 6.1, é apresentado o gráfico com os valores de desequilíbrio para variação da magnitude de uma fase entre $180 \mathrm{~V}$ e $260 \mathrm{~V}$, em passos de $1 \mathrm{~V}$, calculados pelos 4 métodos. As outras duas fases são mantidas ideais.

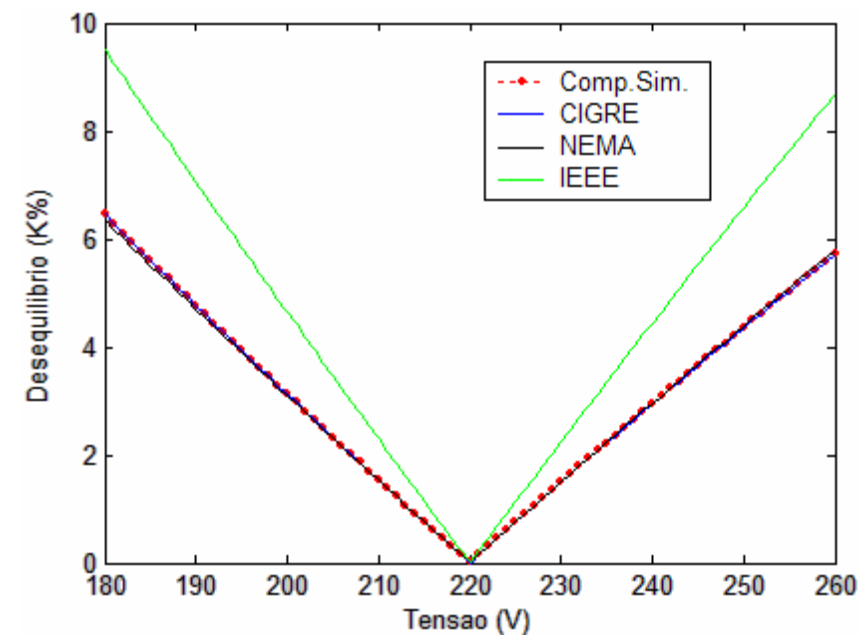

Figura 6.1 - Desequilíbrio considerando variação na magnitude de uma fase 
Em seguida, na Figura 6.2, é traçado o gráfico com os valores de desequilíbrio para variação no ângulo de uma fase entre $80^{\circ}$ e $160^{\circ}$, em intervalos de $1^{\circ}$.

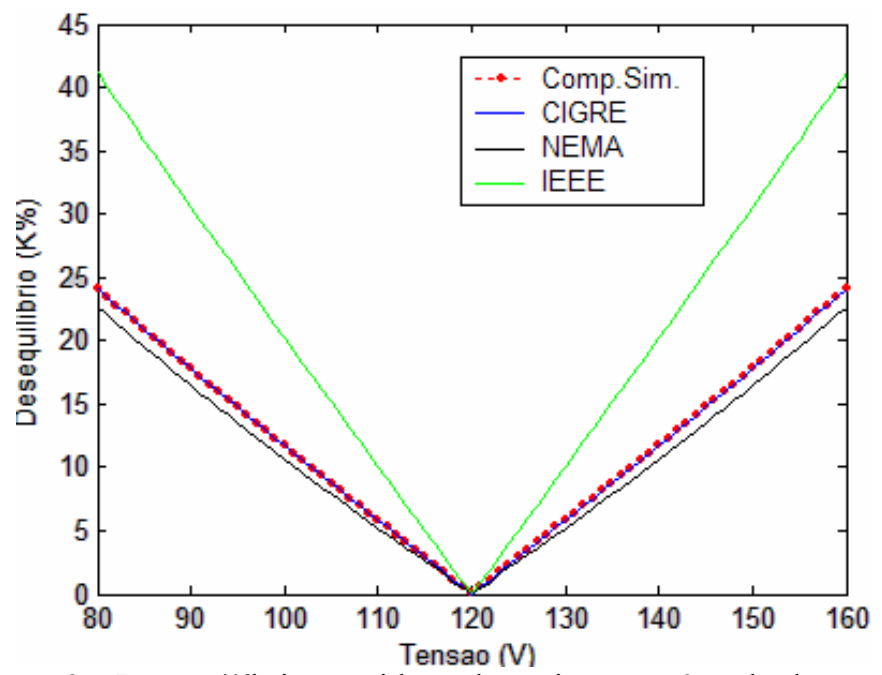

Figura 6.2 - Desequilíbrio considerando variação no ângulo de uma fase

Da comparação entre as Figuras 6.1 e 6.2, é notório que o fator $\mathrm{K}$ é mais sensível às variações nos ângulos das tensões que às variações nas amplitudes. No método das componentes simétricas, quando da alteração da magnitude (Figura 6.1), o desequilíbrio chegou a cerca de $6.5 \%$, enquanto no caso do ângulo obteve-se $\mathrm{K} \%$ aproximadamente igual a $24 \%$ (Figura 6.2).

Verifica-se na Figura 6.1 que, para todo o intervalo de variação, os valores de desequilíbrio calculados pelos métodos CIGRÉ, NEMA e componentes simétricas são praticamente os mesmos. O método do IEEE manteve sempre valores mais elevados do fator K. Porém, chama-se a atenção para o fato de que o desequilíbrio considerando apenas a magnitude não é simétrico em relação às variações para valores menores e maiores de $220 \mathrm{~V}$. Os valores obtidos entre $180 \mathrm{~V}-220 \mathrm{~V}$ são diferentes dos correspondentes entre $220 \mathrm{~V}-260 \mathrm{~V}$. $\mathrm{A}$ redução de $1 \mathrm{~V}$ de tensão produz maiores valores de desequilíbrio à elevação de $1 \mathrm{~V}$ do padrão nominal.

Já na análise dos resultados quando da comparação entre os métodos para a variação angular (Figura 6.2), nota-se um aumento no desvio existente entre os valores calculados pelos diferentes métodos à medida que cresce o desequilíbrio angular. Na comparação entre os métodos NEMA e componentes simétricas, nos valores de $80^{\circ}$ e $160^{\circ}$, a diferença 
absoluta entre os valores calculados chegou a $1,42 \%$ de desequilíbrio, o que configura um erro bastante significativo. Deste modo, comprova-se ser inadequado o uso dos métodos alternativos para a quantificação do fator $\mathrm{K}$, quando se tratar de locais que apresentam alterações angulares relevantes, podendo isto levar a um entendimento iníquo das condições do sistema. O comportamento apresentado na Figura 6.2 é simétrico em torno de $120^{\circ}$.

A Figura 6.3 e a Tabela 1 mostram o resultado da variação conjunta da amplitude e ângulo da tensão de uma fase, nos mesmos intervalos utilizados nos casos anteriores, a partir do método das componentes simétricas.

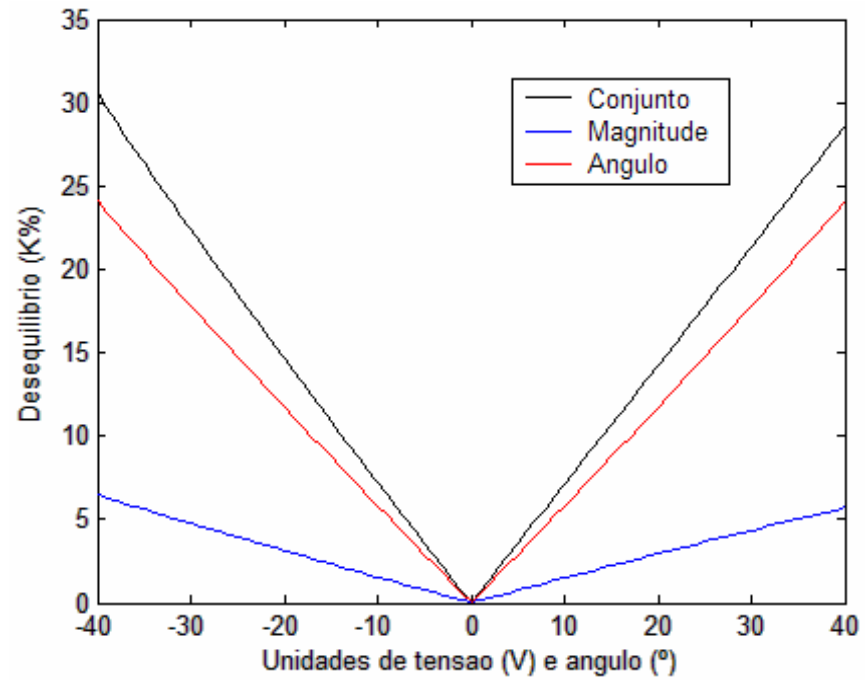

Figura 6.3 - Desequilíbrio considerando variação conjunta na amplitude e no ângulo de uma fase

Tabela 6.1 - Alguns valores encontrados nas simulações da Fig. 6.3

\begin{tabular}{|c|c|c|c|}
\hline \multirow{2}{*}{ Unidades } & \multicolumn{3}{|c|}{ Variação em uma fase } \\
\cline { 2 - 4 } & Mag.(V) & Âng. $\left.{ }^{\circ}\right)$ & Conjunto \\
\hline $\mathbf{V} /{ }^{\circ}$ & \multicolumn{3}{|c|}{ K\% } \\
\hline $207 / 107$ & 2,0093 & 7,5902 & 9,4445 \\
\hline $210 / 110$ & 1,5385 & 5,8301 & 7,2388 \\
\hline $212 / 112$ & 1,2270 & 4,6605 & 5,7783 \\
\hline $216 / 116$ & 0,6098 & 2,3279 & 2,8777 \\
\hline $218 / 118$ & 0,3040 & 1,1637 & 1,4363 \\
\hline $220 / 120$ & 0,0000 & 0,0000 & 0,0000 \\
\hline $222 / 122$ & 0,3021 & 1,1637 & 1,4319 \\
\hline $224 / 124$ & 0,6024 & 2,3279 & 2,8601 \\
\hline $228 / 128$ & 1,1976 & 4,6605 & 5,7077 \\
\hline $230 / 130$ & 1,4925 & 5,8301 & 7,1283 \\
\hline $233 / 133$ & 1,9316 & 7,5902 & 9,2572 \\
\hline \multicolumn{3}{|c|}{} \\
\hline
\end{tabular}


Da análise da Figura 6.3 e da Tabela 6.1, é possível afirmar que, a menos de um desvio muito pequeno, a soma das contribuições individuais de magnitude e ângulo para o desequilíbrio é igual ao valor de desequilíbrio para o caso simultâneo (magnitude e ângulo desequilibrados).

Ainda com relação à Tabela 6.1, nota-se que o valor do $\mathrm{K} \%$ referente às alterações na magnitude representa cerca de $20 \%$ do valor do desequilíbrio apresentado na situação de variação conjunta, enquanto as alterações no ângulo representam $80 \%$.

O patamar comumente utilizado pelas normas para qualificação do desequilíbrio é de $\mathrm{K}=$ 2\%. Observa-se na Tabela I que este valor foi atingido com a redução de $13 \mathrm{~V}$ na magnitude de uma fase e em aproximadamente $3.5^{\circ}$ no ângulo. No caso de uma elevação, é necessária uma alteração de cerca de $14 \mathrm{~V}$ na magnitude, permanecendo $3.5^{\circ}$ no ângulo. Deste modo, é teoricamente possível afirmar que aproximadamente $14 \mathrm{~V}$ de alteração na magnitude de uma fase provocam o mesmo efeito, em termos de desequilíbrio, a $3.5^{\circ}$ no ângulo, ou ainda que $4 \mathrm{~V}$ equivalem a $1^{\circ}$. Mais uma vez, evidencia-se uma maior sensibilidade do $\mathrm{K}$ aos ângulos às magnitudes das tensões.

Outra simulação foi executada, agora com a variação dos valores de magnitude e ângulo de duas fases. O intervalo de variação das magnitudes da fase B foi de 180 a $260 \mathrm{~V}$ e ângulos de -80 a $-160^{\circ}$. A fase $\mathrm{C}$ variou de 260 a $180 \mathrm{~V}$, com ângulos de 160 a $80^{\circ}$. Enquanto isso a fase A foi mantida ideal $\left(220 / 0^{\circ}\right)$.

A Figura 6.4 mostra comportamento do K para as variações de magnitude de duas fases. 


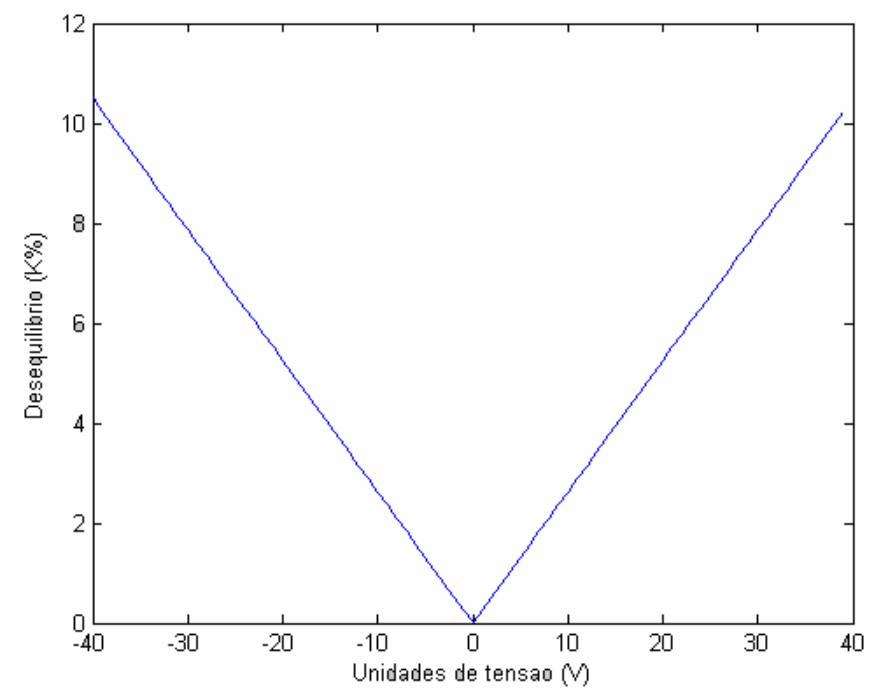

Figura 6.4 - Desequilíbrio considerando variação na magnitude de duas fases

Nota-se na Figura 6.4 que o valor atingido foi superior ao caso de variação de apenas uma fase. A não simetria dos valores de $\mathrm{K}$ em relação às variações para valores menores e maiores de $220 \mathrm{~V}$ é novamente verificada.

A Figura 6.5 expõe o desequilíbrio em função das variações nos ângulos de duas fases.

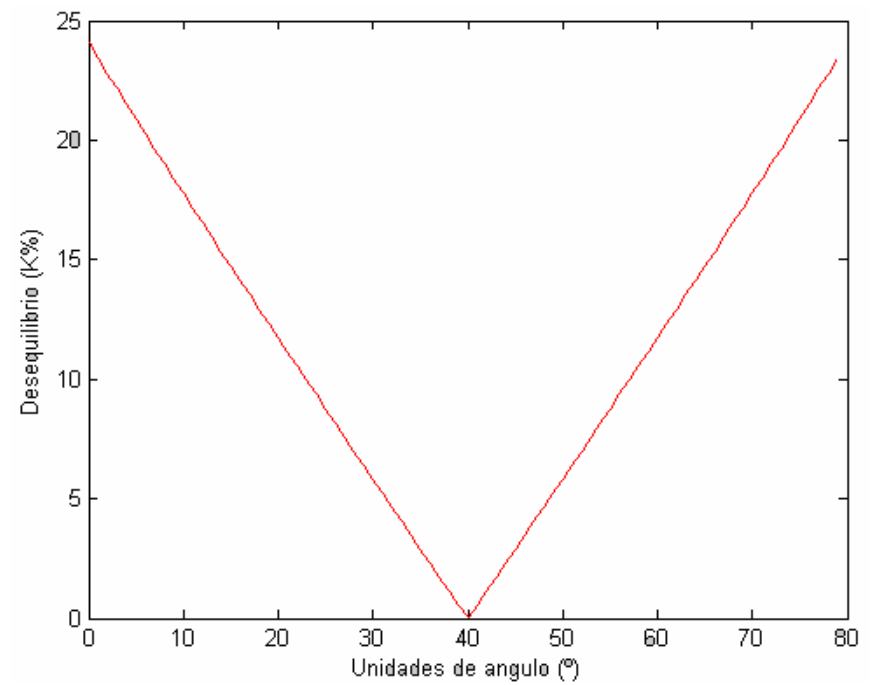

Figura 6.5 - Desequilíbrio considerando variação na magnitude de duas fases

Os valores obtidos para a variação dos ângulos de duas fases foram superiores aos obtidos quando da variação do ângulo de apenas uma fase. Além disso, nota-se que a alteração nos ângulos levou a desequilíbrios maiores que as alterações nas magnitudes. 
A Figura 6.6 e a Tabela 6.2 mostram o resultado da variação conjunta da amplitude e ângulo da tensão de duas fases, nos mesmos intervalos utilizados nos casos anteriores, utilizando o método das componentes simétricas.

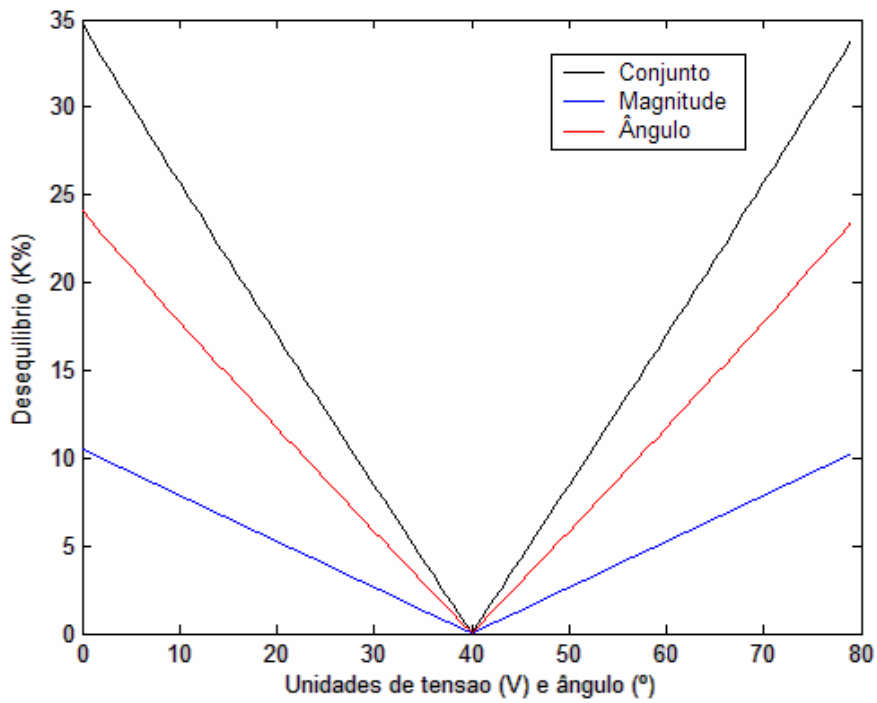

Figura 6.6 - Desequilíbrio considerando variação conjunta na amplitude e no ângulo de duas fases

Tabela 6.2 - Alguns valores encontrados nas simulações da Fig. 6.6

\begin{tabular}{|c|c|c|}
\hline \multicolumn{3}{|c|}{ Variação em duas fases } \\
\hline Mag.(V) & Âng. $\left(^{\circ}\right)$ & Conjunto \\
\hline \multicolumn{3}{|c|}{$K \%$} \\
\hline 10,4973 & 24,0880 & 34,7167 \\
\hline 9.9724 & 22.8055 & 32.8902 \\
\hline 8.3978 & 19.0296 & 27.4941 \\
\hline 7.6105 & 17.1775 & 24.8374 \\
\hline 4.4613 & 9.9511 & 14.4223 \\
\hline 0.0000 & 0.0000 & 0.0000 \\
\hline 4.7238 & 10.5443 & 15.2798 \\
\hline 6.8232 & 15.3458 & 22.2046 \\
\hline 7.8730 & 17.7925 & 25.7202 \\
\hline 8.6603 & 19.6520 & 28.3854 \\
\hline 10.2348 & 23.4451 & 33.8016 \\
\hline
\end{tabular}

Constata-se da Figura 6.6 e da Tabela 6.2 que, como no caso da variação de uma fase, a soma das contribuições individuais dos desequilíbrios provenientes das magnitudes e dos ângulos das tensões é igual ao caso de variação simultânea. No caso da variação de duas 
fases, entretanto, o valor do $\mathrm{K}$ das magnitudes representou cerca de $30 \%$ do desequilíbrio total, enquanto os ângulos foram responsáveis por $70 \%$.

\subsection{Módulo na Ferramenta Computacional}

A metodologia utilizada no programa consiste em, primeiramente, "amarrar" o banco de dados com valores de ângulos ideais (defasagem angular entre fases de $120^{\circ}$ ) e calcular o $\mathrm{K} \%$ levando-se em consideração apenas as magnitudes das tensões medidas. Em seguida, o mesmo procedimento é realizado mantendo-se, agora, as magnitudes ideais (valores nominais) e calculando o K\% com os valores reais dos ângulos medidos. Espera-se conhecer, para um banco de dados específico, a principal causa dos desequilíbrios de tensão, ou seja, se esta é proveniente de distúrbios, majoritariamente, nas magnitudes ou nos ângulos dos fasores de tensão.

Busca-se calcular a porcentagem do desequilíbrio que é advinda das variações nas magnitudes e a porcentagem referente às alterações nos ângulos. Este procedimento é feito baseado nas análises teóricas precedentes, as quais mostraram que o desequilíbrio total é igual à soma do desequilíbrio causado apenas pelas magnitudes com o valor de $\mathrm{K}$ obtido a partir das variações dos ângulos.

Em seguida considera-se a utilização dos valores medidos de uma fase do banco de dados (magnitude e ângulo) enquanto as outras duas são mantidas, em simulação, como ideais. O usuário pode, ainda, escolher usar apenas a magnitude ou o ângulo de uma fase, separadamente. Alternativamente, pode-se combinar, para o cálculo do K, valores medidos de magnitude de uma fase e de ângulo de outra fase, sempre mantendo as demais grandezas ideais. Esse processo permite a verificação de qual fase mais se distancia da situação nominal, e se é pelo seu valor de ângulo ou magnitude.

Em todos os casos de simulação disponíveis, o fator $\mathrm{K}$ é calculado e são disponibilizadas suas estatísticas. São plotados gráficos de barras e do perfil do desequilíbrio para cada situação em análise.

Vale ressaltar que, na análise teórica, foram obtidos resultados que comprovam que o desequilíbrio considerando variações nas magnitudes de duas fases representa uma parcela 
do desequilíbrio total (Tabela 6.2). Entretanto, calcular o desequilíbrio a partir das magnitudes medidas de uma fase e somar com o desequilíbrio calculado com as magnitudes de outra fase, leva a um resultado diferente do $\mathrm{K}$ obtido com as magnitudes das duas fases ao mesmo tempo. Constata-se que, quando o banco de dados apresenta alterações nas magnitudes de duas fases, o K calculado considerando magnitude apenas de uma fase já não representa uma parcela do desequilíbrio total.

Deste modo, a determinação da fase que mais contribui para o desequilíbrio no local em estudo é feita pela comparação, entre si, dos valores de $\mathrm{K}$ resultantes das análises em separado de cada fase. A fase a partir da qual são encontrados os maiores valores de K é a que mais se distancia da situação nominal, contribuindo mais para o grau de desequilíbrio do sistema.

A Figura 6.7 traz a tela da ferramenta referente a essa análise.

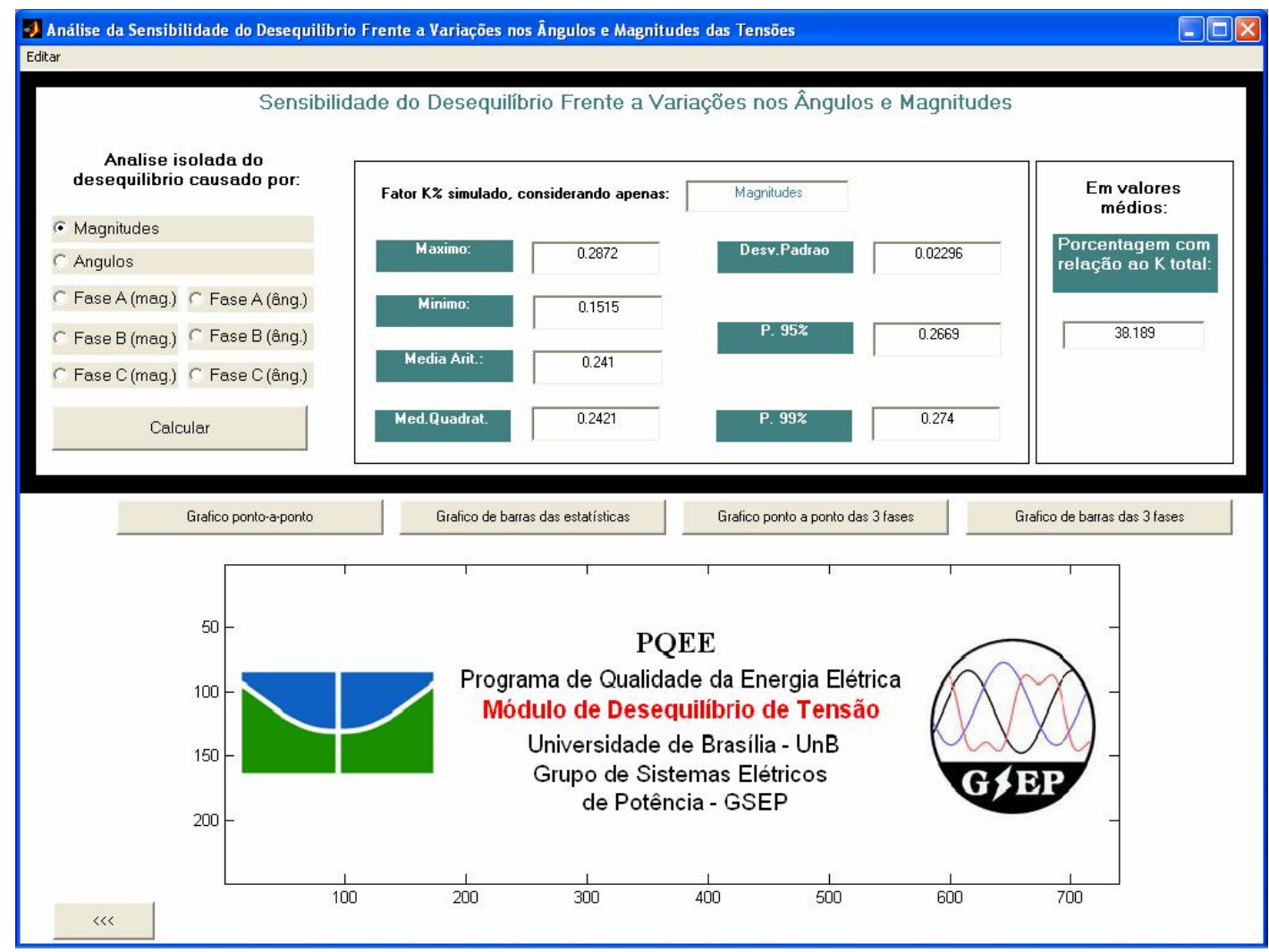

Figura 6.7 - Tela do módulo na ferramenta computacional 


\subsection{Estudo de Caso}

Neste momento é feita a análise da sensibilidade do desequilíbrio frente às variações existentes nos ângulos e magnitudes do local em estudo.

A Figura 6.8 ilustra o perfil do fator $\mathrm{K}$ durante os 7 dias de medição, considerando apenas os valores reais de magnitude medidos.

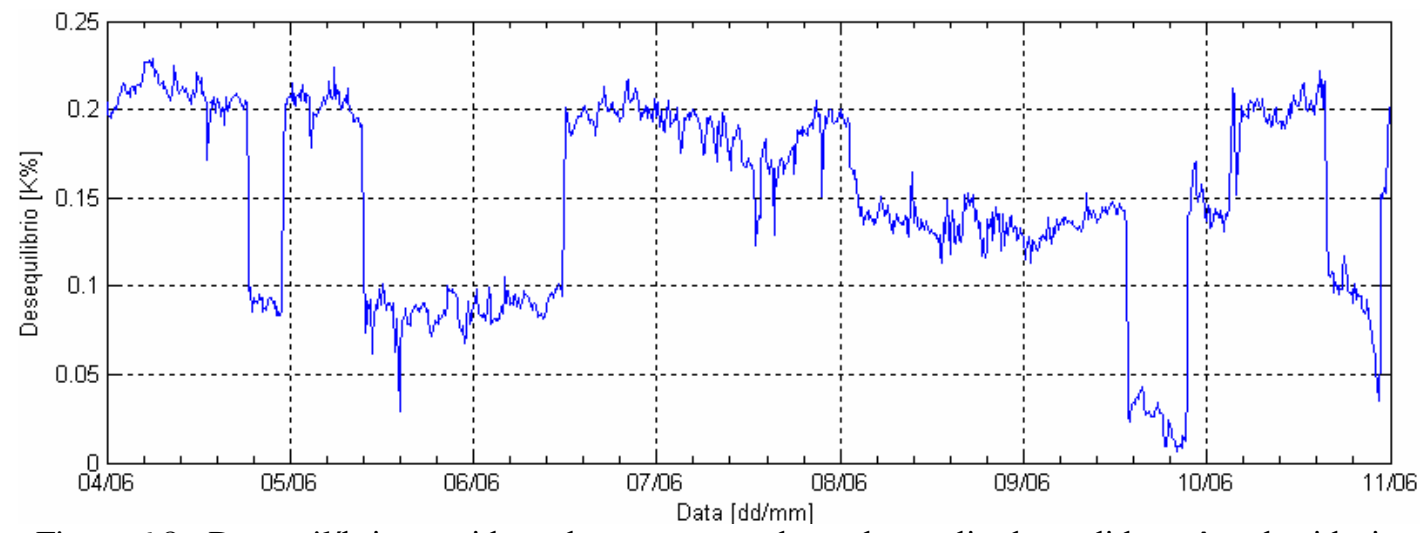

Figura 6.8 - Desequilíbrio considerando apenas os valores de amplitude medidos e ângulos ideais

A Figura 6.9 mostra o K, plotado a partir dos valores reais de ângulos medidos, mantendose as magnitudes ideais.

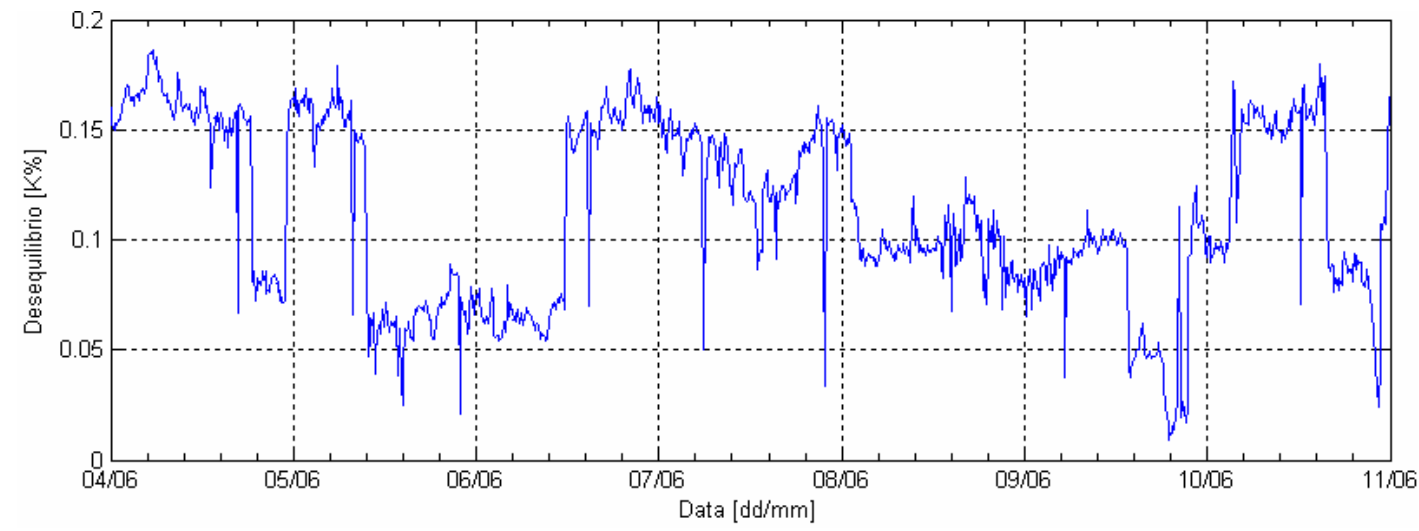

Figura 6.9 - Desequilíbrio considerando apenas os valores de ângulo medidos e amplitudes ideais

Nota-se das Figuras 6.8 e 6.9 que os perfis do desequilíbrio nestas duas simulações são semelhantes. Entretanto, verificam-se intensidades diferentes e algumas discrepâncias pontuais no perfil do $\mathrm{K}$.

As estatísticas calculadas para estes dois casos são apresentadas na Tabela 6.3. 
Tabela 6.3 - Estatística das análises individuais das magnitudes e ângulos

\begin{tabular}{|c|c|c|}
\hline Índice & Magnitudes & Ângulos \\
\hline Máximo & 0,2289 & 0,186 \\
\hline Mínimo & 0,006497 & 0,009309 \\
\hline Média Arit. & 0,149 & 0,1126 \\
\hline Média Quad. & 0,1583 & 0,1197 \\
\hline Desvio Padrão & 0,0533 & 0,04066 \\
\hline P95\% & 0,2121 & 0,1661 \\
\hline P99\% & 0,2226 & 0,1782 \\
\hline
\end{tabular}

Com a análise das estatísticas, observa-se que os valores referentes às magnitudes foram mais acentuados. Da Tabela 5.1 (Capítulo 5), tem-se que a média aritmética calculada dos valores de desequilíbrio total foi de $0,2652 \%$. Verifica-se que o valor da média considerando apenas as magnitudes, mostrado na tabela 3, representa cerca de 57\% desse desequilíbrio total. Já o valor médio oriundo da utilização dos ângulos medidos, constitui aproximadamente $43 \%$. Constata-se, então, que o desequilíbrio de tensão na subestação monitorada é devido, principalmente, aos desbalanços nas magnitudes dos fasores de tensão.

Neste instante, é possível perceber o comportamento do desequilíbrio ocorrido no dia 09/06, que já havia sido mencionado no Capítulo 5, Figura 5.12. Foi verificado que em um período entre $19 \mathrm{~h}$ e $21 \mathrm{~h}$, o método das Componentes Simétricas havia apresentado valores maiores que os demais métodos, fato este atribuído a uma possível assimetria nos ângulos das tensões. A figura 6.10 traz um "zoom" da Figura 6.2, que avalia apenas as alterações nos ângulos, no referido dia. 


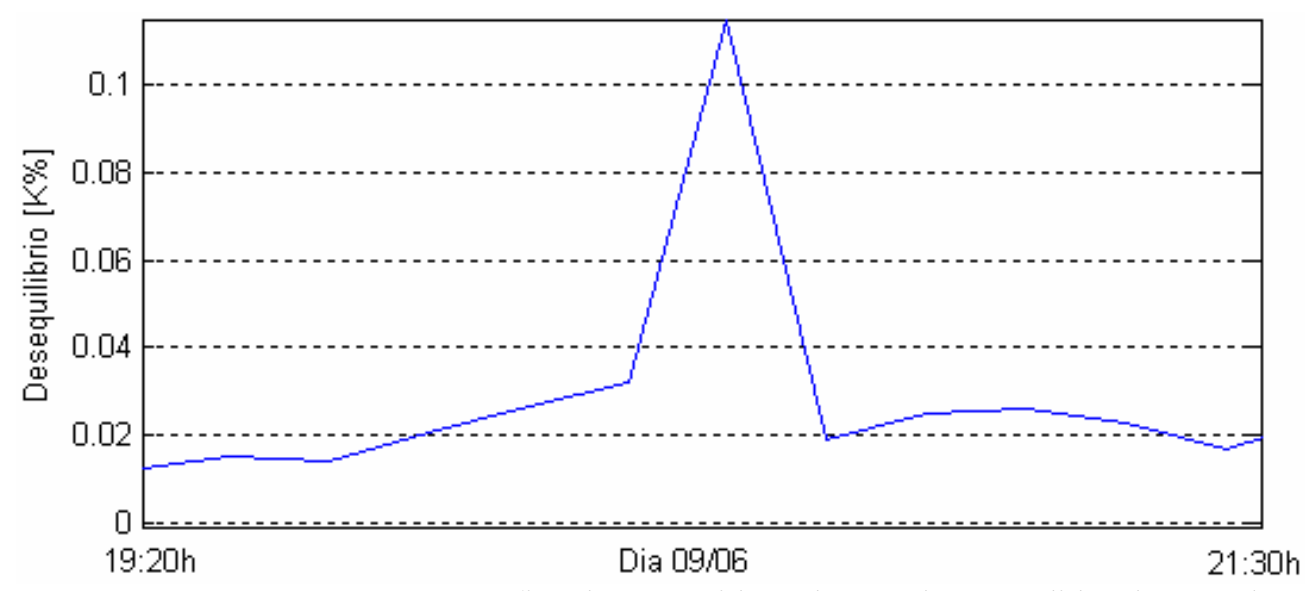

Figura 6.10 - Zoom do gráfico do K considerando os valores medidos dos ângulos

Nota-se uma elevação significativa do desequilíbrio no mesmo período analisado na Figura 5.12. Comprava-se, portanto, a conjetura feita anteriormente.

A análise a seguir leva em conta a utilização dos valores medidos de uma fase do banco de dados (magnitude e ângulo) enquanto as outras duas são mantidas, em simulação, como ideais. Na Figura 6.11 é ilustrado o perfil do fator K, contemplando os valores reais medidos na fase A, estando as fases B e C em condições ideais. Nas Figuras 6.12 e 6.13 seguintes, são tomados, respectivamente, os valores reais medidos na fase $\mathrm{B}$ e na fase $\mathrm{C}$. As demais fases são mantidas ideais.

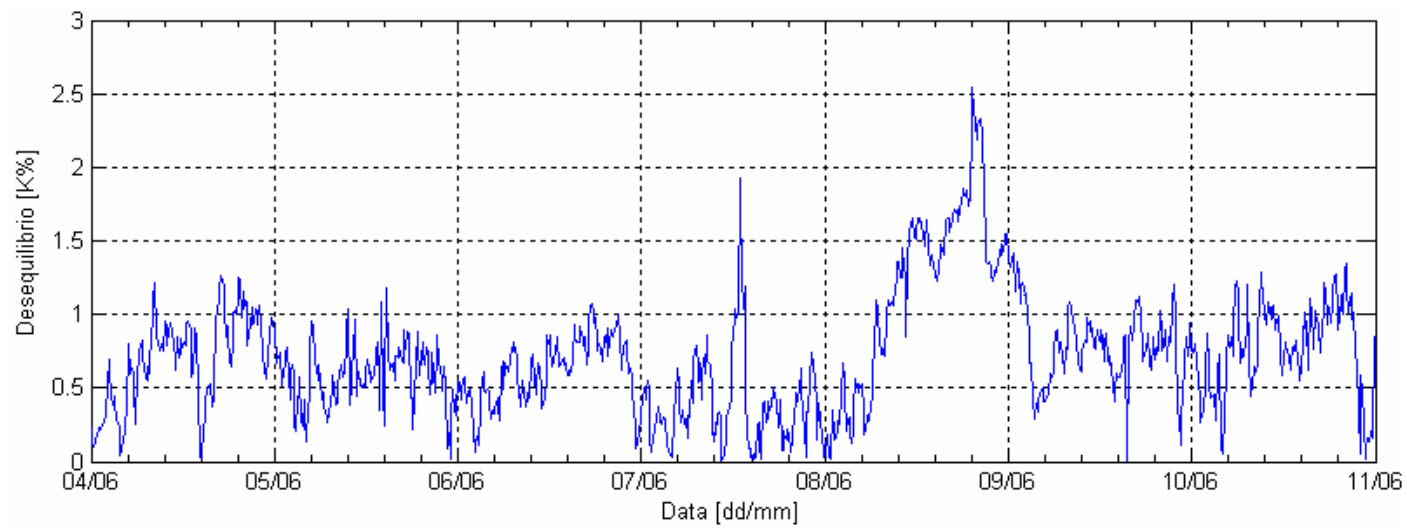

Figura 6.11 - Desequilíbrio considerando os valores medidos da fase A (ângulo e magnitude) 


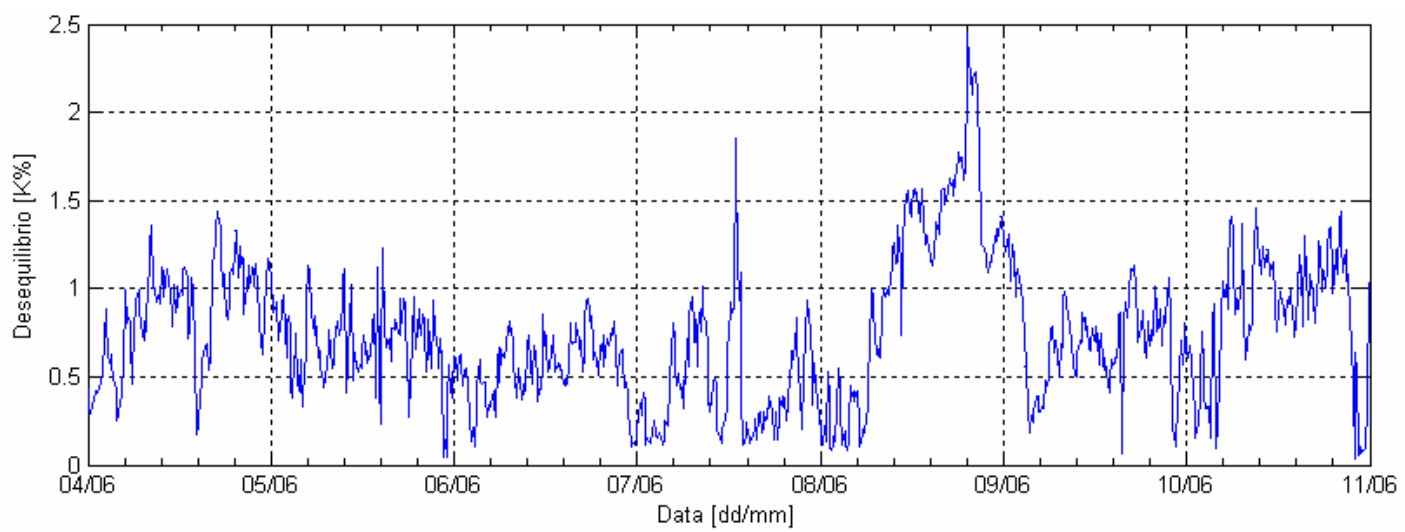

Figura 6.12 - Desequilíbrio considerando os valores medidos da fase B (ângulo e magnitude)

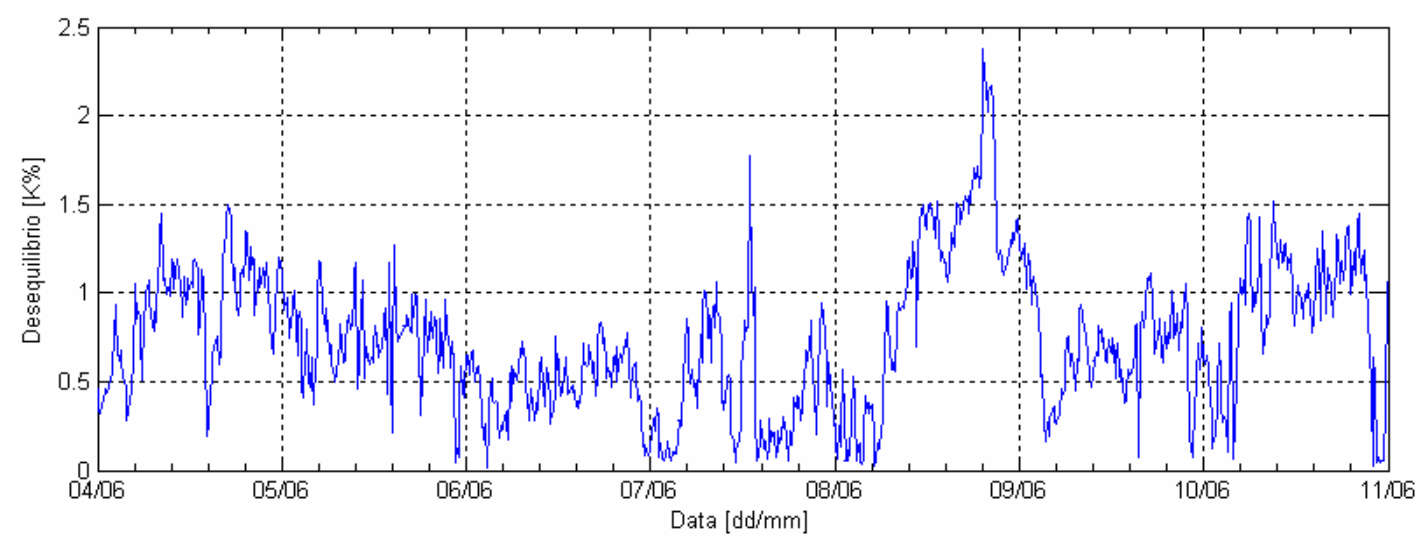

Figura 6.13 - Desequilíbrio considerando os valores medidos da fase C (ângulo e magnitude)

Observa-se que os perfis do desequilíbrios calculados separadamente com os valores reais de cada fase são bastante similares. Os patamares apresentados podem ser notados na Figura 6.14 e na Tabela 6.4, que trazem as estatísticas calculadas para cada simulação.

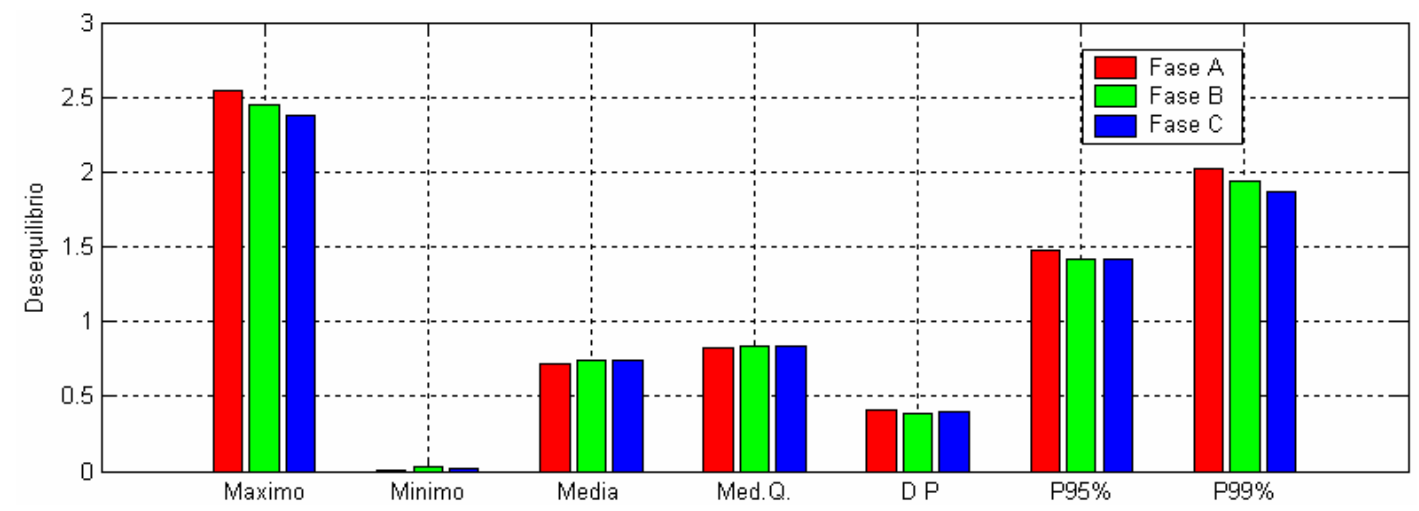

Figura 6.14 - Estatísticas dos desequilíbrios individuais por cada fase 
Tabela 6.4 - Estatísticas das análises individuais das fases

\begin{tabular}{|c|c|c|c|}
\hline Fases => & $\mathrm{A}$ & $\mathrm{B}$ & $\mathrm{C}$ \\
\hline Máximo & 2,541 & 2,454 & 2,379 \\
\hline Mínimo & 0,003398 & 0,02981 & 0,01972 \\
\hline Média Aritmética & 0,7165 & 0,741 & 0,738 \\
\hline Média Quadrática & 0,8247 & 0,8377 & 0,8397 \\
\hline Desvio Padrão & 0,4085 & 0,391 & 0,4008 \\
\hline P95\% & 1,478 & 1,412 & 1,414 \\
\hline P99\% & 2,022 & 1,934 & 1,864 \\
\hline \multicolumn{2}{|l}{}
\end{tabular}

Dos valores da Tabela 6.4, tem-se que a fase A apresentou os mais elevados valores de máximo e de $\mathrm{P} 95 \%$. Porém, os patamares dos três casos são muito próximos entre si, apontando para um comportamento semelhante entre as fases.

Caso se verifique que os valores apresentados por uma das fases são superiores aos demais, um detalhamento da análise é sugerido. Nessas situações, pode-se avaliar o K\% considerando as variações, separadamente, dos módulos e dos ângulos da mesma fase, mantendo-se as demais grandezas ideais.

Este procedimento permite, a partir da detecção da fase que mais apresenta problemas, verificar se os seus distúrbios estão nos valores de magnitude ou de ângulo. Deste modo, as ações a serem tomadas em provimento da mitigação dos níveis de desequilíbrio, podem ser direcionadas para os principais causadores deste fenômeno no local em estudo.

\subsection{Considerações Finais}

No presente capítulo, foi avaliada a sensibilidade do desequilíbrio de tensão frente às variações nas magnitudes e nos ângulos dos fasores de tensão. Foram feitas quantificações das suas contribuições individuais, comparando-as entre si e com o caso de variação simultânea.

Verificou-se, teoricamente, que o desequilíbrio é mais sensível à variação dos ângulos que às alterações nas magnitudes. Nos intervalos considerados na análise, constatou-se que a alteração em uma fase de $4 \mathrm{~V}$ produz o mesmo efeito que a alteração de apenas $1^{\circ}$. 
Realizou-se uma comparação dos resultados oriundos de cálculos do fator $\mathrm{K}$ a partir do método das Componentes Simétricas com os obtidos nos métodos CIGRÉ, NEMA e IEEE, que utilizam apenas os módulos das tensões de linha. Constatou-se que, variando-se somente os módulos das tensões, os valores obtidos foram muito semelhantes, em especial no método CIGRÉ. Já nas alterações angulares, o desvio entre os resultados cresce à medida que se aumenta a assimetria angular.

No estudo de caso apresentado, chegou-se ao resultado de uma contribuição de aproximadamente $57 \%$ do desequilíbrio como sendo advindo das alterações nas magnitudes e $43 \%$ referentes às variações nos ângulos. Na análise individual das fases, constatou-se que as três tiveram contribuição semelhante nos níveis de desequilíbrio total.

Por fim, verifica-se que as análises efetuadas contribuem para investigação das causas do desequilíbrio de tensão no local a ser estudado, auxiliando nos trabalhos voltados à mitigação do distúrbio, direcionando os esforços para o foco principal do problema. $\mathrm{O}$ Apêndice D mostra um estudo semelhante ao efetuado nesse capítulo, utilizando outro banco de dados.

Entretanto, cumpre reconhecer que o presente capítulo demanda um maior aprofundamento da pesquisa, de forma a consolidar as interpretações dos resultados obtidos. A proposta compreende aspectos complexos e necessita de experiência com dados de diversas medições, com vistas ao amadurecimento da metodologia a ser adotada. 


\section{Capítulo 7}

\section{Análise dos Fasores}

\subsection{Considerações Iniciais}

O capítulo vigente é voltado para o estudo do comportamento dos fasores de tensão. Somado a isso, tem-se a análise das componentes simétricas, que, em função da maneira com que são obtidas, trazem informações adicionais a respeito dos desbalanços nos fasores.

É efetuada uma investigação dos valores de ângulos medidos ao longo do período de medição e uma comparação entre as magnitudes das tensões de cada fase. Tenciona-se com isso conhecer o comportamento dos fasores de tensão. A importância da análise da componente de seqüência negativa já é conhecida. Seus efeitos danosos no sistema e nas cargas foram amplamente discutidos anteriormente. Porém, até aqui, as componentes de seqüência positiva e zero não receberam destaque.

Todavia, sabe-se que a componente de seqüência zero indica a possibilidade de circulação de corrente no condutor neutro das instalações e no neutro de dispositivos trifásicos (geradores, transformadores, reatores, motores), justificando seu espaço nesse estudo. A análise da componente de seqüência positiva presta-se quando da sua comparação com os valores nominais de tensão. Considerando que os sistemas equilibrados apresentam somente essa componente, os valores encontrados para ela permitem uma avaliação auxiliar do desequilíbrio existente. Os estudos a seguir procurarão elucidar essa interrelação. 


\subsection{Módulo na Ferramenta Computacional}

No programa computacional, são avaliados as magnitudes e ângulos das tensões de cada fase, além das magnitudes das componentes de seqüência positiva, negativa e zero. $\mathrm{O}$ usuário deve escolher uma dessas grandezas para análise. Em seguida, seleciona os dias que deseja para o estudo. As estatísticas padrão do aplicativo e os gráficos ponto a ponto e de barras são, então, disponibilizados.

A Figura 7.1 exibe a estrutura deste módulo.

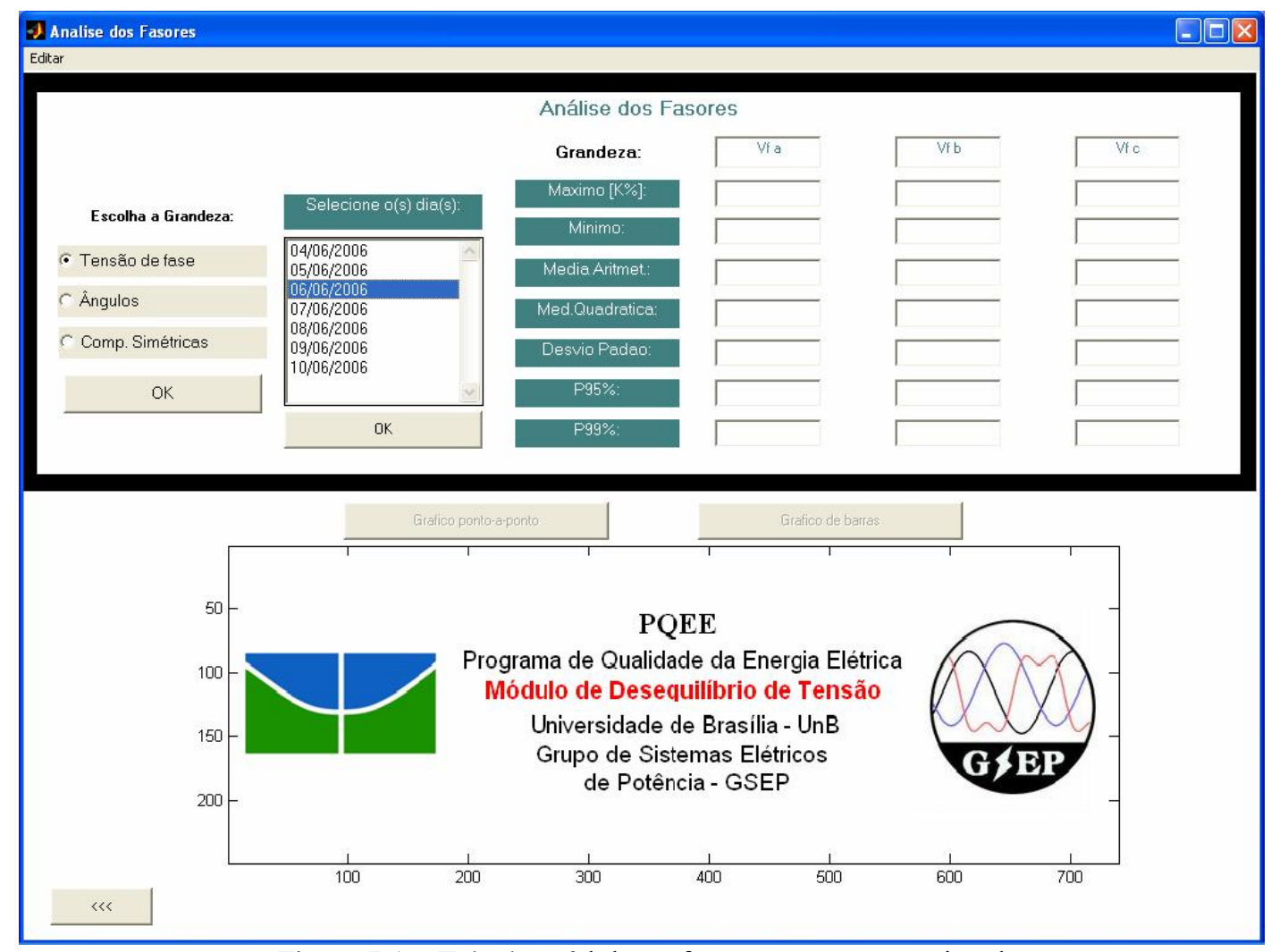

Figura 7.1 - Tela do módulo na ferramenta computacional

Em função da diferença normalmente encontrada entre os valores das componentes de seqüência positiva, negativa e zero, os gráficos dessas grandezas são traçados separadamente, mantendo-se uma escala apropriada para análise de cada uma. O mesmo acontece para os valores de ângulo. Neste caso, isto se deve às pequenas variações usualmente percebidas nessas medidas nos sistemas elétricos. 


\subsection{Estudo de Caso}

Nesta seção o aplicativo será usado para os propósitos supracitados, considerando os dados da SE Carajás.

A Tabela 7.1 e a Figura 7.2 trazem as estatísticas dos valores das tensões de fase medidos.

Tabela 7.1 - Estatísticas dos valores das magnitudes das tensões de fase

\begin{tabular}{|c|c|c|c|}
\hline Estatísticas [V] & $V a$ & $V b$ & $V c$ \\
\hline Máximo & 143.897 & 143.516 & 143.214 \\
\hline Mínimo & 128.138 & 127.733 & 127.488 \\
\hline Média Arit. & 133.833 & 133.369 & 133.176 \\
\hline Média Quad. & 133.874 & 133.410 & 133.218 \\
\hline Desvio Padrão & $3.300,76$ & $3.337,97$ & $3.349,84$ \\
\hline P95\% & 139.467 & 139.051 & 138.903 \\
\hline P99\% & 141.723 & 141.342 & 141.063 \\
\hline
\end{tabular}

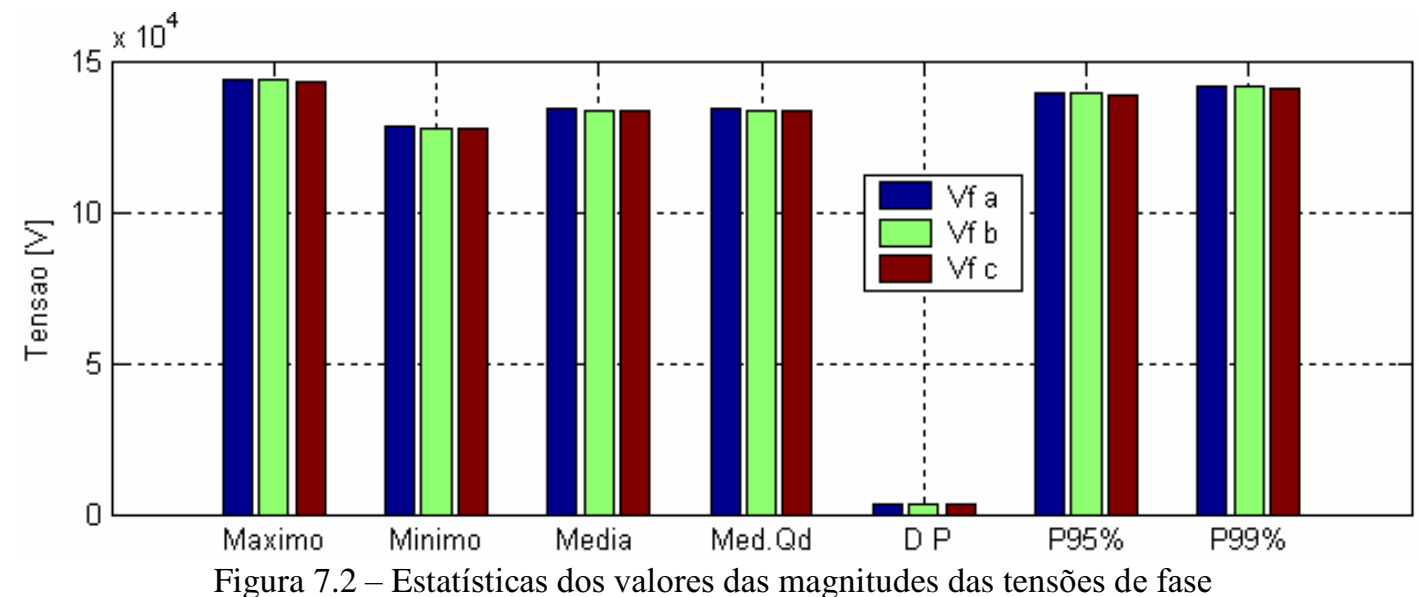

Observa-se na Tabela 7.1 e na Figura 7.2 que as magnitudes das tensões são semelhantes entre si. Todas as estatísticas calculadas forneceram resultados muito próximos. Os valores de desvio padrão obtidos são consideravelmente baixos, o que respalda a proximidade entre os valores máximos e o $\mathrm{P} 99 \%$, por exemplo.

O perfil das magnitudes das tensões pode ser visto na Figura 7.3. 


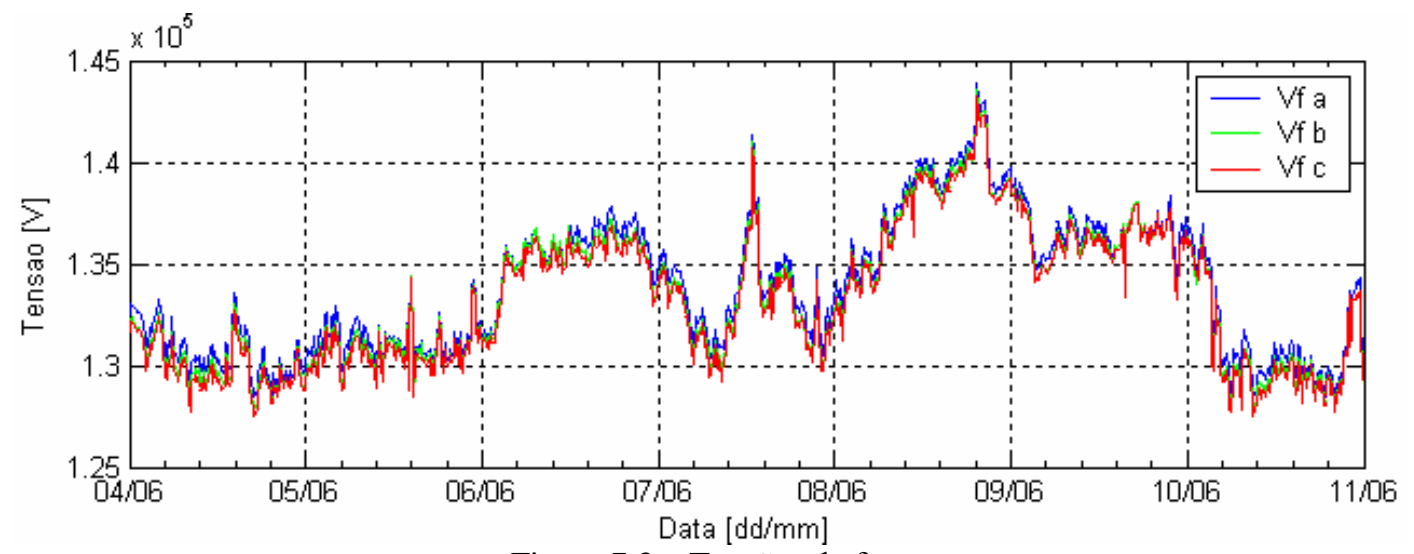

Figura 7.3 - Tensões de fase

Na Figura 7.3, tem-se que as curvas estão quase sobrepostas, salvo em poucos momentos. Uma variação mais acentuada se verifica no dia 7, sem, contudo, trazer conseqüências aos valores de desequilíbrio encontrados, haja vista as demais análises já realizadas. É possível perceber que a fase A esteve com valores mais elevados, mesmo que em patamares muito próximos aos das outras fases.

A Tabela 7.2 apresenta as estatísticas encontradas dos valores de ângulos das fases. Dado que o medidor adota a fase A como referência angular, seus valores são sempre iguais a zero e, por isso, os mesmos não serão mostrados adiante.

Tabela 7.2 - Estatísticas dos valores das magnitudes das tensões de fase

\begin{tabular}{|c|c|c|}
\hline Estatísticas [V] & $A n g . V b$ & $A n g . V c$ \\
\hline Máximo & $-119,931$ & 120,162 \\
\hline Mínimo & $-120,268$ & 119,846 \\
\hline Média Arit. & $-120,162$ & 120,04 \\
\hline Média Quad. & 120,162 & 120,04 \\
\hline Desvio Padrão & 0,0583473 & 0,0596474 \\
\hline P95\% & $-120,055$ & 120,123 \\
\hline P99\% & $-120,022$ & 120,139 \\
\hline
\end{tabular}

Como esperado, nota-se, da Tabela 7.2 que as variações nos ângulos se dão em escalas muito reduzidas. Na fase B os valores estiveram entre $-119,931^{\circ}$ e $-120,268^{\circ}$ e na fase $\mathrm{C}$ entre $119,846^{\circ}$ e $120,162^{\circ}$.

As Figura 7.4 e 7.5 exibem, respectivamente, as curvas dos ângulos das fases B e C durante os 7 dias de monitoramento. 


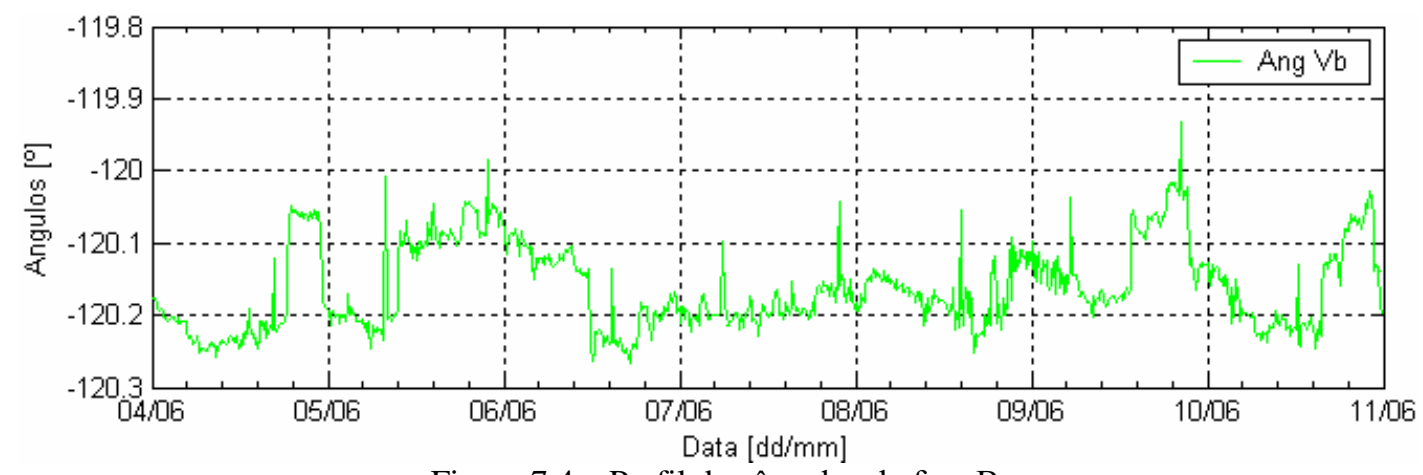

Figura 7.4 - Perfil dos ângulos da fase B

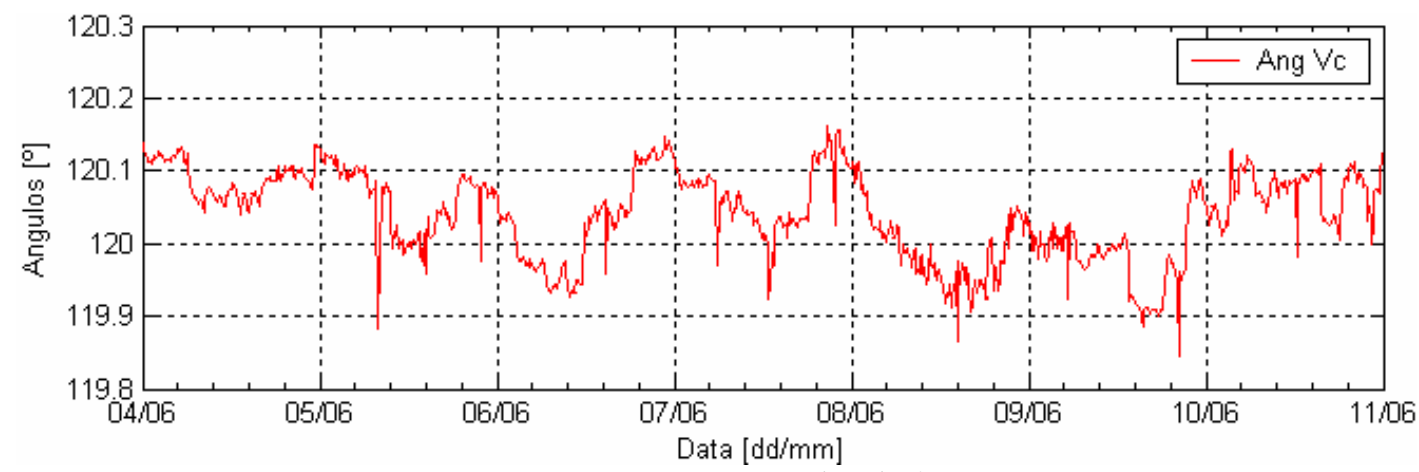

Figura 7.5 - Perfil dos ângulos da fase C

Verifica-se nas Figuras 7.4 e 7.5 que os ângulos das fases possuem perfis diferentes para a maior parte do tempo de análise. Nota-se que a fase B apresentou ângulos quase sempre abaixo do valor nominal $\left(-120^{\circ}\right)$. Na fase $\mathrm{C}$ os ângulos variaram mais em torno do valor $120^{\circ}$, levando a um valor de média mais próximo do ideal.

Porém, percebe-se que os pontos que se sobressaem em ambas as curvas acontecem no mesmo momento e simetricamente nas duas fases. É possível constatar (dia 09/06) que o valor máximo de ângulo da fase B, mostrado na Tabela 7.2, ocorre no mesmo instante que o mínimo da fase C. Este ponto representa a maior assimetria encontrada entre os ângulos dos fasores, justificando o comportamento do desequilíbrio apresentado no dia 09/06, já relatado nos Capítulos 5 e 6 (Figuras 5.12 e 6.10).

Na Tabela 7.3 são expostas as estatísticas calculadas para os valores das componentes de seqüência positiva, negativa e zero. 
Tabela 7.3 - Estatísticas das magnitudes das componentes simétricas

\begin{tabular}{|c|c|c|c|}
\hline Estatísticas [V] & $V+$ & $V-$ & $V o$ \\
\hline Máximo & 143.720 & 544,333 & 77,504 \\
\hline Mínimo & 128.025 & 40,0026 & 13,6294 \\
\hline Média Arit. & 133.631 & 353,527 & 63,2293 \\
\hline Média Quad. & 133.673 & 373,46 & 64,4024 \\
\hline Desvio Padrão & $3.331,22$ & 120,44 & 12,2424 \\
\hline P95\% & 139.314 & 502,071 & 75,2806 \\
\hline P99\% & 141.557 & 530,676 & 76,6543 \\
\hline
\end{tabular}

Observa-se na Tabela 7.3 que a componente de seqüência positiva obteve praticamente as mesmas estatísticas das tensões de fase, fato este que não se é absolutamente inesperado, em função dos baixos valores de desequilíbrio previamente constatados.

A componente de seqüência negativa apresentou variações consideráveis, levando a um desvio padrão da ordem de $34 \%$ do valor da média. Já a componente de seqüência zero apresentou baixo desvio padrão, conduzindo a um valor máximo muito próximo do $\mathrm{P} 95 \%$ e $\mathrm{P} 99 \%$.

As Figuras 7.6, 7.7 e 7.8 ilustram os gráficos correspondentes aos perfis das componentes de seqüência positiva, negativa e zero, respectivamente.

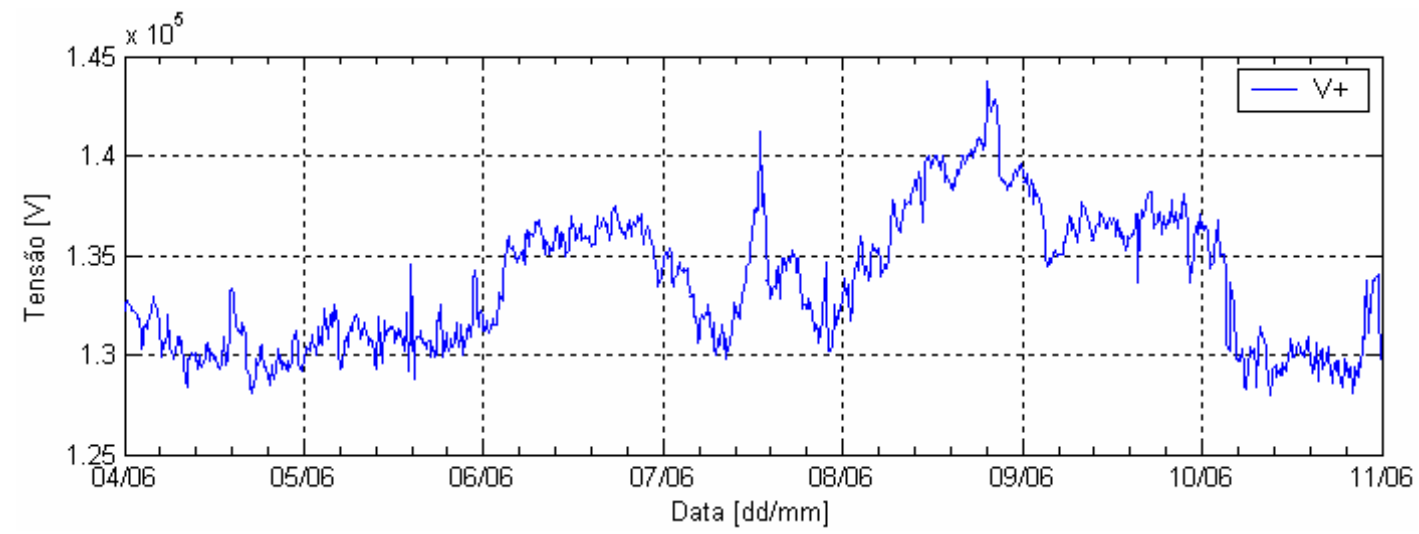

Figura 7.6 - Componente de seqüência positiva

Percebe-se na Figura 7.6 que o perfil da seqüência positiva é idêntico ao das tensões de fase (Figura 7.3). Tal situação é esperada quando constatados baixos valores de fator K. Em situações de desequilíbrios mais elevados, a curva da componente de seqüência 
positiva tende a acompanhar os níveis de tensão da fase que mais se distancia da situação nominal (LEE et al., 1997).

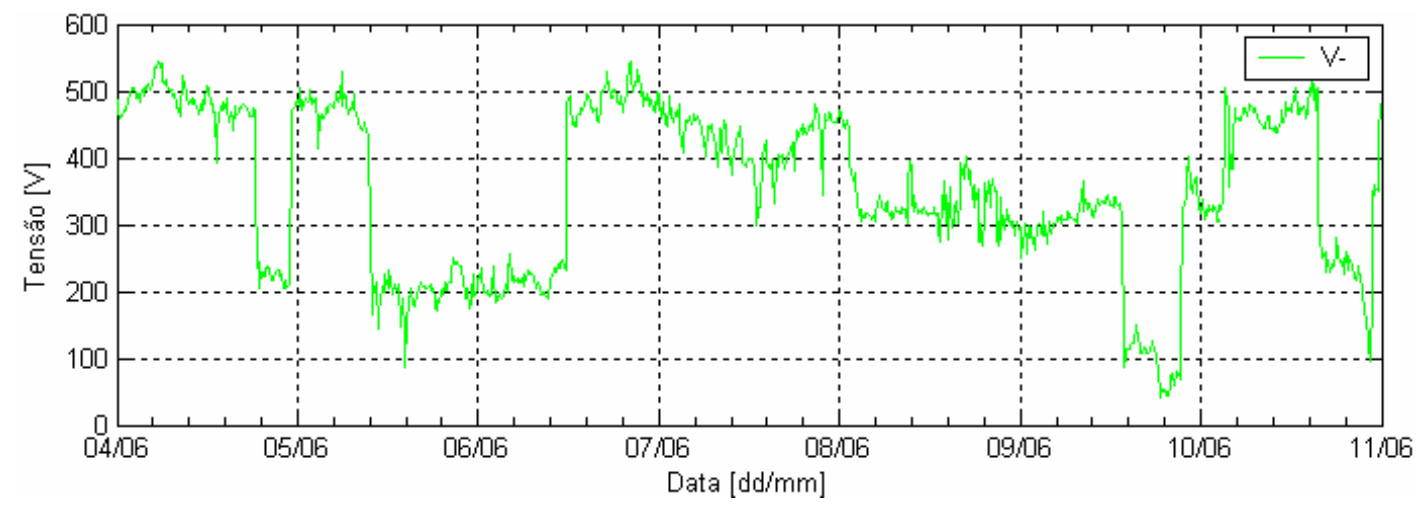

Figura 7.7 - Componente de seqüência negativa

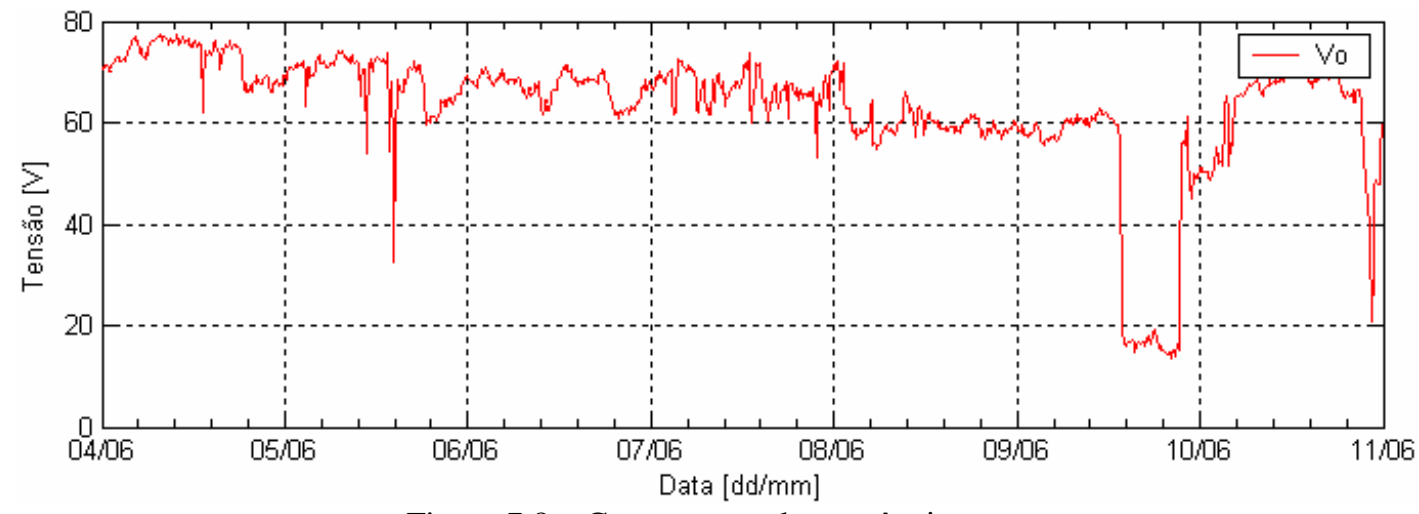

Figura 7.8 - Componente de seqüência zero

A Figura 7.7 mostra a seqüência negativa, que apresenta o mesmo perfil da curva do fator $\mathrm{K}$, inclusive dos métodos que não consideram diretamente os ângulos das tensões em suas expressões (Figura 5.11). Como inferido dos dados estatísticos, a componente de seqüência zero permaneceu com valores dentro de um pequeno intervalo de tensão na grande parte do tempo de monitoração. O período mais atípico dessa componente se deu justamente no dia 9 , já enfatizado no texto.

\subsection{Considerações Finais}

Neste capítulo procurou-se estabelecer uma correlação entre os desequilíbrios constatados nos capítulos antecedentes e o comportamento dos fasores de tensão. Por retratarem o 
efeito do desbalanço nos fasores, as componentes simétricas constituem elementos fundamentais de análise, compondo, por tanto, o módulo do programa computacional vinculado a este estudo.

Do estudo de caso obteve-se que todas as estatísticas calculadas para as magnitudes das tensões forneceram resultados muito próximos. A fase A apresentou valores suavemente mais altos, refletindo no $\mathrm{K}$ mais elevado encontrado na análise em separado para essa fase no Capítulo 6 (Tabela 6.4).

Os ângulos das fases B e C afastaram-se, no máximo em $0,27^{\circ}$ do padrão nominal e apresentaram perfis relativamente brandos, com exceção de pequenos realces na forma de onda, provavelmente advindos de manobras em máquinas rotativas e fornos de indução que compõem o processo industrial da subestação avaliada. Foi possível identificar o desvio nos ângulos dos fasores de tensão ocorrido no dia 9, constatado de outras formas nos Capítulos 5 e 6.

A componente de seqüência positiva obteve praticamente as mesmas estatísticas e perfil das tensões de fase, resultado este esperado dos baixos valores de desequilíbrio apresentados. A seqüência negativa obteve variações no tempo semelhantes ao fator $\mathrm{K} e$ perfil praticamente idêntico. A menos de um curto período, a seqüência zero manteve-se reduzida em praticamente todo tempo.

Assim, este tópico de análise auxiliar possibilita traçar um diagnóstico dos fasores de tensão e, a partir das componentes simétricas, observar as conseqüências das alterações presentes no padrão nominal dos fasores no tocante aos desequilíbrios, mesmo sem que se calcule o fator $\mathrm{K}$. 


\section{Capítulo 8}

\section{Similaridade entre Dias e entre Períodos do Dia}

\subsection{Considerações Iniciais}

Neste capítulo são desenvolvidas análises que buscam a comprovação da existência ou não de similaridade entre os dias monitorados e entre os períodos de um dia. Sabe-se que a maioria das normas e recomendações determinam, quando dos procedimentos para obtenção do valor representativo, um período mínimo de medição. Contudo, as fundamentações para a escolha desse intervalo de monitoramento requerido permanecem obscuras. Concomitantemente, e objetivando cumprir com as exigências precedentes, muitas empresas de energia apresentam dificuldades em seu cotidiano operacional. Quando da necessidade da realização de campanhas de medição em suas subestações, demanda-se elevada quantidade de medidores e a mobilização de um grande número de técnicos, às vezes incompatíveis com a realidade dos agentes.

Visando contribuir para a solução deste cenário, a metodologia aqui adotada permitirá a determinação de um período mínimo de medições, que seja capaz de refletir as características medulares de todo o banco de dados analisado. Deste modo, alcança-se um ponto ótimo entre os procedimentos realmente necessários e os executados.

\subsection{Módulo na Ferramenta Computacional para Similaridade entre Dias}

Este módulo permite a comparação simultânea de 7 dias de medição. São disponibilizadas as estatísticas do fator $\mathrm{K}$ de cada um dos dias e são fornecidas análises gráficas para $\mathrm{o}$ embasamento da comparação. 
A Figura 8.1 ilustra a tela do aplicativo computacional referente a essa etapa.

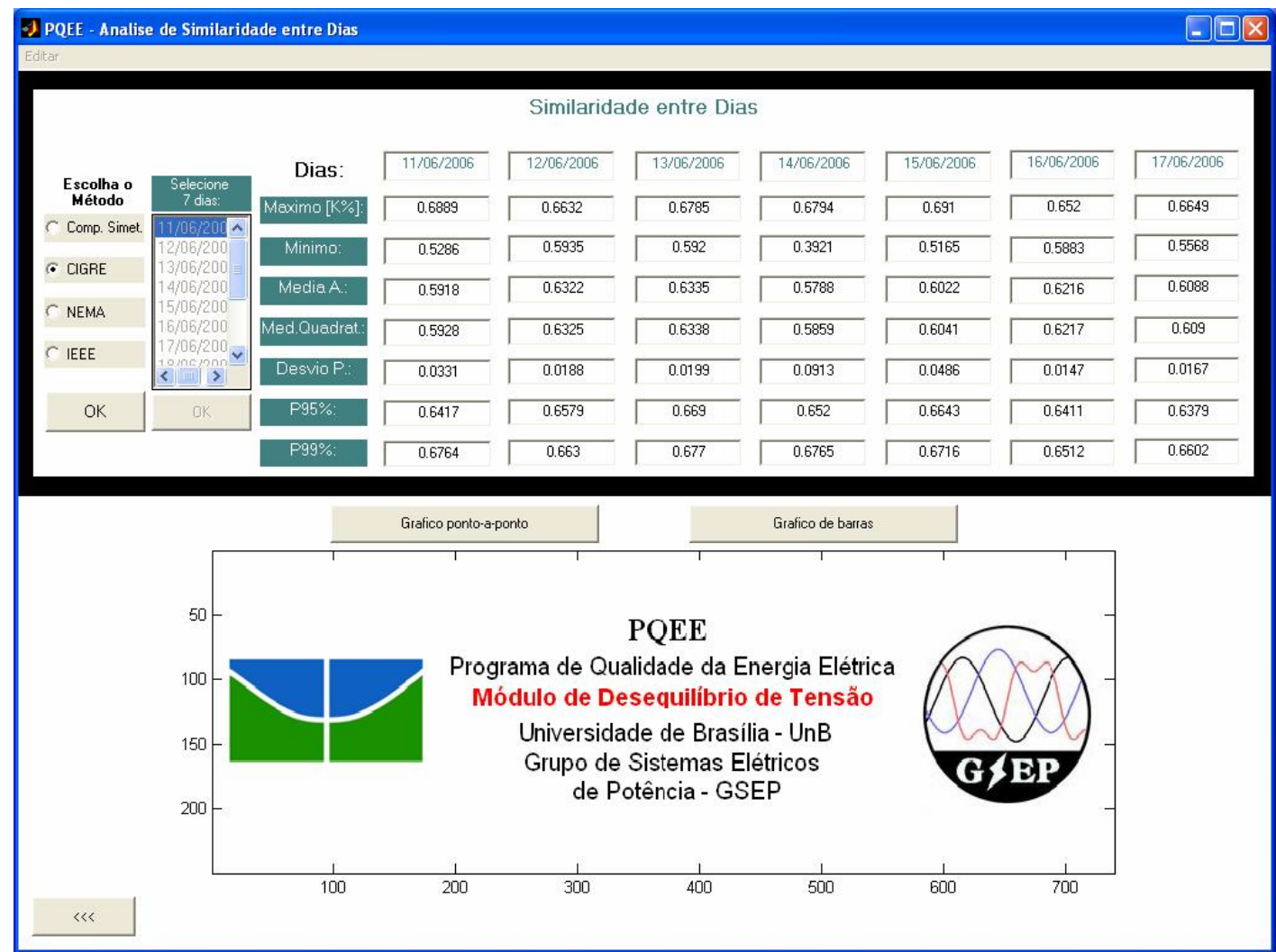

Figura 8.1 - Tela do módulo da ferramenta computacional

O usuário opta por um dos 4 métodos de cálculo e em seguida seleciona 7 dias para análise. A comparação numérica pode ser feita a partir dos valores fornecidos, como mostrado na Figura 8.1. As opções gráficas são o gráfico ponto a ponto e o gráfico de barras.

\subsection{Módulo na Ferramenta Computacional para Similaridade entre Períodos}

O módulo do aplicativo referente a essa análise divide o dia em três intervalos préestabelecidos e permite ao usuário a escolha de um outro período arbitrário. Os intervalos para comparação definidos pelo programa são períodos de $8 \mathrm{~h}$ de duração. São eles: de 00:00 às 08:00h, de 08:00 às 16:00h e de 16:00 às 24:00h. São também oferecidos valores estatísticos e opções gráficas. 
A Figura 8.2 exibe a tela do presente módulo.

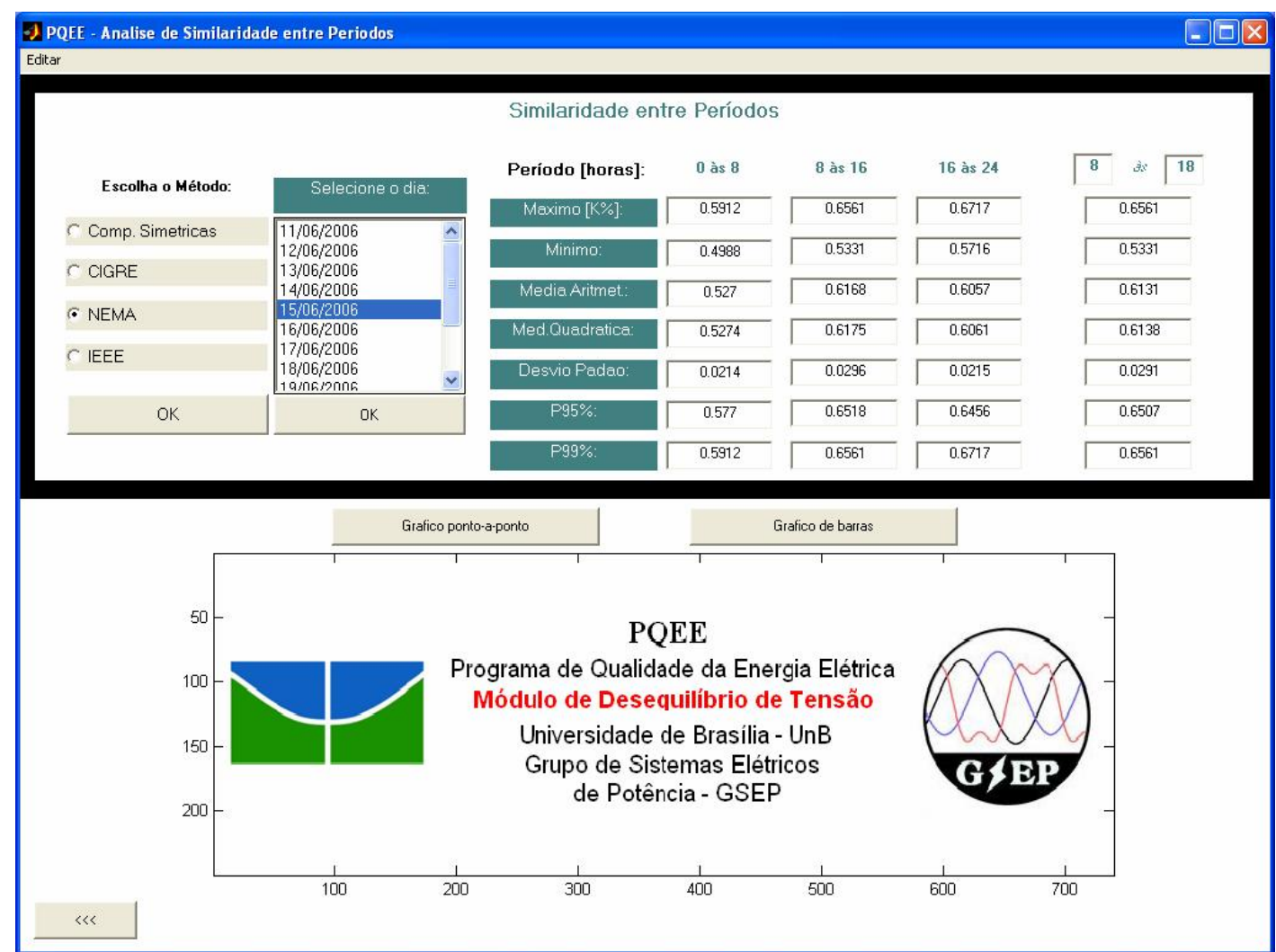

Figura 8.2 - Tela do módulo da ferramenta computacional

Assim como na seção anterior, o usuário deve escolher um método para quantificação. Em seguida, deve-se estabelecer um dia para análise. Nota-se na Figura 8.2 a existência de um período a ser escolhido pelo usuário. Os gráficos do perfil do desequilíbrio e das estatísticas são plotados, simultaneamente, para as quatro faixas de intervalo.

\subsection{Estudo de Caso}

Neste estudo serão investigados os comportamentos do fator $\mathrm{K}$ na semana monitorada da SE Carajás, desejando-se constatar a existência ou não da similaridade entre os dias e entre os períodos de um dia. O método de quantificação utilizado é o das Componentes Simétricas. 


\subsubsection{Análise da Similaridade entre Dias}

A Figura 8.3 apresenta os perfis do fator $\mathrm{K}$ traçados para os 7 dias em apreciação.

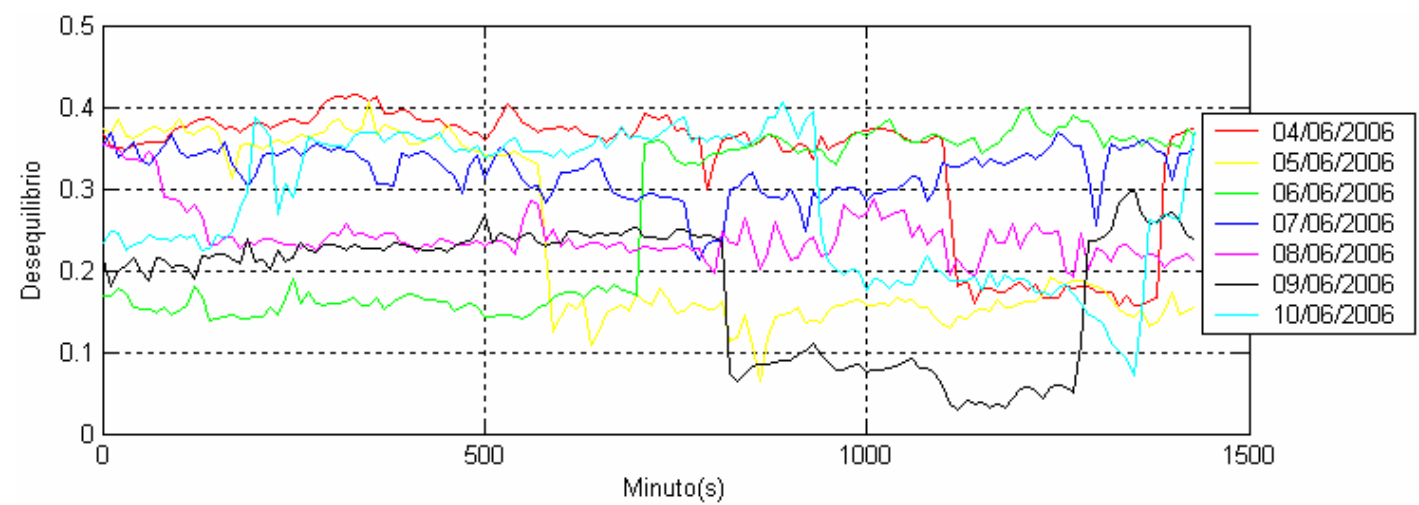

Figura 8.3 - Perfis do desequilíbrio durante os dias de medição

Da Figura 8.3 observa-se que o desequilíbrio esteve, na maior parte do tempo, com valores de $\mathrm{K}$ entre $0,2 \%$ e $0,4 \%$. Os perfis de cada dia mostram-se ligeiramente diferenciados, entretanto compreendidos em patamares muito próximos. Os dias 7 e 8 apresentam um comportamento praticamente constante, enquanto observa-se algumas variações nos níveis ocorridos nos demais dias.

A Tabela 8.1 e a Figura 8.4 trazem as estatísticas dos desequilíbrios encontrados.

Tabela 8.1 - Estatísticas dos valores de desequilíbrio para os sete dias

\begin{tabular}{|c|c|c|c|c|c|c|c|}
\hline Dias: & $04 / 06$ & $05 / 06$ & $06 / 06$ & $07 / 06$ & $08 / 06$ & $09 / 06$ & $10 / 06$ \\
\hline Máximo & 0,4159 & 0,4058 & 0,3989 & 0,3687 & 0,3540 & 0,3000 & 0,4063 \\
\hline Mínimo & 0,1564 & 0,06365 & 0,1387 & 0,2117 & 0,1907 & 0,02939 & 0,07209 \\
\hline Méd.arit. & 0,3336 & 0,2368 & 0,2604 & 0,3204 & 0,2419 & 0,1796 & 0,2839 \\
\hline Méd.quad. & 0,3430 & 0,2586 & 0,2792 & 0,3218 & 0,2439 & 0,1964 & 0,2963 \\
\hline D. Padrão & 0,0799 & 0,1040 & 0,1010 & 0,0303 & 0,0316 & 0,0797 & 0,0851 \\
\hline P 95\% & 0,4041 & 0,3763 & 0,3778 & 0,3563 & 0,3335 & 0,2635 & 0,3841 \\
\hline P 99\% & 0,4133 & 0,387 & 0,3945 & 0,3682 & 0,3505 & 0,2921 & 0,3940 \\
\hline
\end{tabular}




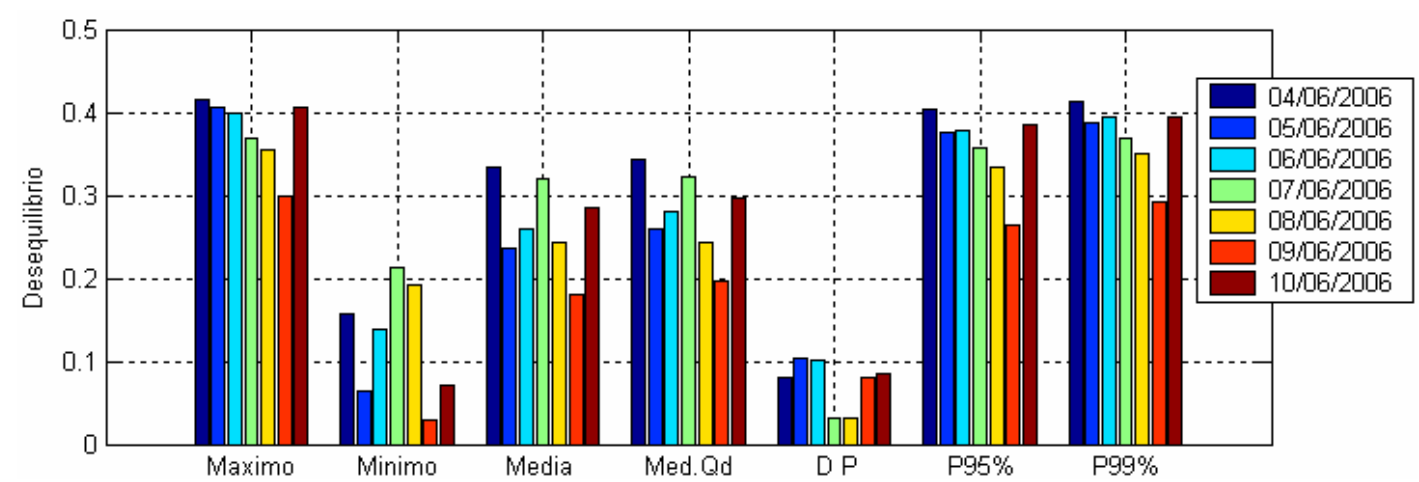

Figura 8.4 - Estatísticas dos valores de desequilíbrio para os sete dias

A pouca variação nos valores de $\mathrm{K}$ dos dias 7 e 8 observada na Figura 8.3 é comprovada pelos baixos valores de desvio padrão constatados na Tabela 8.1 e na Figura 8.4. Observase que o desequilíbrio encontrou-se em patamares mais elevados durante os dias de final de semana (4 e 10). Tal comportamento se deve, provavelmente, ao regime de funcionamento das máquinas da industria, que é diferente nos dias de final de semana. Esse fato já foi observado em outros estudos, como mostrado no Apêndice E.

Curiosamente, ao se observar o gráfico de barras dos índices máximo, $\mathrm{P} 95 \%$ e P99\%, percebe-se uma redução quase que gradativa dos valores de $\mathrm{K}$ do dia 4 até o dia 9 . No domingo, dia 10, o dequilíbrio volta a crescer. Um maior entendimento dos processos desenvolvidos nesta subestação é demandado para que se possa tecer conclusões consistentes sobre esses resultados.

Assim, apesar das diferenças constatadas nos valores de $\mathrm{K}$ para os 7 dias, os baixos patamares apresentados permitem que um dia seja tomado como representativo aos demais. Para este propósito aconselhasse um dia de fim de semana.

\subsubsection{Análise da Similaridade entre Períodos}

Para esta análise, além dos três períodos fixados pelo aplicativo, será utilizado o período de 10:00 às 18:00h. Foi escolhido para análise o dia 4 (domingo), para o qual foram calculados os maiores valores de $\mathrm{K}$.

A Tabela 8.2 e a Figura 8.5 trazem as estatísticas dos desequilíbrios encontrados no dia 4. 
Tabela 8.2 - Estatísticas dos valores de desequilíbrio para o dia 04/06

\begin{tabular}{|c|c|c|c|c|}
\hline Período & $00: 00$ às 8:00 & $8: 00$ às $16: 00$ & $16: 00$ às 24:00 & $10: 00$ às $18: 00$ \\
\hline Máximo & 0,4159 & 0,4023 & 0,3739 & 0,3908 \\
\hline Mínimo & 0,3469 & 0,2995 & 0,1564 & 0,2995 \\
\hline Méd.arit. & 0,3811 & 0,3662 & 0,2535 & 0,3631 \\
\hline Méd.quad. & 0,3815 & 0,3666 & 0,2701 & 0,3634 \\
\hline D. Padrão & 0,0180 & 0,0169 & 0,0942 & 0,0152 \\
\hline P 95\% & 0,4130 & 0,3911 & 0,3716 & 0,3868 \\
\hline P 99\% & 0,4159 & 0,4023 & 0,3739 & 0,3908 \\
\hline
\end{tabular}

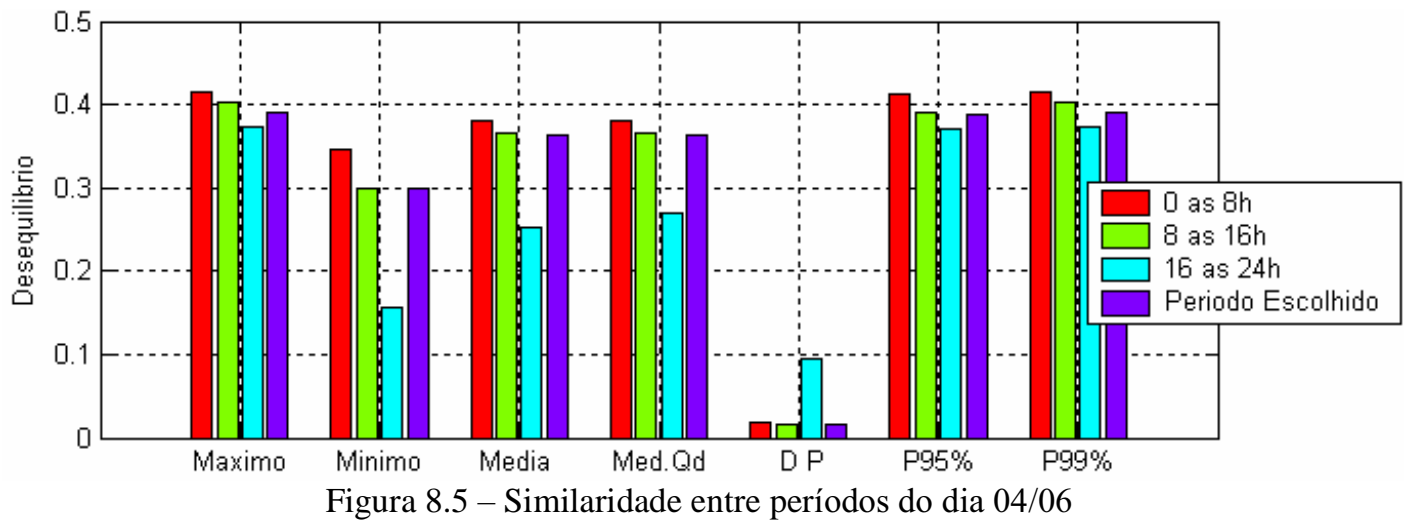

Fica evidente da Tabela 8.2 e da Figura 8.5 que os desequilíbrios são mais intensos durante a madrugada. Neste período o fator $\mathrm{K}$ sofre pouca variação, haja vista o baixo desvio padrão apresentado. $\mathrm{O}$ menor $\mathrm{K}$ e a maior variação entre os valores do fator $\mathrm{K}$ ocorreram entre 16 e $24 \mathrm{~h}$. Os valores de desequilíbrio permaneceram, em média, muito semelhantes durante todo o período de 8 e 18h. A Figura 8.6 traz o perfil do desequilíbrio para o dia em análise.

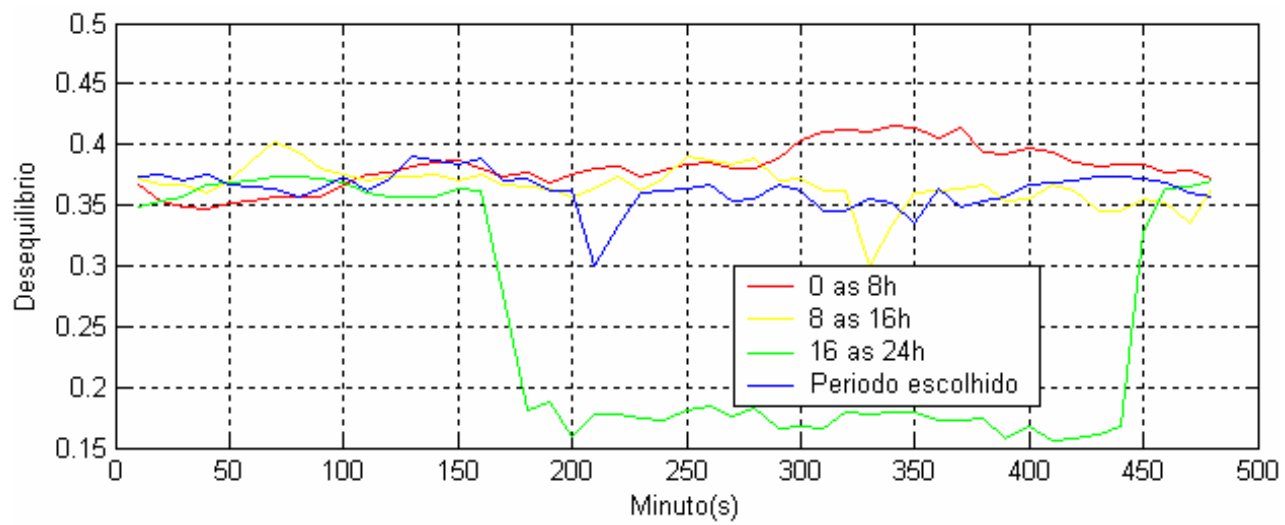

Figura 8.6 - Perfil do K durante o dia 4 
Destaca-se, mais uma vez, o período de 16 às $24 \mathrm{~h}$ com valores diferentes aos demais. Durante a noite ocorre a redução dos níveis de desequilíbrio. Nota-se que, durante a madrugada, os valores do fator $\mathrm{K}$ crescem sutilmente e atingem o seu máximo por volta das 05:45h (minuto 345). Em seguida, sofre uma leve redução, mantendo-se em níveis mais baixos. Isso é percebido na curva do período de 8 às $16 \mathrm{~h}$.

Os períodos analisados mostraram comportamentos semelhantes, com exceção do intervalo que acontece entre 16 e $24 \mathrm{~h}$. Entretanto, como a diferença neste intervalo se dá para índices mais baixos, tal fato não representa motivo de preocupação. Deste modo, por possuir os maiores valores de $\mathrm{K}$, a análise do período de 0 às $8 \mathrm{~h}$ é suficiente para a quantificação dos desequilíbrios.

\subsection{Considerações Finais}

Foram apresentadas análises que intentam a constatação da existência ou não de similaridade entre os dias de medição e entre os períodos de um dia. A motivação se deu, sobretudo, para o auxílio na determinação de um período mínimo necessário para as medições.

Quando da análise voltada à determinação do período mínimo de medição na SE Carajás, constatou-se que um único dia de medição é suficiente. Esse dia deve ser, preferencialmente, no final de semana. Os períodos do dia 4 analisado mostraram-se semelhantes entre si, com níveis ligeiramente mais elevados durante a madrugada. Assim, esse é o período mais adequado para representar as demais amostras.

Uma análise de outras semanas de medição e um maior entendimento dos processos desenvolvidos na subestação estudada são requeridos para a generalização das conclusões. Contudo, indubitavelmente, a metodologia descrita presta-se como auxílio à elaboração de estratégias para campanhas de medição dos desequilíbrios de tensão. 


\section{Capítulo 9}

\section{Análise da Distribuição no Tempo dos Níveis de Desequilíbrio de Tensão}

\subsection{Considerações Iniciais}

Neste item, almeja-se apresentar uma metodologia auxiliar de avaliação que possibilita a análise da distribuição no tempo dos níveis de desequilíbrio de tensão. Será investigado o comportamento das amostras com valores superiores ao $\mathrm{P} 95 \%, \mathrm{P} 99 \%$ e a média quadrática. Aspira-se, a partir dos resultados gerados, concluir quanto à representatividade desses indicadores, quando das suas utilizações em representação aos demais valores medidos. Esses patamares caracterizam-se como os indicadores comumente presentes nas normas e recomendações mundialmente conhecidas sobre a qualidade da energia. Tendo considerado que a norma nacional voltada para o setor de Distribuição encontra-se em elaboração, este estudo poderá caracterizar-se como uma contribuição para o estabelecimento de diretrizes na avaliação do desequilíbrio em campanhas de medição.

Muito embora um determinado local possa apresentar poucos valores elevados de fator $\mathrm{K}$, manifestados concentradamente, estes poderão deteriorar os equipamentos mais sensíveis. Deste modo, a partir da metodologia proposta, caberá aos fabricantes, de posse dos limites de suportabilidade de cada um dos seus equipamentos frente aos desequilíbrios de tensão, entender se o mesmo suporta ou não os níveis apresentados, em função do tempo de exposição.

\subsection{Módulo na Ferramenta Computacional}

O módulo do aplicativo computacional referente a esta etapa permite investigar a distribuição no tempo de um determinado valor limite (VL) de desequilíbrio estabelecido pelo usuário. Este patamar escolhido está, normalmente, relacionado com os limites 
impostos pelas principais normas e recomendações, os limites de suportabilidade de equipamentos elétricos conectados à rede ou os níveis de desequilíbrio em função do seu tempo de exposição. A metodologia proposta oferece:

- Máximo de minutos que o sistema permaneceu acima do valor limite (VL) de $\mathrm{K}$ estabelecido;

Esse valor é calculado considerando todo o período de medição;

- Máximo intervalo de tempo ininterrupto com um valor de K acima de VL;

Representa a pior circunstância em que um equipamento estará exposto ao patamar VL de desequilíbrio especificado, ininterruptamente.

- Máximo intervalo de tempo ininterrupto com um valor de K abaixo de VL.

Com esse intervalo de tempo verifica-se o máximo de minutos que o sistema permaneceu sem apresentar nenhuma ocorrência de valores acima de VL;

Como auxílio à interpretação destes indicadores, tem-se à disposição uma série de gráficos, a saber:

- Valores acima de VL versus tempo total de medição;

- Valores abaixo de VL versus tempo total de medição;

- Intervalos de tempo ininterruptos com valor acima de VL versus tempo total de medição;

- Probabilidade de ocorrência de intervalos de tempo ininterruptos com valor acima de $\mathrm{VL}$;

- Intervalos de tempo ininterruptos com valor abaixo de VL versus tempo total de medição;

- Probabilidade de ocorrência de intervalos de tempo ininterruptos com valor abaixo de $\mathrm{VL}$; 
A Figura 9.1 ilustra a tela do módulo da ferramenta computacional. O usuário deve, primeiramente, escolher um valor limite (VL) de K. Os índices e gráficos supracitados são, então, disponibilizados.

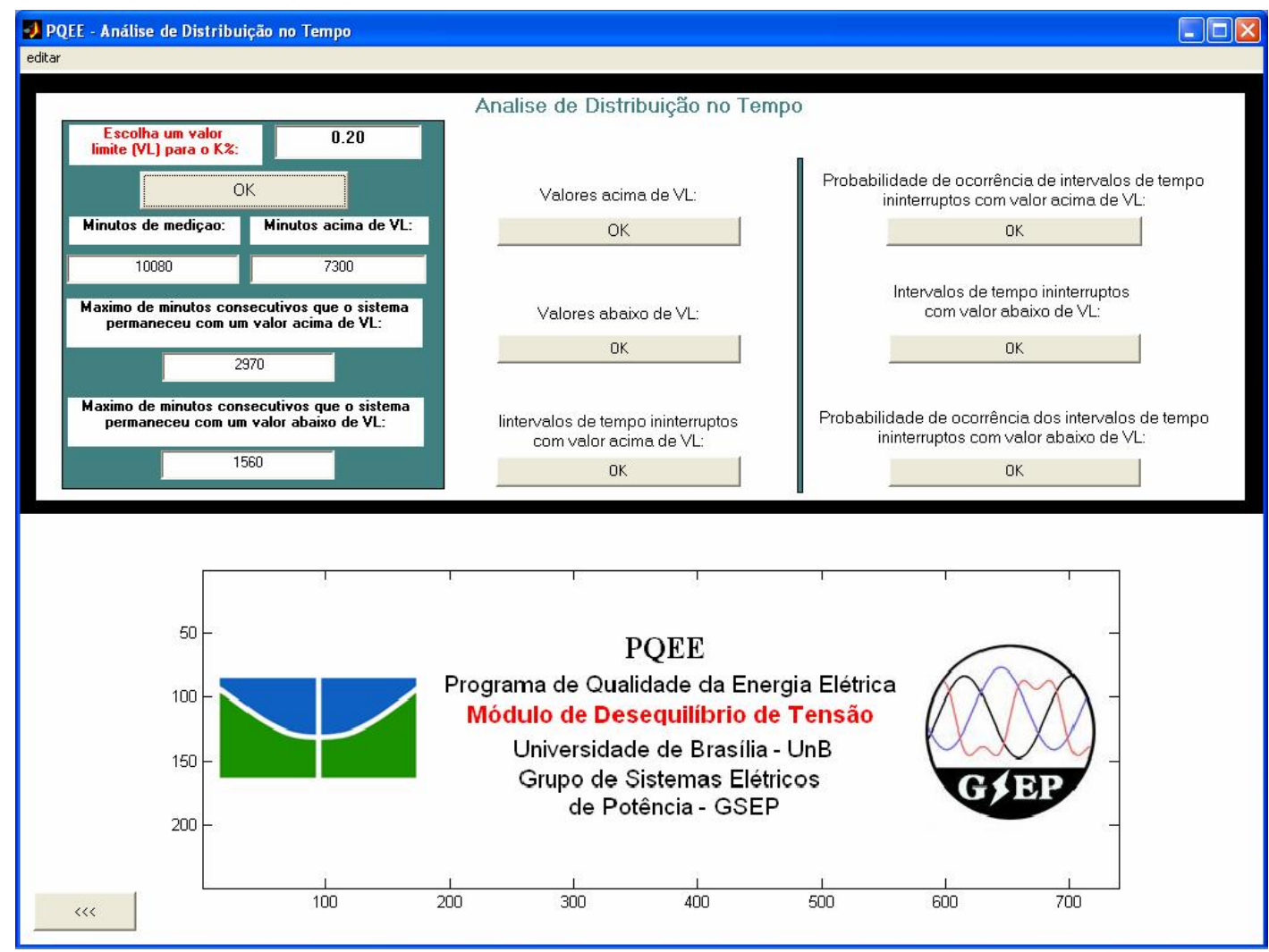

Figura 9.1 - Tela do módulo da ferramenta computacional

\subsection{Estudo de Caso}

Neste estudo, far-se-á uma análise comparativa entre os índices P95\%, P99\% e média quadrática. Serão investigadas as distribuições no tempo dos valores de K referentes a essas estatísticas tomadas na subestação SE Carajás.

O número total de minutos de medição foi de 10.080 minutos. Da utilização da ferramenta, tem-se os resultados da Tabela 9.1. 
Tabela 9.1 - Resultados das análise considerando todos os índices

\begin{tabular}{|c|c|c|c|}
\hline & $\begin{array}{c}\text { Média } \\
\text { Quadrática } \\
(0,2808 \%)\end{array}$ & $\begin{array}{c}\mathrm{P} 95 \% \\
(0,3807 \%)\end{array}$ & $\begin{array}{c}\text { P99\% } \\
(0,4029 \%)\end{array}$ \\
\hline $\begin{array}{c}\text { Total de minutos com } \\
\mathrm{K} \geq \text { índice }\end{array}$ & 4760 & 500 & 100 \\
\hline $\begin{array}{c}\text { Máximo intervalo } \\
\text { ininterrupto de tempo com } \\
\mathrm{K} \geq \text { índice }\end{array}$ & 1500 & 170 & 80 \\
\hline $\begin{array}{c}\text { Máximo intervalo } \\
\text { ininterrupto de tempo com } \\
\text { K<índice }\end{array}$ & 1750 & 4660 & 7730 \\
\hline
\end{tabular}

Da Tabela 9.1, e considerando-se o tempo total com $\mathrm{K} \geq$ índice, pode-se observar uma proporção da forma que se espera das suas respectivas definições, ou seja, o período total com $\mathrm{K} \geq \mathrm{P} 99 \%$ é aproximadamente 5 vezes maior ao com $\mathrm{K} \geq \mathrm{P} 95 \%$. Já para a análise dos máximos intervalos ininterruptos com $\mathrm{K} \geq$ índice e $\mathrm{K}<$ índice, nota-se variações entre os valores adquiridos para cada estudo, indicando que a distribuição no tempo se dá de forma diferente para cada índice.

A seguir serão feitas, separadamente, análises considerando cada um dos indicadores como referência.

\subsubsection{Análise considerando-se o valor de média quadrática como referência}

O valor da média quadrática calculado no Capítulo 5 e repetido na tabela 9.1 é de 0,2808. A Figura 9.2 traz o gráfico de $\mathrm{K} \geq 0,2808 \%$ versus tempo total de medição em minutos. 


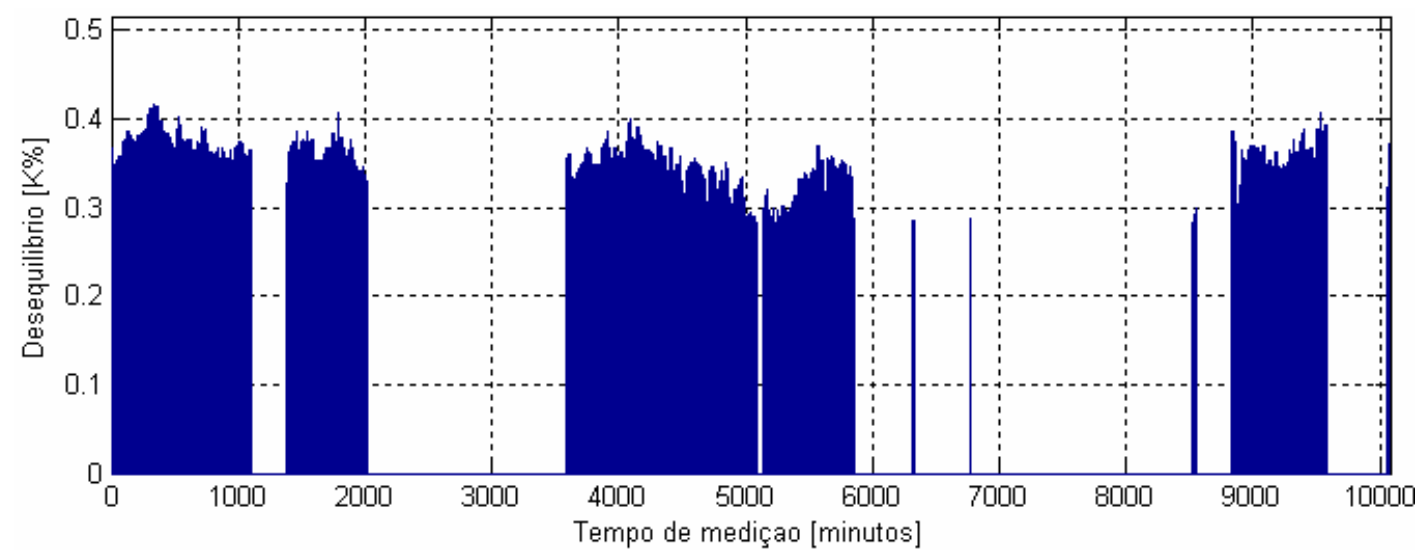

Figura 9.2 - Valores com $\mathrm{K} \geq 0,2808 \%$ versus tempo total de medição em minutos

Nota-se da Figura 9.2 que os valores com $\mathrm{K} \geq 0,2808 \%$ manifestaram-se praticamente durante a metade do tempo total de medição (4760 minutos de um total de 10080). Na Figura 9.3 estão plotados os intervalos ininterruptos de tempo com valores com $\mathrm{K} \geq 0,2808 \%$.

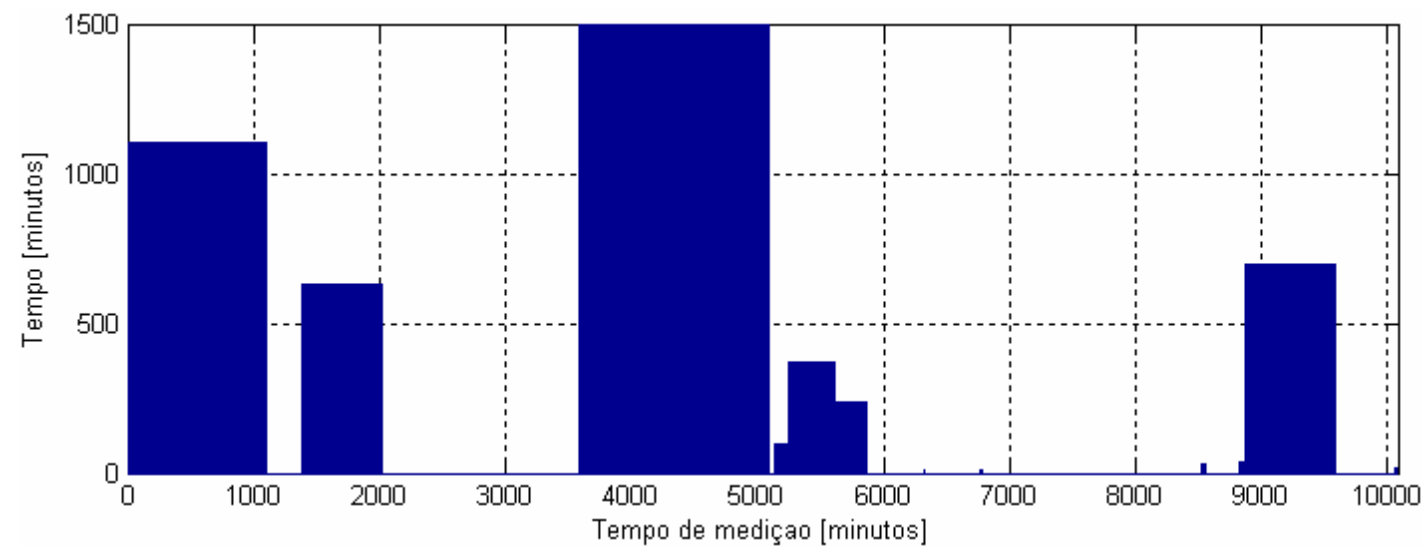

Figura 9.3 - Intervalos ininterruptos de tempo com valores com $\mathrm{C} \%$

Observa-se na Figura 9.3 que o máximo intervalo ininterrupto com $\mathrm{K} \geq 0,2808 \%$ é da ordem de 1500 minutos (pouco mais de um dia). Constata-se, ainda, a presença de dois outros intervalos significativos, sendo um de 1110 minutos (dia 4) e outro de 700 minutos. Notase que os valores com $\mathrm{K} \geq 0,2808 \%$ concentraram-se, acentuadamente, em 5 grupos durante todo o período.

A Figura 9.4 exibe o gráfico com os intervalos ininterruptos de tempo com valores de $\mathrm{K}<0,2808$. 


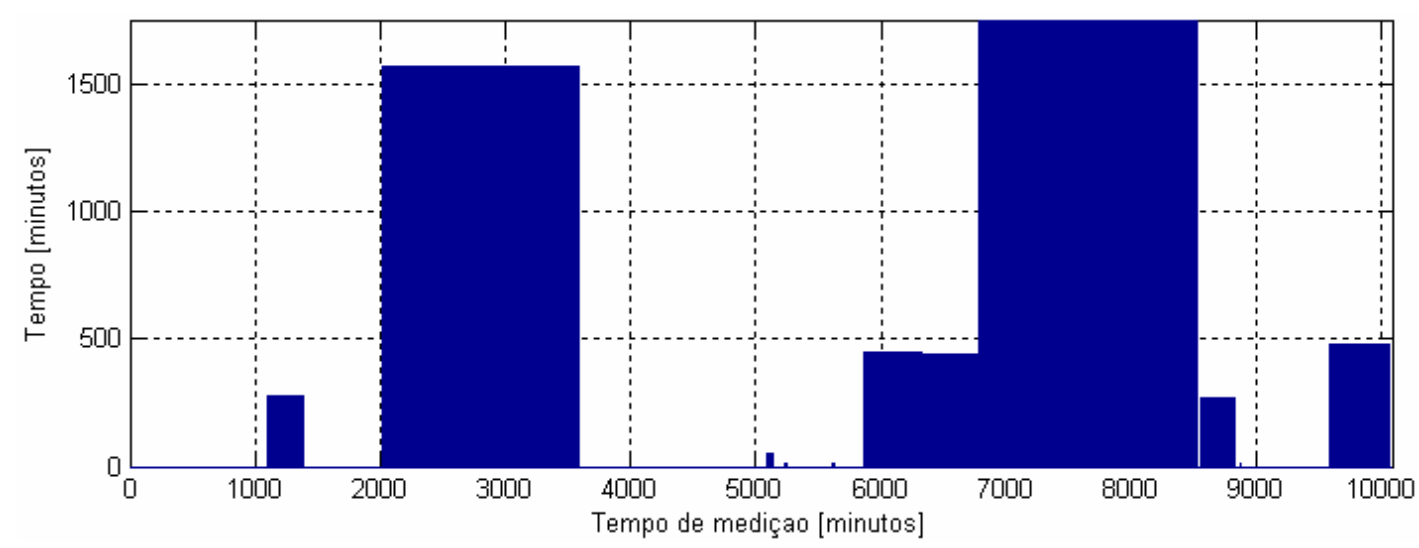

Figura 9.4 - Intervalos ininterruptos de tempo com valores de $\mathrm{K}<0,2808$

Constata-se dois grandes intervalos de tempo sem nenhuma ocorrência de valores acima de 0,2808\%. O máximo intervalo de tempo ininterrupto foi de 1750 minutos, correspondentes a um período de aproximadamente 29 horas. Observa-se um outro período com valores de $\mathrm{K}<0,2808$ com duração maior que um dia, ocorrido no segundo dia de medição e estendendo-se até cerca de 12:00h do terceiro dia.

A Figura 9.5 ilustra o gráfico com as probabilidades de ocorrência dos intervalos ininterruptos de tempo com $\mathrm{K} \geq 0,2808 \%$.

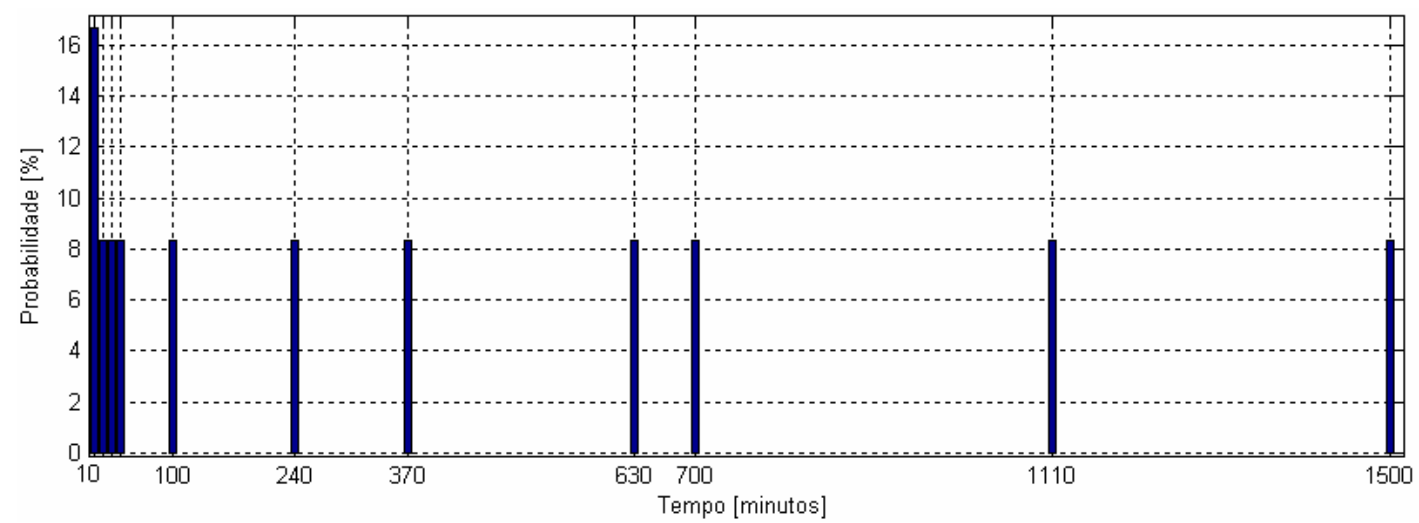

Figura 9.5 - Probabilidades de ocorrência dos intervalos ininterruptos de tempo com $\mathrm{K} \geq 0,2808 \%$

Da Figura 9.5, observa-se que aproximadamente $40 \%$ dos intervalos de tempo com $\mathrm{K} \geq 0,2808 \%$ tem até 40 minutos de duração. $\mathrm{O}$ intervalo de 10 minutos é o que possui a maior probabilidade de ocorrência, cerca de 16,5\%. Entretanto, são encontrados intervalos de 1500 e 1110 minutos consecutivos acima de $0,2808 \%$. 
A Figura 9.5 traça o gráfico com as probabilidades de ocorrência dos intervalos ininterruptos de tempo com $\mathrm{K}<0,2808 \%$.

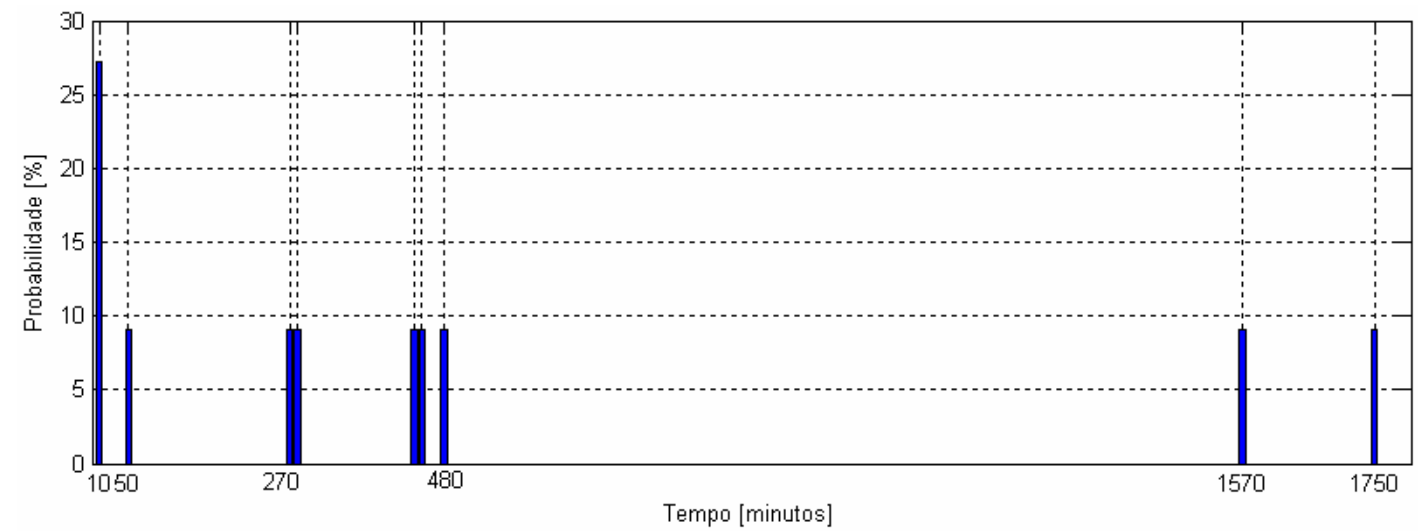

Figura 9.6 - Probabilidades de ocorrência dos intervalos ininterruptos de tempo com $\mathrm{K}<0,2808 \%$

Nota-se da Figura 9.6 que $27 \%$ dos intervalos de tempo com $\mathrm{K}<0,2808 \%$ possui até 10 minutos de duração. Contudo, ressalta-se a existência de alguns intervalos ininterruptos de tempo com $\mathrm{K}<0,2808 \%$ entre 50 e 480 minutos de duração.

Isto indica portanto que, para os 7 dias em estudo, a maioria dos intervalos de tempo com valores de $\mathrm{K} \geq 0,2808 \%$ possuem até 40 minutos de duração, espaçados entre si, predominantemente, por períodos de 10 minutos.

\subsubsection{Análise considerando-se o valor de $\mathbf{P 9 5 \%}$ como referência}

$\mathrm{O}$ valor do P95\% é de 0,3807. A Figura 9.7 traz o gráfico de $\mathrm{K} \geq 0,3807 \%$ versus tempo total de medição, em minutos. 


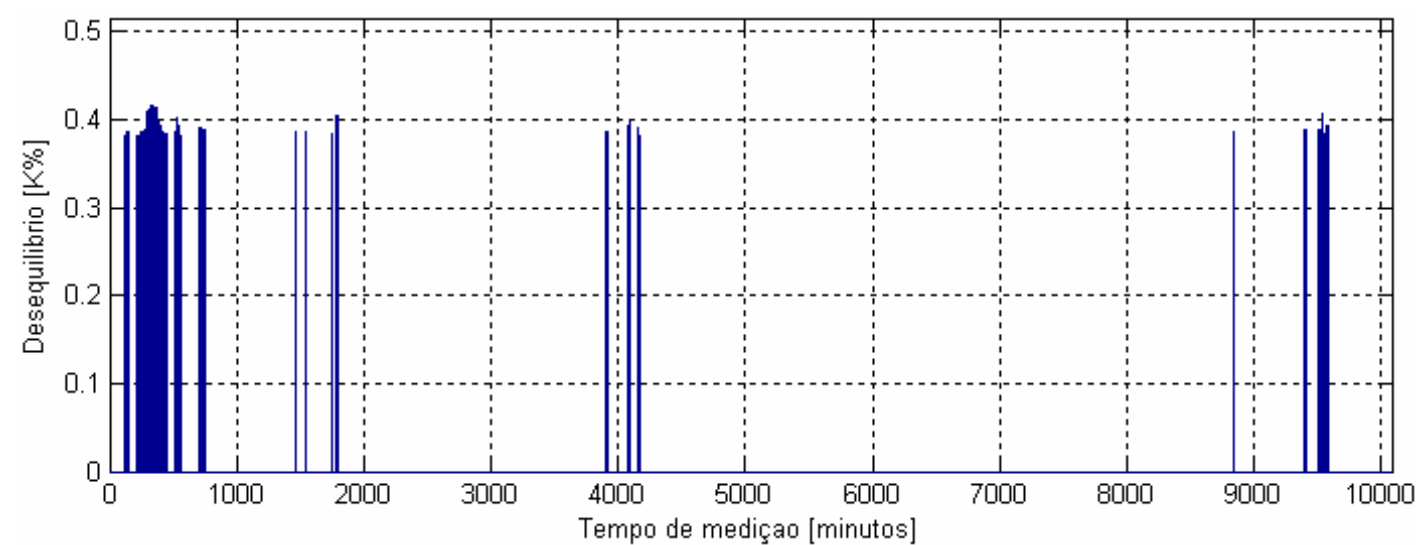

Figura 9.7 - Valores com $\mathrm{K} \geq 0,3807 \%$ versus tempo total de medição em minutos

Observa-se na Figura 9.7 que as amostras acima de 0,3807 estão mal distribuídas no período de medição. Da Tabela 9.1 calcula-se que estes valores somam pouco mais de $8 \mathrm{~h}$ de duração, ao longo de todo período monitorado.

Na Figura 9.8 tem-se o gráfico dos intervalos ininterruptos de tempo com valores com $\mathrm{K} \geq 0,3807 \%$.

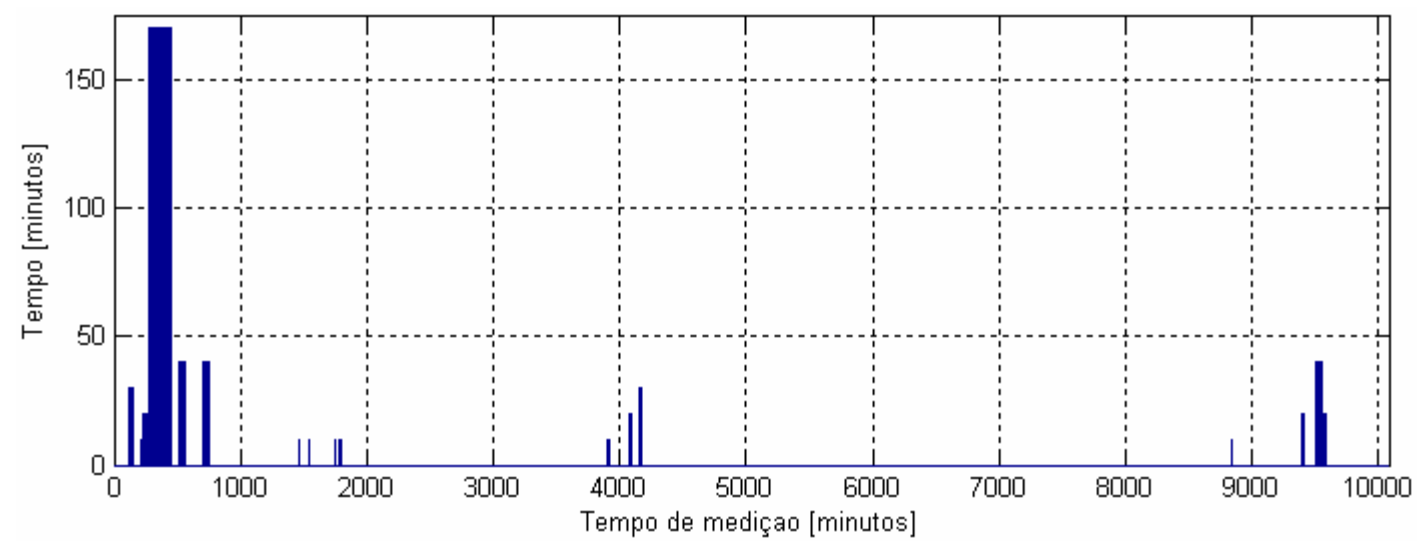

Figura 9.8 - Intervalos ininterruptos de tempo com valores com $\mathrm{K} \geq 0,3807 \%$

Da Figura 9.8 nota-se que o maior intervalo com desequilíbrio acima de 0,3807 foi de 170 minutos. Curiosamente, esse intervalo e o segundo maior intervalo com $\mathrm{K} \geq 0,3807 \%$ se deram nos dias 4 e 10/06, dias de final de semana. Como presumido no Capítulo 5, nesses dias deve haver um regime diferenciado de operação das máquinas rotativas e fornos a arco presentes no consumidor monitorado. 
A Figura 9.9 exibe o gráfico com os intervalos ininterruptos de tempo com valores de $\mathrm{K}<0,3807$.

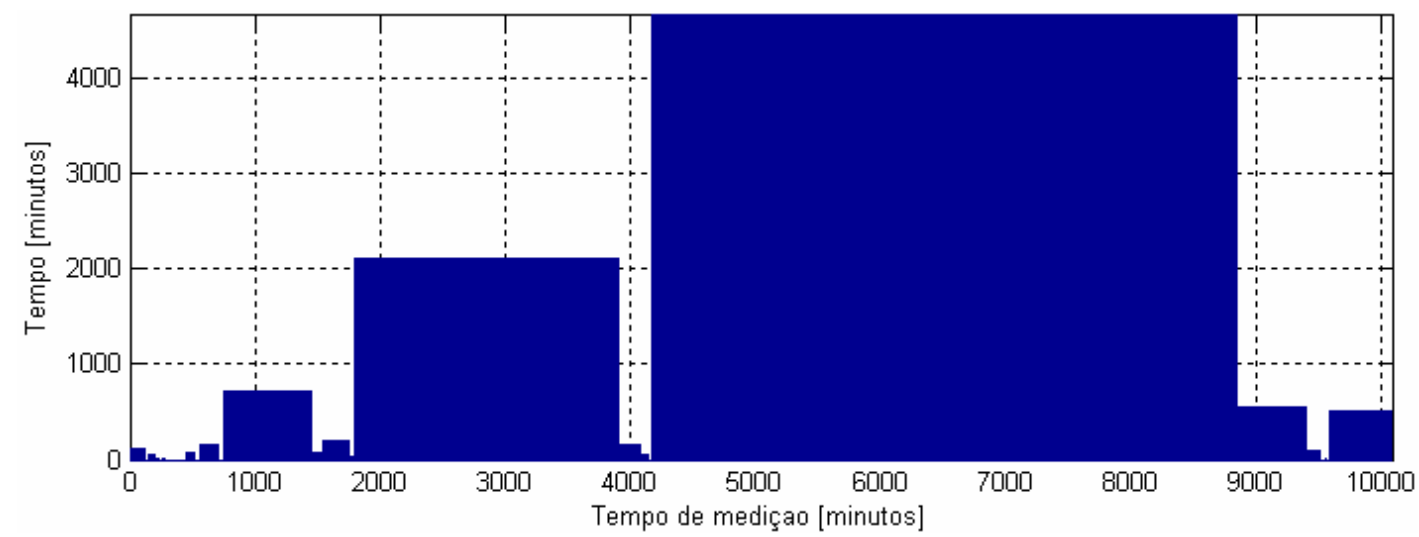

Figura 9.9 - Intervalos ininterruptos de tempo com valores de $\mathrm{K}<0,3807$

Nota-se um longo intervalo de 4660 minutos, correspondentes a 77,5 horas, com valores de $\mathrm{K}<0,3807$. Um outro intervalo com duração de quase 40 horas foi observado.

A Figura 9.10 mostra o gráfico com as probabilidades de ocorrência dos intervalos ininterruptos de tempo com $\mathrm{K} \geq 0,3807 \%$.

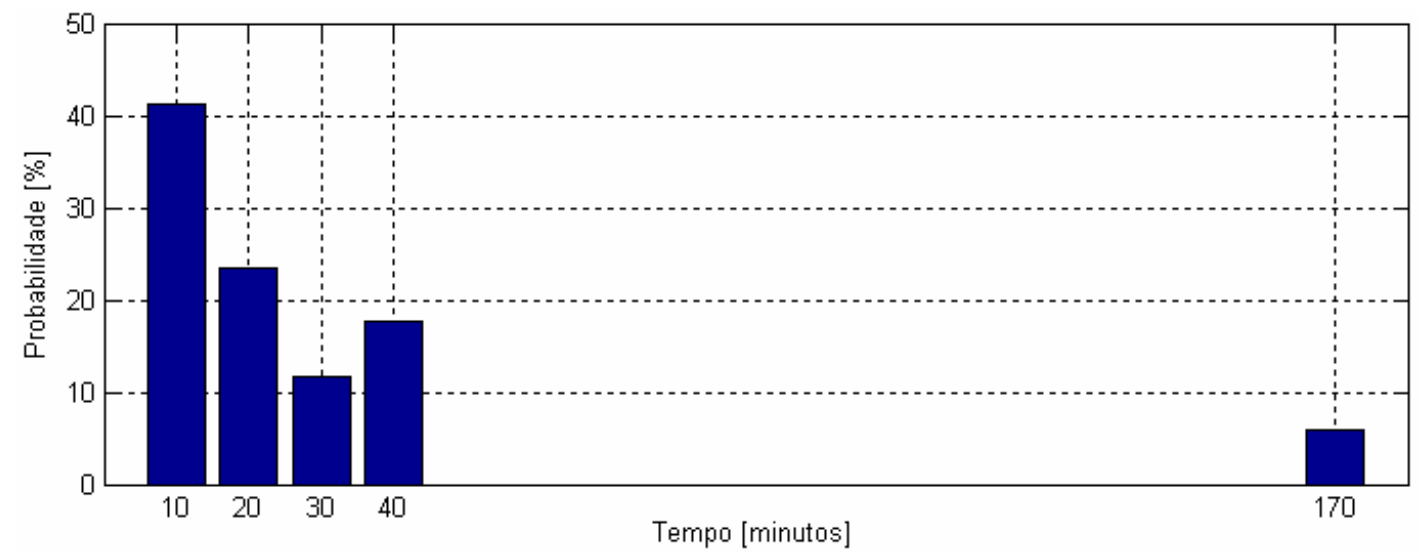

Figura 9.10 - Probabilidades de ocorrência dos intervalos ininterruptos de tempo com $\mathrm{K} \geq 0,3807 \%$

Da Figura 9.10 observa-se que mais de $40 \%$ dos intervalos de tempo ininterruptos com $\mathrm{K} \geq 0,3807 \%$ possuem até 10 minutos de duração. Aproximadamente $93 \%$ das ocorrências desses intervalos de tempo tem até 40 minutos consecutivos. Ou seja, fora o intervalo de 170 minutos ininterruptos com $\mathrm{K} \geq 0,3807 \%$, todos os outros intervalos tiveram menos de 40 minutos de duração. 
A Figura 9.11 exibe o gráfico com as probabilidades de ocorrência dos intervalos ininterruptos de tempo com $\mathrm{K}<0,3807 \%$.

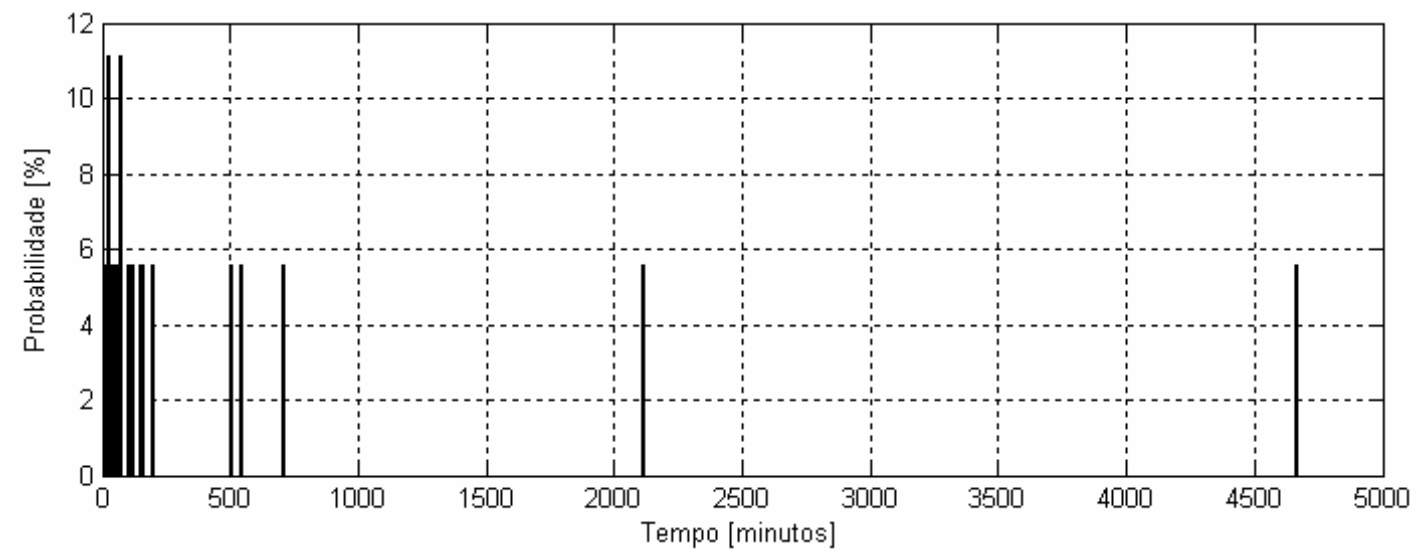

Figura 9.11 - Probabilidades de ocorrência dos intervalos ininterruptos de tempo com $\mathrm{K}<0,3807 \%$

A Figura 9.12 utiliza a opção de zoom do aplicativo para visualizar melhor a faixa que detêm a maior quantidade dos intervalos de tempo.

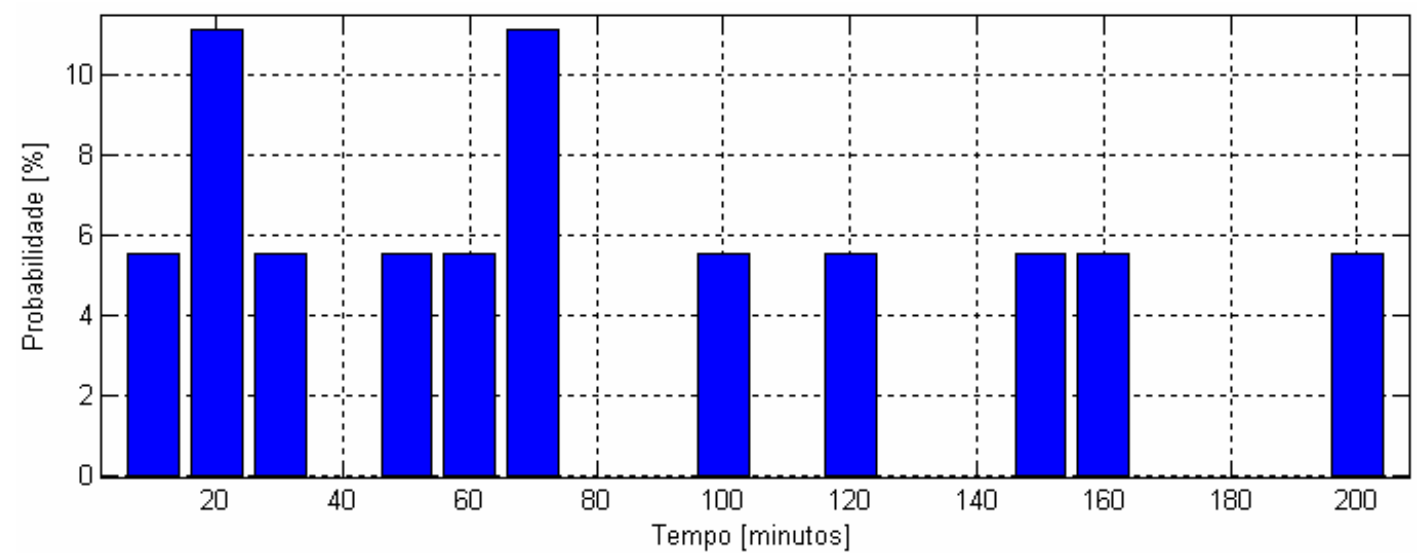

Figura 9.12 - Zoom de um período da figura 9.11

Na Figura 9.11 verifica-se um intervalo ininterrupto de 4660 minutos com $K<0,3807 \%$. Nota-se também a presença de um outro intervalo de longa duração, contendo cerca de 2150 minutos. Da Figura 9.12 observa-se que as maiores probabilidades de ocorrência são de intervalos com 20 e 70 minutos consecutivos com $\mathrm{K}<0,3807 \%$. Todavia, de uma maneira geral, esses intervalos estão concentrados entre 10 e 200 minutos. 
Deste modo, no período analisado, os diversos valores de $\mathrm{K} \geq 0,3807 \%$ estão concentrados em intervalos de curta duração, cerca de 10 minutos, espaçados entre si, na maioria das vezes, por períodos entre 10 e 70 minutos.

\subsubsection{Análise considerando-se o valor de $\mathbf{P 9 9 \%}$ como referência}

O valor do P99\% encontrado foi de $0,4029 \%$. A Figura 9.13 traz o gráfico de $\mathrm{K} \geq 0,4029 \%$ versus tempo total de medição em minutos.

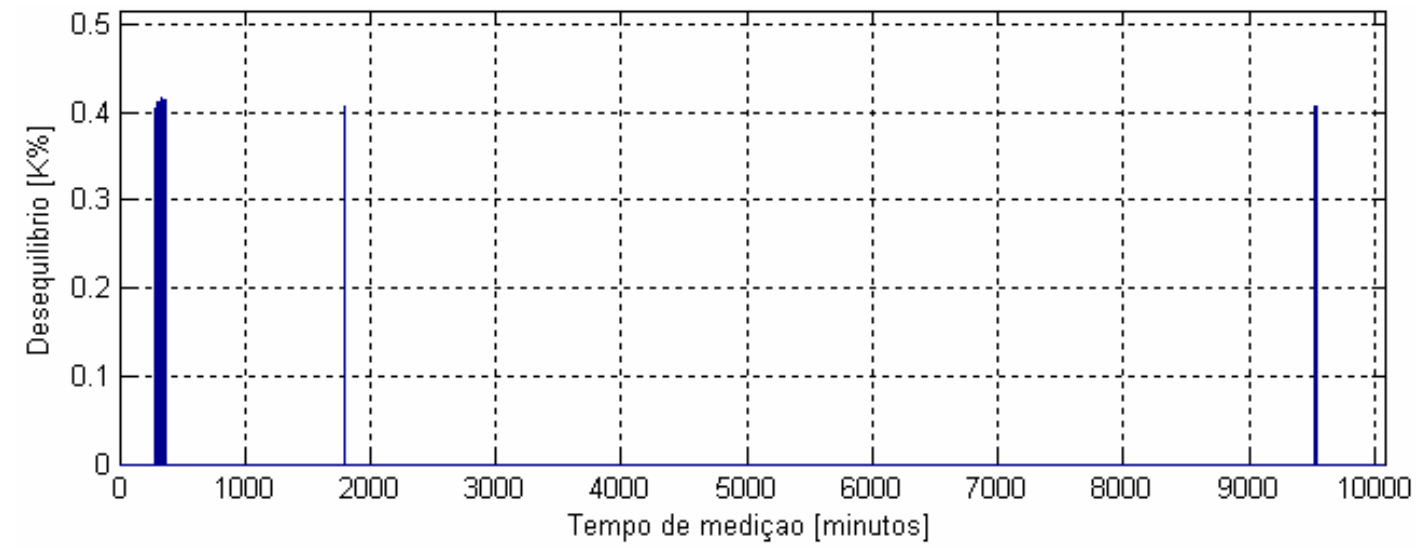

Figura 9.13 - Valores com $\mathrm{K} \geq 0,4029 \%$ versus tempo total de medição em minutos

Novamente, percebe-se que os maiores valores estão mais distribuídos nos dias de fim de semana. Os valores acima de 0,4029\% somam 100 minutos, de um total de 10080 . Na Figura 9.14 são mostrados os intervalos ininterruptos de tempo com valores com $\mathrm{K} \geq 0,4029 \%$.

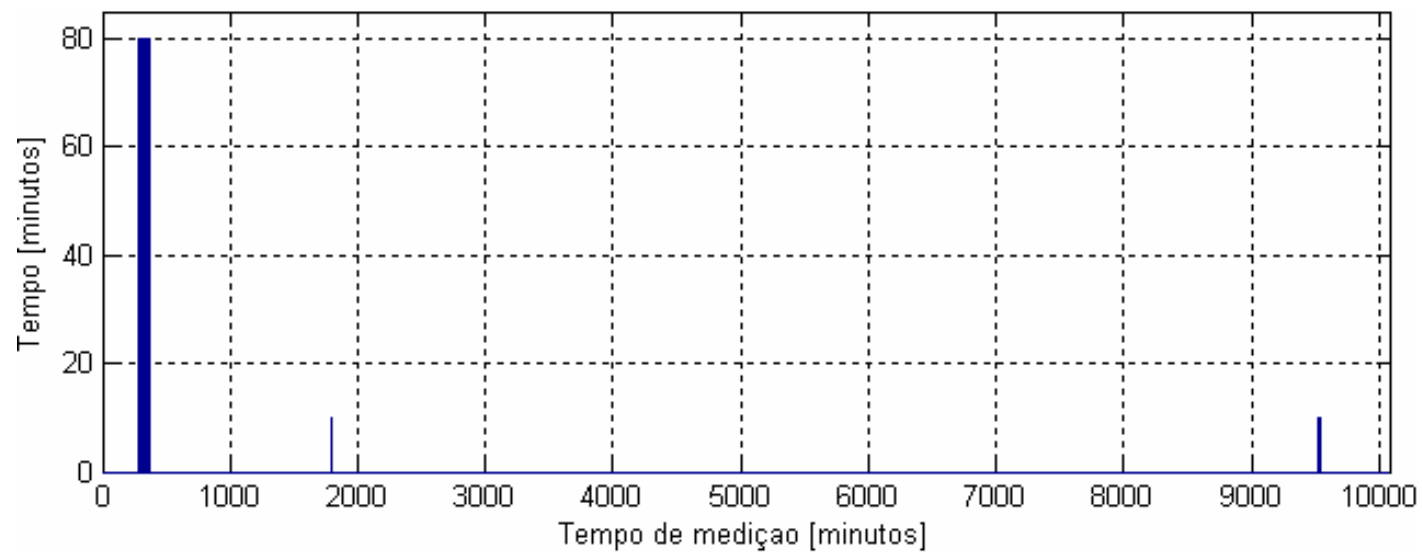

Figura 9.14 - Intervalos ininterruptos de tempo com valores com $\mathrm{K} \geq 0,4029 \%$ 
Da Figura 9.14, nota-se que o maior número de minutos consecutivos com $K \geq 0,4029 \%$ se deu no dia 4 e teve duração de 80 minutos (1 hora e vinte minutos). A Figura 9.15 exibe o gráfico com os intervalos ininterruptos de tempo com valores de $\mathrm{K}<0,4029$.

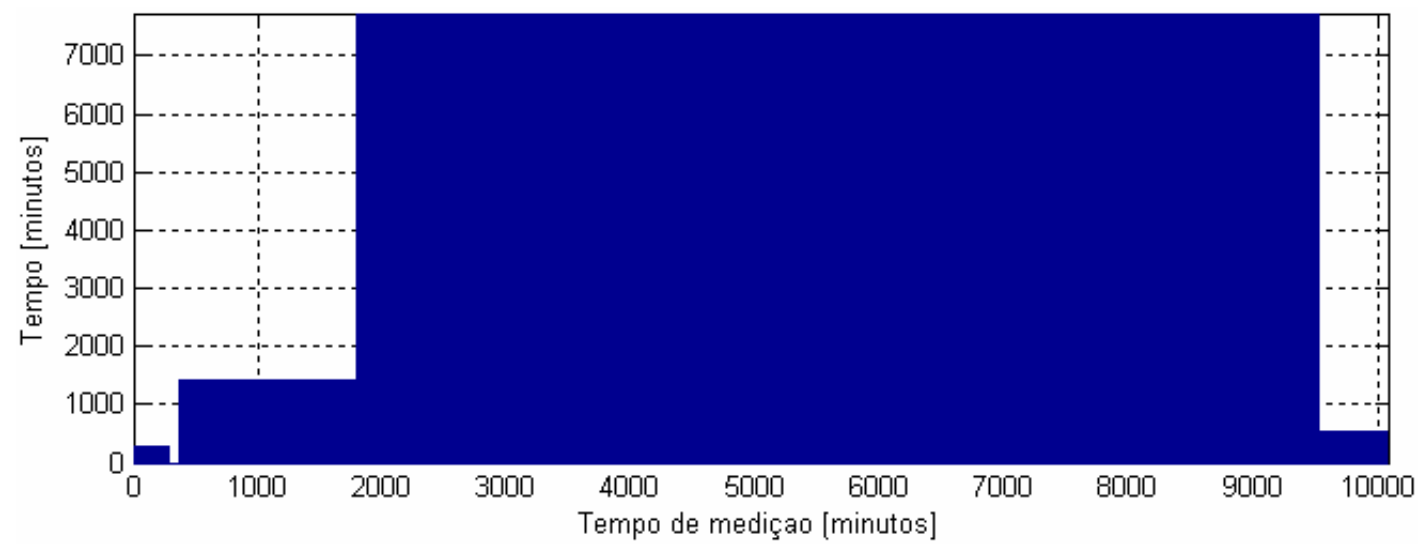

Figura 9.15 - Intervalos ininterruptos de tempo com valores de $\mathrm{K}<0,4029$

Observa-se, na Figura 9.15, que os 7730 minutos em que o sistema permaneceu com $\mathrm{K}<0,4029$ se deram, aproximadamente, entre os minutos 1800 e 9500 . Verifica-se outros intervalos com $\mathrm{K}<0,4029$, contudo com menor duração.

A Figura 9.16 traça o gráfico com as probabilidades de ocorrência dos intervalos ininterruptos de tempo com $\mathrm{K} \geq 0,4029 \%$.

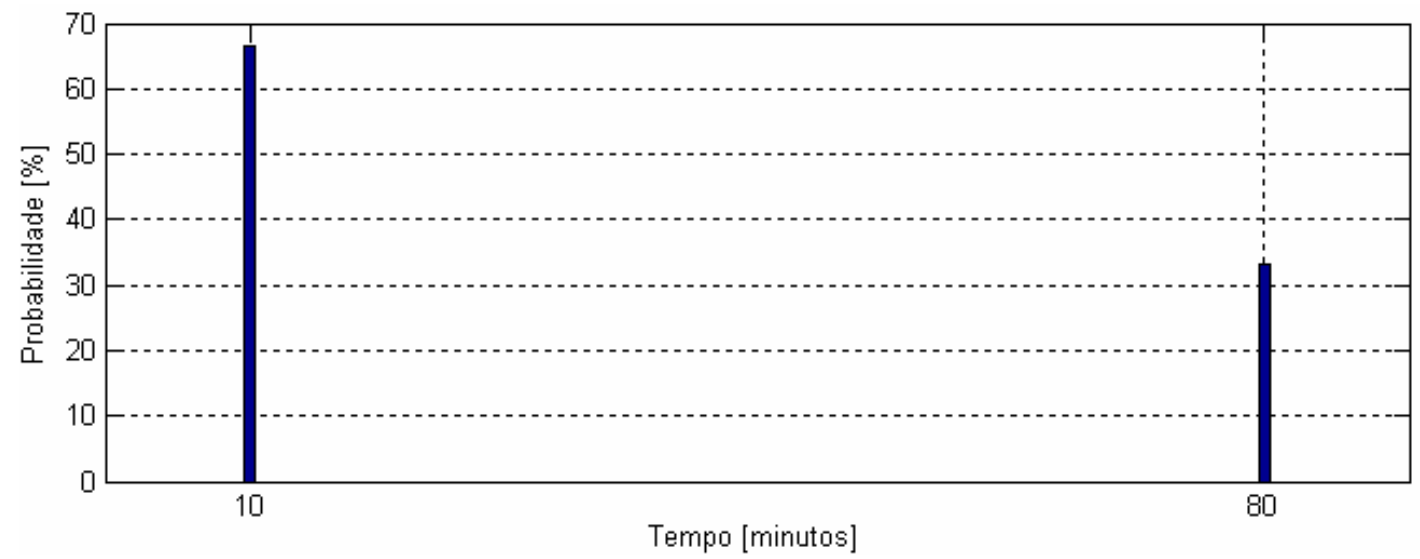

Figura 9.16 - Probabilidades de ocorrência dos intervalos ininterruptos de tempo com $\mathrm{K} \geq 0,4029 \%$

Na Figura 9.16 tem-se que $67 \%$ dos intervalos de tempo ininterruptos com $\mathrm{K} \geq 0,4029 \%$ tem até 10 minutos de duração. $33 \%$ são referentes a intervalos entre 70 e 80 minutos 
consecutivos. A partir desse resultado e da Figura 9.13 é possível concluir que ocorreu um intervalo com duração de 80 minutos e dois com até 10 minutos de duração.

A Figura 9.17 exibe o gráfico com as probabilidades de ocorrência dos intervalos ininterruptos de tempo com $\mathrm{K}<0,4029 \%$.

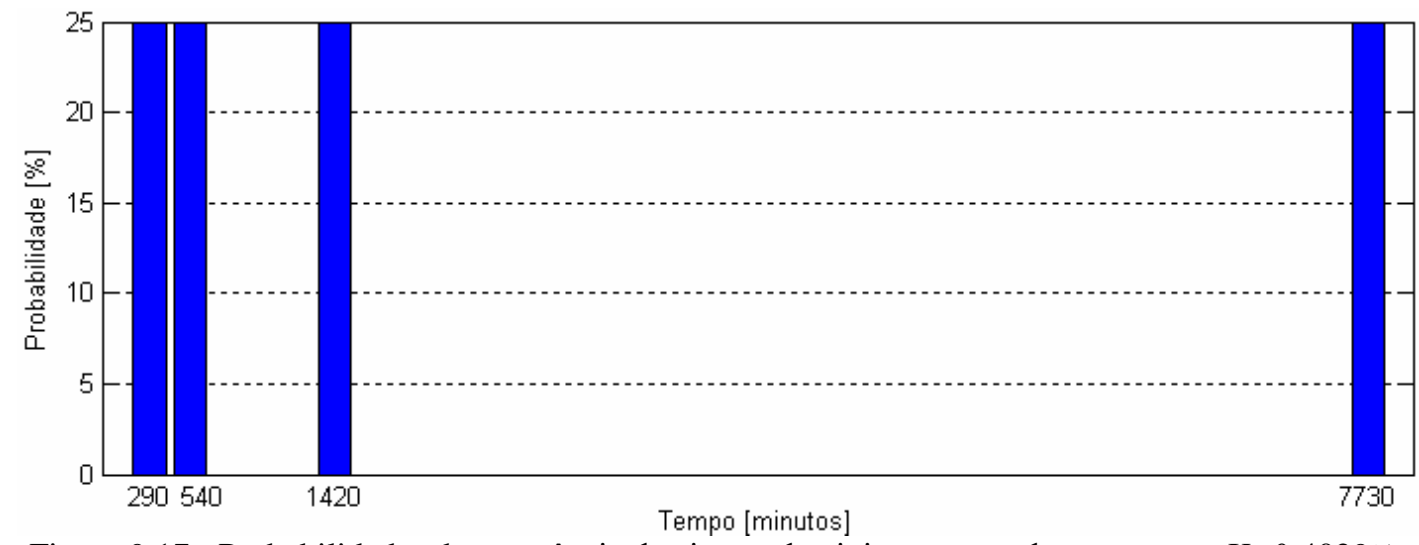

Figura 9.17 - Probabilidades de ocorrência dos intervalos ininterruptos de tempo com $\mathrm{K}<0,4029 \%$

Nota-se que aconteceram 4 intervalos de tempo com longa duração. Estes intervalos estão compreendidos entre 290 e 7730 minutos. Observa-se da Figura 9.15 que o menor intervalo com $\mathrm{K}<0,4029 \%$, 290 minutos, se deu no dia 4.

Das análises das probabilidades de ocorrência tem-se que a maioria dos intervalos ininterruptos de tempo com valores de $\mathrm{K} \geq 0,4029 \%$, cerca de $67 \%$ estão concentrados em períodos de curta duração (10 minutos), espaçados entre si por períodos de longa duração, entre 290 e 1420 minutos, ainda que tenha sido detectado faixa uma com $\mathrm{K} \geq 0,4029 \%$ de 7730 minutos.

\subsection{Considerações Finais}

Este capítulo apresentou os resultados de um estudo que visa contribuir para o estabelecimento de diretrizes para nortear as campanhas de medição de desequilíbrios de tensão. Buscou-se avaliar a relevância de se considerar os índices de P95\%, P99\% e de média quadrática quando de suas utilizações em representação aos demais valores medidos, em um determinado local. 
Verificou-se, devido às diferenças entre o valor médio quadrático e os demais índices, ambos calculados a partir do mesmo conjunto amostral, discrepâncias quanto ao comportamento dos desequilíbrios. No estudo de casos abordado, os valores de K maiores que os índices de P95\% e P99\% estabelecidos estiveram mais concentrados nos dias 4 e 10. Já os valores com $\mathrm{K} \geq$ médiaquadrática ocorreram também em um longo intervalo entre os dias 6 e 7.

Ao comparar o número total de minutos com $\mathrm{K} \geq$ índice, constata-se que cerca de $31 \%$ dos minutos com $\mathrm{K} \geq$ médiaquadrática permaneceram de forma ininterrupta no sistema. $\mathrm{O}$ resultado é semelhante para as amostras de $\mathrm{K} \geq \mathrm{P} 95 \%$, onde os minutos ininterruptos representam aproximadamente $34 \%$ do total. Já para o P99\%, tem-se que $80 \%$ do total de minutos com $\mathrm{K} \geq \mathrm{P} 99 \%$ permaneceram de forma ininterrupta no sistema.

A metodologia auxiliar proposta mostrou-se de importância considerável aos fabricantes e demais interessados em avaliar a suportabilidade de equipamentos frente aos níveis de desequilíbrio apresentados, em função do tempo de exposição. A relevância e a complexidade da escolha por considerar os índices de média quadrática, P95\% e P99\% como valores representativos aos demais fica aqui evidenciada. Recomenda-se fortemente a execução desta mesma análise com dados de outros períodos de medição, com vistas à comprovação ou não do comportamento aqui observado.

O Apêndice G mostra um estudo semelhante ao apresentado neste capítulo, porém com dados de outra subestação. Já o Apêndice E utiliza a metodologia do aplicativo para fazer uma comparação entre locais da distribuição no tempo dos valores de $\mathrm{K} \geq \mathrm{P} 95 \%$. 


\section{Capítulo 10}

\section{Análise da Carga}

\subsection{Considerações Iniciais}

Este capítulo é dirigido para análise das tensões, correntes e potências trifásicas, cuja motivação se dá pela expectativa da percepção do nexo causal existente entre possíveis manobras de cargas e os desequilíbrios de tensão medidos.

Sabe-se que, a partir do estudo da tendência das curvas e dos perfis constatados para as grandezas acima relacionadas, pode-se chegar a algumas conclusões a respeito do comportamento das cargas do sistema. A existência de grandes demandas monofásicas, solicitações de potência reativa, partidas em grandes cargas trifásicas, constituem-se como exemplos de circunstâncias cabíveis de serem inferidas das análises aqui sugeridas.

\subsection{Módulo na Ferramenta Computacional}

No programa são investigados os perfis e as estatísticas das tensões de fase e de linha, correntes de fase e de linha e as potências ativa, reativa e aparente. $\mathrm{O}$ usuário seleciona uma dessas opções de grandezas e escolhe os dias que deseja para analisar. As opções gráficas permitem a comparação entre as tensões e correntes de cada fase e a proporção entre as potências trifásicas. Neste sentido, caso seja necessária uma análise pormenorizada das curvas, deve-se usar a opção "Iniciar zoom" presente no menu padrão desse e de todos os outros módulos do aplicativo.

A Figura 10.1 traz a tela do módulo da ferramenta intitulado "Análise da Carga". 


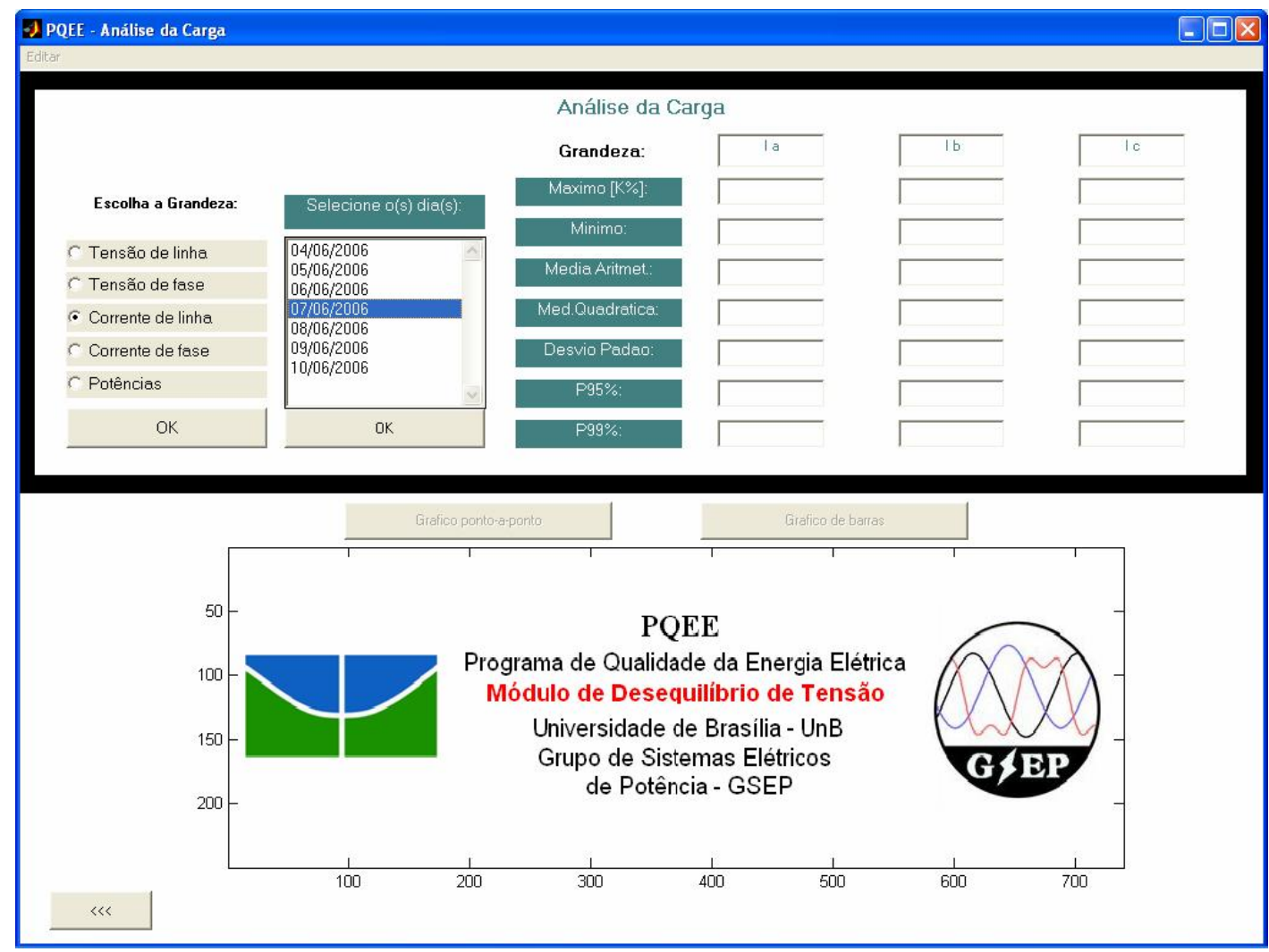

Figura 10.1 - Tela do módulo da ferramenta computacional

\subsection{Estudo de caso}

Seqüencialmente, serão feitas apreciações do comportamento das tensões, correntes e potências medidas na SE Carajás, visando os objetivos outrora relatados.

A Figura 10.2 mostra a curva das correntes de linha nas 3 fases. Por se tratar de medição em um transformador com secundário em estrela, tem-se os mesmos valores para as correntes de fase. 


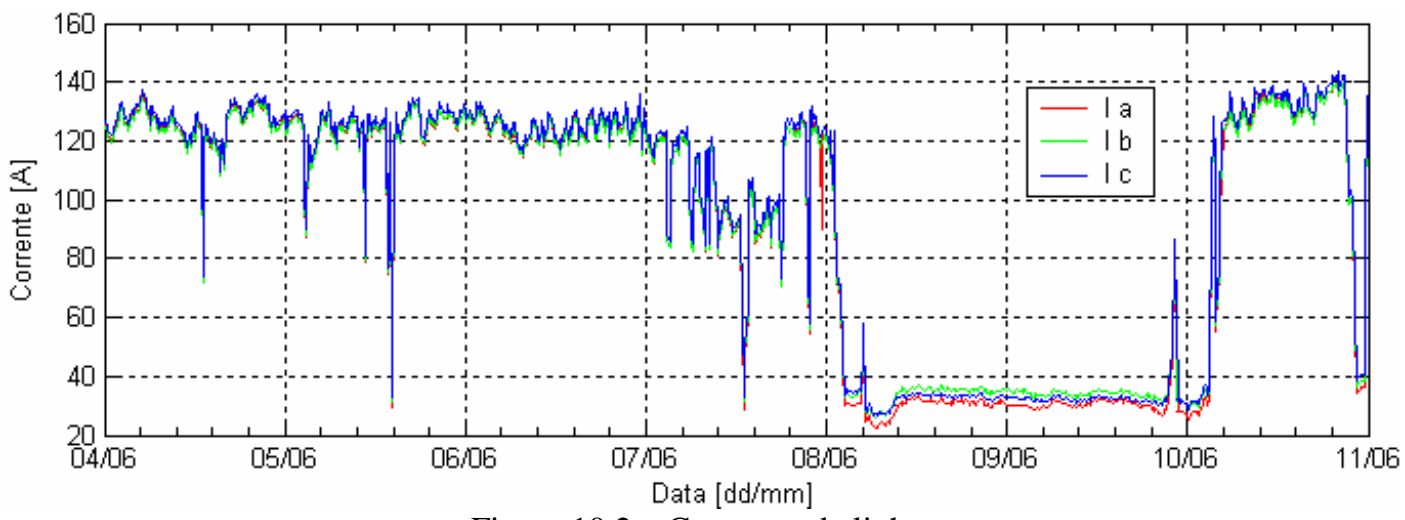

Figura 10.2 - Correntes de linha

Observa-se na Figura 10.2 que as correntes tiveram perfis muito semelhantes nas 3 fases, em todo o período monitorado. Constata-se, a partir daí, uma equidade na distribuição das cargas entre as fases e a ausência de grandes demandas monofásicas. Contudo, percebe-se uma leve queda nas correntes no dia 7 e a retirada das cargas mais significativas em um período que compreende os dias 8 e 9. A presumida manobra de cargas no instante mais singular desse banco de dados (ao final do dia 09/06), é confirmada pelo pico de corrente observado na Figura 10.2.

As estatísticas obtidas para os valores de corrente são mostradas na Tabela 10.1 e na Figura 10.3 .

Tabela 10.1 - Estatísticas das correntes de linha

\begin{tabular}{|c|c|c|c|}
\hline Estatísticas [A] & $I a$ & $I b$ & $I c$ \\
\hline Máximo & 140.897 & 140.773 & 143.351 \\
\hline Mínimo & 22.3102 & 26.2557 & 26.5144 \\
\hline Média Arit. & 93.4273 & 94.3418 & 95.3971 \\
\hline Média Quad. & 102.876 & 102.97 & 104.51 \\
\hline Desvio Padrão & 43.0881 & 41.2816 & 42.7038 \\
\hline P95\% & 134.04 & 133.293 & 135.556 \\
\hline P99\% & 137.851 & 136.994 & 139.328 \\
\hline
\end{tabular}




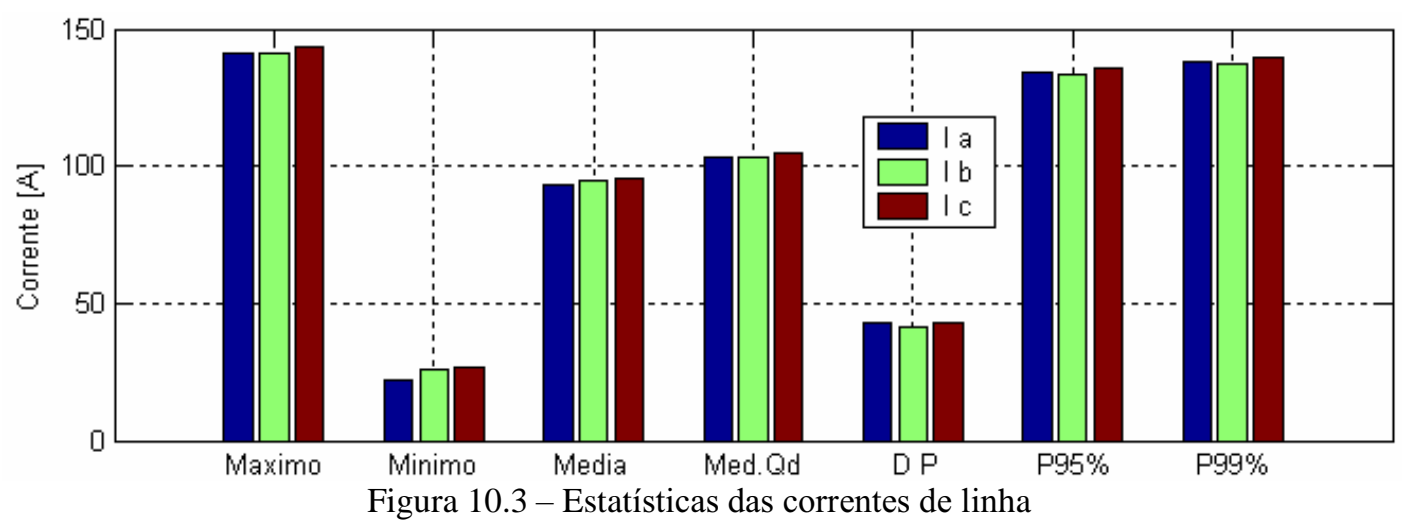

Nota-se da Tabela 10.1 e da Figura 10.3 que os valores de desvio padrão foram elevados. O longo período com valores de corrente muito abaixo da média justifica este fato. A fase C esteve, na maior parte do tempo, com valores mais elevados.

Na Figura 10.4 visualiza-se os dados das tensões de linha colhidos durante os 7 dias de medição. As tensões de fase não serão exploradas aqui, haja vista que tal abordagem fora executada no capítulo 7 (“Análise dos fasores”).

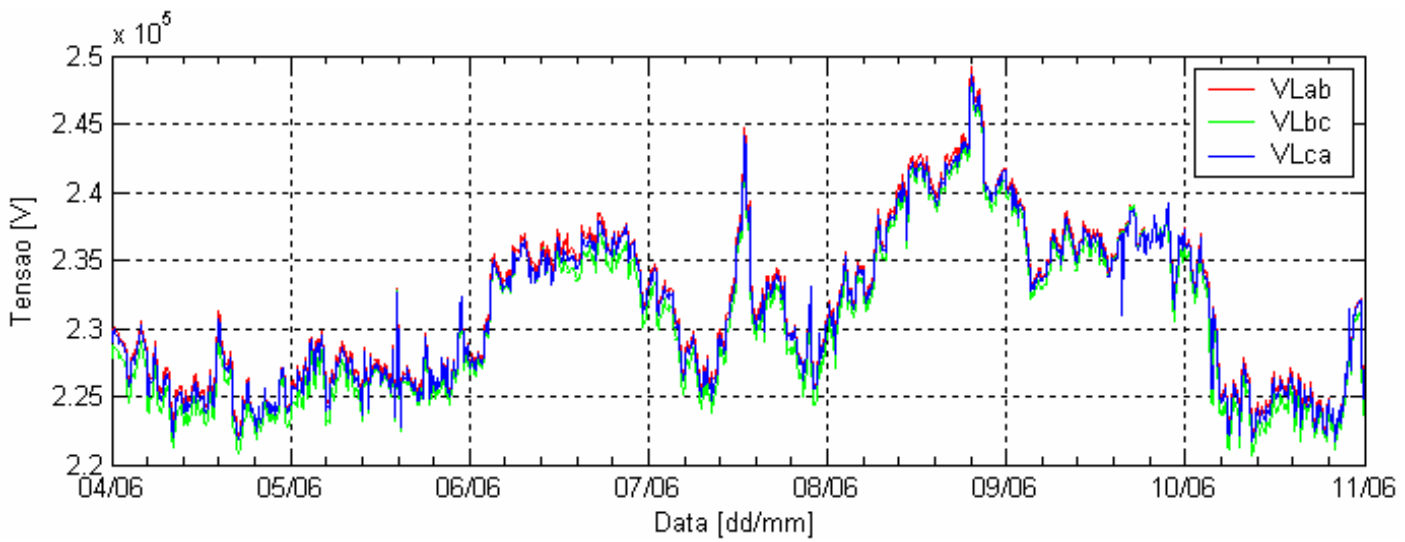

Figura 10.4 - Tensões de linha

Da Figura 10.4, nota-se que as tensões de linha tiveram perfis muito semelhantes. Variações mais acentuadas estiveram presentes nos dia 7 e 8 . Nesses dias, as elevações nos níveis das tensão se deram em função das quedas de corrente ocorridas, como observado a partir da Figura 10.2. Verifica-se que a tensão de linha $V a b$ apresentou, em média, os maiores valores, enquanto os valores de corrente da fase A foram os menores.

A Tabela 10.2 e a Figura 10.5 apresentam as estatísticas referentes às tensões de linha. 
Tabela 10.2 - Estatísticas das tensões de linha

\begin{tabular}{|c|c|c|c|}
\hline Estatísticas [V] & $V a b$ & $V b c$ & $V c a$ \\
\hline Máximo & 249163 & 248136 & 248538 \\
\hline Mínimo & 221717 & 220688 & 221650 \\
\hline Média Arit. & 231590 & 230599 & 231267 \\
\hline Média Quad. & 231661 & 230673 & 231338 \\
\hline Desvio Padrão & 5749.19 & 5835.77 & 5710.25 \\
\hline P95\% & 241403 & 240540 & 241034 \\
\hline P99\% & 245368 & 244408 & 244810 \\
\hline
\end{tabular}

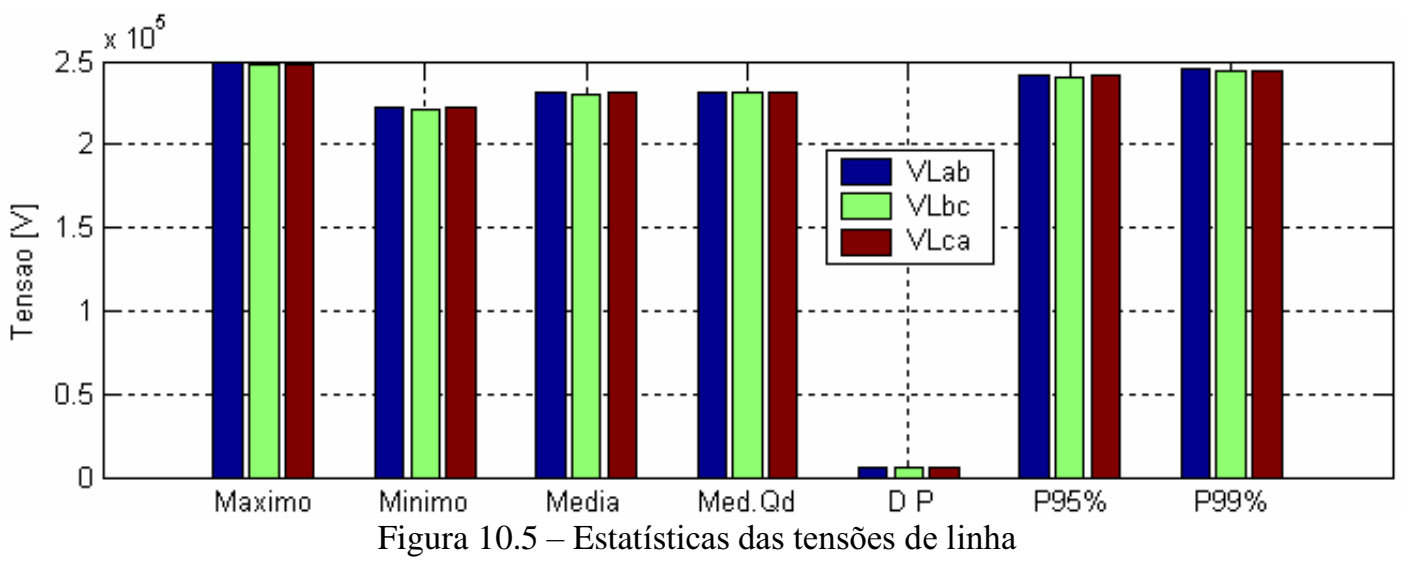

Observa-se na Tabela 10.2 e na Figura 10.5 os baixos valores de desvio padrão encontrados. As médias das três tensões entre fases estiveram próximas entre si e do valor nominal de $230 \mathrm{kV}$.

A Tabela 10.3 traz as estatísticas calculadas para as potências ativa, reativa e aparente $\mathrm{Na}$ Figura 10.6 são traçados os gráficos dessas grandezas.

Tabela 10.3 - Estatísticas das potências ativa, reativa e aparente

\begin{tabular}{|c|c|c|c|}
\hline Estatísticas & Pot. Ativa & Pot. Reativa & Pot. Aparente \\
\hline Máximo & 53892.8 & 8965.24 & 54612.6 \\
\hline Mínimo & 2280.1 & -18110 & 10242 \\
\hline Média Arit. & 35055.7 & -1335.76 & 37410.3 \\
\hline Média Quad. & 40220.6 & 7054.57 & 40864 \\
\hline Desvio Padrão & 19727.8 & 6930.39 & 16450.1 \\
\hline P95\% & 51894.4 & 6364.67 & 52261.4 \\
\hline P99\% & 53177.6 & 7993.36 & 53563.7 \\
\hline
\end{tabular}




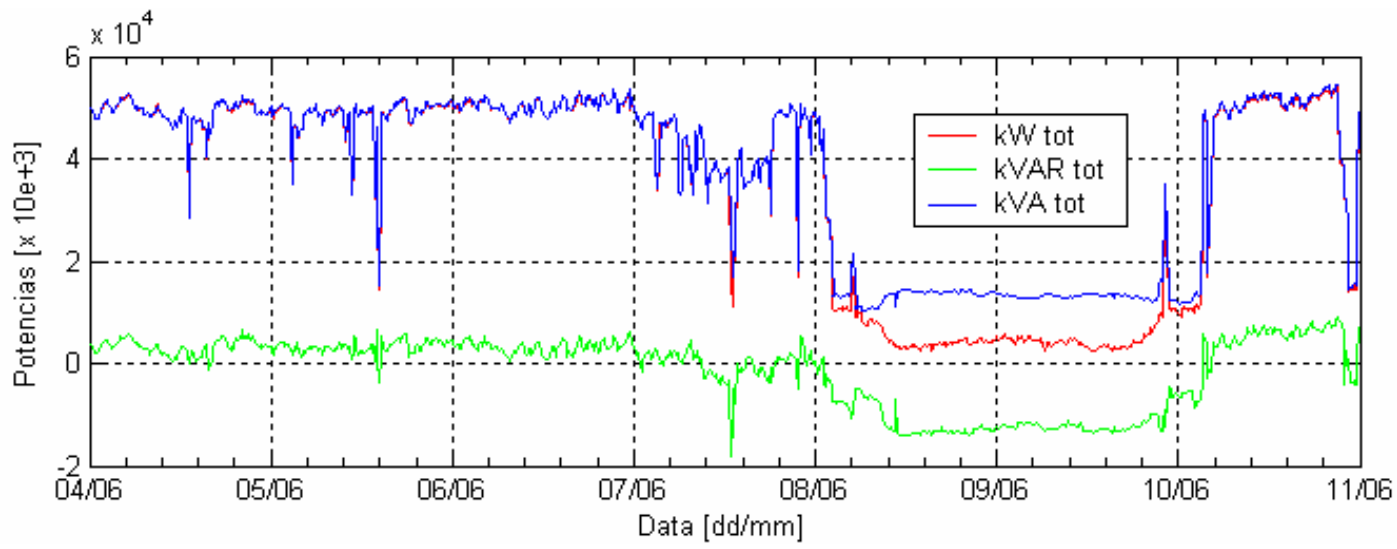

Figura 10.6 - Potências ativa, reativa e aparente

Observa-se na Figura 10.6 que a curva da potência ativa manteve-se praticamente sobreposta à curva da potência aparente. Da Tabela 10.3 tem-se que o fator de potência esteve, em média, em torno de 0,93 . O período onde se verifica uma queda brusca da carga (dias 8 e 9) contribui para a diminuição desse índice, considerando a folga dada na linha e o conseqüente aumento proporcional de reativo. Como esperado, o perfil da potência ativa foi o mesmo apresentado para as correntes na Figura 10.2, inclusive no pico de carga ao final do dia 9.

\subsection{Considerações Finais}

Neste capítulo foi apresentado o módulo da ferramenta computacional que permite a análise da carga, identificando possíveis manobras e compreendendo um pouco mais o regime de funcionamento das cargas que são alimentadas pela subestação de onde as amostras são originadas.

No estudo de caso constatou-se uma similaridade entre as magnitudes das tensões de linha, cujos perfis se alteraram apenas quando das variações de corrente em alguns momentos específicos. A observação dos níveis e perfis das correntes de linha permitiu concluir a respeito da equidade na distribuição das cargas entre as fases e a ausência de grandes demandas monofásicas. Essa análise possibilitou, ainda, a confirmação das hipóteses anteriormente feitas de uma manobra de cargas no dia 09/06, que refletiu nas peculiaridades observadas nos demais capítulos. 
Dado o comportamento uniforme dos valores de tensão e corrente medidos, e constatadas similaridades satisfatórias entre as solicitações das fases, os baixos valores de fator $\mathrm{K}$ obtidos durante os 7 dias de medição são coerentemente justificados. 


\section{Capítulo 11}

\section{Análise da Freqüência de Aquisição dos Dados}

\subsection{Considerações Iniciais}

No capítulo 3, ao serem citados os principais documentos normativos existentes quanto aos desequilíbrios de tensão, ficou clara a correlação presente entre as metodologias e critérios adotados pelos mesmos. O tempo de registro dos dados é, quase que consensualmente, de 10 minutos. Contudo, durante esse intervalo de aquisição, algumas normas e recomendações propõem métodos para tratamento das amostras colhidas em períodos menores que esse, que, quando integralizadas, formarão um dado a cada 10 minutos. Esse tratamento se dá, unicamente, pela aplicação da média quadrática sobre janelas de medição de curtíssima e curta duração (normalmente de 0,1 a 5 segundos) até que se completem 10 minutos. Este último valor obtido deve ser, então, registrado pelos equipamentos de medição.

As análises realizadas neste capítulo estendem a metodologia sugerida por esses documentos, realizando a média quadrática dos valores disponibilizados pelos medidores. Com isso, são formados bancos de dados com amostras espaçadas por maiores intervalos de tempo. A partir daí são investigadas as diferenças existentes entre o banco de dados original e outros com valores tratados pelo aplicativo computacional. Torna-se possível avaliar a pertinência em se utilizar uma freqüência de aquisição dos dados em detrimento a outras. Caso se verifique ser possível a utilização de medições com dados colhidos em maiores intervalos de registro, ganha-se pela menor exigência de memória dos equipamentos e velocidade no processamento das informações. 


\subsection{Módulo na Ferramenta Computacional}

Tomando por base os intervalos de registros dos dados usualmente disponíveis na maioria dos instrumentos de medição, o módulo do programa alusivo a essa seção, viabiliza o estudo para amostras registradas a cada 1, 5, 10, 15, 30 e 60 minutos.

A metodologia segue os passos discriminados abaixo, dependendo da freqüência de aquisição dos dados:

- Para dados registrados de 1 em 1 minuto:

Passo 1: Faz-se a média quadrática para cada 5 registros de 1 em 1 minuto, gerando dados de 5 em 5 minutos;

Passo 2: Dos dados de 5 em 5 minutos toma-se a média quadrática para cada 2 valores para a formação de dados de 10 em 10 minutos;

Passo 3: Ainda com relação aos dados de 5 em 5 minutos, utiliza-se 3 valores para, a partir da média quadrática, chegar a dados de 15 em 15 minutos.

Passo 4: Destes, para cada grupo de 2 valores é feita a média quadrática para obtenção dos dados de 30 em 30 minutos;

Passo 5: Por fim, a média quadrática de cada 2 valores forma dados de 60 em 60 minutos.

- Para dados registrados de 5 em 5 minutos:

Inicia-se no passo 2 descrito acima.

- Para dados registrados de 10 em 10 minutos:

Inicia-se no passo 4, contudo utilizando 3 valores para a obtenção dos dados de $30 \mathrm{em}$ 30 minutos.

- Para dados registrados de 15 em 15 minutos:

Inicia-se no passo 3. 
- Para dados registrados de 30 em 30 minutos:

Inicia-se no passo 4.

Assim como acontece em grande parte dos módulos de análise do aplicativo, inicialmente é requerido que o usuário assinale um método para o cálculo do fator K. Seqüencialmente, o programa executa as operações supranumeradas.

A Figura 11.1 mostra a tela do programa relativa a este módulo.

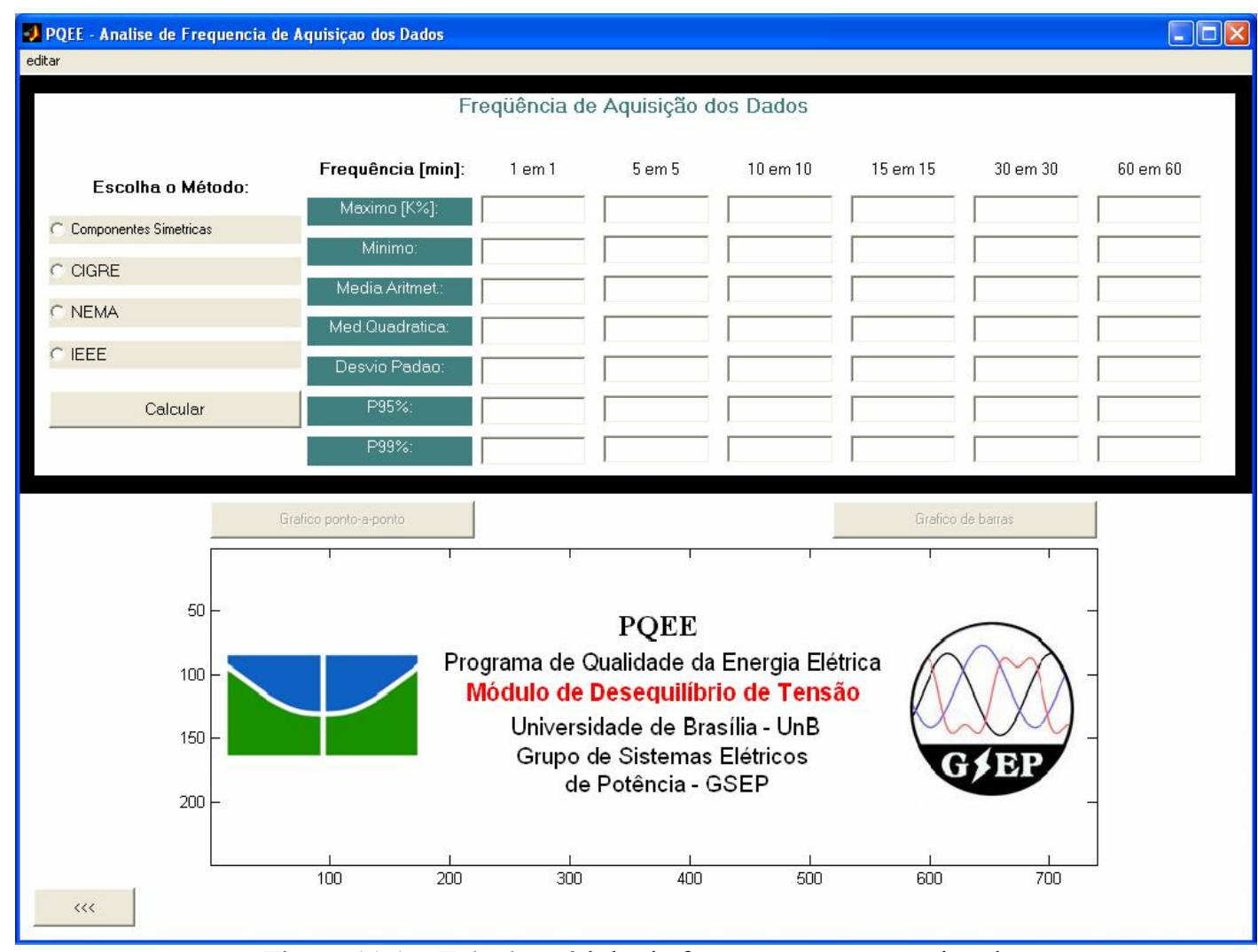

Figura 11.1 - Tela do módulo da ferramenta computacional

Nota-se da Figura 11.1 que nesta análise são calculadas as estatísticas para cada intervalo de tempo entre os dados. Encontram-se também disponíveis os gráficos ponto a ponto e de barras. 


\subsection{Estudo de Caso}

Serão feitas as análises para a freqüência de aquisição dos dados da SE Carajás. Os dados desta subestação estão em intervalos de 10 minutos. Logo, a comparação se dará para dados de 30 em 30 e de 60 em 60 minutos. O método de cálculo utilizado é o das Componentes Simétricas.

A Tabela 11.1 e a Figura 11.2 mostram as estatísticas dos valores de K obtidos.

Tabela 11.1 - Estatísticas dos valores de fator K para cada freqüência de aquisição

\begin{tabular}{|c|c|c|c|}
\hline Estatísticas [K\%] & 10 em 10 min. & 30 em 30 min. & 60 em 60 min. \\
\hline Máximo & 0.4159 & 0.4114 & 0.4112 \\
\hline Mínimo & 0.02939 & 0.0357 & 0.03642 \\
\hline Média Arit. & 0.2652 & 0.2657 & 0.2661 \\
\hline Média Quad. & 0.2808 & 0.2808 & 0.2807 \\
\hline Desvio Padrão & 0.09222 & 0.09085 & 0.0897 \\
\hline P95\% & 0.3807 & 0.3775 & 0.3777 \\
\hline P99\% & 0.4029 & 0.3944 & 0.3943 \\
\hline
\end{tabular}

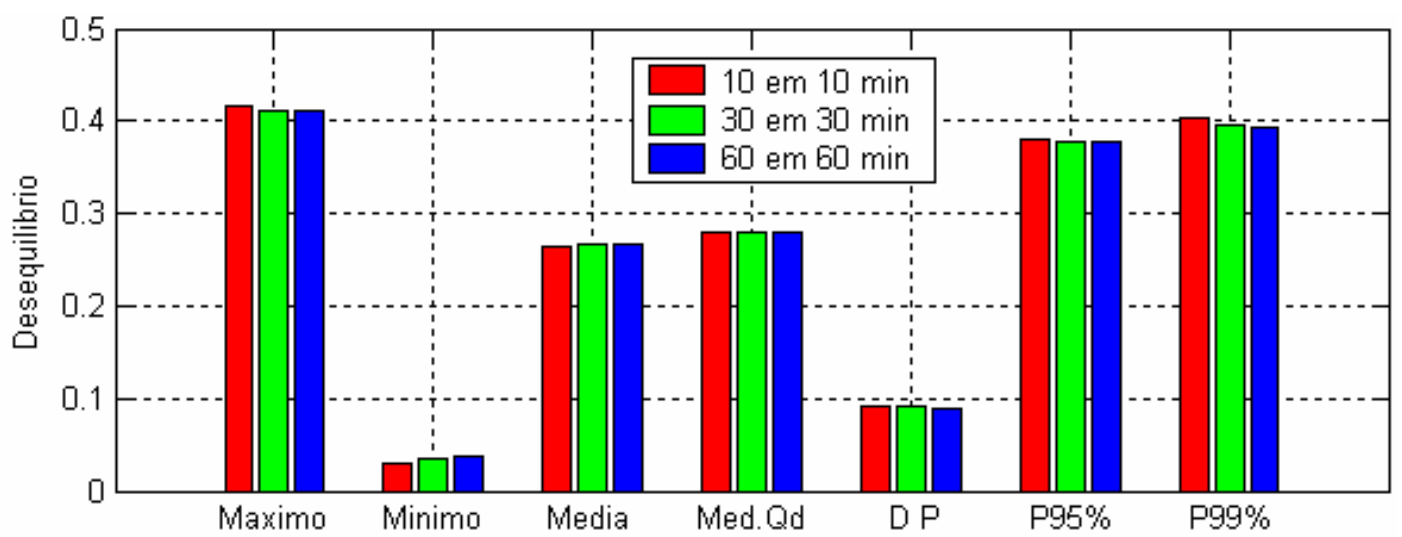

Figura 11.2 - Estatísticas dos valores de fator K para cada frequiência de aquisição

Verifica-se na Tabela 11.1 e na Figura 11.2 que os valores de média aritmética são muito pouco afetados e que a média quadrática fica praticamente constante em todas as freqüências. Os valores máximos e de P99\% sofreram as maiores mudanças, fato esse já esperado simplesmente em função de suas definições e da metodologia adotada. O desvio padrão manteve-se praticamente constante na ordem de 0,09\%. O P95\%, indicador utilizado como valor representativo pela maioria das normas e recomendações, não obteve 
alteração significativa. A maior diferença desse índice foi de $0,003 \%$ de desequilíbrio, entre os intervalos de 10 e 60 minutos.

A Figura 11.3 exibe o perfil do desequilíbrio durante os 7 dias, para cara freqüência de aquisição.

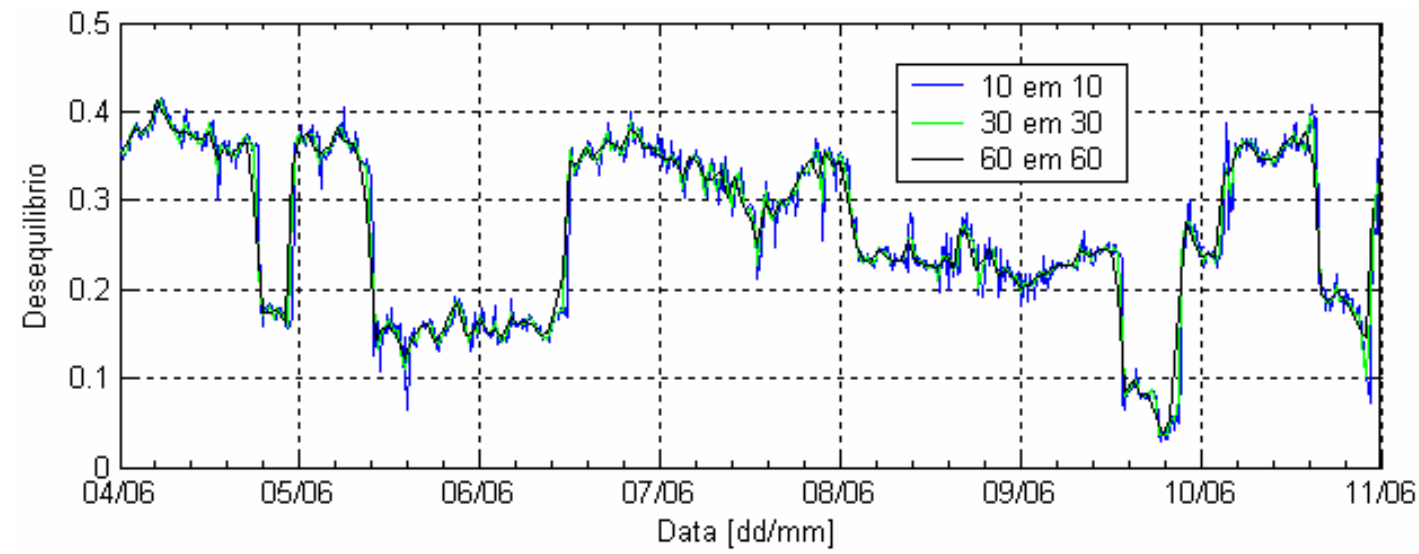

Figura 11.3 - Perfil do desequilíbrio para diferentes freqüências de aquisição

A partir dos perfis visualizados na Figura 11.3 nota-se que as curvas de 10 e 30 minutos estão praticamente sobrepostas na maioria do tempo. Alguns erros mais acentuados acontecem nos momentos onde os dados de 10 em 10 minutos sofrem variações bruscas. Já a curva referente aos dados de 60 em 60 minutos apresenta um perfil com diferenças mais nítidas à curva de 10 em 10 minutos.

\subsection{Considerações Finais}

Este capítulo foi destinado à análise da freqüência de aquisição dos dados. Foram comentados os procedimentos padrões sugeridos pelas normas e recomendações para o registro de grandezas pelos medidores de medição. O mesmo processo foi usado na metodologia proposta, anelando-se a possibilidade de medições com dados colhidos em maiores intervalos de registro.

No estudo de caso, constatou-se que a curva dos intervalos de 30 minutos representa bem o comportamento dos desequilíbrios do local em estudo. Em função das constantes variações percebidas na curva formada pelos dados de 10 em 10 minutos, o perfil referente às 
amostras de 60 em 60 minutos apresentou algumas diferenças consideráveis. Todavia, os valores médios e os índices de P95\% são muito próximos entre si para as três freqüências investigadas.

Assim, dado o objetivo da obtenção de um valor do banco de dados da SE Carajás que possa ser comparado com os limites das normas, o registro dos dados em intervalos de 30 ou 60 minutos não traz prejuízos à determinação estatística desse indicador. 


\section{Capítulo 12}

\section{Qualificação do Desequilíbrio}

\subsection{Considerações Iniciais}

Visando-se uma avaliação qualitativa dos dados oriundos das medições, o presente capítulo expõe o módulo do programa computacional que realiza a apreciação dos valores de fator $\mathrm{K}$ obtidos com os limites estabelecidos pelas normas e recomendações nacionais e internacionais.

Os documentos em análise são os descritos no Capítulo 3, a saber:

- IEC;

- ANSI;

- $\quad$ NRS -48

- CENELEC;

- Procedimentos de Rede (ONS), Submódulo 2.2 (utilização autorizada em caráter provisório);

- Procedimentos de Distribuição (ANEEL), Módulo 8 (em elaboração).

\subsection{Módulo na Ferramenta Computacional}

A tela do módulo "Qualificação do Desequilíbrio" do aplicativo computacional está mostrada na Figura 12.1. 


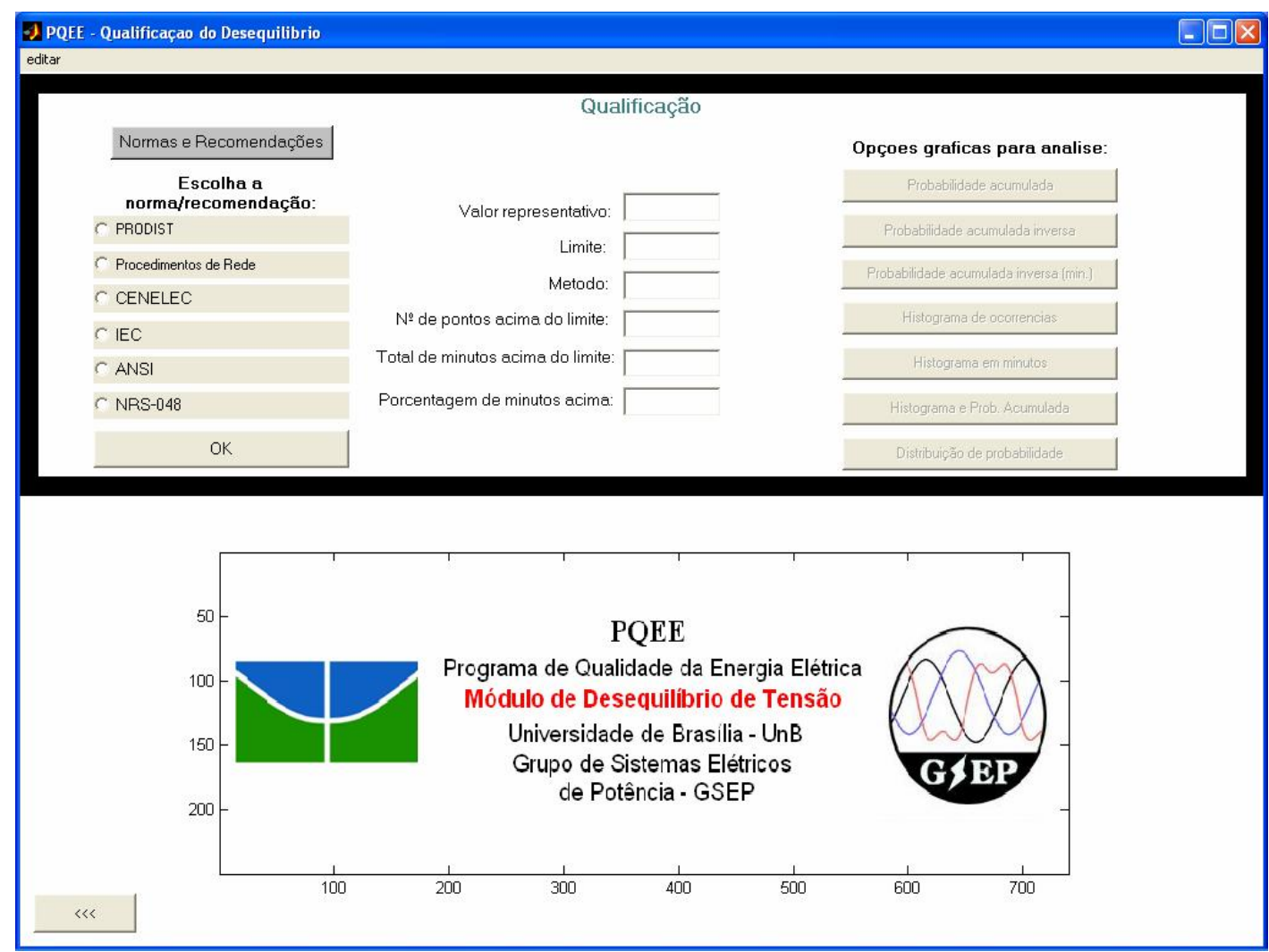

Figura 12.1 - Tela na ferramenta computacional

Nota-se na Figura 12.1 que o usuário deve, primeiramente, selecionar a norma/recomendação com a qual deseja comparar o banco de dados. Caso deseje, um resumo das normas e recomendações é aberto ao se clicar em "Normas e Recomendações".

Após a escolha da norma/recomendação, clicando-se em "OK", é executada a rotina que revela:

- O valor representativo (valor a ser comparado com o limite) da grandeza em apreciação, obtido de acordo com a metodologia da norma/recomendação selecionada;

- O limite imposto pela norma/recomendação;

- O método de quantificação adotado pela norma/recomendação;

- O número de pontos que ultrapassam o valor limite no decurso dos dias selecionados;

- Tempo em que ocorreram amostras de desequilíbrio superiores ao limite, em minutos; 
- Tempo em que ocorreram valores de fator $\mathrm{K}$ superiores ao limite, em porcentagem do tempo total de medição.

Neste módulo, com vistas ao melhor entendimento do comportamento dos desequilíbrios, são disponibilizadas, também, as seguintes análises gráficas:

- Probabilidade acumulada;

- Probabilidade acumulada inversa;

- Probabilidade acumulada inversa em minutos;

- Histograma de ocorrências: Gráfico com o número de ocorrências de algumas faixas de desequilíbrio;

- Histograma de ocorrências em minutos: Levantamento do número de minutos em que o sistema permaneceu dentro de algumas faixas de valores de K;

- Histograma de ocorrências e probabilidade acumulada;

- Distribuição de Probabilidade: Traça as faixas de desequilíbrio versus a probabilidade de suas ocorrências.

\subsection{Estudo de Caso}

Nos estudos de caso feitos nos capítulos anteriores, constatou-se que os valores de desequilíbrio encontrados na SE Carajás estiveram bem abaixo dos limites estabelecidos por todas as normas/recomendações citadas neste trabalho. Em função deste fato, a seguir será realizado um estudo considerando unicamente o documento do PRODIST, apenas para exemplificar a metodologia disponível no aplicativo computacional.

Os resultados obtidos são mostrados na Tabela 12.1. 
Tabela 12.1 - Metodologia da norma/recomendação e resultados da comparação com o valor limite

\begin{tabular}{|c|c|}
\hline Valor representativo & $0.36686 \%$ \\
\hline Limite & $2 \%$ \\
\hline Método & Componentes Simétricas \\
\hline Número de pontos acima do limite & 0 \\
\hline Número de pontos acima do limite & 0 \\
\hline Total de minutos acima do limite & 0 \\
\hline
\end{tabular}

Nota-se a destacada diferença entre o valor representativo e o limite imposto. Ademais, não foram encontrados valores acima de $2 \%$ de desequilíbrio, durante todo o período de medição.

Em seguida serão executadas as análises gráficas disponíveis na ferramenta computacional, com intuito de exemplificar suas utilizações.

A Figura 12.2 ilustra o gráfico da probabilidade acumulada.

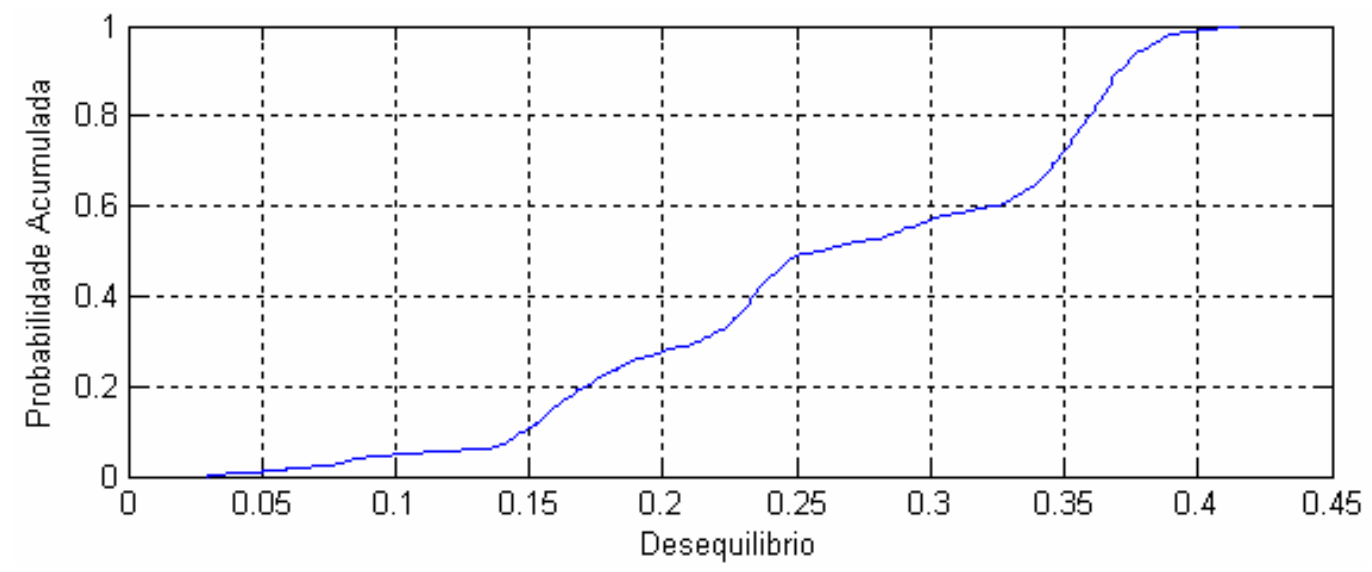

Figura 12.2 - Probabilidade acumulada

Verifica-se na Figura 12.2 que cerca de $55 \%$ dos dados estiveram abaixo de 0,3\% de desequilíbrio. Observa-se uma distribuição relativamente uniforme dos valores de K, não sendo encontradas variações muito abruptas de inclinação na curva.

A Figura 12.3 mostra o gráfico da probabilidade acumulada inversa. 


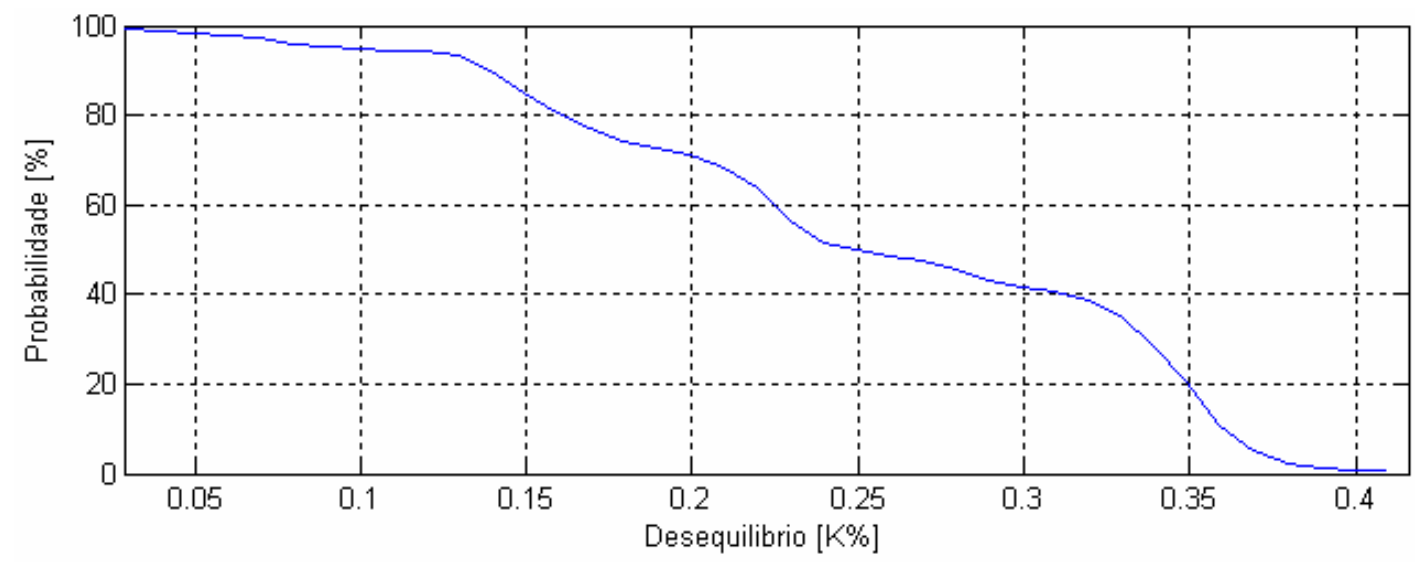

Figura 12.3 - Probabilidade acumulada inversa

As informações que podem ser retiradas da Figura 12.2 são basicamente as mesmas das contidas na figura 12.3, entretanto sob novo aspecto. Nesta última figura observa-se que aproximadamente $45 \%$ dos valores de $\mathrm{K}$ estiveram acima de $0,3 \%$ de desequilíbrio.

Na Figura 12.4 está ilustrada a curva correspondente à probabilidade acumulada inversa, em minutos de medição.

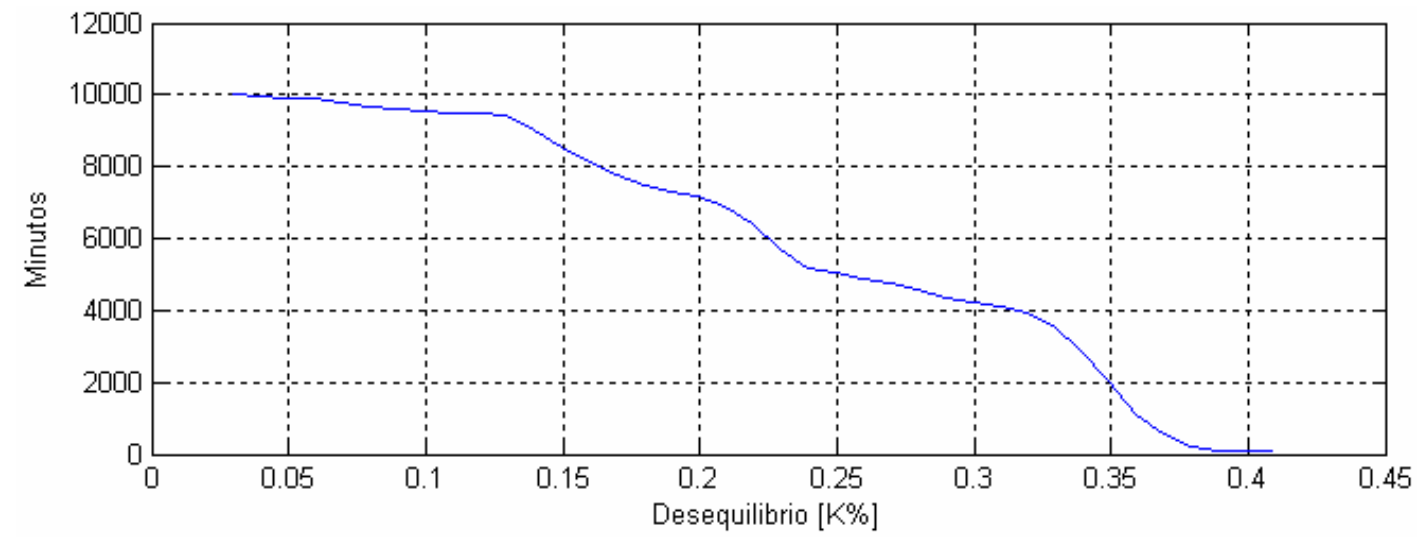

Figura 12.4 - Probabilidade acumulada inversa

Da Figura 12.4 tem-se, por exemplo, que o sistema permaneceu cerca de 4300 minutos acima de $0.3 \%$ de fator $\mathrm{K}$. Lembra-se que o número total de minutos de medição é de 10080 minutos.

A figura 12.5 exibe o gráfico do histograma de ocorrências. 


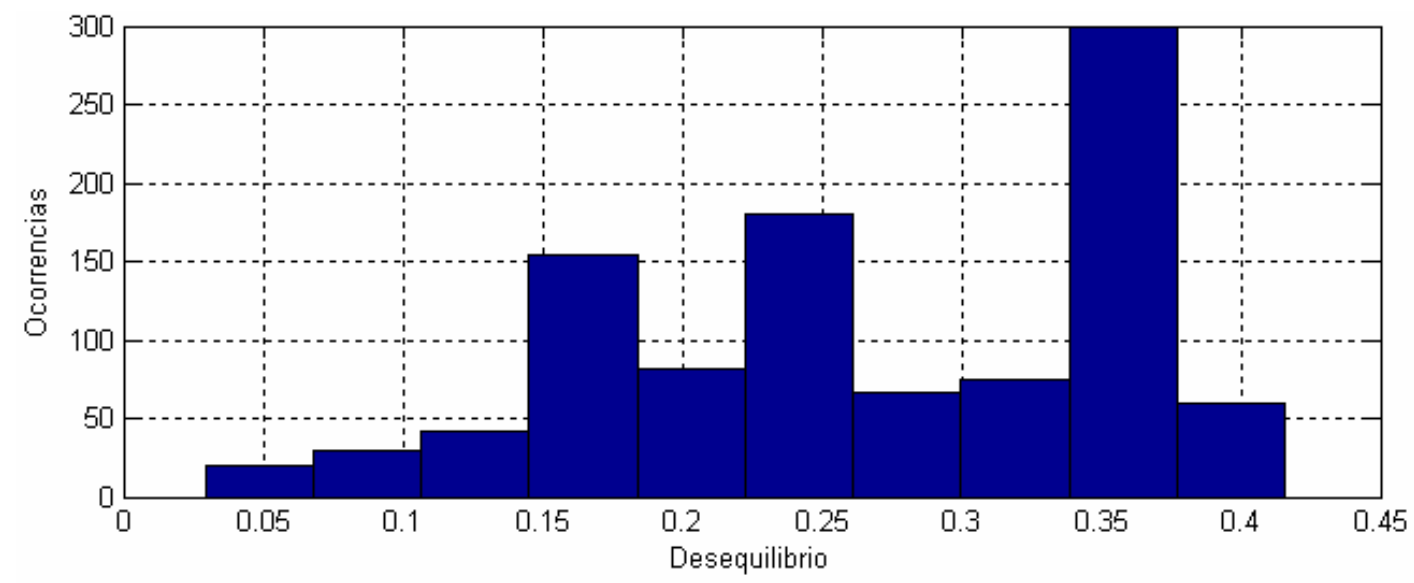

Figura 12.5 - Histograma de ocorrências

Nota-se na Figura 12.5 que foram constatados aproximadamente 300 valores de fator $\mathrm{K}$ entre $0,34 \%$ e $0,37 \%$.

A Figura 12.6 traz o histograma de ocorrências em minutos.

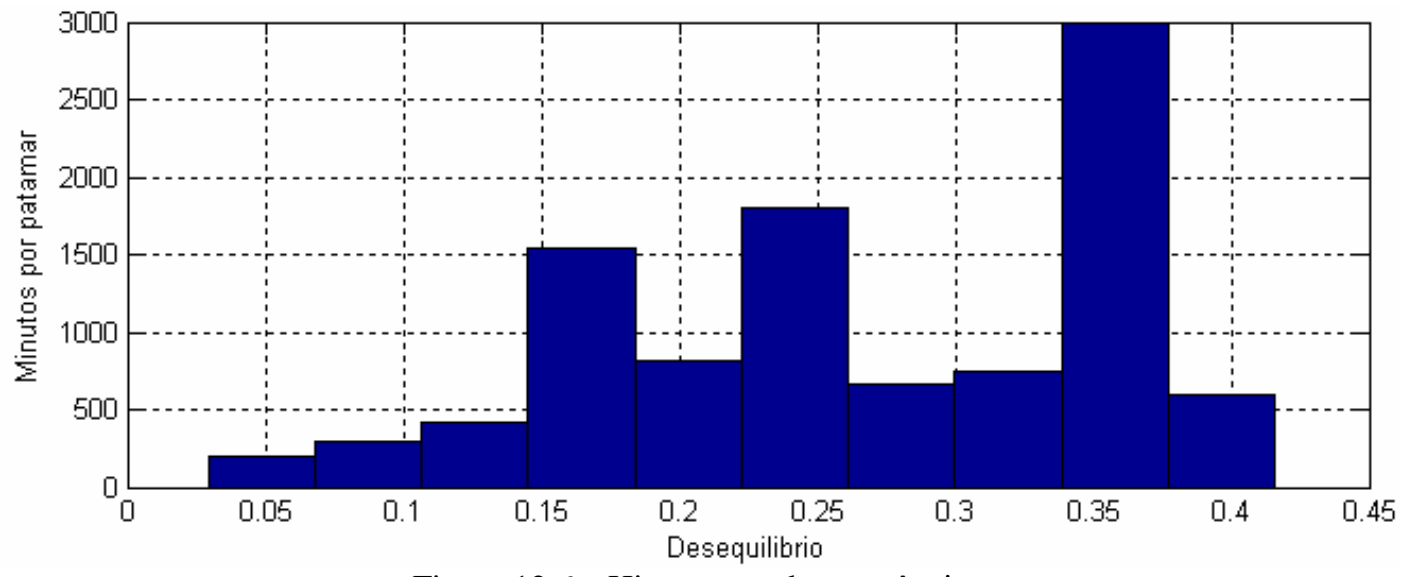

Figura 12.6 - Histograma de ocorrências

Percebe-se da Figura 12.6 que o sistema permaneceu 3000 minutos, de um total de 10080, com desequilíbrio na faixa anteriormente destacada.

Na Figura 12.7 são traçadas as curvas de probabilidade acumulada e de histograma de ocorrências. 


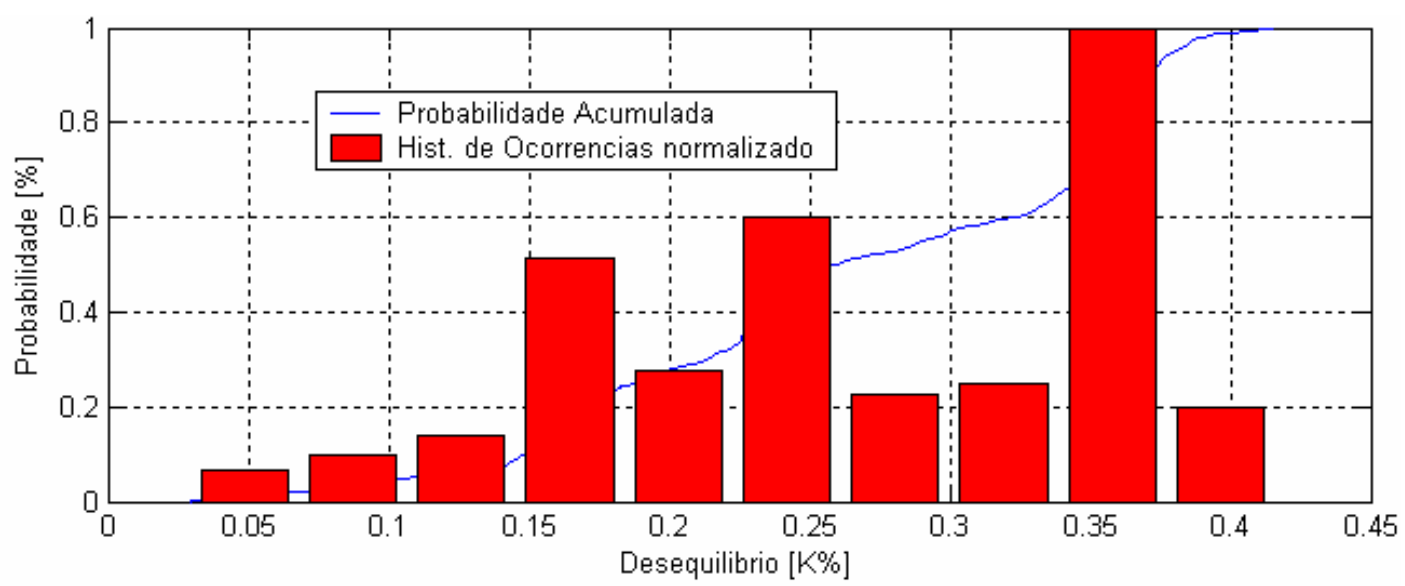

Figura 12.7 - Probabilidade acumulada e histograma de ocorrências normalizado

Apenas para o ajuste do eixo das coordenadas, as barras do número de ocorrências foram normalizadas pelo seu maior valor, diga-se 300. Com o gráfico da Figura 12.7 é possível entender o comportamento da curva de probabilidade acumulada, a partir da constatação dos intervalos de fator K com maior número de ocorrências. Esses intervalos caracterizamse por refletir as maiores derivadas no gráfico de probabilidade.

A Figura 12.8 apresenta o gráfico de distribuição de probabilidade.

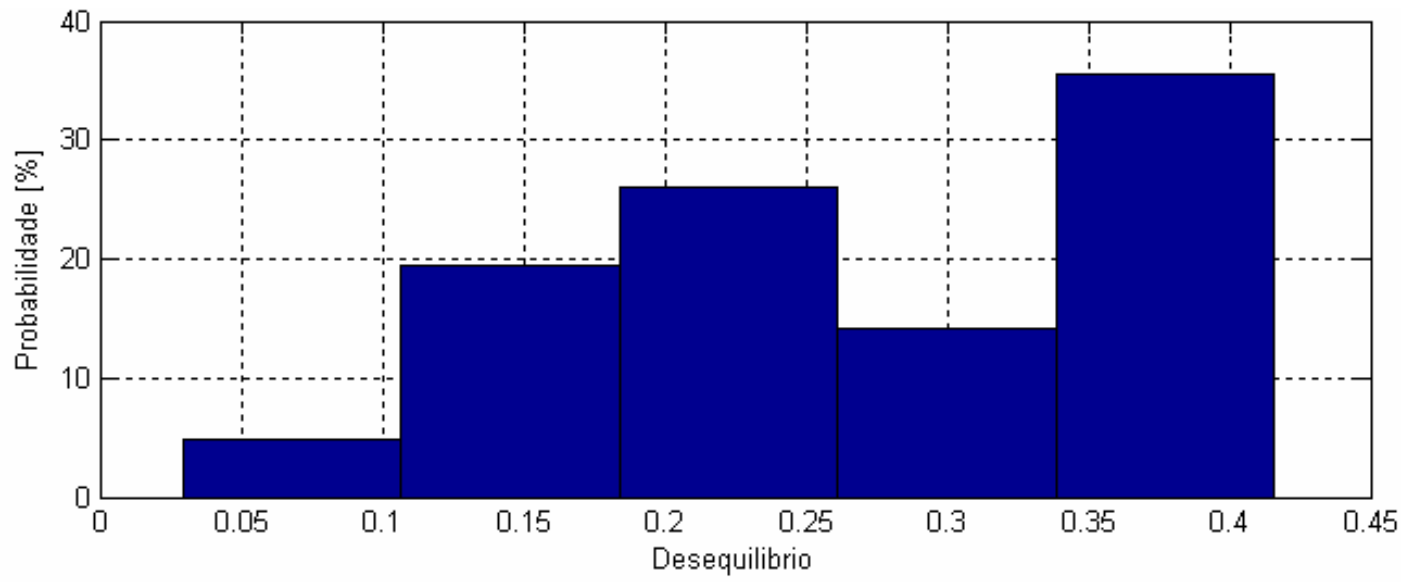

Figura 12.8 - Distribuição de probabilidade

Observa-se da Figura 12.8 que cerca de $35 \%$ dos valores de desequilíbrio estiveram entre $0,34 \%$ e $0,415 \%$ de fator $\mathrm{K}$. A segunda maior probabilidade de ocorrência, em torno de $25 \%$, se deu para a faixa de $0,185 \%$ e $0,26 \%$ de desequilíbrio. 


\subsection{Considerações Finais}

No corrente capítulo foi apresentado o módulo do programa computacional que oferece possibilidades de avaliação dos dados advindos de medições com as diversas normas e recomendações.

As análises gráficas disponíveis formaram o estudo de caso realizado e consolidaram o entendimento dos níveis de desequilíbrios encontrados na subestação em estudo. Os histogramas e os gráficos de probabilidade acumulada revelaram que os diversos valores de desequilíbrio ocorreram uniformemente, a menos de um intervalo entre $0,34 \%$ e $0,37 \%$ de fator $\mathrm{K}$, para o qual se registrou o maior número de ocorrências. Do gráfico da distribuição de probabilidades, verificou-se que a maior probabilidade de ocorrência foi obtida para os maiores valores de desequilíbrio medidos. Constatou-se, mais uma vez, que os valores de desequilíbrio encontrados na SE Carajás estiveram bem abaixo dos limites estabelecidos por todos os documentos normativos citados neste trabalho.

As análises e metodologias expostas mostram-se úteis para auxiliar na qualificação de bancos de dados colhidos em medições, com relação aos desequilíbrios de tensão. 


\section{Capítulo 13}

\section{Conclusões Gerais}

Este relatório apresentou uma ferramenta computacional para a análise, quantificação e qualificação do desequilíbrio de tensão. A partir do software desenvolvido, foram realizados estudos de caso que exemplificaram as metodologias utilizadas pelo aplicativo, com resultados obtidos a cada capítulo. As conclusões serão sintetizadas a seguir.

O Capítulo 1 buscou contextualizar o assunto da qualidade da energia na atual conjuntura do setor elétrico brasileiro, justificando sua importância em meio às novas relações institucionais, à nova esfera de exigências dos consumidores e da difusão do uso de cargas especiais. Nesta vertente, e face à demanda por estudos relacionados aos desequilíbrios de tensão, este trabalho mostrou alternativas de análise que visam amenizar a insipiência encontrada na literatura atual, de ferramentas voltadas para este fim.

O Capítulo 2 trouxe, primeiramente, uma abordagem conceitual sobre a QEE. A partir de uma combinação dos entendimentos de alguns catedráticos da área, pôde-se firmar uma definição do tema para este relatório. Apresentou-se as premissas técnicas que envolvem os principais distúrbios da qualidade da energia, destacando-se a importância de seus estudos, em função dos grandes prejuízos relatados.

O Capítulo 3 constituiu o tópico central de alicerce teórico para a compreensão dos estudos presentes nos capítulos subseqüentes. A partir de uma apresentação sólida dos desequilíbrios de tensão, este capítulo possibilitou, mesmo àqueles que a princípio não detêm informações mínimas sobre o referido fenômeno, um entendimento plausível do mesmo. Foram exibidos os 4 métodos de cálculo do fator de desequilíbrio de tensão, abordados neste trabalho. Em seguida, mostrou-se os efeitos causados na operação de diversos componentes do sistema, ressaltando-se o sobreaquecimento, falha e má operação dos dispositivos de proteção, solicitação indevida do isolamento e a diminuição da vida útil. Ainda nesse capítulo, foram citadas as normas e recomendações existentes 
internacionalmente sobre o desequilíbrio de tensão. Observou-se que, em sua maioria, as mesmas não expõem, ou não deixam claras, as fundamentações dos protocolos de medição requeridos. Adicionalmente, apesar de utilizarem expressões diferentes para a obtenção do fator K, nota-se que os limites impostos são os mesmos (2\%), a menos da norma ANSI (3\%). Quanto ao processo de normatização brasileiro, tem-se que o mesmo encontra-se em processo de elaboração, já carregando traços de semelhança aos critérios e metodologias dos documentos internacionais. Todavia, sabe-se que as condições de operação do sistema brasileiro são singulares em muitos aspectos, cabendo aqui alertar quanto à necessidade da obtenção de normas que venham a refletir, apropriadamente, a realidade nacional relativa ao desempenho da rede.

O Capítulo 4 apresentou a ferramenta computacional. Os módulos que a compõem foram caracterizados de forma sucinta e, a partir de sua interface gráfica, pôde-se concluir ser um software de utilização simples e aplicação direta. As possibilidades de análise oferecidas contemplam resultados numéricos e gráficos que propiciam um estudo conciso do comportamento dos desequilíbrios de tensão.

O Capítulo 5 dedicou-se à quantificação do desequilíbrio e a uma comparação entre os métodos de cálculo do K. O módulo do programa computacional foi apresentado e em seguida aplicado à investigação dos dados da SE Carajás. Do estudo de caso, e em função da experiência adquirida em outros momentos, tem-se que os 4 métodos provêm resultados distintos, onde o método das Componentes Simétricas é o que melhor representa o desequilíbrio de tensão. Verificou-se que a expressão cujo resultado mais se aproxima das Componentes Simétricas corresponde ao método do CIGRÉ. Este é utilizado pelas normas/recomendações do PRODIST (documento em elaboração) e NRS-48. O método NEMA é o que leva aos menores valores de fator $\mathrm{K}$, haja vista considerar o maior desvio das tensões em relação à média. Contrariamente, a expressão sugerida pelo IEEE conduz aos maiores valores de $\mathrm{K}$, uma vez que considera o desvio entre os valores máximos e mínimos de tensão.

No cálculo das diferenças entre os métodos, com referência ao método das Componentes Simétricas, obteve-se um Coeficiente de Semelhança de 97\% para o CIGRÉ, 69\% para o NEMA e 35\% para o IEEE. Assim sendo, o método CIGRÉ é o método mais recomendado 
para a quantificação do desequilíbrio, na ausência de medições dos valores dos ângulos das tensões.

No Capítulo 6 verificou-se, teoricamente, que o desequilíbrio é mais sensível à variação dos ângulos que às alterações nas magnitudes. Constatou-se que, variando-se somente os módulos das tensões, os valores obtidos pelos 4 métodos foram muito semelhantes. Já nas alterações angulares, o desvio entre os resultados cresce à medida que se aumenta a assimetria angular. No banco de dados estudado, encontrou-se uma contribuição maior das magnitudes (57\%) para os valores de desequilíbrio do sistema e uma parcela de $43 \%$ relativa às alterações nos ângulos. Na análise individual das fases, constatou-se que as três tiveram contribuição semelhante nos níveis de desequilíbrio total.

Para esse tópico do relatório, são recomendados estudos futuros para consolidar as interpretações dos resultados obtidos e as metodologias adotadas pelo programa. $\mathrm{O}$ assunto envolve aspectos complexos, vinculados com a variação randômica das tensões e ângulos no sistema.

A investigação dos fasores e de cada uma das componentes de seqüência foi feita no Capítulo 7. As magnitudes das tensões de fase da subestação monitorada tiveram estatísticas e forma de onda muito semelhantes entre si. As variações encontradas para os ângulos foram baixas e não excederam $0,27^{\circ}$ ao valor nominal. A componente de seqüência positiva obteve praticamente as mesmas estatísticas das tensões de fase, fato este que não é absolutamente inesperado, em função dos baixos valores de desequilíbrio previamente constatados. A componente de seqüência negativa apresentou um desvio padrão da ordem de $34 \%$ do valor da média. Seu perfil foi idêntico ao do fator K. Já a componente de seqüência zero apresentou baixo desvio padrão, conduzindo a um valor máximo muito próximo do $\mathrm{P} 95 \%$ e $\mathrm{P} 99 \%$. O módulo da ferramenta apresentado nesse capítulo possibilita observar o que de fato acontece com as magnitudes, ângulos e componentes simétricas ao longo do período em análise.

No estudo de caso apresentado no Capítulo 8, constatou-se que, para subestação analisada, 1 dia de medição seria suficiente para se obter valores de $\mathrm{K}$ representativos aos demais. Os maiores patamares foram registrados em dias de final de semana, no período da madrugada. Assim, sugere-se medição em dias de final de semana, durante a madrugada. 
Ressalta-se que esse resultado se dá exclusivamente em função do regime de funcionamento das cargas do consumidor monitorado. A análise executada pelo software permite a determinação de um período mínimo de medição, não exigindo esforços de processamento e mobilização de equipamentos e técnicos de forma desnecessária.

A metodologia utilizada no Capítulo 9 viabilizou uma comparação da distribuição no tempo dos valores superiores à média quadrática $(0,2808 \%)$, P95\% (0,3807\%) e P99\% (0,4029\%). No período total de medição, 10080 minutos, 4760 minutos estiveram acima de 0,2808\%. Destes, o maior número de minutos consecutivos com $\mathrm{K} \geq 0,2808 \%$ foi de 1500 minutos. A maioria dos intervalos de tempo com valores de $\mathrm{K} \geq 0,2808 \%$ possuem até 40 minutos de duração, espaçados entre si, predominantemente, por períodos de 10 minutos. Ao longo dos 7 dias em apreciação, 500 minutos apresentaram valores de $\mathrm{K} \geq 0,3807 \%$. O maior intervalo ininterrupto com $\mathrm{K} \geq 0,3807 \%$ foi de 170 minutos. Os diversos valores de $\mathrm{K} \geq 0,3807 \%$ estão concentrados em intervalos de curta duração, cerca de 10 minutos, espaçados entre si, na maioria das vezes, por períodos entre 10 e 70 minutos. Para o P99\%, foram encontrados 100 minutos com $\mathrm{K} \geq 0,4029 \%$. O sistema permaneceu 7730 minutos, pouco mais de 5 dias seguidos, sem apresentar valor de $\mathrm{K} \geq 0,4029 \%$. Esses valores ocorreram essencialmente nos dias de final de semana. Ainda com relação ao P99\%, a maioria dos intervalos ininterruptos de tempo com valores de $\mathrm{K} \geq 0,4029 \%$, cerca de $67 \%$, estão concentrados em períodos de curta duração (10 minutos).

A metodologia auxiliar proposta nesse capítulo poderá ser de grande importância, sobretudo aos fabricantes e demais interessados em avaliar a suportabilidade de equipamentos frente aos níveis de desequilíbrio apresentados, em função do tempo de exposição. Além disso, contribui para nortear campanhas de medição e concluir a respeito da representatividade desses indicadores aos demais valores de desequilíbrio medidos.

No estudo de caso do Capítulo 10, a observação dos níveis e perfis das correntes de linha permitiu concluir a respeito da equidade na distribuição das cargas entre as fases e a ausência de grandes demandas monofásicas. Ademais, essa análise possibilitou a confirmação das hipóteses feitas a respeito de uma possível manobra de cargas no dia 09/06, a partir da visualização de um pico de corrente. Esse fato caracterizou o objetivo do aplicativo computacional para esse módulo, possibilitando justificar os valores de 
desequilíbrios constatados neste instante, nos capítulos anteriores. Pôde-se chegar a algumas conclusões a respeito do comportamento das cargas do sistema.

No Capítulo 11 consignou-se que, apesar da maioria dos documentos normativos estabelecerem o intervalo de 10 minutos para o registro dos dados pelos medidores, o estudo propiciado pelo programa levou a resultados que questionam essa exigência. Verificou-se que a curva dos intervalos de 30 minutos representa bem o comportamento dos desequilíbrios do local em estudo. O perfil referente às amostras de 60 em 60 minutos apresentou algumas diferenças, mas obteve estatísticas muito próximas. Deste modo, dado o objetivo da obtenção de um valor do banco de dados da SE Carajás que possa ser comparado com os limites das normas, o registro dos dados em intervalos de 30 ou 60 minutos não traz prejuízos à determinação estatística desse indicador.

Na qualificação dos dados feita no Capítulo 12, tem-se que o ambiente estudado obedece aos requisitos impostos por todas as normas e recomendações elencadas neste trabalho. As opções gráficas disponíveis no módulo da ferramenta são somadas às análises precedentes, culminando em um entendimento cabal do comportamento do local em estudo quanto ao desequilíbrio de tensão.

Muito embora o banco de dados utilizado não tenha apresentado altos patamares de desequilíbrio, e não detendo características peculiares que realçariam as possibilidades e a eficácia da ferramenta computacional, os resultados aqui expostos são suficientes para declarar, por si só, a valia e a proficuidade da mesma nas mais sortidas situações.

Tendo em vista as metas propostas para esse trabalho, e considerando o vultoso desafio do monitoramento e avaliação dos sistemas elétricos quanto à qualidade da energia elétrica, este estudo contribuiu em muitos aspectos, podendo auxiliar em pesquisas futuras sobre os desequilíbrios de tensão. 


\section{REFERÊNCIAS BIBLIOGRÁFICAS}

Afonso J.L e Martins, J.S.. (2004). "Qualidade da Energia Elétrictrica.” Departamento de Electrónica Industrial - Universidade do Minho In: Revista o Electricista n. 9 p6671.

Balzi, A., Silveira, P.M. (2005). "Análise dos Efeitos de Distúrbios da Qualidade da Energia Elétrica em Relés de Proteção Microprocessados" VI SBQEE - Seminário Brasileiro sobre a Qualidade da Energia Elétrica, Belém.

ANEEL, Agência Nacional de Energia Elétrica. (2005). "Procedimentos de Distribuição de Energia Elétrica no Sistema Elétrico Nacional - PRODIST.” Módulo 08, Qualidade da Energia Elétrica.

ANEEL, (2006). Sítio: www.aneel.gov.br

Bergeron, R. (1989) "Voltage Unbalance on Distribution Systems - Phase I", Canadian Electrical Association, Project nº 231 D 488, Canadá.

Bronzeado, H. (2000) "Qualidade da Energia Elétrica - Conceitos, Problemas e Soluções”, Maio de 2000.

Carvalho, P.L. (1997). "Uma Contribuição ao Estudo da Depressão de Tensão". Dissertação de Mestrado - Escola Federal de Engenharia de Itajubá.

Damasceno, F.F., Almeida, W.G. (1995). “Circuitos Polifásicos” Livro - Fundação de Empreendimentos Científicos e Tecnológicos, FINATEC, UnB, Brasília.

Deckmann, S.M. (2000). "Variações Momentâneas de Tensão" ANEEL - Estudos sobre Qualidade da Energia Elétrica.

Delmont, O.F. (2003). "Utilização da Trasnformada Wavelet para Caracterização de Distúrbios na Qualidade da Energia Elétrica." Dissertação de Mestrado - Escola de Engenharia de São Carlos, Universidade de São Paulo, São Carlos, 2003. 
Dugan, R.C., McGranaghan, M.F., Beaty, H.W. (1996). "Electrical Power Systems Quality”. Editora McGraw-Hill, E.U.A..

Emanuel, A., Policarpo, J. A (2002). "Induction Motor Thermal Aging Caused by Voltage Distortion and Imbalance: Loss of Useful Life and Its Estimated Cost", IEEE Trasactions on Industry Applications.

Gafford, W.C.D. e Mosher, C.C. (1959). "Heating of Induction Motors on Unbalanced Voltages" AIEE Transactions, pt. III-A, Power Apparatus and Systems, Vol. PAS84, pp.471-479, Junho.

Garcia, Marcos S. P.; Rolim, Thompson S. (2005a). "Fundamentos de MATLAB 6.5", Curso - Departamento de Engenharia Elétrica - ENE - UnB, Outubro, Brasília.

Garcia, Marcos S. Pinto; Rolim, Thompson S. (2005b), "Manual do ION Enterprise", Curso - Departamento de Engenharia Elétrica - ENE - UnB, Outubro, Brasília.

Gbirard, A.D., Rocha, M.C, e Teixeira, L.A.L. (2002). "Lucratividade e Qualidade na Distribuição de Energia Elétrica" Nova economia, Belo Horizonte.

Jannuzzi, G.M (2003). "Aumentando a eficiência nos usos finais de energia no Brasil" Artigo - UNICAMP, São Paulo.

Jouanne A.V. e Ben, B. (2001). “Assessment of Voltage Unbalance”, IEEE Transaction on Power Delivery, Vol. $16 \mathrm{~N}^{\circ} 4$.

Lee, C.Y, Chen, B.K., Lee, W.J., Hsu, Y.F. (1997). "Effects of Various Voltages on the Operation Performance of an Induction Motor under the Same Unbalance Factor Condition”, IEEE explore.

Mehl, E.L.M. (2004). "Qualidade da Energia Elétrica”. Curso de pós-graduação em Engenharia Elétrica. Universidade Federal do Paraná, Curitiba.

Oleskovixz, M. (2004). "Qualidade da Energia Elétrica” Curso, USP, São Paulo. 
Oliveira, J. C. (2000a). "Contribuições para a Normalização da Qualidade da Energia Elétrica”. Harmônicos e Desequilíbrios nas Redes Elétricas - Estado da Arte. Universidade Federal de Uberlândia, Faculdade de Engenharia Elétrica.

Oliveira, J. C. (2000b). "Contribuições para a Normalização da Qualidade da Energia Elétrica”. Harmônicos e Desequilíbrios nas Redes Elétricas - Protocolos de Medição. Universidade Federal de Uberlândia, Faculdade de Engenharia Elétrica.

Oliveira, J.C (2005). "A Qualidade da Energia Elétrica" 7a Semana de Engenharia Elétrica, UnB, Brasília.

Oliveira, M. A. (2005). "Apostila de Qualidade da Energia Elétrica” Universidade de Brasília, Faculdade de Tecnologia, Departamento de Engenharia Elétrica.

Oliveira, D. (2001). "Quantificação e Qualificação dos Desequilíbrios de Tensão" Projeto Final de Graduação, UnB, Brasília.

ONS, Operador Nacional do Sistema. (2002). Procedimentos de Rede, Módulo - "Padrões de Desempenho da Rede Básica e Requisitos Mínimos para suas Instalações.”

ONS, (2006). Sítio: www.ons.org.br

Pires, J.C.L (2000). "Desafios da Reestruturação do Setor Elétrico Brasileiro" Textos para discussão, BNDES, Rio de Janeiro.

PQC, (2002). "Voltage Unbalance”, Power Quality Centre.

Ramos, A.J.P. (2000a). "Monitoração, Avaliação e Controle da Qualidade da Energia Elétrica - Procedimentos de Medição e Monitoração" ANEEL, Recife.

Ramos, A.J.P. (2000b). "Estado da Arte e Proposição de Indicadores" ANEEL - Avaliação da Qualidade da Energia Elétrica, Recife.

Silveira, M. (2002). "Qualidade da Energia em Estabelecimentos Assistenciais de Saúde" Dissertação - Universidade Federal da Bahia, Salvador. 
Wang, Y.J (2000). "Simulation of Random Variation of Three-phase Voltage Unbalance Resulting from Load Fluctuation Using Correlating Gaussian Random Variables", IEEE Proc. Natl. Counc. Vol. 24, No. 3, pp. 216-225, Taiwan.

Williams (1954). "Operation of Three-Phase Induction Motors on Unbalanced Voltages", AIEE Transactions, Vol.73, Abril.

Xavier, P.A. (2005). “Avaliação das Características Elétricas de Reatores Eletrônicos Utilizados em Lâmpadas Fluorescentes Tubulares" Dissertação - Universidade de Brasília, Brasília. 


\section{APÊNDICE A}

SBQEE - Seminário Brasileiro sobre a Qualidade da Energia Elétrica, 21 a 24 de Agosto de 2005.

"Ferramenta Computacional para Quantificação e Qualificação dos Desequilíbrios de Tensão". 


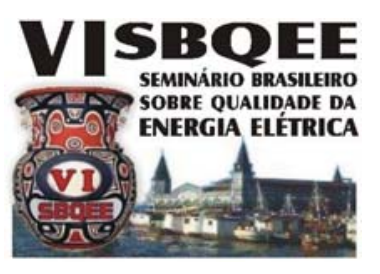

\title{
VI SBQEE
}

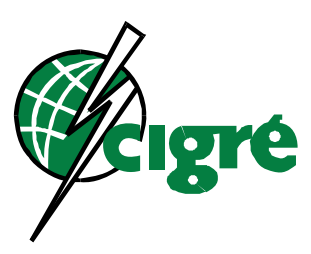

\section{FERRAMENTA COMPUTACIONAL PARA QUANTIFICAÇÃO E QUALIFICAÇÃO DO DESEQUILÍBRIO DE TENSÃO}

\author{
Anésio de Leles F. Filho* (Msc), Marco A. de Oliveira (PhD), Marcos G. da S. Pinto (PIBIC/CNPq)
}

\author{
Universidade de Brasília - UnB
}

\begin{abstract}
RESUMO: Este trabalho visa apresentar uma ferramenta computacional criada a partir da linguagem de programação do MatLab, para a análise do desequilíbrio de tensão. A partir de medições utilizando-se os mais variados tipos de instrumentos, são formados bancos de dados que poderão ser caracterizados, analisados e interpretados segundo diversas normas e recomendações. Indubitavelmente, esta ferramenta tende a consolidar-se como uma metodologia de grande utilidade para concessionárias, universidades e profissionais interessados na quantificação e na qualificação dos desequilíbrios de tensão.
\end{abstract}

PALAVRAS-CHAVE: Qualidade da Energia Elétrica, Desequilíbrio de Tensão, Fator K, Quantificação, Qualificação.

\subsection{INTRODUÇÃO}

O acentuado crescimento de lâmpadas fluorescentes e outros utensílios altamente recomendados durante 0 racionamento de energia elétrica realizado no Brasil no ano de 2001, têm gerado uma preocupação cada vez maior com os problemas associados ao seu suprimento, dentre os quais enquadra-se a questão do desequilíbrio de tensão.

As normas internacionais do IEEE, do IEC e a Européia, bem como a Recomendação Brasileira, estabelecem limites para diversos parâmetros que caracterizam a qualidade da energia elétrica.

Em outra frente, inúmeros instrumentos de medição capazes de armazenar os dados segundo as exigências das normas, estão à disposição no mercado. Contudo, no que diz respeito ao tratamento e análise das amostras, segue incipiente 0 número de ferramentas voltadas a este fim.
Neste ínterim, ergue-se a idéia do desenvolvimento deste estudo, que em linhas gerais visa apresentar uma ferramenta computacional criada a partir da linguagem de programação do MatLab, para a análise do desequilíbrio de tensão. A partir de medições utilizando-se os mais variados tipos de instrumentos, são formados bancos de dados que poderão ser caracterizados, analisados e interpretados segundo diversas normas e recomendações.

A partir do programa computacional é possível calcular o fator $\mathrm{K}$ pelo método das componentes simétricas, do IEEE, do Cigrè e do Nema. Diversos gráficos estão disponíveis para se efetuar comparações entre os resultados obtidos oriundos dos supracitados processos.

Há possibilidade de visualização dos dados referentes aos desequilíbrios de tensão por meio de gráficos do fator $\mathrm{K}$ versus tempo, e de distribuição de probabilidade e de probabilidade cumulativa de ocorrências de desequilíbrios de tensão versus as suas amplitudes. Estes resultados se prestarão para a avaliação dos locais em estudo, quando da comparação com patamares estabelecidos pelas normas internacionais.

A partir da utilização de um ferramental estatístico, a saber: valores máximos, mínimos, médias aritméticas e quadráticas, desvio padrão, valores com probabilidades de $95 \%$ e $99 \%$ de não serem excedidos (P95\% e P99\%), dentre outros, o programa permitirá a avaliação de questões como a similaridade do perfil do comportamento do $\mathrm{K}$ entre os diversos dias de medição, e a determinação do período mínimo necessário para medição.

Tem-se a disposição todos os gráficos voltados à verificação da existência ou não de estacionalidade do fenômeno (média temporal e de probabilidade). 
É ilustrada uma metodologia auxiliar de análise que possibilita, inclusive aos fabricantes, entender se o seu equipamento suporta ou não os níveis de desequilíbrios apresentados, em função do tempo de exposição. Será possível, a partir dos resultados gerados, concluir quanto à distribuição dos valores de fator $\mathrm{K}$ durante todo o período de medição.

\subsection{FATOR $K$ DE DESEQUILÍBRIO: CONCEITUAÇÃO E MÉTODOS PARA 0 CÁLCULO}

\subsection{Conceituação:}

O desequilíbrio de tensão em um sistema elétrico trifásico é uma condição na qual as fases apresentam tensão com módulos diferentes entre si, ou defasagem angular entre as fases diferentes de $120^{\circ}$ elétricos ou, ainda, as duas condições simultaneamente.

Sabe-se que a presença de cargas trifásicas desequilibradas conectadas a um sistema trifásico causa um desequilíbrio de tensão, uma vez que as correntes absorvidas nas três fases não são simétricas, isto é, não são iguais em módulo nem tão pouco defasadas de $120^{\circ}$.

Normalmente, em sistemas de alta tensão não existem grandes desequilíbrios, exceto quando alimentam instalações com cargas monofásicas de grande porte, tais como trens com tração elétrica ou fornos elétricos monofásicos.

Outro fator que causa o aparecimento do desequilíbrio de tensão é a existência de linhas de transmissão mal transpostas, pois as características elétricas destas linhas não serão uniformes no seu percurso.

Os efeitos provocados por um sistema elétrico com a presença de desequilíbrios de tensão estão associados a sobreaquecimentos, mau funcionamento e/ou falhas dos dispositivos de proteção, solicitação do isolamento e redução da vida útil.

O cálculo do nível do desequilíbrio de tensão - fator K - pode ser feito através de quatro diferentes métodos que serão apresentados neste trabalho. $\mathrm{O}$ primeiro método utiliza os módulos e os ângulos das tensões trifásicas para a obtenção do fator K. Os demais utilizam somente os módulos.

Método 1: Componentes Simétricas: Para este método, o desequilíbrio de tensão é definido pela relação entre os módulos da tensão de seqüência negativa e da tensão de seqüência positiva, conforme (2.1).

Onde:
V. $\rightarrow$ Módulo da tensão de seqüência negativa;

$V_{+} \rightarrow$ Módulo da tensão de seqüência positiva;

$$
K \%=\frac{V_{-}}{V_{+}} \times 100
$$

Método 2: NEMA: A norma NEMA-MG-14.34, a fim de se quantificar o desequilíbrio, define o fator $\mathrm{K}$ como a relação entre o máximo desvio da tensão média e a tensão média, tendo como referência às tensões de linha.

$$
K \%=\frac{\Delta V}{V_{m}} \times 100
$$

Onde:

$\Delta \mathrm{V} \rightarrow$ Máximo desvio das tensões de linha em relação ao valor médio;

$\mathrm{V}_{\mathrm{m}} \rightarrow$ Média aritmética dos módulos das tensões trifásicas;

Método 3: CIGRÉ: Um outro procedimento recomendado para a definição do desequilíbrio de tensão pode ser extraído do CIGRÉ, (Congress Internationale des Grand Réseaux Électriques a Haute Tension), que emprega uma expressão para o fator de desequilíbrio a partir de uma grandeza adimensional que correlaciona as tensões de linha.

$$
K \%=\sqrt{\frac{1-\sqrt{3-6 \beta}}{1+\sqrt{3-6 \beta}}} \times 100
$$

Onde:

$$
\beta=\frac{\left|V_{a b}\right|^{4}+\left|V_{b c}\right|^{4}+\left|V_{c a}\right|^{4}}{\left(\left|V_{a b}\right|^{2}+\left|V_{b c}\right|^{2}+\left|V_{c a}\right|^{2}\right)^{2}}
$$

$V_{a b}, V_{b c}, V_{c a} \rightarrow$ Módulo das tensões trifásicas;

Método 4: IEEE: Por fim, o IEEE recomenda que o desequilíbrio de tensão pode ser obtido por uma relação que expressa a maior diferença entre as tensões de linhas medidas e o somatório das mesmas.

$$
K \%=\frac{3(V m a ́ x-V \min )}{V_{a b}+V_{b c}+V_{c a}} \times 100
$$

Onde: 
Vmáx $\rightarrow$ Maior valor dentre os módulos das tensões trifásicas;

Vmín $\rightarrow$ Menor valor dentre os módulos das tensões trifásicas;

$V_{a b}, V_{b c}, V_{c a} \rightarrow$ Módulo das tensões trifásicas;

Apresentam-se, na Tabela (2.1), os índices de conformidade retirados das normas e recomendações utilizadas ao redor do mundo para o controle da Qualidade da Energia Elétrica com relação aos desequilíbrios de tensão (fator $\mathrm{K})$.

Tabela 2.1 - Índices de conformidade

\begin{tabular}{|c|c|}
\hline Recomedação / Norma & Limite \\
\hline IEC & $2 \%$ \\
\hline GCOI/GCPS & $2 \%$ \\
\hline CENELEC & $2 \%$ \\
\hline NRS-048 & $2 \%$ \\
\hline NTSCE & --- \\
\hline ANSI & $3 \%$ \\
\hline
\end{tabular}

A CENELEC e a NRS-048 permitem, em algumas áreas, onde partes dos consumidores são monofásicos ou bifásicos, que o índice de conformidade seja de 3\%.

Verifica-se que a maioria das normas limita em $2 \%$ o desequilíbrio de tensão. Isto mostra que os índices de conformidade convergem para este valor.

\subsection{PROGRAMA COMPUTACIONAL}

Trata-se de uma nova ferramenta auxiliar, desenvolvido em linguagem "MATLAB 6.5", e dotado de vários recursos no sentido de fornecer opções simples e objetivas na análise do desequilíbrio de tensões. A sua aplicação se justifica sobretudo por se tratar de um programa bastante útil aos consumidores, à concessionária e aos fabricantes de equipamentos, quando da avaliação do fator $\mathrm{K}$ em qualquer ambiente do sistema elétrico de potência.

O aplicativo foi dividido em um módulo de entrada e ainda 6 módulos independentes e ao mesmo tempo complementares. Em quase todos, as ferramentas estatísticas de análise disponíveis ao usuário são: valores máximos e mínimos média quadrática e aritmética, desvio padrão, P95\% e P99\%.

A seguir, são caracterizados de forma sucinta, cada um dos módulos que compõem a estrutura geral da ferramenta:

Módulo de entrada: Corresponde ao módulo de inicialização do aplicativo, responsável pela leitura do banco de dados e apresentação de suas principais características. A figura 1 apresenta os tópicos contidos neste item.

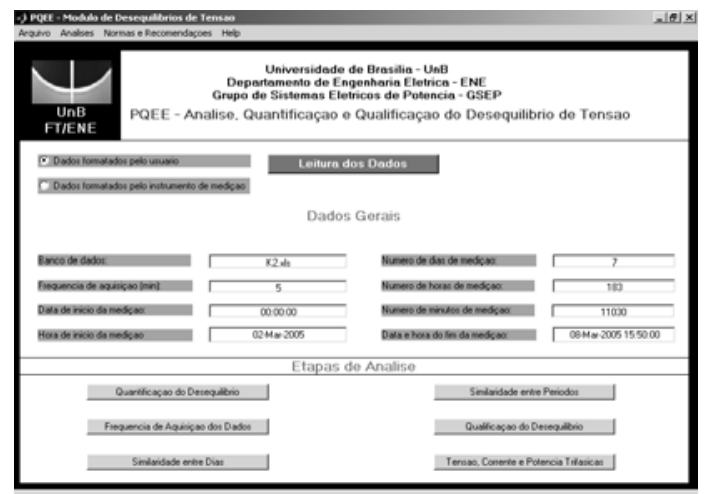

FIGURA 1 - Módulo de Entrada

Da figura 1 observa-se que após a abertura do banco de dados, o programa disponibiliza diversas informações vinculadas à sua a estrutura.

Módulo I - Quantificação do desequilíbrio: Neste módulo é realizado o cálculo do fator $\mathrm{K}$. Inicialmente, o usuário opta por um dos 4 métodos de cálculo. As estatísticas são então calculadas. Em seguida, os gráficos $\mathrm{K} \%$ versus tempo e das estatísticas são disponibilizados. As figuras 2 e 3 mostram a tela inicial do módulo I e o gráfico de $\mathrm{K} \%$ versus tempo, respectivamente.

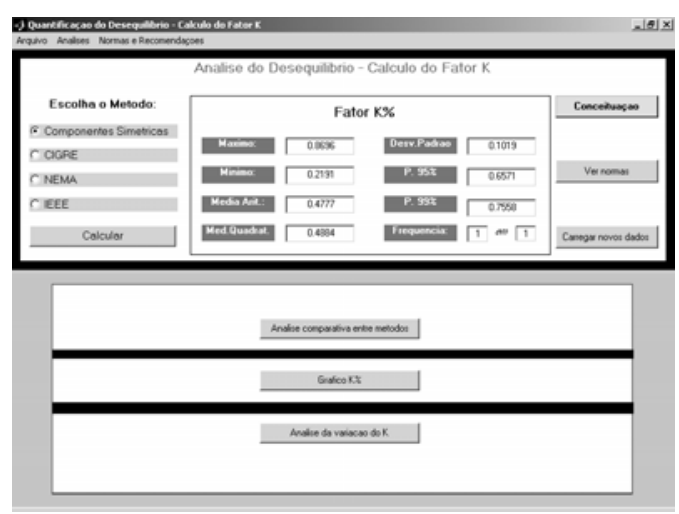

FIGURA 2 - Quantificação do desequilíbrio 


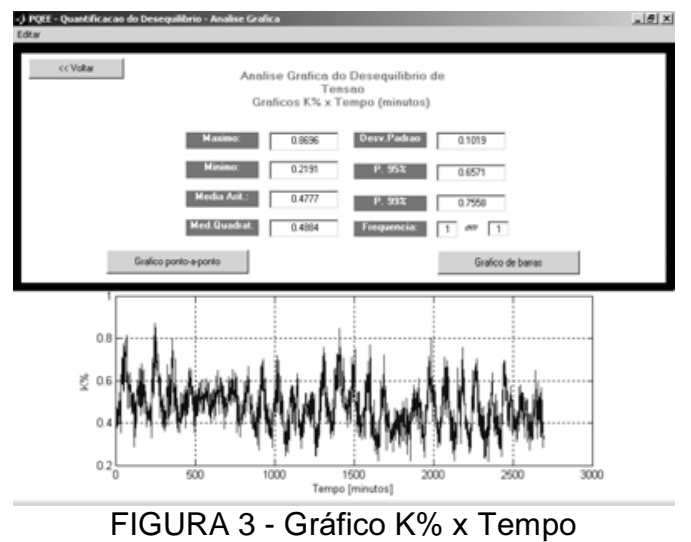

Como mencionado anteriormente, o cálculo do $\mathrm{K}$ pode ser executado a partir da utilização de 4 métodos distintos. Um deles considera os fasores de tensão e os demais apenas os módulos. Sendo assim, no módulo I é disponibilizada ferramenta para a comparação entre os métodos. Pode-se verificar a discrepância entre os valores do $\mathrm{K}$ calculados por todos os métodos simultaneamente ou ainda escolher um método como referencia e calcular o erro absoluto do $\mathrm{K}$ frente aos demais métodos. Esta última opção está ilustrada na figura 4 abaixo.
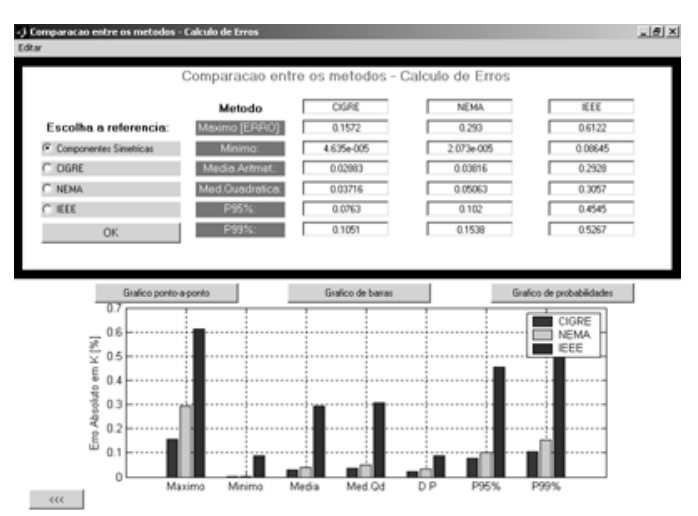

FIGURA 4 - Comparação entre os métodos Cálculo de erros

Módulo II - Freqüência de aquisição dos dados: Permite a apreciação, com vistas a análises da freqüência de aquisição, dos valores médios aritméticos, da média quadrática, do desvio padrão, do $\mathrm{P} 95 \%$, e do $\mathrm{P} 99 \%$, todos calculados quando da execução de medições intercaladas de $1,5,10,15,30$, e 60 minutos, bem como o erro cometido nestas operações, determinados a partir dos dados de um espaçamento preestabelecido. De fato, para o propósito desta etapa do trabalho, faz-se uso de ferramentas gráficas e oriundas de cálculos estatísticos, conforme evidencia a figura
5. Esta estrutura é padronizada para as análises de similaridade entre dias e entre períodos.

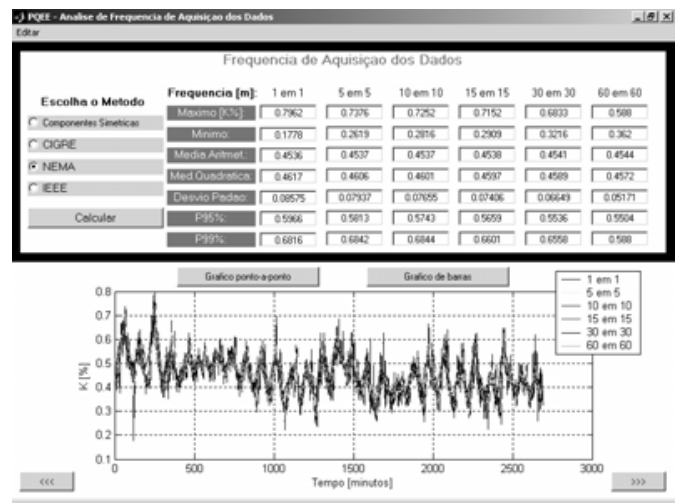

FIGURA 5 - Análise da freqüência de aquisição dos dados

Da figura 6 pode-se observar que o programa disponibiliza os valores de médias, desvios padrão, valores máximos e mínimos, P95\%, P99\%, todos calculados a partir de bancos de dados que consideram dados colhidos de $1 \mathrm{em} 1$ minuto, de 5 em 5, de 10 em 10, de 15 em 15, de 30 em 30 e de 1 em 1 hora. Estão ainda aptas à utilização, as janelas de plotagem do gráfico de barras contendo os resultados supracitados.

Módulo III - Similaridade entre dias: A partir da aplicação dos métodos de análise, busca-se comprovar a existência ou não de similaridade entre dias, com o intuito de reduzir o volume de dados a serem processados. A figura 6 ilustra os tópicos contidos neste módulo.

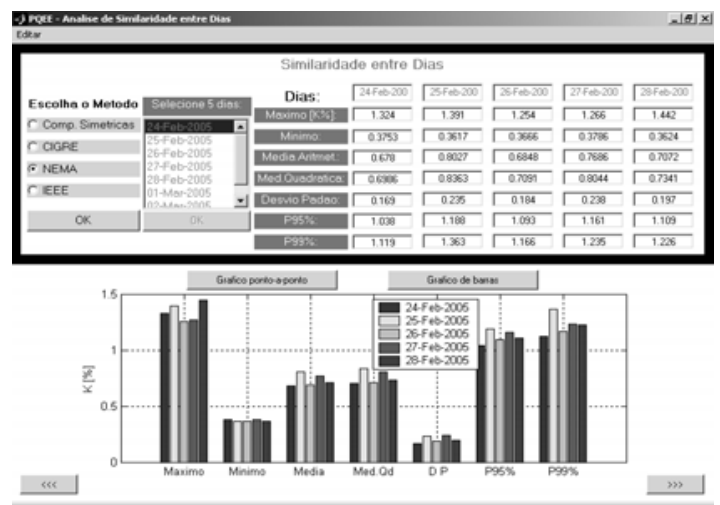

FIGURA 6 - Módulo da similaridade entre dias

Há de se considerar que, comprovando-se a similaridade, pode-se utilizar um dia como representativo aos demais.

Módulo IV - Similaridade entre períodos: A partir da aplicação dos métodos de análise, gera-se a 
possibilidade de execução de uma comparação entre diferentes períodos dentro de um mesmo dia. Busca-se um intervalo de medição no qual se possa obter períodos com valores representativos aos mais elevados patamares de desequilíbrio de um dia. O programa está configurado para o cálculo do desequilíbrio nos períodos de 0 às $8 \mathrm{~h}$, 8 às 16h, 16 às 24h, e ainda permite que 0 usuário escolha um período contínuo qualquer de 8 horas. A figura 7 ilustra os tópicos contidos neste módulo.

A partir deste módulo pode-se comparar estatísticas obtidas dos mais variados períodos de análise. Com isto, chega-se ao período de maior representatividade aos mais elevados valores de desequilíbrios.

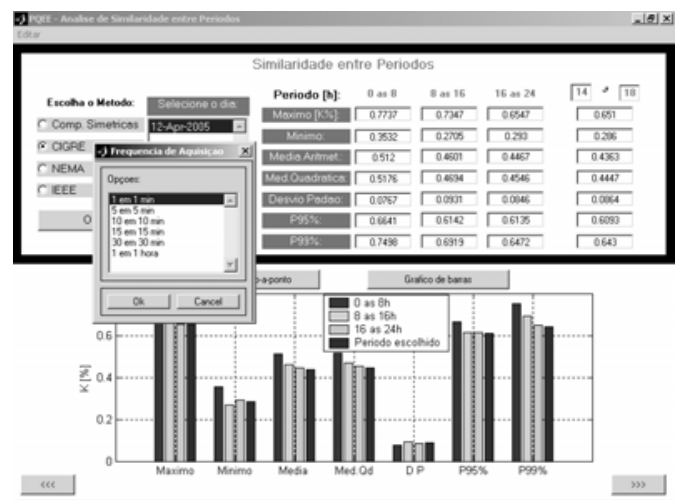

FIGURA 7 - Módulo da similaridade entre períodos

Módulo V - Qualificação do desequilíbrio: Possibilita a apreciação dos dados com respeito aos limites impostos pelas principais normas e recomendações, bem como permite aos usuários entender se os seus equipamentos suportam ou não os níveis de desequilíbrios em função do seu tempo de exposição.

Aqui são disponibilizados gráficos de probabilidade de ocorrência de valores do fator $\mathrm{K}$, média de probabilidade, média temporal, o número total de minutos que o sistema permaneceu com um valor de desequilíbrio acima da uma referência preestabelecida, o máximo tempo que o sistema permaneceu com um valor de desequilíbrio acima e abaixo do da referência ininterruptamente. É esperado que o resultado das análises possa auxiliar na conclusão a respeito da estacionalidade do processo.

Módulo VI - Tensão, corrente e potência trifásicas: Esta etapa presta-se, principalmente, quando da busca das causas dos desequilíbrios apresentados nas análises anteriores. São disponibilizados os gráficos de tensão de linha e de fase, corrente de linha e de fase, potência ativa, reativa e aparente. É possível observar, por exemplo, o comportamento das correntes e concluir a respeito da uniformidade ou não na distribuição da carga. A figura 8 ilustra uma tela deste módulo.

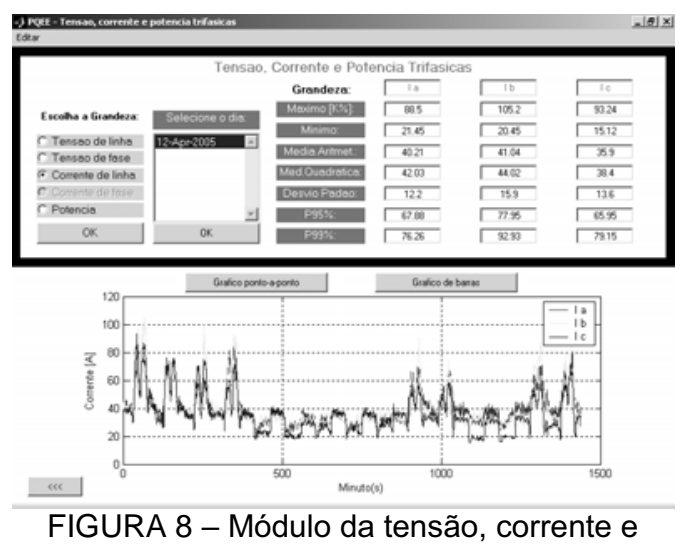
potência trifásicas

Da figura 8 observa-se que com a utilização do supracitado módulo, pode-se visualizar os perfis das tensões, correntes e potência, bem como as estatísticas calculadas a partir dos dados medidos.

\subsection{CONCLUSÂO}

A síntese das principais normas pertinentes indicou que, nada se tem registrado quanto aos fundamentos e definições estatísticas relacionadas aos métodos utilizados para 0 estabelecimento dos limites. As informações são vagas, porém apontam a importância de tratamentos baseados em conceitos estatísticos. Estes fatos nortearam e justificaram 0 desenvolvimento do programa computacional apresentado neste trabalho.

O aplicativo foi dividido em um módulo de entrada e outros 6 independentes e ao mesmo tempo complementares. Na maioria das vezes, estes módulos foram sustentados por ferramentas estatísticas como os valores máximos e mínimos, média quadrática e aritmética, desvio padrão, P95\% e P99\%.

O programa, quando da sua aplicação à uma situação real, mostrou-se simples, e sobretudo capaz de propiciar análises baseadas em conceitos estatísticos. Destaca-se que os índices e resultados gerados pela ferramenta conduzem a um retrato fiel dos níveis de desequilíbrios presentes em instalações elétricas residenciais, comerciais e industriais.

O tratamento estatístico dos dados, efetuado a partir da utilização dos módulos de análise, permite estabelecer um período típico que melhor 
caracteriza os níveis de desequilíbrio de uma dada instalação, e ainda avalia questões como a escolha de um dia como representativo aos demais.

Com vistas a apreciação da freqüência de aquisição, são calculados os valores médios e várias outras estatísticas, determinadas a partir das simulações de medições intercaladas de 1,5 , $10,15,30$, e 60 minutos, bem como o erro cometido nestas operações, determinados a partir dos dados de um espaçamento preestabelecido.

A metodologia utilizada na análise de "Qualificação do desequilíbrio", permite ao fabricante, de posse dos níveis máximos de suportabilidade ao fator $\mathrm{K}$, em função do tempo de exposição às mesmas, atestar se o seu produto pode ou não ser utilizado, sem riscos de danos, causados por um sistema como o em estudo. Pode-se ainda atestar se o local em estudo atende aos limites impostos pela Norma IEEE, Norma Européia e a Recomendação Brasileira.

Da utilização dos módulos que constituem a ferramenta computacional, é possível contribuir para o estabelecimento de diretrizes para nortear as campanhas de medição de desequilíbrios de tensão.

Embora os resultados obtidos não possam ser imediatamente generalizados para outras cargas, a metodologia apresentada pode ser de grande utilidade para empresas e profissionais interessados na quantificação e na qualificação dos desequilíbrios de tensão.

\subsection{REFERÊNCIAS BIBLIOGRAFICAS}

[1] Bronzeado, H. S.; Ramos, A. J. P.; Lira, D. P. C. P. de; Qualidade da Energia Elétrica Aspectos Práticos, Curso Especial - Qualidade da Energia Elétrica - Conceitos Problemas e Soluções, Recife, 2000.

[2] Dugan, R. C.; Mcgranaghan, M. F.; Beauty, H. W.; Electrical Power System Quality, Editora McGraw-Hill, EUA, 1996.

[3] Oliveira, David; Análise, Quantificação e Qualificação do Desequilíbrio de Tensão, UnB, 2001.

[4] Ferreira Filho, Anésio de Leles; OLiveira, de Hwang, Gisele. Voltage Unbalance Monitoring in CEB Systems. In: 10 TH INTERNATIONAL CONFERNCE ON HARMONICS, 2002 Rio de Janeiro. 10 th International Conference on Harmonics em CD. EFEI, 2002.

[5] Almeida, W.G.; Freitas, F.D. Circuitos Polifásicos. Fundação de Empreendimentos Científicos e Tecnológicos. Brasília, 1995.

\section{BIOGRAFIA}

Marco De Oliveira (M'91-SM'98) nasceu em 20 de Dezembro de 1958 no Rio de Janeiro, Brasil. Graduou-se na Universidade de Brasília em 1982. Adquiriu o grau de mestre e doutor pela Universidade de Paris (França) em 1989 e 1994 respectivamente. Entre 1982 e 1988 compôs a Divisão de Operação da Eletronorte envolvido com estudos de fluxo de carga, estabilidade e transientes eletromagnéticos. Ingresssou na Universidade de Brasília no ano de 1994, onde é, até este momento, professor do Departamento de Engenharia Elétrica. Sua linha de pesquisa inclui eletrônica de potência e qualidade da energia.

Anésio de Leles Ferreira Filho nasceu em 26 de Dezembro de 1971 em Patos de Minas, Brasil. Graduou-se na Universidade Federal de Uberlândia (Brasil) em 1994, onde recebeu também o título de mestre em 1997. Ingressou na Universidade de Brasília em 1997, onde é hoje professor do Departamento de Engenharia Elétrica. Seus interesses em pesquisa incluem eletrônica de potência e qualidade da energia.

Marcos Garcia da Silva Pinto nasceu em 17 de Janeiro de 1984 em Brasília, Brasil. É aluno de graduação do Departamento de Engenharia Elétrica da Universidade de Brasília, tendo ingressado no ano de 2002. Atualmente é bolsista de iniciação científica com projeto apoiado pela UnB, FINATEC e CNPq. 


\section{APÊNDICE B}

T\&D - Transmission and Distribution Conference and Exposition Latin America, 15 a 18 de Agosto de 2006, Caracas, Venezuela.

"A Computational Tool to Analyze, Quantify and Classifying Voltage Imbalance in Electrical Power Systems". 


\title{
A Computational Tool to Analyze, Quantify and Classifying Voltage Imbalance in Electrical Power Systems
}

\author{
Anésio de L. F. Filho, Member, IEEE, Marco A. de Oliveira, Senior Member, IEEE, and Marcos G. da \\ S. Pinto
}

\begin{abstract}
The aim of the present paper is to describe a computational tool designed to analyze voltage imbalance. This tool was developed with the Matlab programming language and utilizes measurements from a variety of instruments for the purpose of creating databases which may then be characterized, analyzed and interpreted in accordance with several different standards and electrical recommendations. As a result, this article initially presents the definition of voltage imbalance, some basic considerations on its causes and effects, its main calculating methods and finally a brief overview of the main standards involved. From this point a software program is proposed to analyze the mentioned parameters.

The relevance of this tool resides in its ability to assist electrical companies, universities, and those professionals interested in quantifying and classifying voltage imbalances.
\end{abstract}

Index Terms - K factor, Classifying, Quantification, Power Quality, Voltage Imbalance.

\section{INTRODUCTION}

$\mathrm{T}$ here have bean observed, recently, a variety of effects caused by the use of industrial three-phase machines and their increasing demand for greater quantities of power. Moreover, this situation has been accentuated by the growing utilization of appliances, computers and lowconsumption electrical devices such as fluorescent light bulbs - a factor which has expanded in Brazil since its electrical energy shortage in 2001. As a result, there is increased preoccupation concerning the supply of energy and of relevance to this study, the role of voltage imbalance in this context. Though such electrical devices use little power individually, there are thousands of new loads being randomly connected and disconnected to and from the power grid. Thus, in the foreseeable future, we will be faced with the necessity of controlling the degree of voltage imbalance not only in the industrial sector but also in the area of commercial and residential loads.

The international IEEE, IEC, and European standards, among others, have set limits for this phenomenon.

A. L. F. Filho, Department of Electrical Engineering, University of Brasilia, Brazil (e-mail: leles@ene.unb.br).

M. A. G. de Oliveira, Department of Electrical Engineering, University of Brasilia, Brazil (e-mail: mago@ene.unb.br).

M. G. da S. Pinto, Department of Electrical Engineering, University of Brasília, Brazil (e-mail: marcos.unb@gmail.com).
Furthermore, there are several measurement devices already on the market capable of obtaining the data in accordance with the requirements established by these standards. However, more specific tools designed for the treatment and analysis of samples remain scarce.

Consequently, the Power Quality Studies Group at the University of Brasilia has suggested improving this scenario through quantifying and classifying voltage imbalance research. As a result, this article initially presents the definition of voltage imbalance, some basic considerations on its causes and effects, its main calculating methods and finally a brief overview of the main standards involved. From this point a software program is proposed to analyze the mentioned parameters.

Through the use of a statistical toolset comprised of maximum and minimum values with $95 \%$ and $99 \%$ probability not to be exceeded (P95\% and $\mathrm{P} 99 \%$ ), the software allows the evaluation of questions such as the similarity or not in the behavior of the imbalance profile among the measurements over several days, as well as determining the minimum period necessary for measurement. In addition, figures obtained using the methodology led to establishing solid research on the behavior of imbalances. Under these conditions, it will be possible, for instance, for the software users to detect if their equipment can handle the levels of imbalance to which it will be subjected to during an established period of time.

The relevance of this study resides in the fact that acquiring the knowledge of the phenomenon of voltage imbalance behavior over time will allow measures to be taken which could minimize its damaging effects on electrical systems as well as on a variety of equipment.

\section{ImbalanCE K FACTOR: DEFinition AND CALCUlating METHODS}

The voltage imbalance in an electrical system is a condition in which the phases differ in their magnitude, have a different phase displacement from $120^{\circ}$, or experience both simultaneously.

It is known that the presence of imbalanced three-phase loads connected to a three-phase system causes a voltage imbalance, since the currents absorbed in each phase are not symmetrical, i.e., they have not got the same magnitude 
and/or are not offset by $120^{\circ}$.

Usually there are not great imbalances in high tension systems, except when they supply large single-phase loads, such as electric trains or industrial ovens.

Another factor that generates voltage imbalance is the existence of badly transposed transmission lines, since the electrical properties of these lines will not be the same throughout their length.

The effects caused by electrical systems that have voltage imbalances are associated with overheating, malfunctioning and/or protection device failures, insulation damage, and duration of lifetime.

Estimating the imbalance level $-\mathrm{K}$ factor - may be executed through four different methods. The first uses the three-phase modules and offsets to obtain the $\mathrm{K}$ factor. The remaining three depend only on the magnitude of the line-toline voltages.

\section{A. Symmetrical Components Method}

In this method, the voltage imbalance is defined as the ratio of the module of the negative and positive sequences, as shown in (1).

$$
K \%=\frac{V_{-}}{V_{+}} \times 100
$$

Where:

$\mathrm{V}-\rightarrow$ Module of the negative sequence voltage;

$\mathrm{V}+\rightarrow$ Module of the positive sequence voltage;

\section{B. NEMA Method}

In order to quantify the imbalance, the NEMA-MG-14.34 standard calculates the $\mathrm{K}$ factor as the ratio of the maximum measured deviation from the average voltage and the average voltage itself, using the three-phase voltages as a reference as seen in (2).

$$
K \%=\frac{\Delta V}{V_{m}} \times 100
$$

\section{Where:}

$\Delta \mathrm{V} \rightarrow$ Maximum measured deviation from the average three-phase voltage to the average value;

$\mathrm{Vm} \rightarrow$ Arithmetic mean of the three-phase absolute values of tension;

\section{CIGRÉ Method}

Another recommended procedure to calculate the voltage imbalance comes from CIGRÉ (Congress Internationale des Grand Réseaux Électriques a Haute Tension). In this approach, an expression obtained from the three-phase tensions is used to obtain the $\mathrm{K}$ factor.

$$
K \%=\sqrt{\frac{1-\sqrt{3-6 \beta}}{1+\sqrt{3-6 \beta}}} \times 100
$$

Where:

$$
\beta=\frac{\left|V_{a b}\right|^{4}+\left|V_{b c}\right|^{4}+\left|V_{c a}\right|^{4}}{\left(\left|V_{a b}\right|^{2}+\left|V_{b c}\right|^{2}+\left|V_{c a}\right|^{2}\right)^{2}}
$$

$V_{a b}, V_{b c}, V_{c a} \rightarrow$ Modules of the three-phase voltages;

\section{IEEE Method}

The IEEE recommends that the $\mathrm{K}$ factor should be obtained through the following expression, which yields the greatest difference between the measured three-phase tensions and their sum, as seen in (5).

$$
K \%=\frac{3(V \max -V \min )}{V_{a b}+V_{b c}+V_{c a}} \times 100
$$

Where:

Vmax $\rightarrow$ Maximum value among the three-phase voltages;

Vmin $\rightarrow$ Minimum value among the three-phase voltages;

$V_{a b}, V_{b c}, V_{c a} \rightarrow$ Modules of the three-phase voltages;

Table I presents the limits of voltage imbalance (K factor) found in the standards and recommendations adopted worldwide for controlling electrical Power Quality.

TABLE I

CONFORMITY LIMITS

\begin{tabular}{|c|c|}
\hline Recommendation/Standard & Limit \\
\hline IEC & $2 \%$ \\
\hline GCOI/GCPS & $2 \%$ \\
\hline CENELEC & $2 \%$ \\
\hline NRS-048 & $2 \%$ \\
\hline ANSI & $3 \%$ \\
\hline
\end{tabular}

Both CENELEC and NRS-048 allow that the conformity limit be $3 \%$ in some areas where part of the consumers are single-phase or two-phase power.

Most of the standards agree on limiting the voltage imbalance to $2 \%$. This demonstrates that the limits established globally converge on this point. 


\section{COMPUTATIONAL TOOL}

This software consists of a new auxiliary tool, developed with the aid of "MATLAB 6.5", and has several capabilities which provide simple and objective options in the analysis of voltage imbalance. Its application is justified particularly because it is a program that is beneficial to its users, such as electric companies and other users of electrical equipment, when evaluating the $\mathrm{K}$ factor in any electrical power system part.

The program has been divided into an entrance module and six fully independent, though complementary modules. In nearly all of them, the statistical analysis tools available to the user are: maximum and minimum values; arithmetic mean; square mean; standard deviation; $\mathrm{P} 95 \%$ and $\mathrm{P} 99 \%$.

The following parts will succinctly describe each of the modules that make up the program:

\section{A. Entry Module}

The initial page of the application module is responsible for reading the database and presenting its main features. After opening the database, the program provides information regarding its structure as can be seen in the figure 1 screenshot from this module.

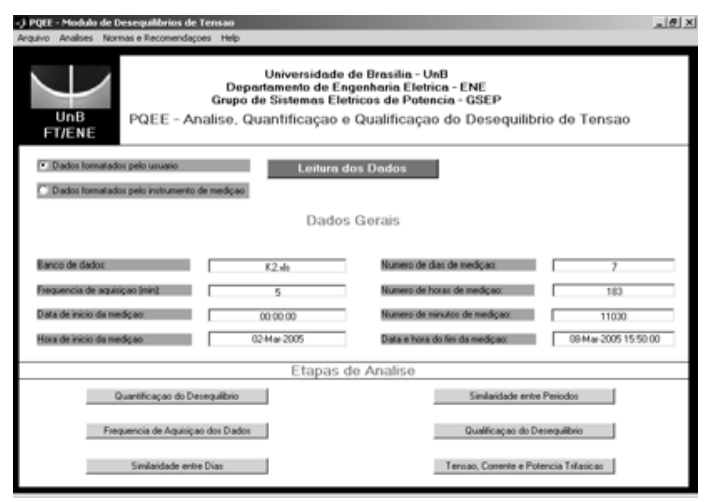

Fig. 1. Entry Module.

\section{B. Module I-Imbalance quantifying}

In this section, the $\mathrm{K}$ factor is calculated. First of all, the user will choose one of the four calculating methods. The statistics will then be calculated, and after the $\mathrm{K} \%$ graphs will be displayed. Figures 2 and 3 respectively show the initial screen of Module I and the K\% versus time graph.

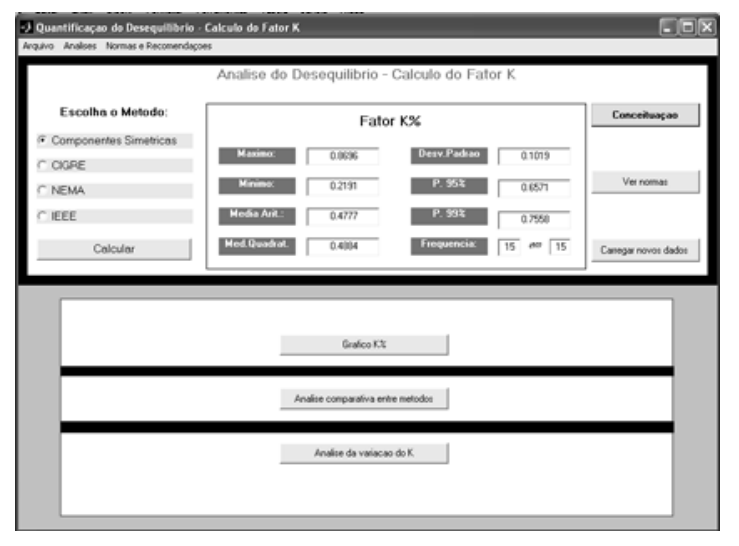

Fig. 2. Imbalance quantifying.

Since there are four methods with which the users can calculate $\mathrm{K}$, one of them uses phasors while the other three consider only the magnitudes of the three-phase voltages. Module I has a feature which compares the results obtained from the different methods. It allows the verification of the differences in $\mathrm{K} \%$ according to each of the four methods simultaneously or by choosing one of the methods as a reference and displaying the absolute error of each of the other three methods, as may be seen in figure 4 .

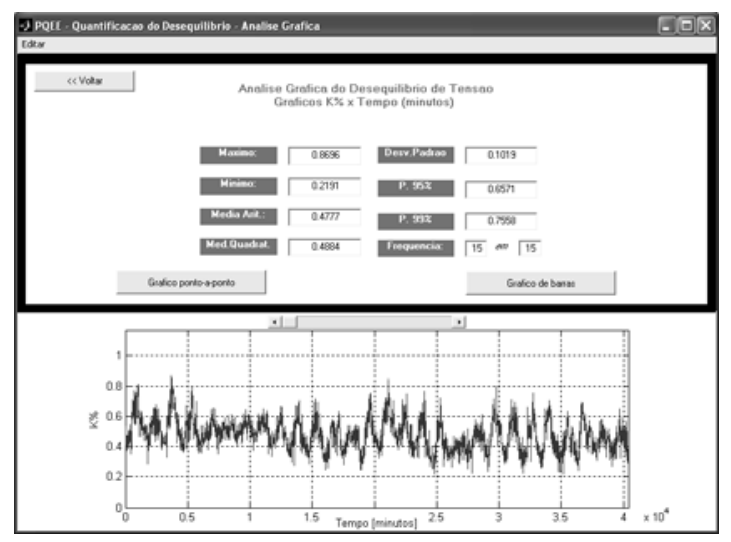

Fig. 3. $\mathrm{K} \%$ as a function of time.

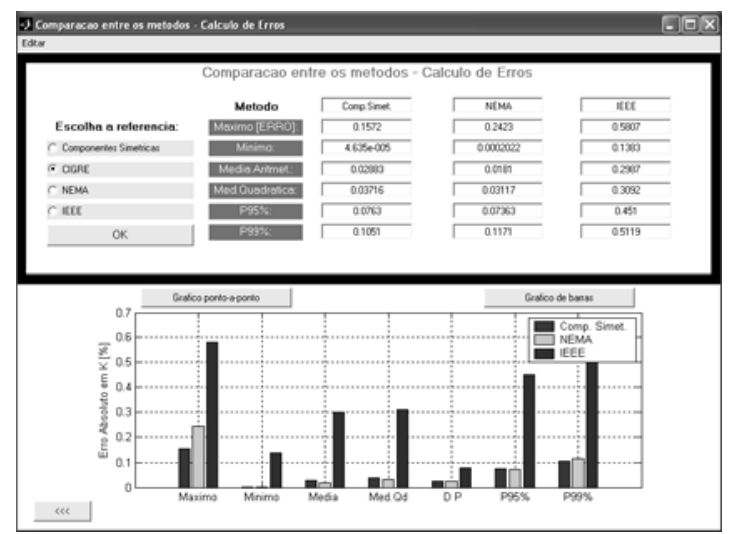

Fig. 4. Comparison between different methods and error calculation. 


\section{Module II - Data acquisition frequency}

Module II allows viewing the frequency analysis results such as the arithmetic means, the square mean, the standard deviation, $\mathrm{P} 95 \%$ and $\mathrm{P} 99 \%$ : all of them calculated when measuring takes place, in intervals of $1,5,10,15,30$ or 60 minutes. In this part of the procedure, graphical tools from statistical calculations are used, as figure 5 shows. This structure is standardized for the analysis of inter-day and inter-period similarity.

From figure 5 it may be observed that the program displays the mean values, standard deviations, maximum and minimum values, $\mathrm{P} 95 \%$ and $\mathrm{P} 99 \%$, all based on databases which consider data that was collected in intervals of 1,5 , $10,15,30$ or 60 minutes. All of these results may be seen in the bar graph plotting window.

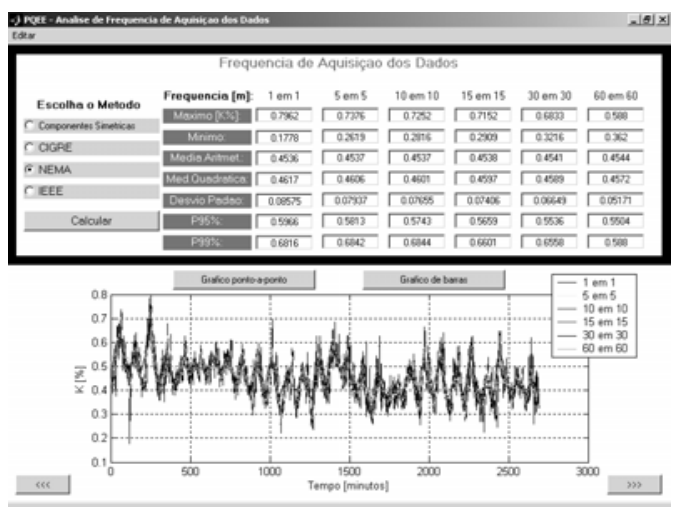

Fig. 5. Data sampling frequency analysis.

\section{Module III - Inter-day Similarity}

With the output from the application of the data analysis, the program tries to prove the existence or not of an interday similarity, with the goal of reducing the amount of data to be processed. Figure 6 shows the fields displayed in this section.

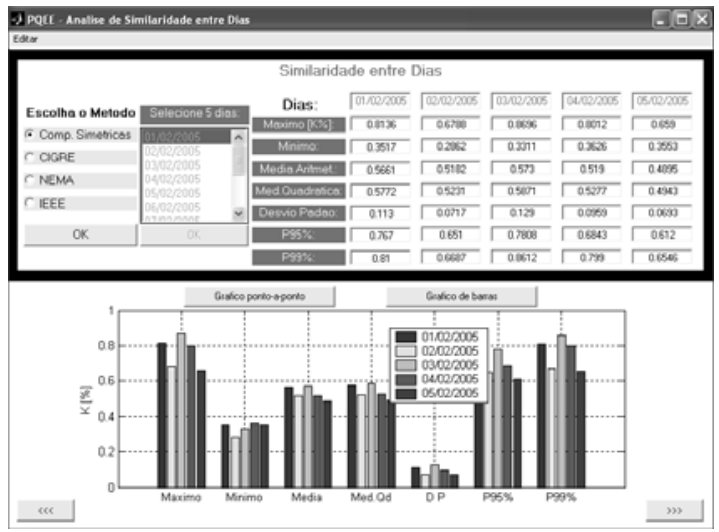

Fig. 6. Inter-day similarity.
It's important to take into account that once the similarity is proven, one day may be utilized as a representation of the rest.

\section{E. Module IV-Inter-periodic similarity}

From the application of the analyzing methods, the possibility of a comparison between different parts within a same day rises. Thus, a measuring interval can be sought in which there may be found samples corresponding to the highest imbalance values in a given day. The program is configured to calculate the imbalance between midnight and 8:00 a.m., from 8:00 a.m. to 4:00 p.m. and from 4:00 p.m to midnight, besides allowing the user to choose any given 8 hours long continuous time period. Figure 7 is a sample image of this module.

From this module, statistics obtained from any given analyzed moment of time may be compared. Therefore, the period of time with the foremost occurrences of imbalances may be reached.

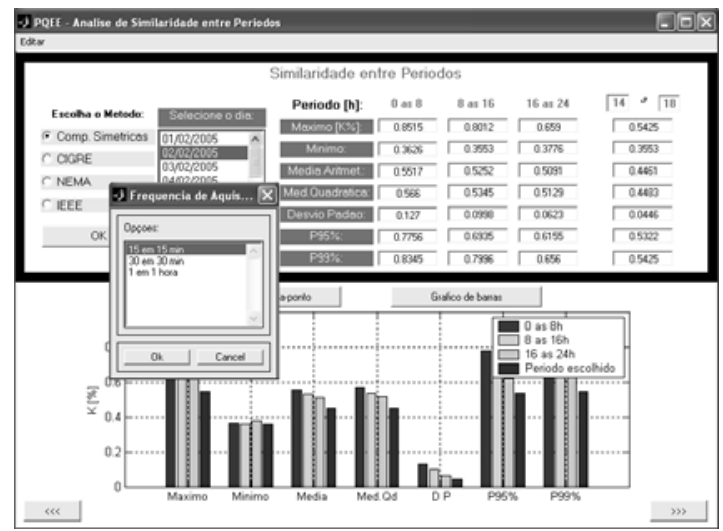

Fig 7. Inter-periodic similarity module.

\section{F. Module V-Imbalance classifying}

This module allows comparing the imbalance obtained to the limits imposed by the main recommendations and standards, as well as offering the users the ability to know if their equipment will be able to withstand the voltage imbalance during a certain amount of time.

Here we have access to: probability graphs of occurrence of determined $\mathrm{K}$ factor values; the probability average; the time average; the overall number of minutes in which the system presented a higher imbalance then a previously determined reference and the maximum uninterrupted amount of time the system remained with an imbalance superior or inferior to a given reference.

Figure 8 present the initial screen of Module V, where we can see one of the above mentioned graphics. 

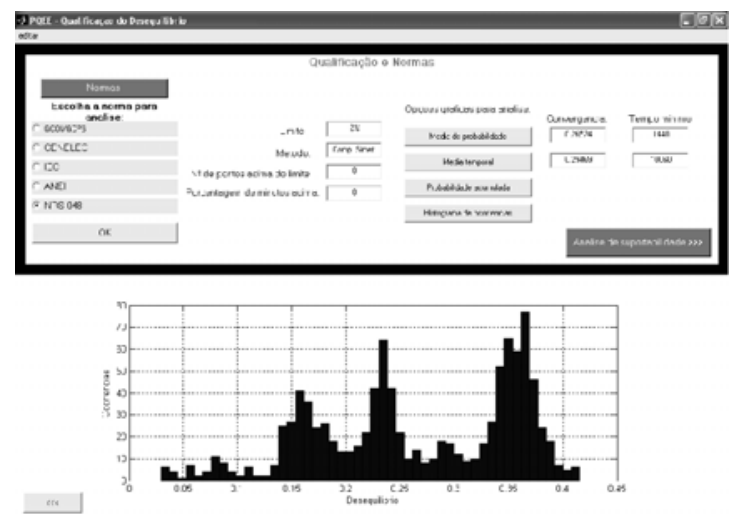

Fig. 8. Imbalance classifying.

Figure 9 illustrates a sub-module of Module V, and is dedicated to analyze the distribution time of the voltage imbalance.

From $\mathrm{P} 95 \%$ as reference, for example, it can be calculated the total minutes with $\mathrm{K} \geq \mathrm{P} 95 \%$, the maximum uninterrupted interval of time with values of $\mathrm{K} \geq 95 \%$, probabilities of occurrence of the uninterrupted intervals of time with $\mathrm{K} \geq \mathrm{P} 95 \%$, the maximum uninterrupted interval of time with values of $\mathrm{K}<\mathrm{P} 95 \%$ and the probabilities of occurrence of the uninterrupted intervals of time with $\mathrm{K} \leq \mathrm{P} 95 \%$.
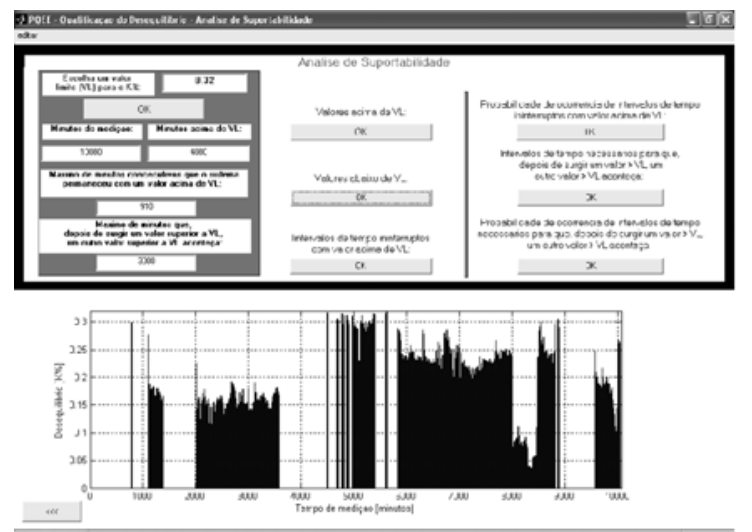

Fig. 9. Distribution in time - Uninterrupted intervals of time with values of $\mathrm{K}<\mathrm{P} 95 \%$ versus total time of measurement in minutes

\section{G. Module VI-Three-phase voltage, current and power}

This stage intends mainly to aid in the search for the causes of the imbalance detected in the previous analyses Three-phase and single-phase voltage graphs are available, along with three-phase and single-phase current, active, reactive and apparent power. It is possible to observe, for instance, the behavior of the currents and conclude the uniformity in the load distribution. In fig. 10, which presents a screenshot from this module, it may be observed that utilizing this module, the tension, current and power profiles, as well as some statistics from the measured data become available.

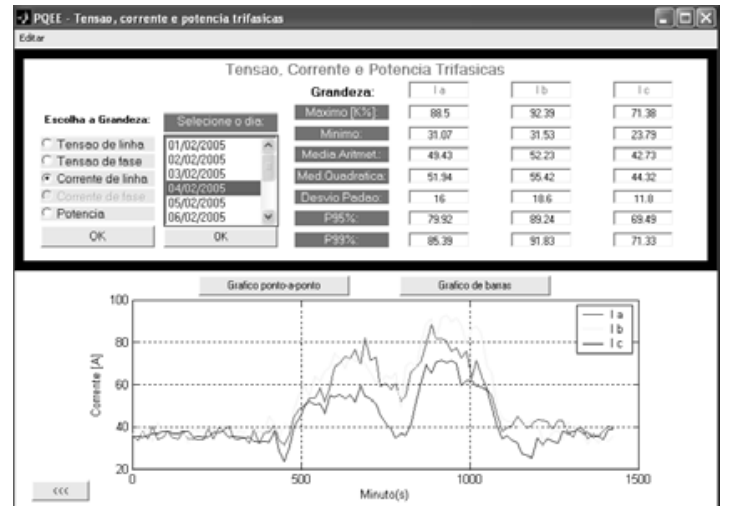

Fig. 10. Three-phase voltage, current and power.

\section{CONCLUSION}

The synthesis of the main standards related to our subject has indicated that there are no rules on the fundamentals and statistical definitions related to the methods used to set an imbalance limit. However, though superficial, the information points to the importance of a statistical-based handling of the subject. These facts have led the way in the process of developing the software presented in this paper.

The application has been divided in an entry module and 6 independent, though complementary modules. For the most part, these modules have relied on statistical calculations as the maximum and minimum values of a set, square mean and arithmetic mean, standard deviation, P95\% and $\mathrm{P} 99 \%$.

The software has shown itself to be simple and, above all, capable of handling statistical-supported analyses. It should also be remarked that the results obtained through the computational tool seek to dependably portray the condition of the imbalances present in residential, commercial and industrial electrical installations.

The statistical treatment of the data was subjected to different modules that allow the establishment of a typical period of time which best characterizes the imbalance levels of a given system and it still evaluates questions such as the choice of day to represent any day.

Regarding the acquisition frequency, mean values are calculated along with several other statistics, determined from the measuring (which can be taken in intervals of 1,5 , $10,15,30$ or 60 minutes), as well as the error found in those operations, determined through the data obtained in a established time period.

The methodology used in the imbalance classifying analysis allows the user, once possessing the maximum levels of $\mathrm{K}$ factor to which the equipment can resist for a given time, may verify if his product may be used without risking damage by a system as the one studied. If the area tested complies with the limits set by the IEEE standard or the European standard, among a set of other standards can also be verified.

Through using the modules that integrate the 
computational tool, it is possible to contribute to the setting of standards to guide the voltage imbalance measurements.

Although the results attained may not be immediately generalized to other loads, the methodology presented may be useful for professionals and enterprises interested in classifying and quantifying the voltage imbalances.

\section{ACKNOWLEDGMENT}

The authors gratefully acknowledge the contributions of Otávio V. Caixeta, student of University of Brasilia, for his hard work in the construction of this paper.

\section{REFERENCES}

[1] H. S. Bronzeado, A. J. P. Ramos and D. P. C. P. de Lira, "Qualidade da Energia Elétrica - Aspectos Práticos" in Curso Especial Qualidade da Energia Elétrica - Conceitos Problemas e Soluções, Recife, 2000.

[2] R. C. Dugan, M. F. Mcgranaghan and H. W. Beauty, "Electrical Power System Quality”, New York: McGraw-Hill, 1996.

[3] Oliveira, José Carlos. Harmônicos e Desequilíbrios, Junho/2000.

[4] David Oliveira, "Análise, Quantificação e Qualificação do Desequilíbrio de Tensão”, Brasília: UnB, 2001.

[5] Anésio de L. F. Filho and G. de H. Oliveira, "Voltage Unbalance Monitoring in CEB Systems", in 10th International Conference on Harmonics, Rio de Janeiro: EFEI, 2002.

[6] W. G. Almeida and F. D. Freitas, "Circuitos Polifásicos", Brasília: Fundação de Empreendimentos Científicos e Tecnológicos, 1995.

[7] Anésio de L. F. Filho, et. all, "Voltage Imbalance Analysis in Eletronorte Systems - Substations with $230 \mathrm{kV}$ ", X Symposium of Specialists in Electric Operational and Expansion Planning, 2006.

\section{BIOGRAPHIES}

Marco De Oliveira (M'91-SM'98) was born in Rio de Janeiro, Brazil, on December 20th, 1958. He has a degree (1982) in Electrical Engineering from UnB (the University of Brasília). He has a Master's Degree (1989) and a PhD (1994) from the University of Paris (France). From 1982 to 1988, he took part in Eletronorte's Operation Division where he was involved in studies of load flux, stability and electromagnetic transients. He joined the University of Brasília in 1994, where he became a professor for the Department of Electrical Engineering, a position he still holds. His line of research includes power electronics and power quality.

Anésio de Leles Ferreira Filho was Born in Patos de Minas, Brazil, on December 26th, 1971. He has a 1994 Electrical Engineering degree from the Federal University of Uberlândia (Brazil), where he also attained his MS in 1997. He joined the University of Brasília in the same year, where he still holds a position as a lecturer in the Electrical Engineering department. His research interests include power electronics and power quality.

Marcos Garcia da Silva Pinto was born in Brasília, Brazil, on January 17th, 1984. He is currently an Electrical Engineering graduation student in the University of Brasilia, where he began his studies on 2002. He is currently vice-president of UnB's Electrical Engineering student body. His research interests include power quality, specially the voltage imbalance. 


\section{APÊNDICE C}

$2^{\circ}$ Congresso de Iniciação Científica do DF e XI Congresso de Iniciação Científica da UnB, 23 a 26 de Agosto de 2005.

Resumo - "Quantificação e Qualificação dos Desequilíbrios de Tensão".

$3^{\circ}$ Congresso de Iniciação Científica do DF e XII Congresso de Iniciação Científica da UnB, 12 a 15 de Setembro de 2006.

Resumo - "Monitoramento dos Desequilibrios de Tensão em Cargas com Perfil Comercial". 


\title{
QUANTIFICAÇÃO E QUALIFICAÇÃO DOS DESEQUILÍBRIOS DE TENSÃO
}

\author{
$\underline{\text { RESUMO }}$
}

Marcos Garcia da S. Pinto

Anésio de Leles Ferreira Filho

Marco Aurélio de Oliveira

\section{PALAVRAS-CHAVE}

Qualidade da Energia

Desequilíbrios de Tensão

Quantificação

Qualificação

\section{INTRODUÇÃO}

Em face da proliferação do uso de equipamentos altamente sensíveis e vulneráveis à qualidade da tensão de alimentação, o estudo da qualidade da energia, onde destaca-se o fenômeno do desequilíbrio de tensão, tem assumido grande importância.

Em contrapartida, a literatura atinente e as metodologias de tratamento dos dados voltadas para este fim mostram-se insuficientes. Neste ínterim, ergue-se a idéia deste estudo, que visa apresentar uma ferramenta computacional para a análise do desequilíbrio de tensão. A partir de medições com os mais variados tipos de instrumentos, são formados bancos de dados que poderão ser caracterizados e interpretados segundo diversas normas e recomendações.

\section{METODOLOGIA}

O programa está fundamentado na linguagem MATLAB 6.5, que é bastante utilizada para criação e simulação de modelos matemáticos aplicados às mais diversas áreas. Com atenção para a interface gráfica, o software foi desenvolvido de forma que as etapas de análise nele presentes contemplem gráficos, valores absolutos e um grande ferramental estatístico (máximos, mínimos, médias aritmética e quadrática, desvio padrão, probabilidades de $95 \%$ e $99 \%$ de não serem excedidos).

$\mathrm{Na}$ metodologia adotada houve a preocupação em permitir-se comprovar a existência de similaridade entre dias e períodos do dia, bem como a estacionalidade do processo, com vista a reduzir o volume de dados a serem analisados. 


\section{RESULTADOS}

O aplicativo final foi dividido em um módulo de entrada e ainda 6 módulos independentes e ao mesmo tempo complementares. Todo cuidado foi tomado para que o banco de dados por ele gerado fosse preciso e conclusivo, quando da emissão de diagnósticos para os sistemas elétricos por ele monitorados. Destaca-se que, hoje, os índices e resultados gerados pela ferramenta conduzem a um retrato fiel dos níveis de desequilíbrios presentes em instalações elétricas residenciais, comerciais e industriais.

A sua aplicação se justificou sobretudo por se tratar de um programa bastante útil aos consumidores, à concessionária e aos fabricantes de equipamentos, quando da avaliação do desequilíbrio (fator K) em qualquer ambiente do sistema elétrico de potência. Tal fato confirmou-se quando da aceitação para publicação do trabalho no maior e mais especializado congresso nacional da área (Seminário Brasileiro sobre a Qualidade da Energia Elétrica).

$\mathrm{Na}$ verificação da literatura atinente, tanto no início quanto ao fim do projeto, foi possível questioná-la e verificar o quanto a mesma se encontra incipiente e inconclusiva. Confirmou-se então, que o projeto aqui desenvolvido irá firmar-se em um instrumento capaz de esclarecer pontos que hoje se mostram obscuros para uma grande gama de profissionais da área.

\section{CONCLUSÃO}

O programa, quando da sua aplicação à uma situação real, mostrou-se simples e sobretudo capaz de propiciar análises baseadas em conceitos estatísticos. Da utilização dos módulos que o constituem, é possível obter um quadro real dos níveis de desequilíbrio existentes e ainda uma série de etapas que otimizam a análise.

Esta ferramenta tende a consolidar-se como uma metodologia de grande utilidade a todos os profissionais interessados na quantificação e qualificação dos desequilíbrios de tensão. 


\title{
MONITORAMENTO DOS DESEQUILÍBRIOS DE TENSÃO EM CARGAS COM PERFIL COMERCIAL
}

\author{
RESUMO
}

Marcos Garcia da S. Pinto

Anésio de Leles Ferreira Filho

Marco Aurélio de Oliveira

\section{PALAVRAS-CHAVE}

Qualidade da Energia

Desequilíbrios de Tensão

Quantificação

Qualificação

\section{INTRODUÇÃO}

Os avanços tecnológicos trazidos pela eletrônica de potência e a crescente preocupação com a eficiência energética inseriram nos sistemas elétricos cargas especiais, que contribuem para o surgimento de problemas relacionados com a qualidade da energia. Especialistas da área têm se reunido por meio de diversos fóruns a fim de tratarem dos aspectos técnicos que possam amenizar tais problemas. Normas internacionais foram criadas e estabelecem limites para diversos índices que são usados como base para avaliar a qualidade da energia elétrica. Entretanto seguem insuficientes os estudos dedicados à monitoração e análise das causas e efeitos dos desequilíbrios de tensão.

\section{METODOLOGIA}

Este trabalho propôs efetuar um levantamento do desequilíbrio de tensão considerando vários locais simultaneamente. Foram medidas as magnitudes e os ângulos da tensão de cada fase, coletados nas entradas de diferentes consumidores comerciais, repletos de cargas especiais. Os supracitados locais foram monitorados com intuito de se levantar o perfil do desequilíbrio nestes ambientes. Trata-se de medições com uma semana de duração, com dados sendo integralizados a cada dez minutos. A comparação dos resultados destes locais foi feita por meio de tabelas, gráficos e do uso de um ferramental estatístico, a partir da utilização da ferramenta computacional a priori desenvolvida.

\section{RESULTADOS}

A partir dos valores encontrados de máximos, mínimos, média aritmética e quadrática, desvio padrão, valores com probabilidade de $95 \%$ e $99 \%$ de não serem excedidos, observou-se que os locais monitorados possuem patamares de desequilíbrio muito próximos entre si. Pôde-se ainda avaliar questões como a similaridade do comportamento do desequilíbrio entre os diversos dias de medição e entre os períodos de um dia, com vistas à diminuição do número de dados necessários à quantificação. Na maioria dos locais, constatou-se que uma medição de um dia no horário comercial é suficiente para se ter amostras representativas às demais, caracterizando corretamente os pontos 
monitorados. Foram traçados gráficos do perfil do desequilíbrio em função do tempo, gráficos de probabilidade acumulada e histogramas de ocorrência de desequilíbrios, dentre outros.

Verificou-se que, para a semana especificada nos estudos, os consumidores monitorados apresentaram valores do fator de desequilíbrio dentro dos requesitos estabelecidos pelas principais normas e recomendações. Naturalmente, dependendo da sensibilidade das cargas em análise, recomenda-se fortemente uma avaliação pormenorizada da distribuição no tempo dos mais elevados valores de desequilíbrio durante o intervalo em estudo. Muito embora um determinado local possa apresentar poucos valores elevados, se todos eles se manifestarem concentradamente, esta condição poderá ser suficiente para deteriorar os equipamentos mais sensíveis.

\section{CONCLUSÃO}

Este trabalho é de importância evidente, possibilitando ações que poderão minimizar os danosos efeitos dos desequilíbrios sobre o sistema. Os gráficos expostos prestam-se para formação de um banco de dados contendo valiosas informações quanto às amplitudes e o perfil do supracitado fenômeno em alguns consumidores comerciais de Brasília. A metodologia utilizada mostrou-se satisfatória, sendo aplicável nos diversos ambientes do sistema elétrico de potência 


\section{APÊNDICE D}

CIDEL - International Congress on Electricity Distribution, de 27 a 29 de novembro de 2006, Buenos Aires, Argentina.

"Análise da Sensibilidade do Desequilibrio de Tensão frente a Variações nos Ángulos e Magnitudes das Tensões". 


\title{
ANÁLISE DA SENSIBILIDADE DO DESEQUILÍBRIO DE TENSÃO FRENTE A VARIAÇÕES NOS ÂNGULOS E MAGNITUDES DAS TENSÕES
}

\author{
Marco Aurélio Gonçalves de Oliveira, Phd* \\ mago@ene.unb.br \\ Anésio de Leles Ferreira Filho, Msc \\ leles@ene.unb.br \\ Marcos Garcia da Silva Pinto, Grd \\ marcos.unb@gmail.com
}

\author{
Universidade de Brasília - UnB, Brasil \\ Faculdade de Tecnologia - FT \\ Departamento de Engenharia Elétrica - ENE \\ Campus Universitário Darcy Ribeiro - Asa Norte \\ Cep: 70910-900, Brasília - DF \\ (55) (61) 3307-2308; Fax: (61) 3307-2309
}

\section{RESUMO}

O aumento acentuado no volume de cargas não lineares nos sistemas elétricos tem causado preocupação, mais notadamente nos últimos anos, devido principalmente aos problemas relacionados à qualidade da energia, onde enquadra-se o desequilíbrio de tensão.

Embora os estudos em diversas frentes vinculadas à qualidade da energia estejam avançando, seguem incipientes as investigações direcionadas ao desequilíbrio de tensão. Sabe-se, porém, que a presença de altos níveis de desequilíbrio pode acarretar sérios danos ao sistema, principalmente em decorrência da circulação de correntes de seqüência zero, como é o caso da terceira harmônica, entre fonte e carga com ligação em delta. Adicionalmente, o desequilíbrio pode causar sobreaquecimento de transformadores e motores trifásicos, podendo ainda disparar erroneamente a proteção dos mesmos. Apesar do conhecimento de alguns dos seus efeitos, muito pouco se conhece sobre suas causas.

Neste contexto, este estudo visa apresentar uma metodologia de análise da sensibilidade do desequilíbrio frente às variações nas magnitudes e ângulos dos fasores de tensão. Será possível identificar a parcela do desequilíbrio que é proveniente das alterações nos módulos e ângulos das tensões, por meio de análise em separado das suas contribuições. Pode-se ainda conhecer qual das três fases contribui mais para os níveis de desequilíbrio apresentados.

São também quantificados os desvios encontrados na avaliação do desequilíbrio, quando o fator k é calculado a partir das componentes simétricas e dos outros três métodos que consideram apenas as magnitudes das tensões de linha, a saber, CIGRÉ, NEMA e IEEE.

Para o estudo de caso apresentado são utilizados dados oriundos de medições de 7 dias consecutivos em um consumidor com característica comercial, com amostras integralizadas a cada 10 minutos.

Este estudo é de importância evidente, haja vista que o conhecimento do comportamento de fenômenos como o desequilíbrio de tensão, culmina em ações que poderão minimizar os danosos efeitos do mesmo sobre os sistemas elétricos de potência e sobre as cargas.

\section{PALAVRAS-CHAVE}

Desequilíbrio de Tensão, Fator K, Quantificação, Qualificação, causas, módulos e ângulos das tensões 


\section{INTRODUÇÃO}

O setor elétrico experimenta nos últimos anos uma mudança significativa nas características das cargas que alimenta, fruto do desenvolvimento tecnológico e da expansão do uso da eletrônica de potência. Trata-se de cargas com perfil fortemente não linear, que trazem grandes perturbações ao sistema, gerando, muitas vezes, prejuízos incomensuráveis.

A partir desse cenário, e com vista na crescente taxa da demanda por serviços de excelência, esforços têm sido tomados em direção à busca perene pela eficiência, racionalização e qualidade da energia elétrica. A este último conceito está atrelada a questão dos desequilíbrios de tensão.

Nos sistemas de distribuição e transmissão observa-se comumente a presença de motores de indução, sistemas a tração e uma grande gama de cargas monofásicas com processamento eletrônico da energia. Tais elementos são, contudo, exemplos de causadores de desequilíbrios na rede elétrica.

Estes provocam, dentre outros problemas, perdas excessivas, sobreaquecimento, solicitação do isolamento e redução de vida útil de motores e transformadores e o acionamento indevido dos seus sistemas de proteção, levando à parada dos processos de produção. Ademais, sob condições de desequilíbrio, pode ocorrer a circulação de correntes harmônicas não características, tornando ainda mais árdua a tentativa de mitigação dos seus efeitos.

Nesse sentido, normas internacionais estabelecem limites para tal fenômeno. Em outra frente, inúmeros instrumentos de medição capazes de armazenar os dados segundo as exigências das normas estão à disposição no mercado. Contudo, no que diz respeito ao tratamento e análise das amostras, segue incipiente o número de ferramentas voltadas a este fim.

Nesse ínterim, a Universidade de Brasília, através do grupo de estudos da Qualidade da Energia, tem procurado contribuir por meio de investigações voltadas à quantificação e qualificação do desequilíbrio de tensão.

Este estudo em particular, visa apresentar uma metodologia de análise da sensibilidade do desequilíbrio frente às variações nas magnitudes e ângulos dos fasores de tensão. Será possível identificar a parcela do desequilíbrio que é proveniente das alterações nos módulos e ângulos das tensões, por meio de análise em separado das suas contribuições. Podese ainda conhecer qual das três fases contribui mais para os níveis de desequilíbrio apresentados.

São também quantificados os desvios encontrados na avaliação do desequilíbrio, quando o fator $\mathrm{k}$ é calculado a partir das componentes simétricas e dos outros três métodos que consideram apenas as magnitudes das tensões de linha, a saber, CIGRÉ, NEMA e IEEE.

Para o estudo de caso apresentado são utilizados dados oriundos de medições de 7 dias consecutivos em um consumidor com característica comercial, com amostras integralizadas a cada 10 minutos.

Este estudo é de importância evidente, haja vista que o conhecimento do comportamento de fenômenos como o desequilíbrio de tensão, culmina em ações que poderão minimizar os danosos efeitos do mesmo sobre os sistemas elétricos de potência e sobre as cargas.

Este estudo é de importância evidente, haja vista que o conhecimento do comportamento de fenômenos como o desequilíbrio de tensão, culmina em ações que poderão minimizar os danosos efeitos do mesmo sobre os sistemas elétricos de potência e sobre as cargas.

2. ESTUDO DA SENSIBILIDADE DOS DESEQUILÍBRIOS FRENTE A VARIAÇÕES NAS AMPLITUDES E ÂNGULOS DAS TENSÕES

Em um sistema trifásico balanceado as três tensões fase-neutro são iguais em magnitude e defasadas entre si de $120^{\circ}$ elétricos. Qualquer diferença encontrada nesta condição, seja na magnitude, na defasagem angular, ou nestes dois parâmetros simultaneamente, caracteriza um sistema desequilibrado.

$\mathrm{O}$ desequilíbrio de tensão (fator $\mathrm{K}$ ) é definido, fazendo-se uso das componentes simétricas, como a relação entre a componente de seqüência negativa e a componente de seqüência positiva, em porcentagem desta última.

$$
K \%=\frac{V_{-}}{V_{+}} \times 100
$$


Onde V. e $V_{+}$são os módulos das componentes de seqüência negativa $\mathrm{e}$ positiva, respectivamente.

Entretanto, em decorrência da indisponibilidade dos valores de ângulos dos fasores das tensões em alguns equipamentos de medição, foram criados 3 métodos alternativos para a determinação do valor do fator $K$, que levam em consideração apenas as amplitudes das tensões trifásicas. São eles, NEMA, CIGRÉ e IEEE.

O método NEMA é definido como a relação entre o máximo desvio entre as tensões de linha e a média das tensões, e a média aritmética dos módulos das tensões.

$$
K \%=\frac{\text { máximo desvio entre as tensões e a média }}{\text { média aritmética das tensões trifásicas }}
$$

No método do CIGRÉ, o K\% é obtido a partir de uma grandeza adimensional, a saber:

$$
K \%=\sqrt{\frac{1-\sqrt{3-6 \beta}}{1+\sqrt{3-6 \beta}}} \times 100
$$

Onde,

$$
\beta=\frac{\left|V_{a b}\right|^{4}+\left|V_{b c}\right|^{4}+\left|V_{c a}\right|^{4}}{\left(\left|V_{a b}\right|^{2}+\left|V_{b c}\right|^{2}+\left|V_{c a}\right|^{2}\right)^{2}}
$$

Por fim, o IEEE recomenda que o desequilíbrio de tensão pode ser obtido pela razão da maior diferença entre as tensões de linhas medidas e o somatório das mesmas.

$$
K \%=\frac{3(\text { Vmáx }-V \min )}{V_{a b}+V_{b c}+V_{c a}} \times 100
$$

Em estudos anteriores realizados na Universidade de Brasília, observou-se que, normalmente, os valores de desequilíbrio obtidos pelo método das componentes simétricas e por cada um dos três métodos alternativos são distintos entre si. $\mathrm{Na}$ verdade, sabe-se que a imprecisão ou não no uso destes métodos está ligada às características dos locais em estudo, quais sejam, ângulos e magnitudes das tensões.

Neste contexto, serão efetuadas simulações que levam à percepção da relevância de se considerar ou não os ângulos das tensões na quantificação do desequilíbrio. A partir dos resultados obtidos, é possível avaliar a sensibilidade do $\mathrm{K} \%$ em função das alterações nos ângulos e magnitudes. a) Comportamento do fator $K$ em função da variação, em separado, dos ângulos e das amplitudes das tensões:

Neste trabalho, a situação ideal é considerada com amplitudes das tensões fase-neutro em $220 \mathrm{~V}$ e defasagem angular entre fases de $120^{\circ}$ elétricos entre si.

Para conhecimento do comportamento do desequilíbrio em função da variação do módulo e dos ângulos das tensões, efetuaram-se simulações com variações pré-estabelecidas.

Primeiramente, é apresentado o gráfico com os valores de desequilíbrio para variação da magnitude de uma fase entre $180 \mathrm{~V}$ e $260 \mathrm{~V}$, em passos de $1 \mathrm{~V}$, calculado pelos 4 métodos (Figura I). Em seguida, é plotado o gráfico com os valores de desequilíbrio para variação no ângulo de uma fase entre $80^{\circ}$ e $160^{\circ}$, em intervalos de $1^{\circ}$ (Figura II).

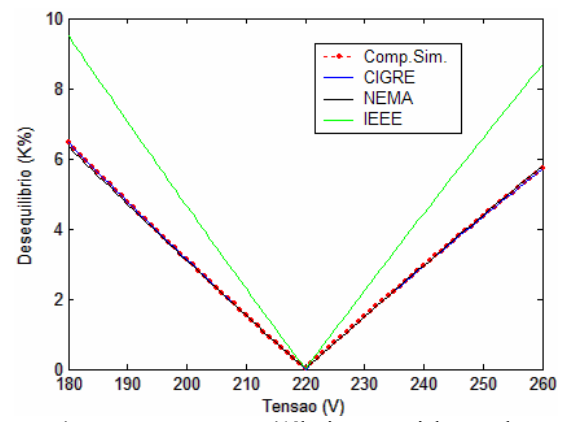

Figura I - Desequilíbrio considerando variação na magnitude de uma fase

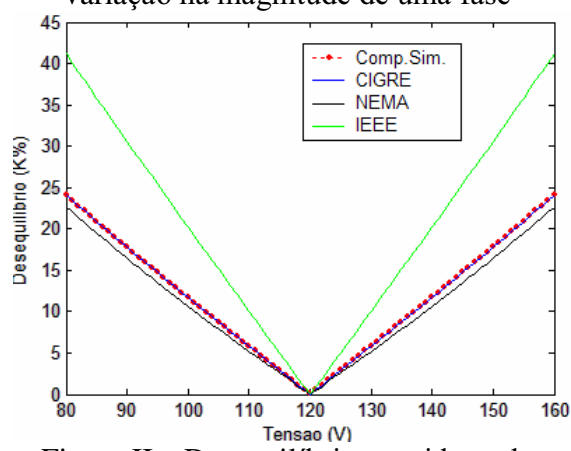

Figura II - Desequilíbrio considerando variação no ângulo de uma fase

Da comparação entre as figuras I e II, é notório que o fator $\mathrm{K}$ é mais sensível às variações nos ângulos das tensões às variações nas amplitudes. No método das componentes simétricas, quando da alteração da magnitude, o desequilíbrio chegou a cerca de $6.5 \%$, enquanto no caso 
do ângulo tivemos $\mathrm{K} \%$ aproximadamente igual a $24 \%$. Verifica-se também que para todo o intervalo de variação na magnitude da tensão de uma fase, os valores de desequilíbrio calculados pelos métodos CIGRÉ, NEMA e componentes simétricas são praticamente os mesmos. O método do IEEE manteve sempre valores mais elevados do fator $\mathrm{K}$.

Porém, chama-se a atenção para o fato de que o desequilíbrio considerando apenas a magnitude não é simétrico em relação às variações para valores menores e maiores de $220 \mathrm{~V}$. Os valores obtidos entre 180V-220V são diferentes dos correspondentes entre $220 \mathrm{~V}-260 \mathrm{~V}$. A elevação de $1 \mathrm{~V}$ de tensão produz maiores valores de desequilíbrio à redução de $1 \mathrm{~V}$ do padrão nominal.

Já na análise dos resultados quando da comparação entre os métodos para a variação angular, nota-se um aumento no desvio existente entre os valores calculados pelos diferentes métodos à medida que se altera o desequilíbrio angular. O comportamento é simétrico em torno de $120^{\circ}$.

$\mathrm{Na}$ comparação entre os métodos NEMA e componentes simétricas, nos valores de $80^{\circ}$ e $160^{\circ}$, a diferença absoluta entre os valores calculados chegou a $1.42 \%$ de desequilíbrio, o que configura um erro bastante significativo. Deste modo, comprova-se ser inadequado o uso dos métodos alternativos para a quantificação do fator $\mathrm{K}$, quando se tratar de locais que apresentem alterações angulares relevantes, podendo isto levar a um entendimento iníquo das condições do sistema.

A figura III e a tabela I mostram o resultado da variação conjunta da amplitude e ângulo da tensão de uma fase, nos mesmos intervalos utilizados nos casos anteriores, a partir do método das componentes simétricas.

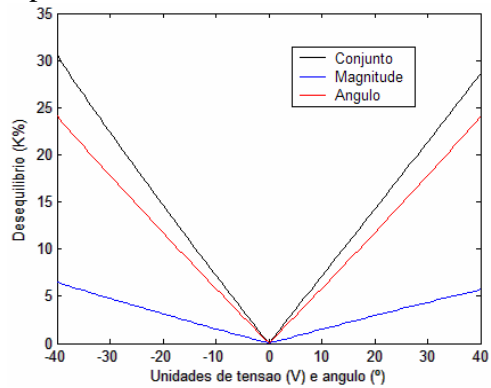

Figura III - Desequilíbrio considerando variação conjunta na amplitude e no ângulo de uma fase
Tabela I - Alguns valores encontrados nas simulações da Fig. III

\begin{tabular}{|c|l|l|l|}
\hline \multirow{2}{*}{ Unidades } & \multicolumn{3}{|c|}{ Variação } \\
\cline { 2 - 4 } & Mag.(V) & Âng. $\left(^{\circ}\right)$ & Conj. \\
\hline $\mathbf{V} /{ }^{\circ}$ & \multicolumn{3}{|c|}{ K\% } \\
\hline $207 / 107$ & 2.0093 & 7.5902 & 9.4445 \\
\hline $210 / 110$ & 1.5385 & 5.8301 & 7.2388 \\
\hline $212 / 112$ & 1.2270 & 4.6605 & 5.7783 \\
\hline $216 / 116$ & 0.6098 & 2.3279 & 2.8777 \\
\hline $218 / 118$ & 0.3040 & 1.1637 & 1.4363 \\
\hline $220 / 120$ & 0.0000 & 0.0000 & 0.0000 \\
\hline $222 / 122$ & 0.3021 & 1.1637 & 1.4319 \\
\hline $224 / 124$ & 0.6024 & 2.3279 & 2.8601 \\
\hline $228 / 128$ & 1.1976 & 4.6605 & 5.7077 \\
\hline $230 / 130$ & 1.4925 & 5.8301 & 7.1283 \\
\hline $233 / 133$ & 1.9316 & 7.5902 & 9.2572 \\
\hline $234 / 134$ & 2.0772 & 8.1788 & 9.9665 \\
\hline
\end{tabular}

Da análise da figura III e da tabela I, é possível afirmar que, a menos de um desvio muito pequeno, a soma das contribuições individuais de magnitude e ângulo para o desequilíbrio é igual ao valor de desequilíbrio para o caso simultâneo (magnitude e ângulo desequilibrados).

Ainda com relação à tabela I, nota-se que o valor do $\mathrm{K} \%$ referente às alterações na amplitude representa cerca de $20 \%$ do valor do desequilíbrio apresentado na situação de variação conjunta, enquanto as alterações no ângulo representam $80 \%$.

O patamar comumente utilizado pelas normas para qualificação do desequilíbrio é de $\mathrm{K}=2 \%$. Observa-se na tabela I que este valor foi atingido com a elevação de $13 \mathrm{~V}$ na amplitude e em aproximadamente $3.5^{\circ}$ no ângulo. No caso de uma redução, é necessária uma alteração de cerca de $14 \mathrm{~V}$ na magnitude, permanecendo $3.5^{\circ}$ no ângulo. Deste modo, é teoricamente possível afirmar que aproximadamente 14V de alteração na amplitude de uma fase provoca o mesmo efeito, em termos de desequilíbrio, a $3.5^{\circ}$ no ângulo, ou ainda que $4 \mathrm{~V}$ equivalem à $1^{\circ}$.

Mais uma vez, evidencia-se uma maior sensibilidade do $\mathrm{K}$ aos ângulos às amplitudes das tensões.

As metodologias apresentadas em seguida prestam-se para avaliação dos pontos em estudo e auxiliam na identificação e resolução dos problemas relacionados aos desequilíbrios. 
3. METODOLOGIA DE ANÁLISE DOS DESEQUILÍBRIOS DE TENSÃO A PARTIR DA INVESTIGAÇÃO, EM SEPARADO, DOS ÂNGULOS E MAGNITUDES DAS TENSÕES:

Nesta seção será apresentada uma metodologia que busca identificar, para um dado local, o comportamento dos desequilíbrios de tensão, por meio de análise separada das magnitudes e ângulos das tensões. Espera-se conhecer, para um banco de dados específico, a principal causa dos desequilíbrios de tensão, ou seja, se esta é proveniente de distúrbios, majoritariamente, nas magnitudes ou nos ângulos dos fasores de tensão.

No estudo de caso apresentado é quantificada a porcentagem $\mathrm{d}$ o valor do desequilíbrio total que é oriundo do desbalanço nas magnitudes e a porcentagem devido aos ângulos. Ressaltase que na seção precedente foi verificado teoricamente que o valor de desequilíbrio total é a soma das contribuições individuais do desequilíbrio causado pelo módulo e pelos ângulos das tensões.

É possível ainda identificar qual das três fases mais influencia no valor de desequilíbrio, permitindo que ações corretivas possam ser feitas de maneira mais eficaz, diminuindo os danosos efeitos do supracitado fenômeno sobre o sistema de potência e suas cargas.

A metodologia foi construída com auxílio de uma linguagem de programação computacional. Primeiramente, consiste em "amarrar" o banco de dados com valores de ângulos ideais e calcular o $\mathrm{K} \%$ levando em conta apenas as magnitudes das tensões medidas. Em seguida, o mesmo procedimento é realizado, mantendo-se agora as magnitudes ideais e calculando o $\mathrm{K} \%$ com os valores reais dos ângulos medidos.

Os valores ideais adotados foram de $220 \mathrm{~V}$ para a magnitude da tensão e defasamento angular de $120^{\circ}$ entre si.

O banco de dados utilizado é advindo de uma subestação que alimenta cargas com característica comercial, com medição de 7 dias consecutivos (1 semana), durante o mês de novembro de 2005. Neste período, o $\mathrm{P} 95 \%$ (valor com probabilidade de $95 \%$ de não ser excedido) foi aproximadamente $0.56 \%$, calculado a partir das componentes simétricas.

A figura IV ilustra o perfil do fator $\mathrm{K} \%$ durante os 7 dias em estudo, considerando apenas os valores reais de magnitude medidos.

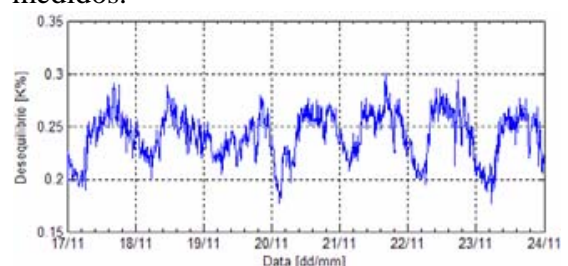

Figura IV-Desequilíbrio considerando apenas os valores de amplitude medidos e ângulos ideais

Para este caso, o valor de P95\% encontrado foi de $0.2734 \%$.

A figura $\mathrm{V}$ apresenta o perfil do fator $\mathrm{K} \%$ durante $\mathrm{O}$ período estudado, considerando apenas os valores reais de ângulos medidos.

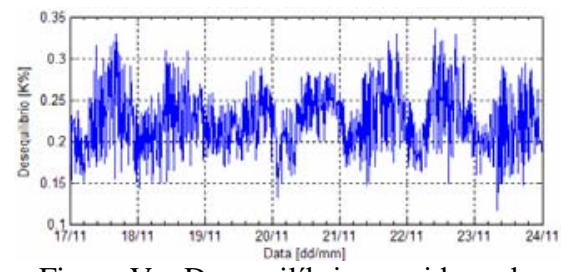

Figura V - Desequilíbrio considerando apenas os valores de ângulo medidos e amplitudes ideais

Das figuras IV e $\mathrm{V}$ nota-se que $\mathrm{o}$ desequilíbrio devido aos ângulos possui um perfil mais variável com o tempo. Á propósito, a faixa de variação no segundo caso é maior. De fato, os valores de $\mathrm{k}$ oscilam entre $0.12 \%$ a $0.33 \%$, enquanto para a variação oriunda das magnitudes tem-se $0.18 \%$ e $0.3 \%$.

Um fato merece destaque: os maiores valores do $\mathrm{K} \%$ referentes às alterações nos ângulos ocorreram no horário de funcionamento da carga da instalação, mostrando que a solicitação da rede provocou um defasamento não simétrico entre os ângulos dos fasores.

Considerando-se ainda a figura $\mathrm{V}$, ressalta-se que o valor de $\mathrm{P} 95 \%$ encontrado foi de $0.2887 \%$. Este valor representa cerca de $51 \%$ do desequilíbrio total, enquanto a variação nas magnitudes culmina em aproximadamente $49 \%$. Estes valores sugerem que, para o local em estudo, o desequilíbrio é proveniente de contribuições equivalentes dos desbalanços nas magnitudes e nos ângulos.

A análise a seguir considera a utilização dos valores medidos de uma fase do banco de dados (magnitude e ângulo) enquanto 
as outras duas são mantidas, em simulação, como ideais. Esse processo permite a verificação de qual fase mais se distancia da situação nominal.

$\mathrm{Na}$ figura VI é ilustrado o perfil do $\mathrm{K}$ considerando os valores reais medidos na fase A, com as fases B e C em condições ideais.

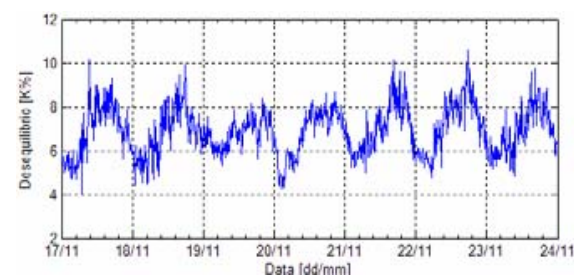

Figura VI - Desequilíbrio considerando os valores medidos da fase A (ângulo e magnitude)

Para esta condição o P95\% calculado foi de $8.732 \%$.

$\mathrm{Na}$ figura VII apresenta-se o perfil do K considerando os valores reais medidos na fase B, com as fases A e C em condições ideais.

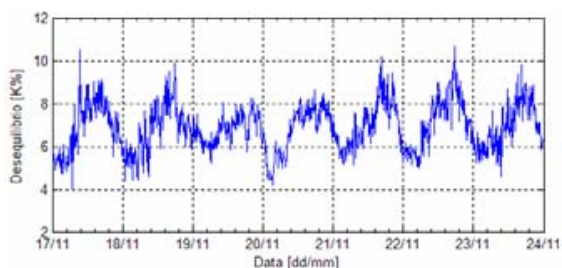

Figura VII - Desequilíbrio considerando os valores medidos da fase B (ângulo e magnitude)

Da figura VII com o auxílio de uma ferramenta computacional tem-se que o P95\% calculado foi de $8.716 \%$.

$\mathrm{Na}$ figura VIII apresenta-se o perfil do $\mathrm{K}$ considerando os valores reais medidos na fase $\mathrm{B}$, com as fases $\mathrm{A}$ e $\mathrm{C}$ em condições ideais.

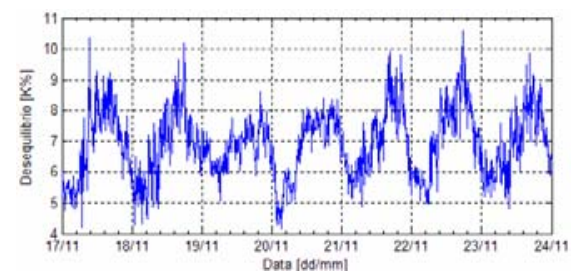

Figura VIII - Desequilíbrio considerando os valores medidos da fase C (ângulo e magnitude)
Das figuras VI, VII e VIII tem-se que a fase $\mathrm{C}$ foi a que apresentou o maior valor de $\mathrm{P} 95 \%$, sendo este igual a $8.765 \%$.

A figura IX e a tabela II trazem os resultados dos cálculos das estatísticas adquiridas a partir da análise da simulação realizada em cada fase.

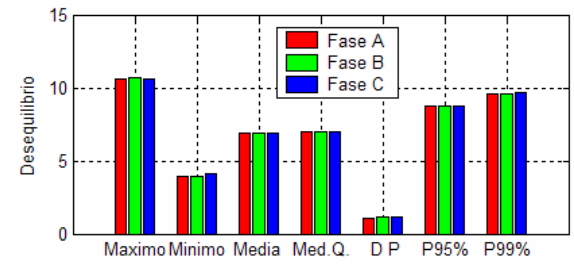

Figura IX - Estatísticas dos desequilíbrios individuais por cada fase

Tabela II - Estatísticas das análises individuais das fases

\begin{tabular}{|c|c|c|c|}
\hline Fases $=>$ & A & B & C \\
\hline Máximo & 10.57 & 10.66 & 10.61 \\
\hline Mínimo & 3.969 & 3.960 & 4.153 \\
\hline Média Q. & 6.987 & 6.880 & 6.994 \\
\hline Desvio P. & 1.110 & 1.114 & 1.111 \\
\hline P95\% & 8.732 & 8.716 & 8.765 \\
\hline
\end{tabular}

A fase $\mathrm{C}$ apresentou os maiores valores de média quadrática e de P95\%. Observa-se, porém, que os patamares são muito próximos, apontando para um comportamento semelhante entre as fases.

Caso se verifique que os valores apresentados por uma das fases são superiores aos das demais, um detalhamento da análise é sugerido. Nessas situações, pode-se avaliar o $\mathrm{K} \%$ considerando as variações, separadamente dos módulos da fase investigada, ou dos ângulos, mantendo-se as demais fases ideais.

Este procedimento permite, a partir da detecção da fase que mais apresenta problemas, verificar se os seus distúrbios estão nos valores de magnitude ou de ângulo. Deste modo, as ações a serem tomadas em provimento da mitigação dos níveis de desequilíbrio, são facilmente direcionadas para os principais agentes deste fenômeno no local em estudo.

Ainda com relação aos esforços para a identificação da(as) fase(es) que mais compromete(em) a qualidade da rede, em relação aos desequilíbrios, prestam-se os gráficos a seguir.

As figuras $X$, XI e XII exibem, respectivamente, $\mathrm{o}$ perfil do $\mathrm{K}$ considerando os valores reais de módulos 
e ângulos medidos nas fase "A e B", "B e C" e "C e A".

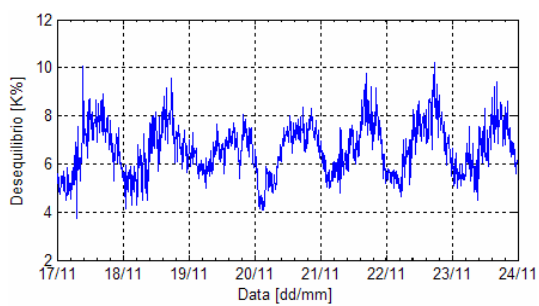

Figura $\mathrm{X}$ - Desequilíbrio considerando os valores medidos das fases A e B (ângulo e magnitude)

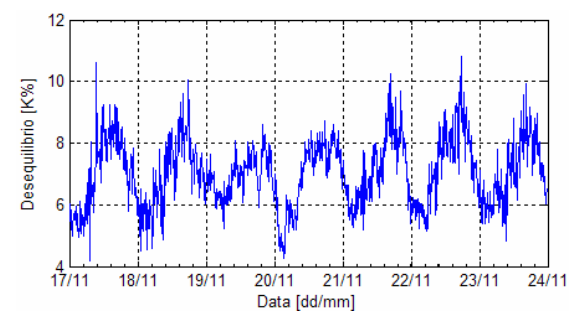

Figura XI - Desequilíbrio considerando os valores medidos das fases B e C (ângulo e magnitude)

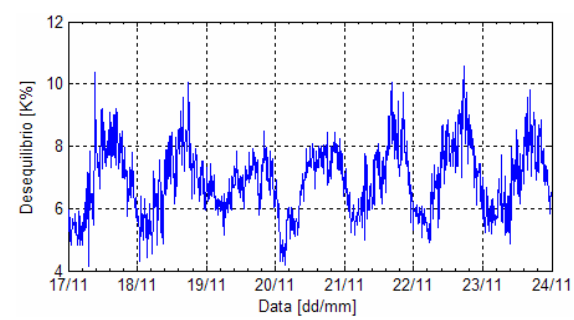

Figura XII - Desequilíbrio considerando os valores medidos das fases $\mathrm{Ce} \mathrm{A}$ (ângulo e magnitude)

Nestes casos, as fases C, A e B, respectivamente, foram mantidas em condições ideais. Nota-se, mais uma vez, que os valores e os perfis são praticamente os mesmos, comprovando uma semelhança entre as contribuições das fases para os valores totais de desequilíbrio.

\section{CONCLUSÕES}

Neste trabalho, foi avaliada a sensibilidade do desequilíbrio de tensão frente às variações nas magnitudes e nos ângulos dos fasores de tensão. Foram feitas quantificações das suas contribuições individuais, comparando-as entre si e com o caso de variação simultânea.

Verificou-se teoricamente que o desequilíbrio é mais sensível à variação dos ângulos às alterações nas magnitudes. Nos intervalos considerados neste estudo, constatou-se que a alteração de $4 \mathrm{~V}$ em uma fase produz o mesmo efeito que a alteração de apenas $1^{\circ}$, também em uma fase.

Realizou-se uma comparação dos resultados oriundos de cálculos do $\mathrm{K} \%$ a partir do método das componentes simétricas com os obtidos nos métodos CIGRÉ, NEMA e IEEE, que utilizam apenas os módulos das tensões de linha.

Constatou-se que, variando-se somente os módulos das tensões, os valores obtidos foram muito semelhantes, em especial no método CIGRÉ. Já nas alterações angulares, o desvio entre os resultados cresce à medida que se aumenta $o$ desequilíbrio angular.

Por fim, verifica-se que a metodologia destinada à análise do desequilíbrio examinando, em separado, os ângulos e magnitudes das tensões, contribui para investigação das causas deste fenômeno no local a ser estudado.

Da utilização da metodologia supradita, mostrou-se ser possível identificar a parcela do desequilíbrio proveniente das alterações nos módulos e nos ângulos das tensões, individualmente. Ademais, podese conhecer qual das fases mais contribui para os níveis de $\mathrm{K} \%$ apresentados.

Deste modo, a metodologia exposta auxilia nos trabalhos voltados à mitigação do distúrbio, direcionando os esforços para o foco principal do problema.

Indubitavelmente, este trabalho é de grande importância aos interessados na quantificação e qualificação do desequilíbrio de tensão, cooperando para diminuição dos danosos efeitos do mesmo sobre o sistema elétrico e suas cargas.

\section{BIBLIOGRAFIA}

[1] S. Pinto, Marcos G.; F. Filho, Anésio de L.; Oliveira, Marco A. G.; Ferramenta Computacional para Quantificação $e$ Qualificação dos Desequilíbrios de Tensão, VI SBQEE, Brasil, 2005.

[2] Dugan, R. C.; Mcgranaghan, M. F.; Beauty, H. W.; Electrical Power System Quality, EUA, 1996. 


\section{APÊNDICE E}

SEPOPE - X Simpósio de Especialistas em Planejamento da Operação e Expansão Elétrica, 21 a 25 de maio de 2006, Florianópolis, Brasil.

"Análise dos Desequilibrios de Tensão no Sistema ELETRONORTE Subestações em $230 \mathrm{kV}$ '. 


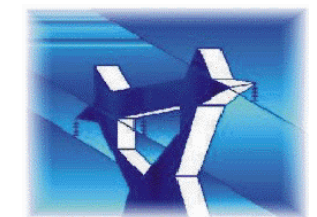

X SEPOPE
X SIMPÓSIO DE ESPECIALISTAS EM PLANEJAMENTO DA OPERAÇÃO

E EXPANSÃO ELÉTRICA

X SYMPOSIUM OF SPECIALISTS IN ELECTRIC OPERATIONAL AND EXPANSION PLANNING

21 a 25 de maio de 2006

May $-21^{\text {st }}$ to $25^{\text {th }}-2006$

FLORIANÓPOLIS (SC) - BRASIL

\title{
Análise dos Desequilíbrios de Tensão no Sistema ELETRONORTE Subestações em 230 kV
}

\author{
*Josias M. de Araújo, Onivaldo A. Fernandes, Cecília M. Francisco, Anésio de L. F. \\ Filho, Marco A. G. de Oliveira, Marcos G. da S. Pinto \\ * ELETRONORTE, Universidade de Brasília - UnB \\ Brasil
}

\section{RESUMO}

Embora a questão Qualidade da Energia Elétrica venha sendo tratada por especialistas da área, segue incipiente o número de trabalhos de investigação voltados a Desequilíbrio de Tensão.

Neste ínterim, este estudo objetiva analisar, quantificar e qualificar os aspectos relacionados a tal fenômeno em redes de $230 \mathrm{kV}$ da Eletronorte. Os resultados aqui ilustrados tornar-se-ão parte de um banco de dados contendo valiosas informações quanto às amplitudes e o comportamento dos desequilíbrios nas localidades examinadas, além de se prestarem à minimização dos danosos efeitos dos mesmos sobre o sistema de potência. Será efetuada, conjuntamente, uma análise dos níveis e perfis do desequilíbrio nas subestações de 3 consumidores industriais, a partir de medições de 12 dias consecutivos em cada ponto.

Inicialmente, são descritos os 4 métodos existentes para o cálculo do desequilíbrio de tensão (fator K). A quantificação do desequilíbrio é exibida a partir de uma metodologia que visa identificar o período mínimo necessário de medição para a caracterização estatística dos dados. Em seguida, é posta à apreciação a qualificação do fator $\mathrm{K}$, segundo as principais normas mundialmente conhecidas.

\section{PALAVRAS-CHAVE}

Desequilíbrio de Tensão, Fator K, Quantificação, Qualificação, Sistema Eletronorte. 


\section{Introdução}

O avanço da eletrônica de potência e o acentuado crescimento de cargas não-lineares no sistema elétrico têm gerado uma preocupação cada vez maior com os problemas associados ao seu suprimento. Além de provocarem deterioração e poluição na rede elétrica, essas cargas são, em sua maioria, altamente sensíveis e vulneráveis à qualidade de sua tensão de alimentação.

Embora os estudos direcionados a qualidade da energia estejam avançando, seguem incipientes as pesquisas voltadas para o desequilíbrio de tensão. Sabe-se, porém, que a presença de altos níveis de desequilíbrio pode acarretar sérios danos ao sistema, principalmente em decorrência da circulação de correntes de seqüência zero, como é o caso da terceira harmônica e seus múltiplos. Adicionalmente, tal fenômeno pode causar sobreaquecimento, solicitação do isolamento e redução da vida útil de equipamentos como transformadores e motores trifásicos.

Dentre as causas de desequilíbrios em sistemas de transmissão está elencada a presença de subestações de onde originam-se linhas de alimentação de usinas siderúrgicas e de mineração que fazem uso de fornos a arco e de um grande número de máquinas rotativas.

Neste contexto, este estudo efetua um levantamento dos níveis de desequilíbrio em três grandes consumidores do sistema Eletronorte em $230 \mathrm{kV}$. Trata-se de medições de 12 dias consecutivos no mês de fevereiro de 2006. A comparação dos resultados nestes locais é feita por meio de tabelas, gráficos e do uso de um ferramental estatístico (valores máximos, mínimos, média aritmética e quadrática, desvio padrão e valores com probabilidade de $95 \%$ e $99 \%$ de não serem excedidos). Serão traçados gráficos do perfil do desequilíbrio em função do tempo, podendo-se ainda avaliar questões como a existência ou não de similaridade no comportamento do desequilíbrio entre os diversos dias de medição.

Por fim, é efetuada uma análise comparativa dos indicadores adquiridos quando da qualificação dos locais com os patamares estabelecidos pelas normas e recomendações nacionais e internacionais.

Este trabalho é de importância evidente, tendo considerado que o conhecimento do comportamento de fenômenos como o desequilíbrio de tensão, culmina em ações que poderão minimizar os danosos efeitos dos mesmos sobre os sistemas de transmissão e sobre os diversos tipos de equipamentos. Além disto, os gráficos expostos se prestam para formação de um banco de dados contendo valiosas informações quanto às amplitudes e o perfil dos desequilíbrios de tensão nos locais supramencionados.

\section{Desequilíbrio de Tensão}

Os desequilíbrios presentes nas redes elétricas são fenômenos referentes a alterações dos padrões trifásicos de sistemas de transmissão/distribuição. É a condição na qual as fases apresentam tensão com módulos diferentes entre si, ou defasagem angular entre as fases diferentes de $120^{\circ}$ elétricos ou ainda, as duas condições simultaneamente.

Como alguns instrumentos de medição não disponibilizam os ângulos dos fasores, foram criadas formas alternativas para quantificação do desequilíbrio de tensão, aqui denominado de Fator $\mathrm{K}$, ou simplesmente K Tais métodos serão, detalhadamente, descritos a seguir.

\subsection{Métodos de Cálculo do Desequilíbrio (Fator K)}

Componentes Simétricas: Neste método o desequilíbrio de tensão é definido pela razão entre os módulos das tensões de seqüência negativa e positiva, em porcentagem, conforme Eq.(2). No Brasil, este método é o adotado pelo ONS (Operador Nacional do Sistema).

Onde:

$\mathrm{V}_{\text {. }} \rightarrow$ Módulo da tensão de seqüência negativa;

$\mathrm{V}_{+} \rightarrow$ Módulo da tensão de seqüência positiva; 


$$
K \%=\frac{V_{-}}{V_{+}} \times 100
$$

CIGRÉ (Congress Internationale des Grand Réseaux Électriques a Haute Tension): Emprega-se uma expressão para o fator de desequilíbrio a partir de uma grandeza adimensional que correlaciona as tensões de linha.

$$
K \%=\sqrt{\frac{1-\sqrt{3-6 \beta}}{1+\sqrt{3-6 \beta}}} \times 100
$$

Onde:

$$
\beta=\frac{\left|V_{a b}\right|^{4}+\left|V_{b c}\right|^{4}+\left|V_{c a}\right|^{4}}{\left(\left|V_{a b}\right|^{2}+\left|V_{b c}\right|^{2}+\left|V_{c a}\right|^{2}\right)^{2}}
$$

$V_{a b}, V_{b c}, V_{c a} \rightarrow$ Módulo das tensões trifásicas;

NEMA: A norma NEMA-MG-14.34, a fim de se quantificar o desequilíbrio, define o fator K como a relação entre o máximo desvio da tensão média e a tensão média, tendo como referência às tensões de linha.

$$
K \%=\frac{\Delta V}{V_{m}} \times 100
$$

Onde:

$\Delta \mathrm{V} \rightarrow$ Máximo desvio das tensões de linha em relação ao valor médio;

$\mathrm{V}_{\mathrm{m}} \rightarrow$ Média aritmética dos módulos das tensões trifásicas;

IEEE: Por fim, o IEEE recomenda que o desequilíbrio de tensão deve ser obtido por uma relação que expressa a maior diferença entre as tensões de linhas medidas e o somatório das mesmas.

$$
K \%=\frac{3(V m a ́ x-V \min )}{V_{a b}+V_{b c}+V_{c a}} \times 100
$$

Onde:

Vmáx $\rightarrow$ Maior valor dentre os módulos das tensões trifásicas;

Vmín $\rightarrow$ Menor valor dentre os módulos das tensões trifásicas; 
$V_{a b}, V_{b c}, V_{c a} \rightarrow$ Módulo das tensões trifásicas;

Neste trabalho, as componentes simétricas constituem a metodologia aplicada no cálculo do fator $\mathrm{K}$.

\subsection{Normas e Recomendações}

Apresenta-se na Tabela I, os índices de conformidade retirados das normas e recomendações utilizadas ao redor do mundo para o controle da Qualidade da Energia Elétrica, com relação aos desequilíbrios de tensão (fator K). No Brasil tem-se os Procedimentos de Rede que determinam como limite o patamar de 2\%. Quando da determinação do indicador a ser comparado com tal limite deve-se:

1) identificar qual é o valor com probabilidade de $95 \%$ de não ser excedido calculado considerando 1 dia, para todos os 7 dias em análise.

2) o valor indicador corresponde ao maior dentre os sete adquiridos anteriormente, em base diária.

Tabela I: Índices de conformidade

\begin{tabular}{|c|c|}
\hline Recomedação / Norma & Limite \\
\hline IEC & $2 \%$ \\
\hline GCOI/GCPS & $2 \%$ \\
\hline CENELEC & $2 \%$ \\
\hline NRS-048 & $2 \%$ \\
\hline NTSCE & --- \\
\hline ANSI & $3 \%$ \\
\hline
\end{tabular}

A CENELEC e a NRS-048 permitem, em algumas áreas onde parte dos consumidores são monofásicos ou bifásicos, que o índice de conformidade seja igual a $3 \%$.

Verifica-se que a maioria das normas limita em $2 \%$ o desequilíbrio de tensão. Isto mostra que os índices de conformidade convergem para este valor.

\section{Estudo de Caso}

Neste tópico serão apresentados resultados de análises de amostras colhidas em três locais simultaneamente, aqui designados como consumidores A, B e C.

O consumidor A é uma usina metalúrgica localizada em Breu Branco/PA. Nesta empresa se produz silício metálico e liga de alumínio. A alimentação segue de Tucuruí em $230 \mathrm{kV}$.

O consumidor B é um complexo de produção alumina-alumínio. A energia demandada neste estabelecimento representa $15 \%$ do que é gerado em Tucuruí. Entretanto, a tensão de alimentação de $230 \mathrm{kV}$, é oriunda da subestação Vila do Conde.

$\mathrm{O}$ consumidor $\mathrm{C}$ é uma empresa de mineração de cobre, com exploração e aproveitamento de jazidas minerais no município de Canaã dos Carajás/PA. Sua alimentação vem de Tucuruí por meio da Subestação Marabá, em 230 kV. 
As medições ocorreram entre os dias 1 a 12 de Fevereiro de 2006. A frequência de aquisição dos dados coletados foi de 10 minutos, segundo o demandado pelos Procedimentos de Rede.

Inicialmente, serão ilustrados os resultados numéricos das quantificações estatísticas dos valores de desequilíbrio medidos em todo o período. Em seguida, são expostos os gráficos do fator $\mathrm{K}$ versus tempo de medição com vistas ao atendimento dos objetivos almejados.

\subsection{Quantificação do Desequilíbrio}

A tabela II mostra os resultados estatísticos, onde $\mathrm{P} 95 \%$ e P99\% representam, respectivamente, os valores com probabilidade de $95 \%$ e $99 \%$ de não serem excedidos.

Tabela II - Valores de desequilíbrio medidos

\begin{tabular}{|c|c|c|c|}
\hline Valores Estatísticos (K\%) & $\begin{array}{c}\text { Consumidor } \\
\text { A }\end{array}$ & $\begin{array}{c}\text { Consumidor } \\
\text { B }\end{array}$ & $\begin{array}{c}\text { Consumidor } \\
\text { C }\end{array}$ \\
\hline Máximo & 0.4233 & 0.3477 & 0.4745 \\
\hline Mínimo & 0.1835 & 0.09563 & 0.05811 \\
\hline Média Aritmética & 0.2908 & 0.2252 & 0.2353 \\
\hline Média Quadrática & 0.2915 & 0.2325 & 0.2628 \\
\hline Desvio Padrão & 0.01932 & 0.05787 & 0.117 \\
\hline P95\% & 0.3206 & 0.3213 & 0.4373 \\
\hline P99\% & 0.3462 & 0.3379 & 0.4564 \\
\hline
\end{tabular}

Em uma análise preliminar, nota-se da tabela II que todos os três locais estiveram com os níveis de desequilíbrio dentro dos requesitos ilustrados na tabela I. Nota-se pequenos valores de desvio padrão, sobretudo se comparados com medições em consumidores de baixa tensão, onde a variação da carga com o tempo é mais acentuada. Dadas as semelhanças técnicas existentes entre estes locais, observa-se que os valores da tabela são muito próximos entre si.

A figura 1 apresenta o gráfico com o comportamento do fator $\mathrm{K}$ durante todos os dias em estudo, medidos no consumidor A.

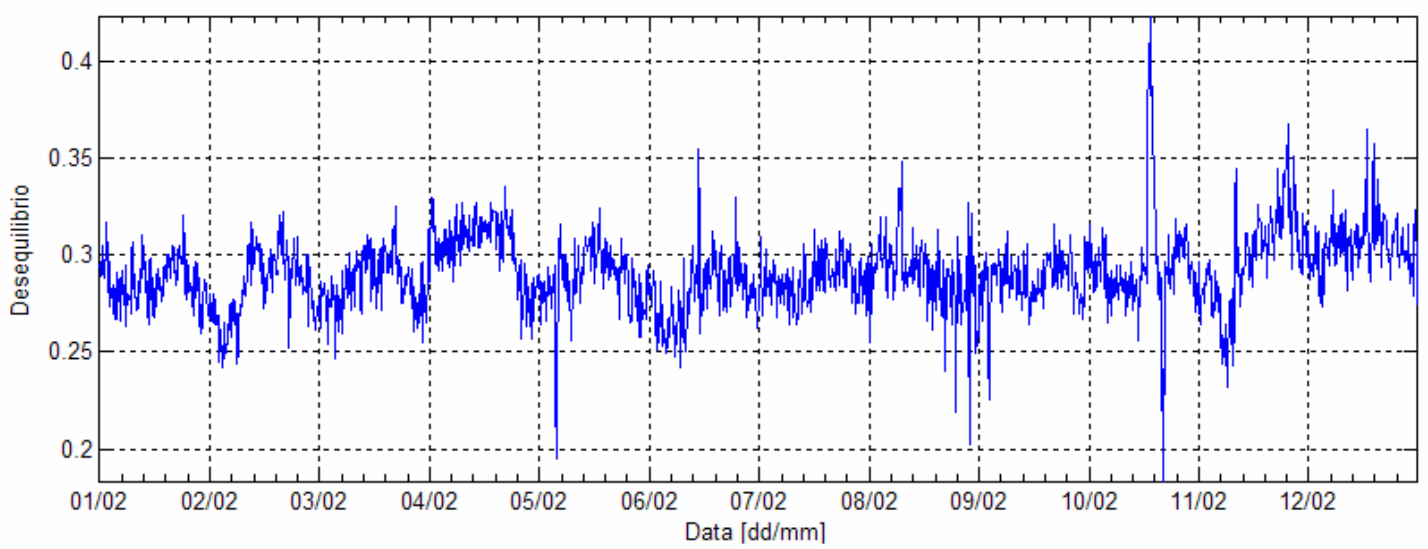

Figura 1 - Fator K versus período de medição - Consumidor A 
Na figura 1, observa-se um comportamento uniforme em torno de $0.3 \%$, com apenas um valor de fator $\mathrm{K}$ próximo de $0.5 \%$. Da análise do perfil, observa-se discrepantes valores do fator $\mathrm{K}$ para todo o período ilustrado, o que justifica a diferença entre o valor máximo constatado e o P95\%.

A figura 2 ilustra o gráfico com o comportamento do fator $\mathrm{K}$ durante todos os dias em estudo, medidos no consumidor B.

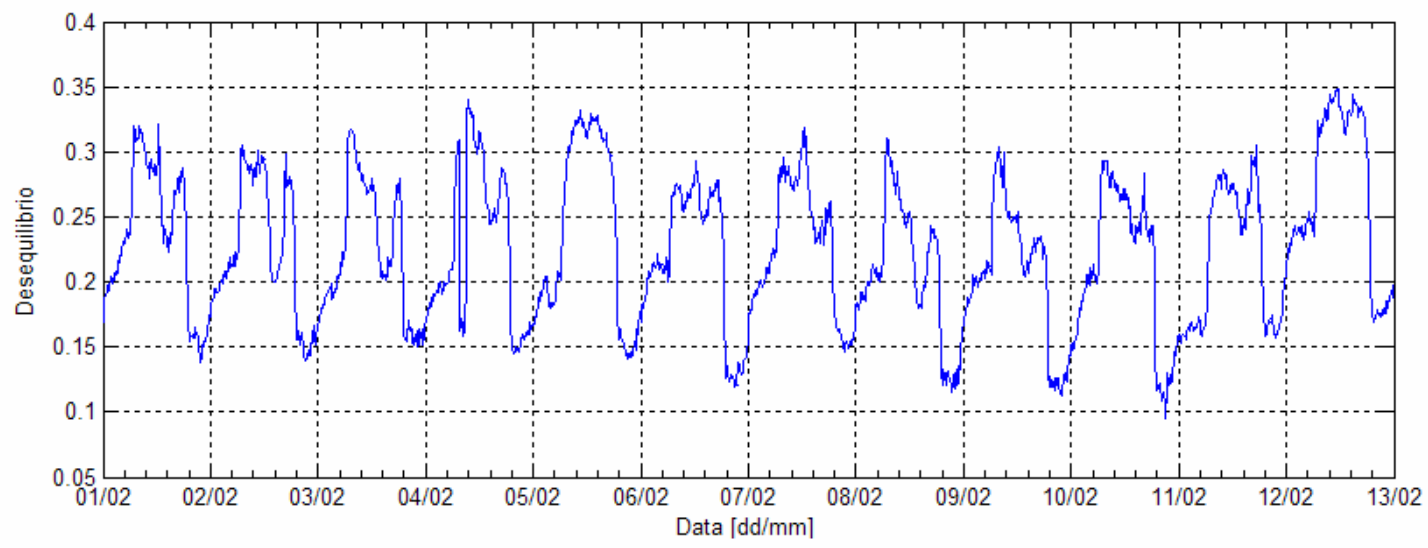

Figura 2 - Fator K versus período de medição - Consumidor B

Da figura 2 percebe-se que o perfil apresentado é característico da maioria das cargas comerciais/industriais dos sistemas elétricos. Durante o dia no horário comercial, o desequilíbrio atinge índices mais elevados, neste caso da ordem de $0.3 \%$.

A figura 3 apresenta o gráfico com o comportamento do fator $\mathrm{K}$ durante todos os dias em estudo, medidos na consumidor $\mathrm{C}$.

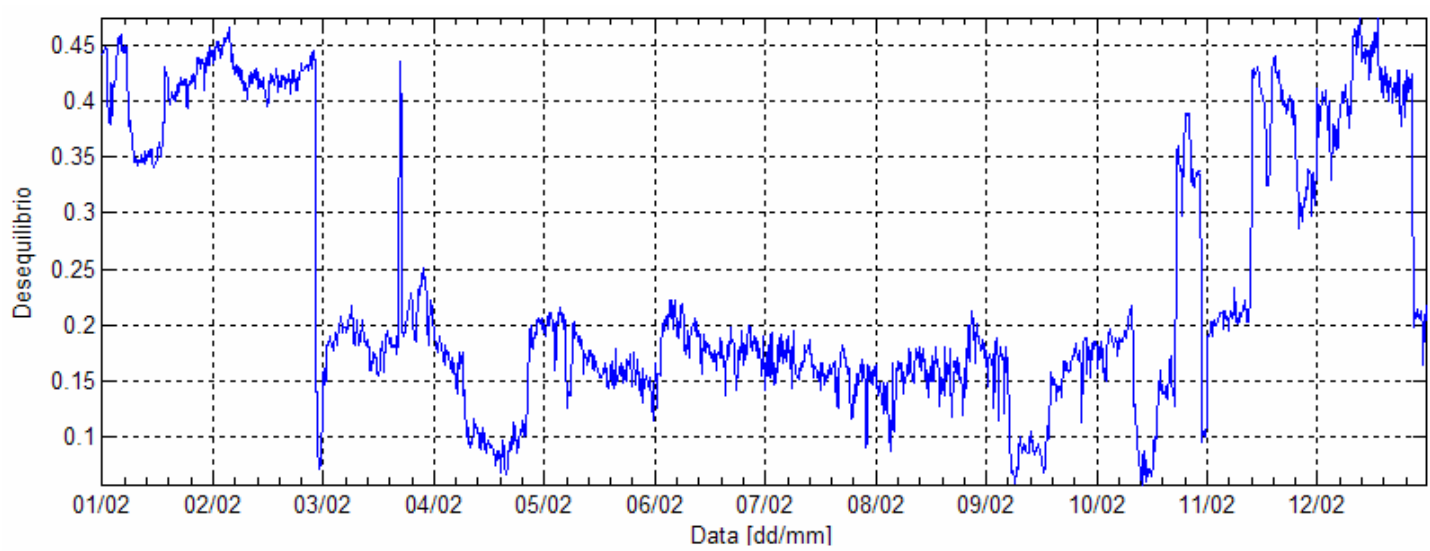

Figura 3 - Fator K versus período de medição - Consumidor C

No caso do consumidor C, figura 3, tem-se para o final de semana dos dias 11 e 12 de fevereiro a constatação dos maiores valores de desequilíbrio registrados até então neste estudo. Este comportamento representa, muito provavelmente, a manobra de alguma carga que acarreta tal 
desbalanço. No entanto, as semelhanças entre os patamares de fator $\mathrm{K}$ calculados para os consumidores A e B continuam evidentes.

\subsection{Similaridade entre os dias e entre períodos do dia}

Nesta seção serão exibidas as análises destinadas à comprovação da existência ou não da similaridade entre os dias de medição, e ainda, entre os períodos de um único dia. Este estudo se presta para determinação do período mínimo de medições, com o intuito de se possibilitar rapidez e segurança no processamento dos dados. Para os três locais, a análise se deu na semana de 04/02 (sábado) a 10/02 (sexta-feira).

As figuras 4 e 5 ilustram, respectivamente, as estatísticas e os perfis do fator $\mathrm{K}$ calculados para o consumidor A, considerando-se os 7 dias em apreciação.

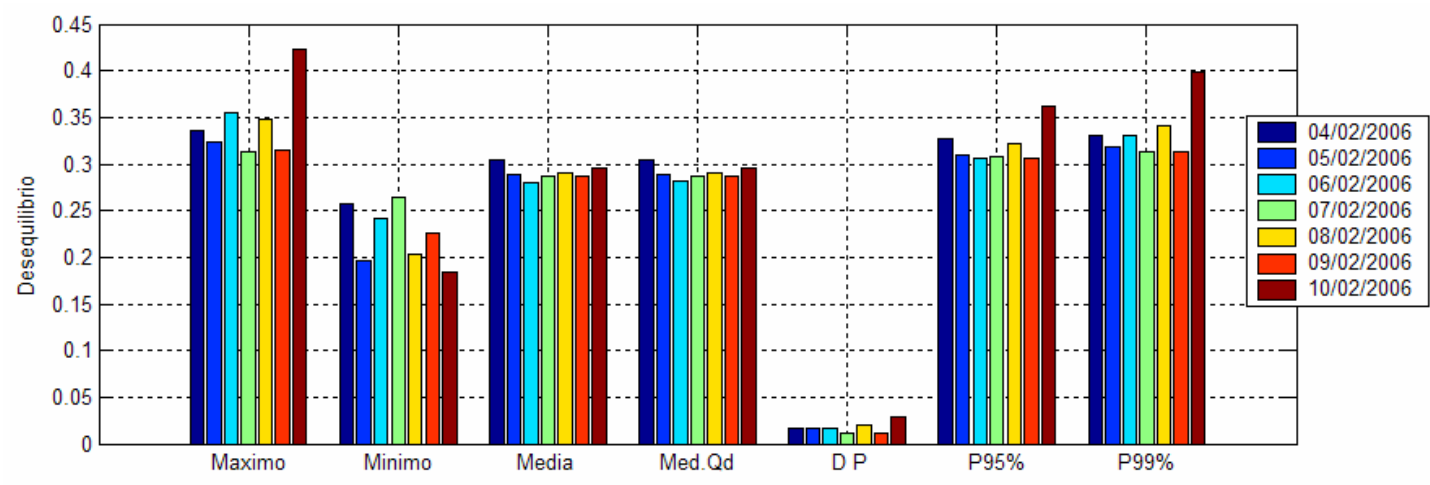

Figura 4 - Similaridade entre os dias - Consumidor A

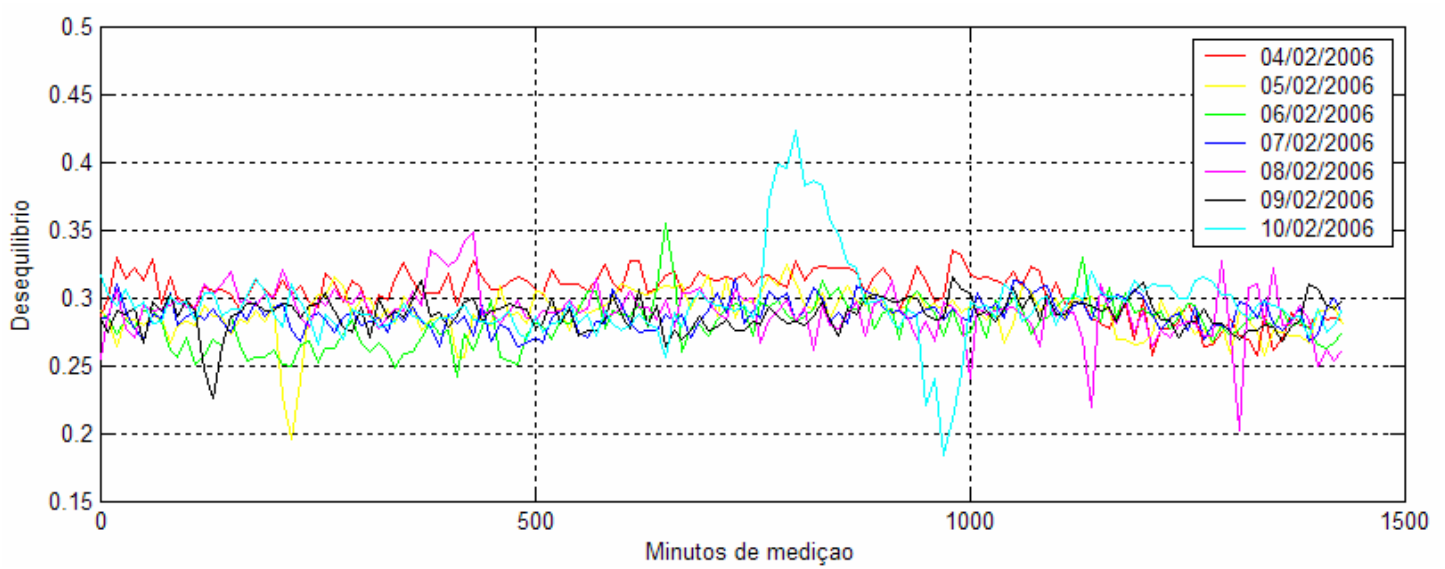

Figura 5 - Similaridade entre os dias - Consumidor A

Na figura 4, a análise das médias em conjunto com os desvios padrão evidenciam a semelhança de comportamento entre os dias. Na figura 5 verifica-se que os valores do $\mathrm{K}$ estão, na maior parte do tempo, compreendidos entre $0,25 \%$ e $0,35 \%$.

A figura 6 apresenta as estatísticas calculadas considerando-se os valores de fator $\mathrm{K}$ de um único dia, separados em intervalos de medição, para o consumidor A. 


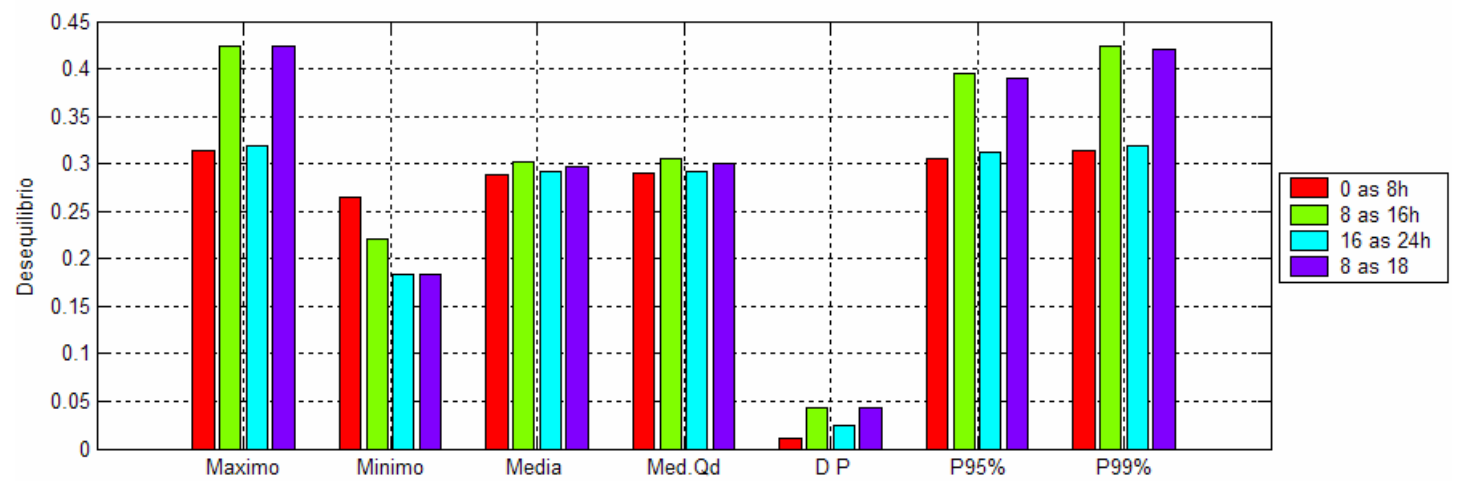

Figura 6 - Similaridade entre períodos do dia 10/02 - Consumidor A

Note da figura 6 que, os valores médios calculados para cada período do dia apresenta níveis semelhantes e próximos de $0.3 \%$. Entretanto, como esperado, os valores máximos ocorrem no período de 8 às 18h, sendo esse o mais recomendado para estudos onde se determina os indicadores para a comparação com os limites estabelecidos na norma.

As figuras 7 e 8 ilustram, respectivamente, as estatísticas e os perfis do fator $\mathrm{K}$ calculados para o consumidor B, considerando-se os 7 dias de medição.

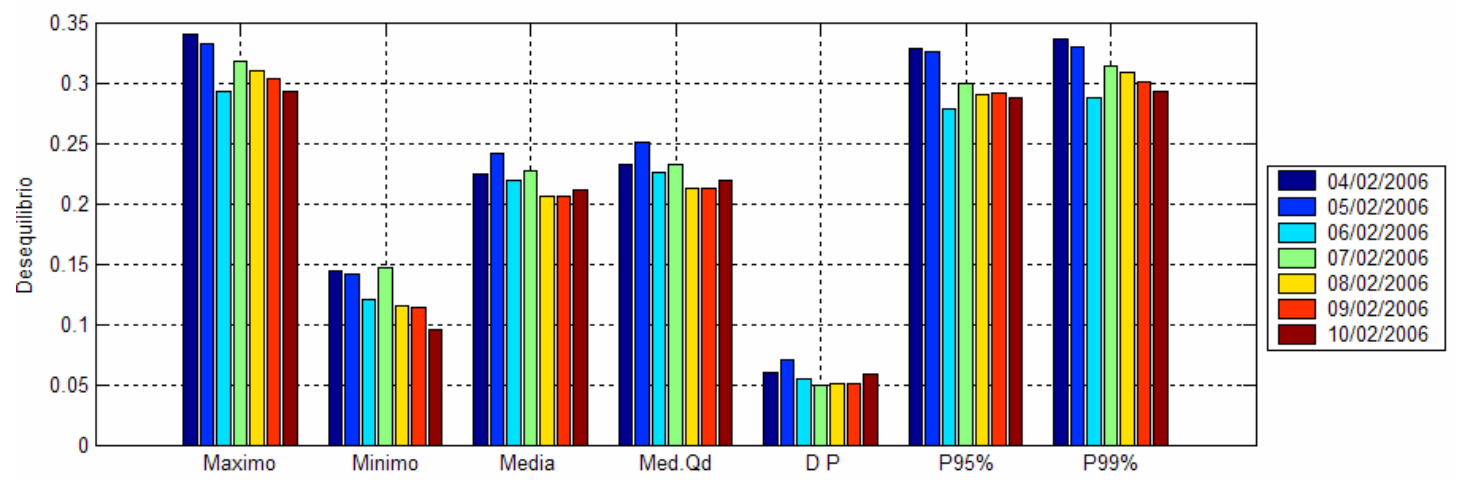

Figura 7 - Similaridade entre dias - Consumidor B

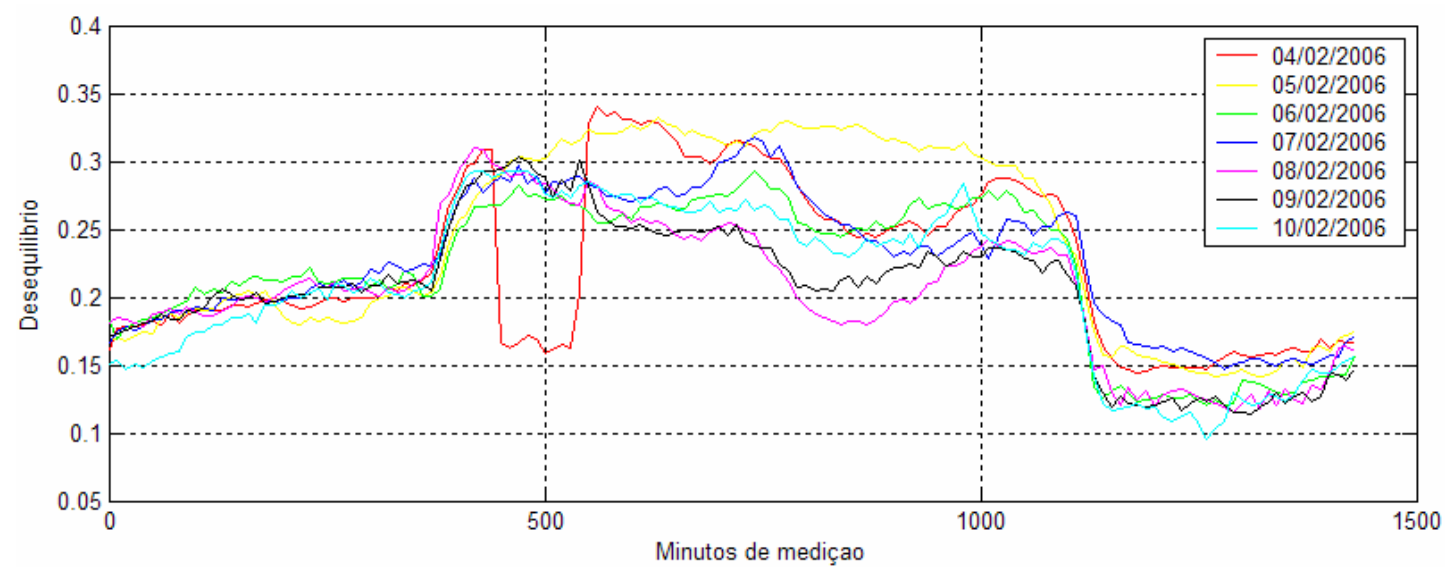

Figura 8 - Similaridade entre dias - Consumidor B

Pela figura 7, observa-se a presença dos maiores patamares de desequilíbrios no fim de semana dos dias 04 e 05/02. A concentração dos mais elevados valores de fator $\mathrm{K}$ no final de semana já foi 
constatada na abordagem dos dados do consumidor C, figura 3. De fato, as elevações registradas não caracterizam a existência de patamares preocupantes, segundo os limites das normas (tabela I). Ainda com as diferenças citadas, pode-se considerar a semelhança entre os dias para o local em estudo.

A figura 9 apresenta as estatísticas calculadas considerando-se os valores de fator $\mathrm{K}$ de um único dia, separados em intervalos de medição, para o consumidor B.

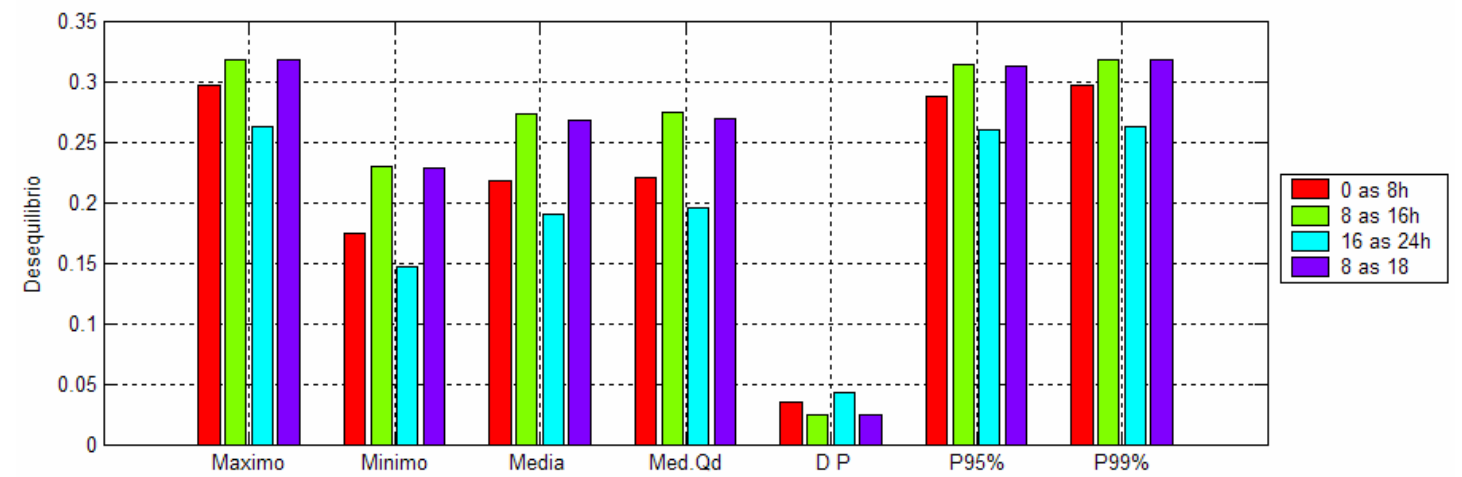

Figura 9 - Similaridade entre períodos do dia 07/02 - Consumidor B

Nota-se da figura 9 que, o período apresentando desequilíbrios de maneira mais acentuada corresponde ao horário comercial, aqui expresso como sendo de 8 às $18 \mathrm{~h}$.

As figuras 10 e 11 mostram, respectivamente, as estatísticas e os perfis do fator $\mathrm{K}$ calculados para o consumidor $\mathrm{C}$, considerando-se os 7 dias de medição.

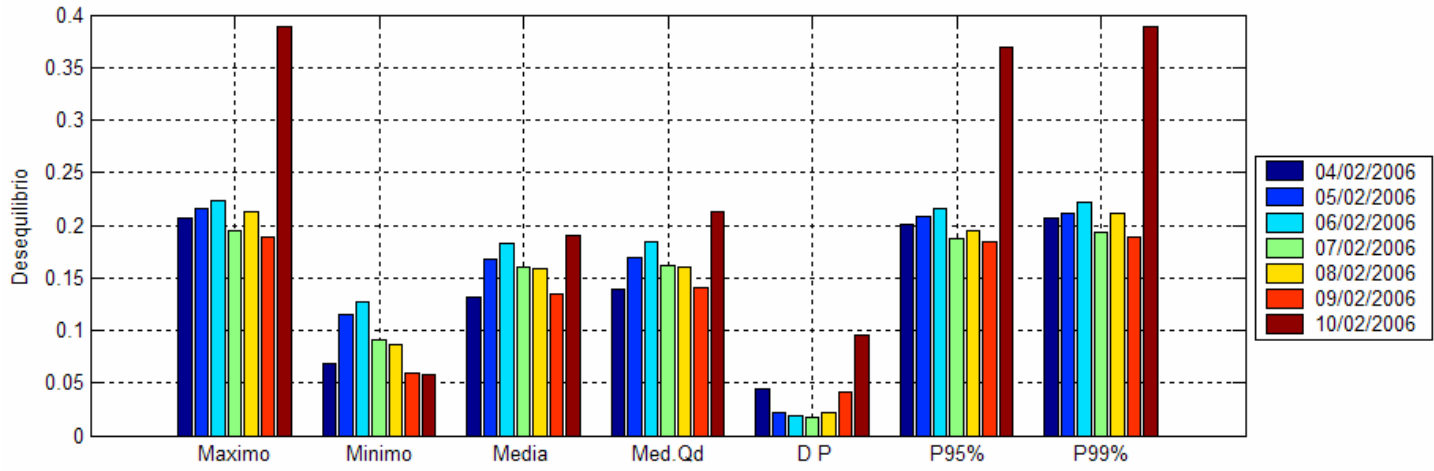

Figura 10 - Similaridade entre dias - Consumidor C

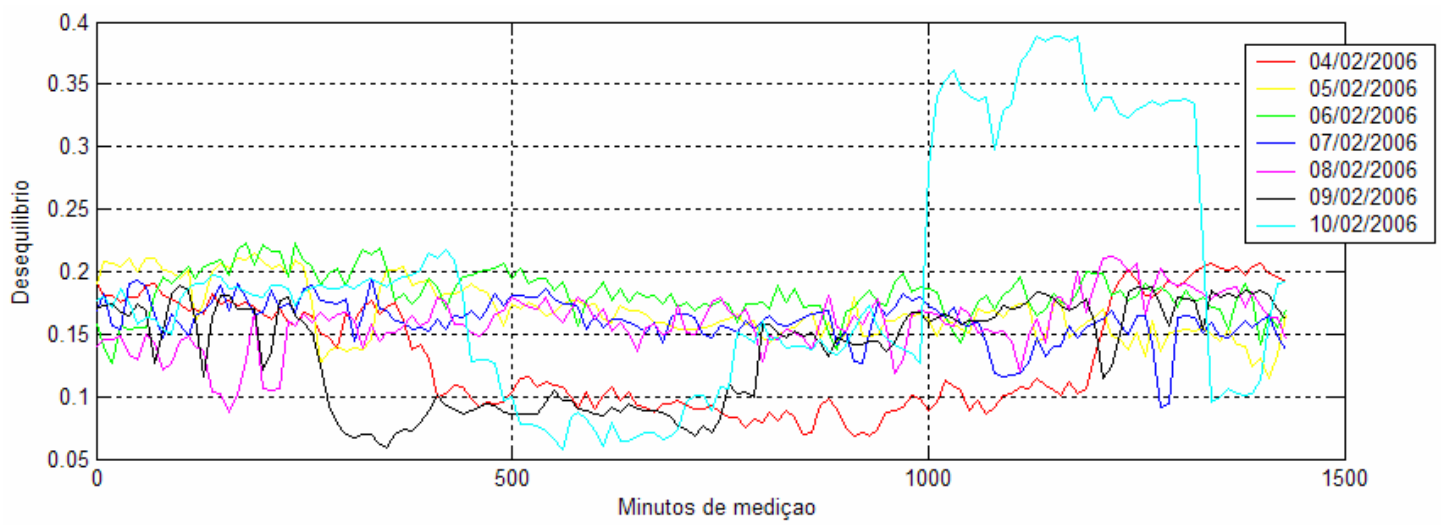

Figura 11 - Similaridade entre dias - Consumidor C 
Considerando-se as figuras 10 e 11, observa-se a presença de um período com valores diferentes aos demais. Trata-se de um intervalo com início na noite do dia 10/02, incluindo o sábado e o domingo posteriores (figura 3).. Nestas datas tem-se o maior e o menor valor do fator K, o que culmina no mais elevado desvio padrão encontrado nesta avaliação. Pelo perfil nota-se valores próximos ao dobro da média encontrada nos outros dias (figura 10). Ressalta-se porém que, ainda nestas condições, os patamares são bem inferiores aos limites das normas. Neste caso recomenda-se um pouco mais de cautela quando da escolha do dia representativo aos demais. Novas investigações são sugeridas.

A figura 12 apresenta as estatísticas calculadas considerando-se os valores de fator $\mathrm{K}$ de um único dia, separados em intervalos de medição, para o consumidor C.

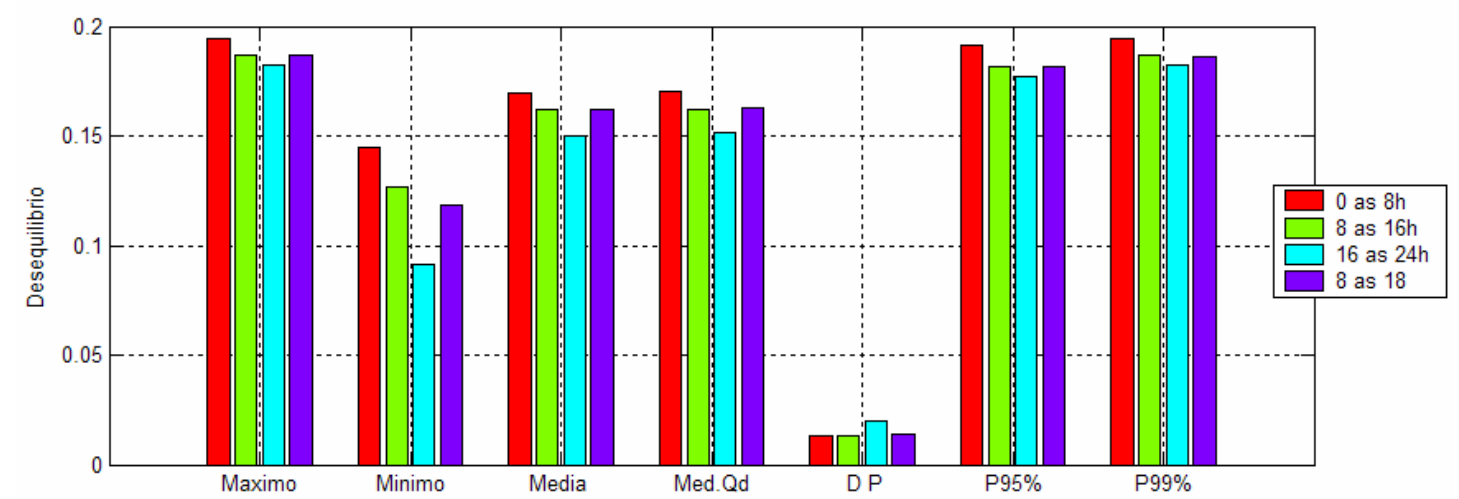

Figura 12 - Similaridade entre períodos do dia 07/02 - Consumidor C

Da figura 12, tem-se que os valores médios estiveram entre $0,1504 \%$ e $0,1697 \%$, apresentando baixo desvio padrão em todos os períodos. Logo, conclui-se que há similaridade entre eles, podendo-se utilizar o intervalo comercial como representativo aos demais.

Naturalmente, dependendo da sensibilidade do equipamento e dos níveis de desequilíbrios apresentados nas análises, recomenda-se fortemente uma avaliação pormenorizada da distribuição dos mais elevados valores de fator $\mathrm{k}$ durante o intervalo em estudo. Muito embora um determinado local possa apresentar poucos valores próximos ao máximo, se todos eles se manifestarem concentradamente, esta condição poderá ser suficiente para deteriorar os equipamentos mais sensíveis.

\subsection{Qualificação dos valores determinados na análise}

Verificou-se que, no período das medições de todos os locais apresentados neste trabalho, não foram detectadas ocorrências de valores superiores e nem próximos a $2 \%$ de desequilíbrio de tensão.

As figuras 13 e 14 apresentam a distribuição acumulada de probabilidade e a distribuição de ocorrências considerando-se o consumidor C, onde obteve-se os mais elevados valores de P95\%.

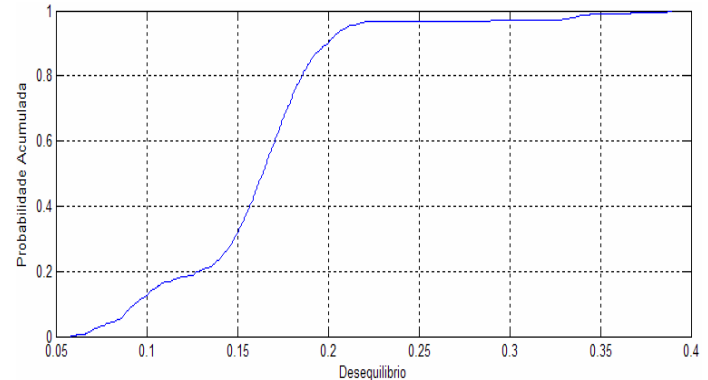

Figura 13 - Probabilidade Acumulada

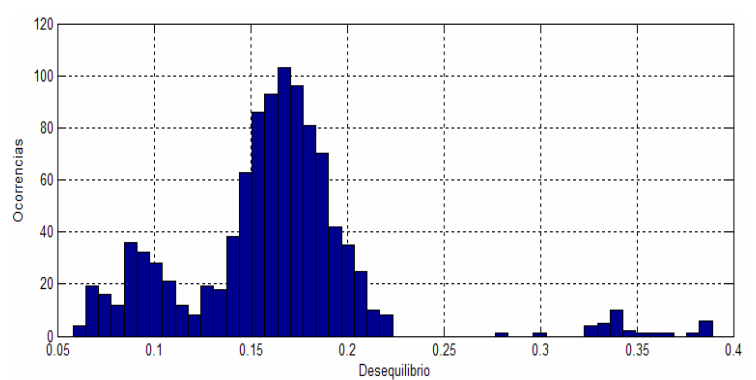

Figura 14 - Número de ocorrências do K\% 
Verifica-se que a grande maioria dos dados compreende-se entre $0.15 \%$ e $0,2 \%$. O valor máximo determinado encontra-se bem abaixo aos $2 \%$ estabelecido como limite na maioria das normas.

\section{Conclusões}

Este trabalho apresentou os resultados do levantamento do desequilíbrio de tensão no sistema Eletronorte em subestações de $230 \mathrm{kV}$. As etapas desenvolvidas serviram para analisar, quantificar e qualificar o fenômeno supracitado a partir de um intenso volume de dados, e fazendo uso de um ferramental estatístico.

Estas informações foram processadas, culminando-se em gráficos do perfil do fator K em função do tempo e possibilitando análises de similaridade entre dias e entre períodos do dia. Verificou-se que, para a semana especificada nos estudos, os consumidores A, B e C apresentaram valores com patamares muito próximos entre si.

Quando da análise voltada à determinação do período mínimo de medição, constatou-se que para os consumidores A e B, um único dia de medição no período comercial é suficiente. Já para o consumidor $\mathrm{C}$, recomenda-se a análise de outros intervalos de medição para a constatação do perfil que melhor representa o comportamento das amostras em avaliação.

Em relação à qualificação dos locais, ou seja, a comparação dos indicadores determinados com os limites das normas, conclui-se que como não ocorreram valores superiores a $0.5 \%$ de desequilíbrio de tensão no período em análise, os consumidores A, B e C em avaliação obedecem aos requisitos exigidos por todas as recomendações e normas apresentadas neste trabalho.

Embora os resultados obtidos não possam ser imediatamente generalizados para outros consumidores, a metodologia apresentada pode ser de grande utilidade para empresas e profissionais interessados na quantificação e na qualificação dos desequilíbrios de tensão.

\section{Bibliografia}

[1] WESTINGHOUSE ELECTRIC CORPORATION, Transmission and Distribution - Reference Book, East Pittsburgh, PA, 1950.

[2] Dugan, R. C.; Mcgranaghan, M. F.; Beauty, H. W.; Electrical Power System Quality, Editora McGraw-Hill, EUA, 1996.

[3] Agência Nacional de Energia Elétrica (ANEEL) - "Procedimentos de Distribuição de Energia Elétrica no Sistema Nacional - PRODIST”, Módulo 8 - Qualidade da Energia, 2005, Brasil.

[4] Operador Nacional do Sistema (ONS) - "Definição das Metodologias e Procedimentos Necessários às Campanhas de Medição dos Indicadores de Desempenho", Re.ONS - 2.1 $028 / 2005$.

[5] S. Pinto, Marcos Garcia; F. Filho, Anésio de Leles; Oliveira, Marco A. G.; Ferramenta Computacional para Análise, Quantificação e Qualificação dos Desequilíbrios de Tensão, VI SBQEE, Belém/PA, Brasil. 


\section{APÊNDICE F}

CIDEL - International Congress on Electricity Distribution, de 27 a 29 de novembro de 2006, Buenos Aires, Argentina.

"Monitoramento dos Desequilibrios de Tensão em Cargas com Perfil Industrial". 


\title{
MONITORAMENTO DOS DESEQUILÍBRIOS DE TENSÃO EM CARGAS COM PERFIL INDUSTRIAL
}

\author{
Marco Aurélio Gonçalves de Oliveira, Phd \\ mago@ene.unb.br \\ Anésio de Leles Ferreira Filho, Msc* \\ leles@ene.unb.br \\ Marcos Garcia da Silva Pinto, Grd \\ marcos.unb@gmail.com \\ Onivaldo A. Fernandes, Eng. \\ onivaldo@eln.gov.br
}

\author{
Universidade de Brasília - UnB, Brasil \\ Faculdade de Tecnologia - FT \\ Departamento de Engenharia Elétrica - ENE \\ Campus Universitário Darcy Ribeiro - Asa Norte \\ Cep: 70910-900, Brasília - DF \\ (55) (61) 3307-2308 r.214; Fax: (61) 3274-6651
}

\section{RESUMO}

Embora a questão Qualidade da Energia Elétrica venha sendo tratada por especialistas da área, segue incipiente o número de trabalhos de investigação voltados a Desequilíbrio de Tensão.

Assim sendo, este estudo objetiva quantificar, analisar no que diz respeito a distribuição no tempo, e qualificar o desequilíbrio de tensão, de forma que os resultados aqui encontrados e a metodologia apresentada se prestem não só para minimizar os danosos efeitos sobre o sistema elétrico, mas também auxiliar nas campanhas de medição onde se pretenda estudar o fenômeno supracitado.

Fazendo-se uso de tais resultados, será possível aos fabricantes e interessados, a partir dos limites de suportabilidade de cada aparelho frente aos desequilíbrios de tensão, determinar se o seu equipamento suporta ou não os níveis detectados, em função do tempo de exposição. Por fim, é posta em prática a comparação dos indicadores adquiridos com os patamares estabelecidos pelas normas internacionais.

Tratam-se de medições de 12 dias consecutivos no mês de fevereiro de 2005 em 03 consumidores industriais, conectados em redes de $230 \mathrm{kV}$ do sistema Eletronorte, Brasil.

\section{PALAVRAS-CHAVE}

Desequilíbrio de Tensão, Fator K, Quantificação, Qualificação, Distribuição no tempo. 


\section{INTRODUÇÃ̃O}

No Brasil, na fase de elaboração e adaptação de documentos, ainda em andamento, a Agência Nacional de Energia Elétrica, ANEEL, tem promovido fóruns de debates, realizando extensas campanhas de medição, dentre outras atividades, contando com a participação de universidades, centros de pesquisa, fabricantes de equipamentos e consumidores, para que, desta forma, as normas venham a refletir apropriadamente a realidade nacional concernente ao desempenho da rede e à qualidade da energia.

É importante nesta etapa ponderar criteriosamente sobre a adoção, proposição e definição de índices de qualidade, para que estes tenham uma identidade do ponto de vista físico, e para que seus valores limites tenham uma correspondência evidente e interrelacionada com aspectos fundamentais da qualidade da energia e suas implicações, quais sejam:

- operação normal do sistema;

- atendimento aos consumidores dentro de padrões de qualidade satisfatórios;

- preservação da vida útil dos elementos e equipamentos do sistema de forma aceitável;

- eficiência energética;

- atribuições de responsabilidades;

- e as questões de caráter econômico e legal.

Neste contexto, qualquer que seja a medida a ser tomada, esta deve apoiar-se em resultados de medições que evidenciem a realidade dos nossos sistemas nos atuais dias.

Vale mencionar que, embora os estudos direcionados a qualidade da energia estejam avançando, seguem incipientes as pesquisas voltadas para o desequilíbrio de tensão.

Assim sendo, este estudo objetiva quantificar, analisar no que diz respeito a distribuição no tempo, e qualificar o desequilíbrio de tensão, de forma que os resultados aqui encontrados e a metodologia apresentada se prestem não só para minimizar os danosos efeitos sobre o sistema elétrico, mas também auxiliar nas campanhas de medição onde se pretenda estudar o fenômeno supracitado.

Fazendo-se uso de tais resultados, será possível aos fabricantes e interessados, a partir dos limites de suportabilidade de cada aparelho frente aos desequilíbrios de tensão, determinar se o seu equipamento suporta ou não os níveis detectados, em função do tempo de exposição. Por fim, é posta em prática a comparação dos indicadores adquiridos com os patamares estabelecidos pelas normas internacionais.

Tratam-se de medições de 12 dias consecutivos no mês de fevereiro de 2005 em 03 consumidores industriais, conectados em redes de $230 \mathrm{kV}$ do sistema Eletronorte, Brasil.

\section{DESEQUILÍBRIO DE TENSÃO}

Os desequilíbrios presentes nas redes elétricas são fenômenos referentes a alterações dos padrões trifásicos de sistemas de transmissão/distribuição. É a condição na qual as fases apresentam tensão com módulos diferentes entre si, ou defasagem angular entre as fases diferentes de $120^{\circ}$ elétricos ou ainda, as duas condições simultaneamente.

Como alguns instrumentos de medição não disponibilizam os ângulos dos fasores, foram criadas formas alternativas para quantificação do desequilíbrio de tensão, aqui denominado de Fator $\mathrm{K}$, ou simplesmente K. Tais métodos serão, detalhadamente, descritos a seguir.

a) Métodos de Cálculo do Desequilíbrio (Fator K)

- Componentes Simétricas: Neste método o desequilíbrio de tensão é definido pela razão entre os módulos das tensões de seqüência negativa e positiva, em porcentagem, conforme Eq.(1). No Brasil, este método é o adotado pelo ONS (Operador Nacional do Sistema).

Onde:

$V_{\text {_ }} \rightarrow$ Módulo da tensão de seqüência negativa;

$\mathrm{V}_{+} \rightarrow$ Módulo da tensão de seqüência positiva;

$$
K \%=\frac{V_{-}}{V_{+}} \times 100
$$

- CIGRÉ (Congress Internationale des Grand Réseaux Électriques a Haute Tension): Emprega-se uma expressão para o fator de desequilíbrio a partir de uma grandeza adimensional que correlaciona as tensões de linha Eq.(2). 


$$
K \%=\sqrt{\frac{1-\sqrt{3-6 \beta}}{1+\sqrt{3-6 \beta}}} \times 100
$$

Onde:

$$
\beta=\frac{\left|V_{a b}\right|^{4}+\left|V_{b c}\right|^{4}+\left|V_{c a}\right|^{4}}{\left(\left|V_{a b}\right|^{2}+\left|V_{b c}\right|^{2}+\left|V_{c a}\right|^{2}\right)^{2}}
$$

$V_{a b}, V_{b c}, V_{c a} \rightarrow$ Módulo das tensões trifásicas;

- NEMA: A norma NEMA-MG-14.34, a fim de se quantificar o desequilíbrio, define $\mathrm{o}$ fator $\mathrm{K}$ como a relação entre $\mathrm{o}$ máximo desvio da tensão média e a tensão média, tendo como referência às tensões de linha, Eq.(4).

$$
K \%=\frac{\Delta V}{V_{m}} \times 100
$$

Onde:

$\Delta \mathrm{V} \rightarrow$ Máximo desvio das tensões de linha em relação ao valor médio;

$\mathrm{V}_{\mathrm{m}} \rightarrow$ Média aritmética dos módulos das tensões trifásicas;

IEEE: Por fim, o IEEE recomenda que o desequilíbrio de tensão deve ser obtido por uma relação que expressa a maior diferença entre as tensões de linhas medidas e o somatório das mesmas Eq.(5).

$$
K \%=\frac{3(V m a ́ x-V \min )}{V_{a b}+V_{b c}+V_{c a}} \times 100
$$

Onde:

Vmáx $\rightarrow$ Maior valor dentre os módulos das tensões trifásicas;

Vmín $\rightarrow$ Menor valor dentre os módulos das tensões trifásicas;

$V_{a b}, V_{b c}, V_{c a} \rightarrow$ Módulo das tensões trifásicas;

Neste trabalho, as componentes simétricas constituem a metodologia aplicada no cálculo do fator $\mathrm{K}$.

\section{b) Normas e Recomendações}

Apresentam-se na tabela I, os índices de conformidade retirados das normas e recomendações utilizadas ao redor do mundo para o controle da Qualidade da Energia Elétrica, com relação aos desequilíbrios de tensão (fator $\mathrm{K}$ ). No Brasil tem-se os Procedimentos de Rede que determinam como limite o patamar de
2\%. Quando da determinação do indicador a ser comparado com tal limite deve-se:

1) identificar qual é o valor com probabilidade de $95 \%$ de não ser excedido (P95\%) calculado considerando 1 dia, para todos os 7 dias em análise.

2) o valor indicador corresponde ao maior dentre os sete adquiridos anteriormente, em base diária.

Tabela I: Índices de conformidade

\begin{tabular}{|c|c|}
\hline $\begin{array}{c}\text { Recomendação / } \\
\text { Norma }\end{array}$ & Limite \\
\hline IEC & $2 \%$ \\
\hline $\begin{array}{c}\text { Procedimentos } \\
\text { de Rede }\end{array}$ & $2 \%$ \\
\hline CENELEC & $2 \%$ \\
\hline NRS-48 & $2 \%$ \\
\hline ANSI & $3 \%$ \\
\hline
\end{tabular}

A CENELEC e a NRS-048 permitem, em algumas áreas onde parte dos consumidores são monofásicos ou bifásicos, que o índice de conformidade seja igual a $3 \%$.

Verifica-se que a maioria das normas limita em $2 \%$ o desequilíbrio de tensão. Isto mostra que os índices de conformidade convergem para este valor.

\section{ESTUDO DE CASO}

Neste tópico serão apresentados resultados de análises de amostras colhidas em três locais simultaneamente, aqui designados como consumidores $\mathrm{A}, \mathrm{B}$ e $\mathrm{C}$.

O consumidor A é uma usina metalúrgica. Nesta empresa se produz silício metálico e liga de alumínio. A alimentação segue da Usina de Tucuruí em $230 \mathrm{kV}$.

O consumidor B é um complexo de produção alumina-alumínio. A energia demandada neste estabelecimento representa $15 \%$ do que é gerado em Tucuruí. A tensão de alimentação de 230 $\mathrm{kV}$, é oriunda da subestação Vila do Conde.

O consumidor C é uma empresa de mineração de cobre, com exploração e aproveitamento de jazidas minerais no município de Canaã dos Carajás/PA, Brasil. Sua alimentação vem de Tucuruí por meio da Subestação Marabá, em 230 $\mathrm{kV}$.

As medições ocorreram entre os dias 1 e 12 de Fevereiro de 2005. A frequência de aquisição dos dados coletados foi de 10 minutos, segundo o demandado pelos Procedimentos de Rede. 
Inicialmente, serão ilustrados os resultados numéricos das quantificações estatísticas dos valores de desequilíbrio medidos em todo o período. Em seguida, são expostos os gráficos do fator $\mathrm{K}$ versus tempo de medição com vistas ao atendimento dos objetivos almejados.

\section{a) Quantificação do desequilíbrio}

A tabela II exibe os resultados estatísticos, onde $\mathrm{P} 95 \%$ e $\mathrm{P} 99 \%$ representam, respectivamente, os valores com probabilidade de $95 \%$ e $99 \%$ de não serem excedidos.

Tabela II - Valores de desequilíbrio medidos

\begin{tabular}{|c|c|c|c|}
\hline $\begin{array}{c}\text { Estatísticas } \\
(\mathrm{K} \%)\end{array}$ & $\mathrm{A}$ & $\mathrm{B}$ & $\mathrm{C}$ \\
\hline Máximo & 0.4233 & 0.3477 & 0.4745 \\
\hline Mínimo & 0.1835 & 0.09563 & 0.05811 \\
\hline $\begin{array}{c}\text { Média } \\
\text { Aritmética }\end{array}$ & 0.2908 & 0.2252 & 0.2353 \\
\hline $\begin{array}{c}\text { Média } \\
\text { Quadrática }\end{array}$ & 0.2915 & 0.2325 & 0.2628 \\
\hline Desvio Padrão & 0.01932 & 0.05787 & 0.117 \\
\hline P95\% & 0.3206 & 0.3213 & 0.4373 \\
\hline P99\% & 0.3462 & 0.3379 & 0.4564 \\
\hline
\end{tabular}

Em uma análise preliminar, nota-se da tabela II que todos os três locais estiveram com os níveis de desequilíbrio dentro dos requesitos ilustrados na tabela I. Observase pequenos valores de desvio padrão, sobretudo se comparados com medições em consumidores de baixa tensão, onde a variação da carga com o tempo é mais acentuada. Dadas as semelhanças técnicas existentes entre estes locais, destaca-se que os valores da tabela são muito próximos entre si.

A figura I apresenta o gráfico com o comportamento do fator $\mathrm{K}$ durante todos os dias em estudo, medidos no consumidor A.

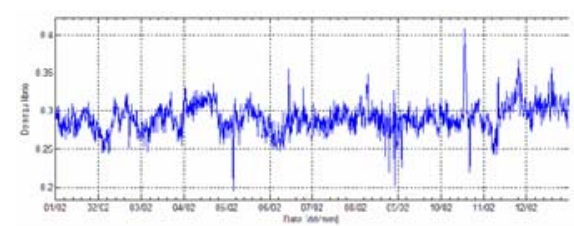

Figura I - Fator K versus período de medição - Consumidor A

$\mathrm{Na}$ figura I, observa-se variações em torno de $0.3 \%$. Entretanto, alguns valores discrepatnes destacam-se, o que justifica a diferença entre o valor máximo constatado e o $\mathrm{P} 95 \%$.
A figura II ilustra o gráfico com o comportamento do fator $\mathrm{K}$ durante todos os dias em estudo, medidos no consumidor B.

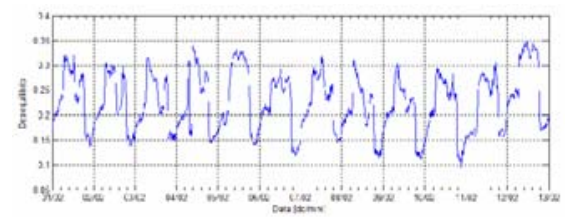

Figura II - Fator K versus período de medição - Consumidor B

Da figura II percebe-se que o perfil apresentado é característico da maioria das cargas comerciais/industriais dos sistemas elétricos. Durante o dia no horário comercial, o desequilíbrio atinge índices mais elevados, neste caso da ordem de $0.3 \%$. A média quadrática indica patamares inferiores aos registrados para 0 consumidor A. Porém, considerando-se somente o período comercial, pode-se observar uma semelhança entre os valores dos consumidores A e B.

A figura III apresenta o gráfico com o comportamento do fator $\mathrm{K}$ durante todos os dias em estudo, medidos na consumidor C.

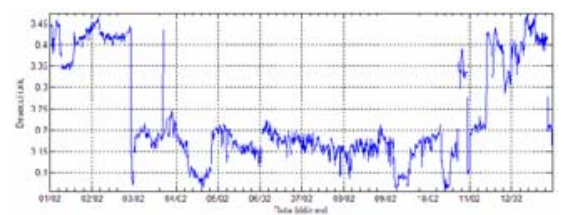

Figura III - Fator K versus período de medição - Consumidor $\mathrm{C}$

No caso do consumidor C, figura III, tem-se para o final de semana dos dias 11 e 12 de fevereiro a constatação dos maiores valores de desequilíbrio registrados até então neste estudo. Este comportamento representa, muito provavelmente, a manobra de alguma carga que acarreta tal desbalanço. A média, contudo, sinaliza uma semelhança com o consumidor B. Mas a análise do perfil culmina no entendimento de que durante os dias utéis os valores oscilam em torno de $0.2 \%$.

\section{b) Estudo da distribuição no tempo dos níveis de desequilíbrio}

O objetivo principal deste item é apresentar os resultados da aplicação de uma metodologia auxiliar de avaliação que possibilita a análise da distribuição no 
tempo das amostras com valores superiores a P95\%. Aspira-se, a partir dos resultados gerados, concluir quanto à representatividade dos índices $\mathrm{P} 95 \%$ quando das suas utilizações em representação aos demais valores medidos.

Após tal apresentação, será efetuada uma análise comparativa considerando-se os 3 locais em estudo. Adicionalmente, caberá aos fabricantes, de posse dos limites de suportabilidade de cada um dos seus equipamentos frente aos desequilíbrios de tensão, entender se o seu equipamento suporta ou não os níveis apresentados, em função do tempo de exposição.

Devido a limitação de espaço, somente para um local serão ilustrados os gráficos. Os outros 2 pontos terão seus resultados expressos a partir de uma tabela.

c) Análise considerando-se o valor de $\mathbf{P 9 5} \%$ como referência para o local A

O valor de P95\% calculado a partir dos dados em estudo foi de $0.3206 \%$. A figura IV apresenta o gráfico de $\mathrm{K} \geq 0.3206 \%$ versus tempo total de medição em minutos.

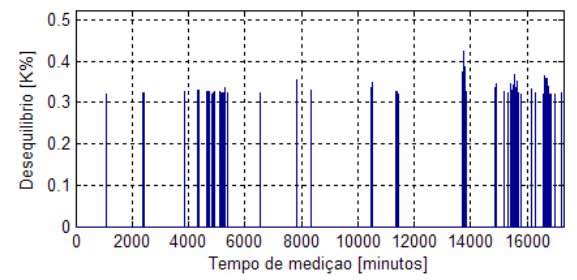

Fig. IV - Valores com $\mathrm{K} \geq 0.3206 \%$ versus tempo total de medição

Da figura IV e com o auxílio de uma rotina computacional, observa-se que, de todo o período de medição em análise, aproximadamente 17280 minutos, cerca de 860 detêm $\mathrm{K} \geq 0.3206 \%$.

A figura $\mathrm{V}$ exibe o gráfico com os intervalos ininterruptos de tempo com valores de $\mathrm{K} \leq 0.3206 \%$.

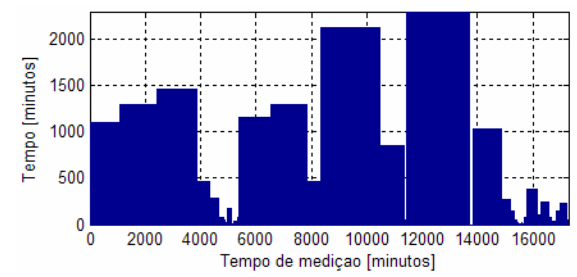

Fig. V - Intervalos ininterruptos de tempo com valores de $\mathrm{K} \leq 0.3206 \%$.
Da figura $\mathrm{V}$, destaca-se que o máximo intervalo ininterrupto de tempo com $\mathrm{K} \leq$ $0.3206 \%$ é de aproximadamente 2290 minutos, ou seja, 38.17 horas, de um total de 17280 minutos de medição. O período entre 6000 e 8000 minutos do gráfico, corresponde a dias de final de semana. Apesar disso, constatam-se valores acima do $\mathrm{P} 95 \%$ neste intervalo, indicando presença de cargas em funcionamento nesses dias.

A figura VI trás a vista o gráfico com os intervalos ininterruptos de tempo com valores de $\mathrm{K} \geq 0.3206 \%$.

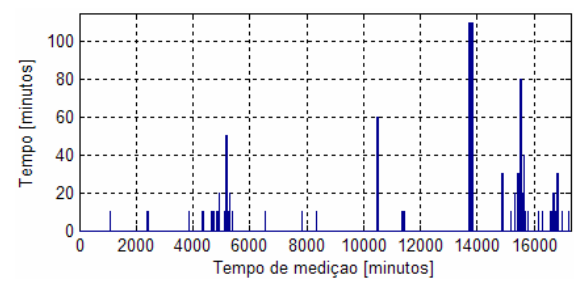

Fig. VI - Intervalos ininterruptos de tempo com valores de $K \geq 0.3206 \%$, versus tempo total de medição.

Da figura VI, salienta-se que o máximo intervalo ininterrupto de tempo com $\mathrm{K} \geq$ $0.3206 \%$ é de aproximadamente 110 minutos, cerca de 1.83 horas, de um total de 17280 minutos em medição.

A figura VII ilustra o gráfico com as probabilidades de ocorrência dos intervalos ininterruptos de tempo com $\mathrm{K} \geq$ $0.3206 \%$.

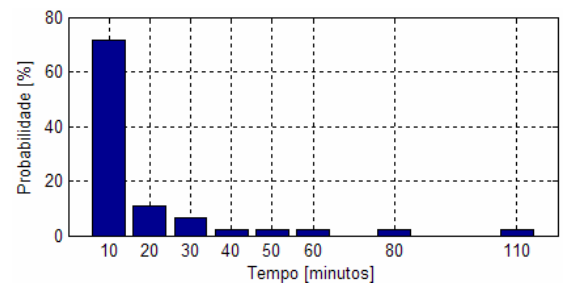

Fig. VII - Probabilidades de ocorrência dos intervalos ininterruptos de tempo com $\mathrm{K} \geq$ $0.3206 \%$

Nota-se da figura VII que cerca de $70 \%$ dos intervalos ininterruptos de tempo com $\mathrm{K} \geq 0.3206 \%$ têm até 10 minutos de duração. Entretanto, ressalta-se a existência de intervalos ininterruptos de tempo com $\mathrm{K} \geq 0.3206 \%$ com 80 e 100 minutos de duração.

A figura VIII apresenta o gráfico com as probabilidades de ocorrência dos intervalos ininterruptos de tempo com $\mathrm{K} \leq$ $0.3206 \%$. 


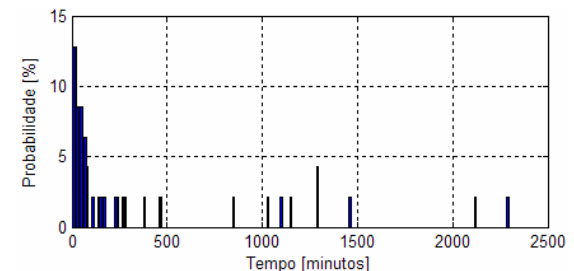

Fig. VIII - Probabilidades de ocorrência dos intervalos ininterruptos de tempo com $\mathrm{K} \leq 0.3206 \%$.

Nota-se da figura VIII que cerca de $13 \%$ dos intervalos ininterruptos de tempo com $\mathrm{K} \leq 0.3206 \%$ têm até 50 minutos de duração. Contudo, ressalta-se a existência de alguns intervalos ininterruptos de tempo com $\mathrm{K} \leq 0.3206 \%$ entre 50 e 500 minutos e outros de aproximadamente 2200 minutos de duração.

Isto indica portanto que, para os 12 dias em estudo, a maioria dos intervalos de tempo com valores de $\mathrm{K} \geq 0.3206 \%$ estão concentrados em intervalos de curta duração, com cerca de 10 minutos, espaçados entre si, quase sempre por períodos entre 50 e 500 minutos.

d) Análise comparativa considerando-se o valor de $\mathbf{P 9 5 \%}$ como referência

Os valores de $\mathrm{P} 95 \%$ calculados a partir dos dados dos consumidores A, B e C são, respectivamente, $0.3206 \%, \quad 0.3213 \%$ e $0.4373 \%$. Os dois primeiros locais apresentam tal índice com valores próximos entre si, enquanto o $\mathrm{C}$ encontrase um pouco maior.

A tabela III apresenta os resultados encontrados quando da geração de análises semelhantes à efetuada no item a), considerando os 3 locais abordados.

Tabela III - Resultados das análises nos consumidores A, B e C

\begin{tabular}{|c|c|c|c|}
\hline & A & B & C \\
\hline $\begin{array}{c}\text { Total de } \\
\text { minutos com } \\
\mathrm{K} \geq \mathrm{P} 95 \%\end{array}$ & 860 & 840 & 860 \\
\hline $\begin{array}{c}\text { Máximo } \\
\text { intervalo } \\
\text { ininterrupto } \\
\text { de tempo com } \\
\mathrm{K} \geq \mathrm{P} 95 \%\end{array}$ & 110 & 260 & 210 \\
\hline $\begin{array}{c}\text { Máximo } \\
\text { intervalo } \\
\text { ininterrupto } \\
\text { de tempo com } \\
\mathrm{K} \leq \mathrm{P} 95 \%\end{array}$ & 2290 & 9630 & 12490 \\
\hline
\end{tabular}

Da tabela III pode observar uma grande semelhança para os tempos com $\mathrm{K} \geq$ P95\%. Já para a análise dos máximos intervalos com $\mathrm{K} \geq \mathrm{P} 95 \%$ e $\mathrm{K} \leq \mathrm{P} 95 \%$, notase variações entre os valores adquiridos para cada local, indicando que a distribuição no tempo se dá, em uma primeira análise, de forma diferente. Certamente isto está relacionado as atividades desenvolvidas em cada local em estudo. A dinâmica do lugar em análise justifica os resultados exibidos.

Quando da análise das probabilidades dos intervalos de tempo ininterruptos com $\mathrm{K} \geq \mathrm{P} 95 \%$ e $\mathrm{K} \leq \mathrm{P} 95 \%$ para os locais $\mathrm{B}$ e $\mathrm{C}$, temos:

1) No consumidor B, $50 \%$ dos intervalos ininterruptos de tempo com $\mathrm{K} \geq 0.3213 \%$ têm até 10 minutos de duração. Intervalos com 250 e 260 minutos de duração também se destacam. Ademais, a maioria dos intervalos de tempo com $\mathrm{K} \leq 0.3213 \%$ tem até 70 minutos de duração. Assim, para o consumidor $\mathrm{B}$, a maioria dos intervalos de tempo com valores de $\mathrm{K} \geq$ $0.3213 \%$ estão concentrados em intervalos de aproximadamente 10 minutos, espaçados entre si, em geral, por períodos de até 70 minutos.

2) No caso do consumidor $\mathrm{C}$, a maioria dos intervalos ininterruptos de tempo com valores de $K \geq 0.4373 \%$ têm entre 10 e 20 minutos, espaçados entre si, na maioria das vezes, por períodos de até 30 minutos.

Percebe-se, apesar da maioria dos intervalos ininterruptos de $\mathrm{K} \geq \mathrm{P} 95 \%$ serem de 10 minutos, uma diferença entre os patamares quando da comparação entre os consumidores. O mesmo acontece para intervalos ininterruptos com $\mathrm{K} \leq \mathrm{P} 95 \%$. Neste caso, embora a maioria dos intervalos tenha cerca de 50 minutos, há a presença de vários outros que consolidam as discrepâncias supracitadas.

Assim sendo, recomenda-se quando da análise da distribuição no tempo dos níveis de desequilíbrios medidos, uma análise pormenorizada para cada local, separadamente.

\section{QUALIFICAÇÃO DOS VALORES} DETERMINADOS NA ANÁLISE

Verificou-se que, no período das medições de todos os locais apresentados neste trabalho, não foram detectadas ocorrências de valores superiores e nem próximos a $2 \%$ de desequilíbrio de tensão.

Considerando-se o consumidor $\mathrm{C}$, onde obteve-se os mais elevados valores do fator $\mathrm{k}$, verifica-se que a grande maioria dos dados compreende-se entre $0.15 \%$ e $0,2 \%$. O valor máximo determinado 
encontra-se bem abaixo aos $2 \%$ estabelecido como limite na maioria das normas. Os consumidores A e B, como pode-se imaginar, também apresentaram valores abaixo do supra dito patamar.

\section{CONCLUSÕES}

Este trabalho apresentou os resultados do levantamento do desequilíbrio de tensão no sistema Eletronorte, Brasil, em subestações de $230 \mathrm{kV}$. As etapas desenvolvidas serviram para quantificar, analisar, no que diz respeito à distribuição no tempo, e qualificar o desequilíbrio de tensão a partir de um intenso volume de dados, e fazendo uso de um ferramental estatístico.

Dos gráficos ilustrados na análise pormenorizada, observou-se, em cada local, que os valores estão concentrados, na maioria das vezes, em intervalos de curta duração, espaçados entre si, através de períodos de 10 minutos. Contudo, há de se ressaltar a existência de alguns intervalos ininterruptos com durações mais elevadas, que culminam nas diferenças entre os comportamentos do fator $\mathrm{k}$ dos locais.

Das análises efetuadas, cumpre-se destacar a existência de uma significativa similaridade entre o número de valores com $\mathrm{K} \geq \mathrm{P} 95 \%$, considerando-se os 3 locais. Contudo, na análise dos máximos intervalos com $\mathrm{K} \geq \mathrm{P} 95 \%$ e $\mathrm{K} \leq \mathrm{P} 95 \%$, nota-se variações entre os valores adquiridos para cada local, indicando que a distribuição no tempo se dá de forma diferente. Certamente isto se deve devido às atividades desenvolvidas em cada consumidor em estudo. A dinâmica do lugar em análise justifica os resultados exibidos.
Esta constatação culmina em dois aspectos a se considerar, sejam eles, a necessidade de investigações análogas a aqui exposta, contemplando-se novos locais, e a demanda por novos estudos voltados a suportabilidade de equipamentos frente aos níveis de desequilíbrios.

A metodologia utilizada permite ao fabricante, de posse dos níveis máximos de suportabilidade ao fator $\mathrm{K}$, em função do tempo de exposição aos mesmos, atestar se o seu produto pode ou não ser utilizado, sem riscos de danos, causados por um sistema como o em estudo.

Em relação à qualificação dos locais, ou seja, a comparação dos indicadores determinados com os limites das normas observou-se que não ocorreram valores superiores a $0.5 \%$ de desequilíbrio de tensão no período em análise. Logo, os pontos em avaliação obedecem aos requisitos exigidos por todas as recomendações e normas apresentadas neste trabalho.

Embora os resultados obtidos não possam ser imediatamente generalizados para outros consumidores, a metodologia apresentada pode ser de grande utilidade para empresas e profissionais interessados na quantificação e na qualificação dos desequilíbrios de tensão.

\section{BIBLIOGRAFIA}

[1] S. Pinto, Marcos G.; F. Filho, Anésio de L.; Oliveira, Marco A. G.; Ferramenta Computacional para Quantificação e Qualificação dos Desequilíbrios de Tensão, VI SBQEE, Brasil, 2005.

[2] Dugan, R. C.; Mcgranaghan, M. F.; Beauty, H. W.; Electrical Power System Quality, EUA, 1996. 


\section{APÊNDICE G}

ICHQP - International Conference on Harmonics and Quality of Power, 1 a 5 de Outubro de 2006, Cascais, Portugal.

"Comparative Analysis Among Indexes Related to Quantifying Voltage Imbalance". 


\title{
Comparative Analysis Among Indexes Related to Quantifying Voltage Imbalance
}

\author{
Marco A. de Oliveira, Senior Member, IEEE, Anésio de L. F. Filho, Member, IEEE, and Marcos G.
} da S. Pinto

\begin{abstract}
Aiming at contributing to making the most adjusted choice of the index of voltage imbalance for the Brazilian Resolution on power quality, this study illustrates a methodology for an analysis of the distribution time of the samples with values superior to the square mean and to the values with probability of $90 \%, 95 \%$ and $99 \%$ of not being exceeded, acquired in measurements. With the methodology it will be possible to evaluate how representative these indexes are, when used as a representation for all measured values. These patterns are characterized as the indicators standardally used in the recommendations/standards known world-wide. Making use of such results, it will be left to the manufacturers having the information made available in the analysis concluded here, while also considering the support limits of their equipment in relation to voltage imbalances to determine if such equipment can support or not the levels presented, in function of the time of exposure.
\end{abstract}

Index Terms - Measurements, indices, voltage imbalance, Standard.

\section{INTRODUCTION}

$\mathrm{R}$ ecently, it has been seen the effects caused by the industrial three-phase machines, which demand huge amounts of power added to the effects from the accentuated growth in electrical appliances, computers and lowconsumption devices such as the fluorescent light bulbs, whose usage has expanded remarkably on the occasion when Brazil had a shot age of electrical energy in 2001, creating a rising preoccupation towards electrical supply, among which lies the voltage imbalance. Though these devices use little power individually, there are thousands of these new loads being randomly connected and disconnected from the power grid. Thus, we are faced in the foreseeable future with the necessary control of the voltage imbalance degree not only in the industrial sector, but also for commercial and residential loads.

The international IEEE, IEC and European standards, among others, set limits to this phenomenon. Furthermore, there are several measurement devices on the market capable of obtaining the data according to the standards requirements. However, tools designed for treatment and analysis of samples remain scarce.

A. L. F. Filho, Department of Electrical Engineering, University of Brasilia, Brazil (e-mail: leles@ene.unb.br).

M. A. G. de Oliveira, Department of Electrical Engineering, University of Brasilia, Brazil (e-mail: mago@ene.unb.br).

M. G. da S. Pinto, Department of Electrical Engineering, University of Brasília, Brazil (e-mail: marcos.unb@gmail.com).
Consequently, the University of Brasília, through the Power Quality Studies Group, has suggested improvement in this scenario through quantifying and classifying the imbalance research. As a result, this article presents, initially, the definition of voltage imbalance, some basic considerations on its causes and effects, its main calculating methods and a brief overview of the main standards involved.

This study illustrates a methodology for an analysis of the distribution time of the samples with values superior to the square mean and to the values with probability of $90 \%, 95 \%$ and $99 \%$ of not being exceeded, acquired in measurements. With the methodology it will be possible to evaluate how representative these indexes are, when used as a representation for all measured values.

These patterns are characterized as the indicators standardally used in the recommendations/standards known world-wide. Under these conditions, it will be left to the manufacturers, having the information made available in the analysis concluded here, while also considering the support limits of their equipment in relation to voltage imbalances, to determine if such equipment can support or not the levels presented, and moreover, if the differences determined by the analysis taking into account the values of $\mathrm{P} 90 \%, \mathrm{P} 95 \%$ and P99\% influence aspects such overheating, reduction of the duration of the equipment and malfunctioning loads.

Thus, it is possible to have an idea of the degree of severity that the measured value has in reference to the support limits of the equipment. Finally, data evaluation is made, making a comparison of the indexes acquired with the patterns established by the international standards.

This paper is of evident importance, considering that the knowledge of the behavior in time of phenomena such as voltage imbalance leads to actions which might minimize their damaging effects on electrical systems and different kinds of equipment.

\section{ImBALANCE FACTOR: DeFINITION AND CALCULATING METHODS}

The voltage imbalance in an electrical system is a condition in which the phases differ in their magnitude, have a different phase displacement from $120^{\circ}$, or both simultaneously.

It is known that the presence of imbalanced three-phase loads connected to a three-phase system causes a voltage imbalance, since the currents absorbed in each phase are not symmetrical, i.e., they have not got the same magnitude and/or 
are not offset by $120^{\circ}$.

Usually there are not great imbalances in high tension systems, except for when they supply large single-phase loads, such as electric trains or ovens.

Another factor that generates the voltage imbalance is the existence of badly transposed transmission lines, since these lines electrical properties will not be the same throughout their length.

The effects caused by an electrical system with voltage imbalance are associated with overheating, malfunctioning and/or protection device failures, insulation damages and diminution of lifetime.

The estimation of the imbalance level $-\mathrm{K}$ factor - may be executed through four different methods. The first uses the three-phase modules and offsets to obtain the $\mathrm{K}$ factor. The remaining three depend only on the magnitude of the line-toline voltages.

\section{A. Symmetrical Components Method}

In this method, the voltage imbalance is defined as the ratio of the module of the negative and positive sequences, as in (1).

$$
K \%=\frac{V_{-}}{V_{+}} \times 100
$$

Where:

$\mathrm{V}-\rightarrow$ Module of the negative sequence voltage;

$\mathrm{V}+\rightarrow$ Module of the positive sequence voltage;

\section{B. NEMA Method}

The NEMA-MG-14.34 standard, in order to quantify the imbalance, calculates the $\mathrm{K}$ factor as the ratio of the maximum measured deviation from the average voltage and the average voltage itself, taking the three-phase voltages as a reference.

$$
K \%=\frac{\Delta V}{V_{m}} \times 100
$$

\section{Where:}

$\Delta \mathrm{V} \rightarrow$ Maximum measured deviation from the average three-phase voltage to the average value;

$\mathrm{Vm} \rightarrow$ Arithmetic mean of the three-phase absolute values of tension;

\section{CIGRÉ Method}

Another recommended procedure to calculate the voltage imbalance comes from CIGRÉ (Congress Internationale des Grand Réseaux Électriques a Haute Tension). In this approach, an expression obtained from the three-phase tensions is used to reach the $\mathrm{K}$ factor.

$$
K \%=\sqrt{\frac{1-\sqrt{3-6 \beta}}{1+\sqrt{3-6 \beta}}} \times 100
$$

Where:

$$
\beta=\frac{\left|V_{a b}\right|^{4}+\left|V_{b c}\right|^{4}+\left|V_{c a}\right|^{4}}{\left(\left|V_{a b}\right|^{2}+\left|V_{b c}\right|^{2}+\left|V_{c a}\right|^{2}\right)^{2}}
$$

$V_{a b}, V_{b c}, V_{c a} \rightarrow$ Modules of the three-phase voltages;

\section{IEEE Method}

The IEEE recommends that the $\mathrm{K}$ factor should be obtained through the following expression, which yields the greatest difference between the measured three-phase tensions and their sum.

$$
K \%=\frac{3(V \max -V \min )}{V_{a b}+V_{b c}+V_{c a}} \times 100
$$

Where:

Vmax $\rightarrow$ Maximum value among the three-phase voltages; Vmin $\rightarrow$ Minimum value among the three-phase voltages; $V_{a b}, V_{b c}, V_{c a} \rightarrow$ Modules of the three-phase voltages;

Table I presents the limits of voltage imbalance ( $\mathrm{K}$ factor) found in the standards and recommendations adopted around the world for the control of the electrical Power Quality.

TABLE I

CONFORMITY LIMITS

\begin{tabular}{|c|c|}
\hline Recommendation/Standard & Limit \\
\hline IEC & $2 \%$ \\
\hline ONS/BRAZIL & $2 \%$ \\
\hline CENELEC & $2 \%$ \\
\hline NRS-048 & $2 \%$ \\
\hline NTSCE & --- \\
\hline ANSI & $3 \%$ \\
\hline
\end{tabular}

Both CENELEC and NRS-048 allow, in some areas where part of the consumers are single-phase or two-phase powered, that the conformity limit be $3 \%$.

Most of the standards agree on limiting the voltage imbalance to $2 \%$. This acts as evidence that the global limit converges to that point.

\section{EXPERIMENTAL RESULTS}

Here are shown the results of measuring made in a located metallurgic plant called, for the intentions of this work, 
consumer $\mathrm{A}$, in a range of one up to 12 days. This industry produces silicon and metallic aluminum alloy. The alimentation follows in $230 \mathrm{kV}$.

Table II displays the statistical results, where P90\%, P95\% and $\mathrm{P} 99 \%$ represent, respectively, the values with probability of $90 \%, 95 \%$ and $99 \%$ of not to be exceeded, calculated from the samples collected in the supply mentioned period. For the following analyses, these patterns will be used as reference.

TABLE II

Voltage IMBALANCE

\begin{tabular}{|c|c|}
\hline Statistical Values (K\%) & Consumer A \\
\hline Maximum & 0.4233 \\
\hline Minimum & 0.1835 \\
\hline Mean & 0.2908 \\
\hline Square mean & 0.2915 \\
\hline Standard deviation & 0.0193 \\
\hline P90\% & 0.3123 \\
\hline P95\% & 0.3206 \\
\hline P99\% & 0.3462 \\
\hline
\end{tabular}

Figure 1 presents the graph with the behavior of factor $\mathrm{K}$ during every day in study, measured in the consumer A.

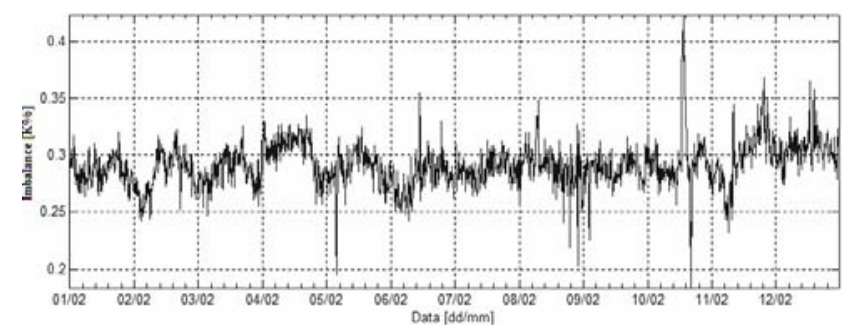

Fig. 1. K factor versus period of measurement

In figure 1, it is observed variations around $0.3 \%$. Nevertheless, some different values are distinguished, which justifies the difference between the maximum value evidenced and $\mathrm{P} 95 \%$. Still from figure 1, and considering the values of table II, we verify the well-known time-varying nature of the phenomenon.

In table II it is observed that the square mean presents a difference to $\mathrm{P} 90 \%$ of about $6.66 \%$. Considering P90\% and $\mathrm{P} 95 \%, \mathrm{P} 95 \%$ and $\mathrm{P} 99 \%$, we have, respectively, the following discrepancies: $2.58 \%$ and $7.39 \%$. However, the biggest difference among $\mathrm{P} 90 \%, \mathrm{P} 95 \%$ and $\mathrm{P} 99 \%$ reached values of $9.79 \%$. This is a significant value when a comparison is made between one of these indexes with the limits of the standard. Thus, this fact justifies a detailed analysis about the behavior of the measured values that transgress each of these indexes.

\section{A. Study of the distribution in time of the levels of voltage imbalance}

The main objective of this item is to present an auxiliary methodology that makes possible the analysis of the distribution time of the samples with superior values $\mathrm{P} 90 \%$,
$\mathrm{P} 95 \%, \mathrm{P} 99 \%$ and the square mean. It is aimed, from the generated results, to understand how representative these indexes are, when used in representation of all measured values. Additionally, it will be left to the manufacturers, having the information made available in the analysis concluded here, while also considering the support limits of their equipment in relation to voltage imbalances, to determine if such equipment can support or not the levels presented, and moreover, if the differences determined by the analysis taking into account the values of $\mathrm{P} 90 \%, \mathrm{P} 95 \%$ and $\mathrm{P} 99 \%$ influence aspects such overheating, reduction of the duration of the equipment and malfunctioning loads. Thus, it is possible to have an idea of the degree of severity that the measured value has in reference to the support limits of the equipment.

Due to limitation of space, only for one index, in the case P95\%, will be illustrated all the graphical results. The other 3 groups of simulation will have their results expressed on a table.

\section{B. Analysis considering the $P 95 \%$ as a reference}

The calculated value of $\mathrm{P} 95 \%$ from the data in study was of $0.3206 \%$. Figure 2 presents the graph of $\mathrm{K} \geq 0.3206 \%$ versus total time of measurement in minutes.

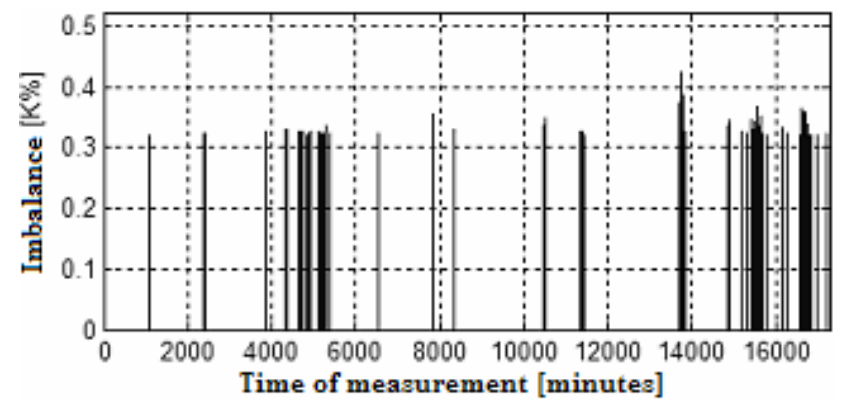

Fig. 2 Values with $\mathrm{K} \geq 0.3206 \%$ versus total time of measurement in minutes.

In figure 2, and with the aid of a computational routine, it is observed that, of all the period of measurement in analysis, approximately 17290 minutes, about 860 withhold $\mathrm{K} \geq 0.3206 \%$. In this monitoring load, we can observe values with $\mathrm{K} \geq 0.3206 \%$ including the weekends, probably showing some maneuver with those industrial loads.

Figure 3 shows the graph with the uninterrupted intervals of time with values of $\mathrm{K} \leq 0.3206 \%$.

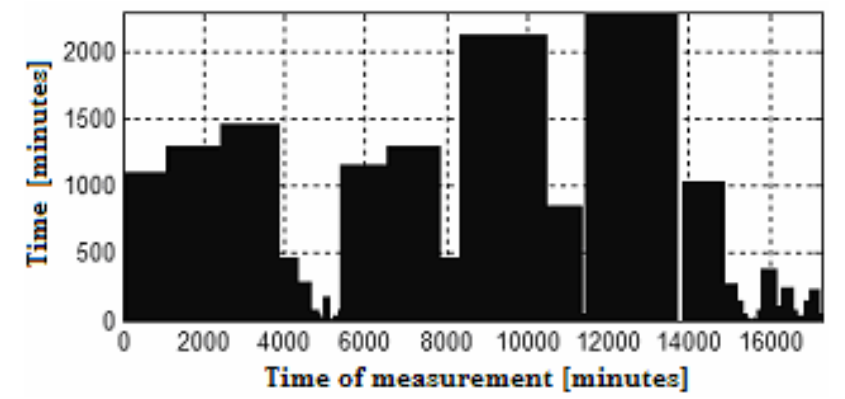


Fig. 3 Uninterrupted intervals of time with values of $\mathrm{K} \leq 0.3206 \%$ versus total time of measurement in minutes.

In figure 3 , it is highlighted that the maximum uninterrupted interval of time with $\mathrm{K} \leq 0.0 .3206 \%$ is approximately 2290 minutes, that is, 38.18 hours, of a total of 17290 in measurement.

Figure 4 shows the graph with the uninterrupted intervals of time with values of $\mathrm{K} \geq 0.3206 \%$.

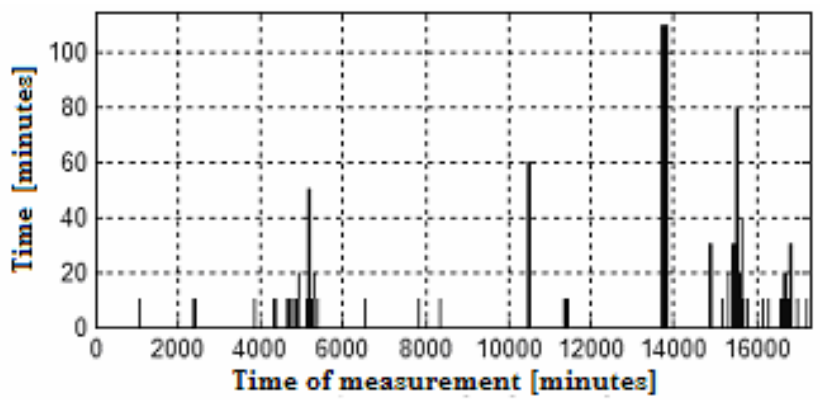

Fig. 4. Uninterrupted intervals of time with values of $K \geq 0.3206 \%$ versus total time of measurement in minutes.

In figure 4 , it is pointed out that the maximum uninterrupted interval of time with $\mathrm{K} \geq 0.3206 \%$ is of approximately 110 minutes, about 1.83 hours, of a total of 17290 minutes in measurement.

Figure 5 illustrates the graph with the probabilities of occurrence of the uninterrupted intervals of time with $\mathrm{K} \geq 0.3206 \%$.

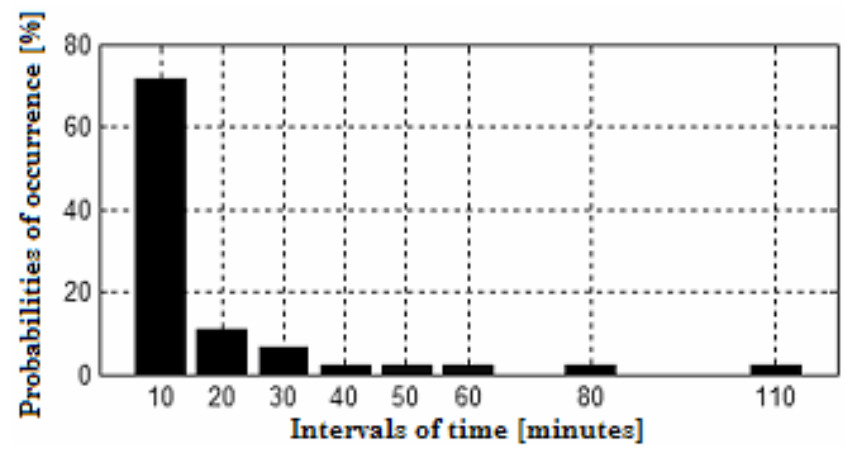

Fig. 5. Probabilities of occurrence of the uninterrupted intervals of time with $\mathrm{K} \geq 0.3206 \%$.

It is noticed on figure 5 that about $70 \%$ of the uninterrupted intervals of time with $\mathrm{K} \geq 0.3206 \%$ have up to 10 minutes of duration. Yet, it is emphasized the existence of uninterrupted intervals of time with $\mathrm{K} \geq 0.3206 \%$ with 80 and 100 minutes of duration.

Figure 6 presents the graph with the probabilities of occurrence of the uninterrupted intervals of time with $\mathrm{K} \leq 0.3206 \%$.

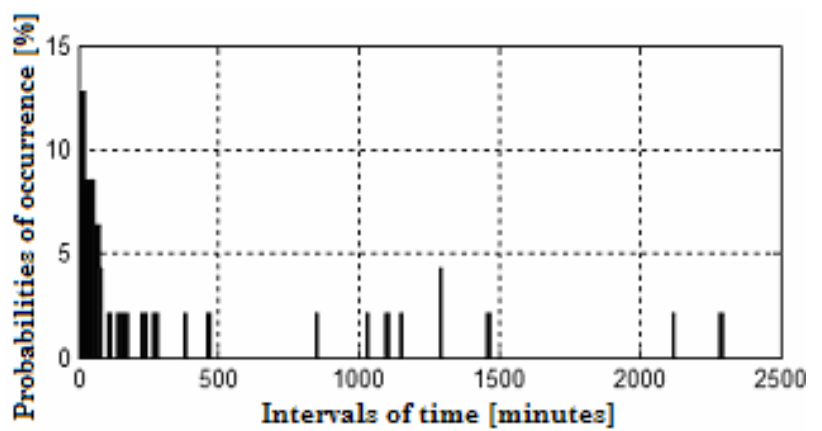

Fig. 6. Probabilities of occurrence of the uninterrupted intervals of time with $\mathrm{K} \leq 0.3206 \%$.

From figure 6 we can see that about $13 \%$ of the uninterrupted intervals of time with $\mathrm{K} \leq 0.3206 \%$ have up to 10 minutes of duration. Nevertheless, it is known the existence of some uninterrupted intervals of time with $\mathrm{K} \leq 0.3206 \%$ between 50 and 500 minutes and others of 2200 minutes of duration.

Therefore, this indicates that, for the 12 days in study, the majority of the intervals of time with values of $\mathrm{K} \geq 0.3206 \%$ are concentrated in intervals of short duration, with about 10 minutes, spaced between themselves, almost always, for periods between 10 and 500 minutes.

\section{Comparative analysis among indexes}

The values of $\mathrm{P} 90 \%, \mathrm{P} 95 \%, \mathrm{P} 99 \%$ and the square mean calculated from the data of the consumer in study are, respectively, $0.3123 \%, 0.3206 \%, 0.3462 \%$ and $0.2915 \%$.

The first three indexes present similar values among themselves, while the square mean is a little smaller.

Table III presents the results found when generating similar analyses to the one made in the item $A$, considering all the indexes in evaluation.

Figures 7, 8 and 9 present the graphics of $\mathrm{K} \geq 0.2915 \%$ (square means), $\mathrm{K} \geq 0.3123 \%$ (P90\%) and $\mathrm{K} \geq 0.3462 \%$ (P99\%), versus total time of measurement, in minutes.
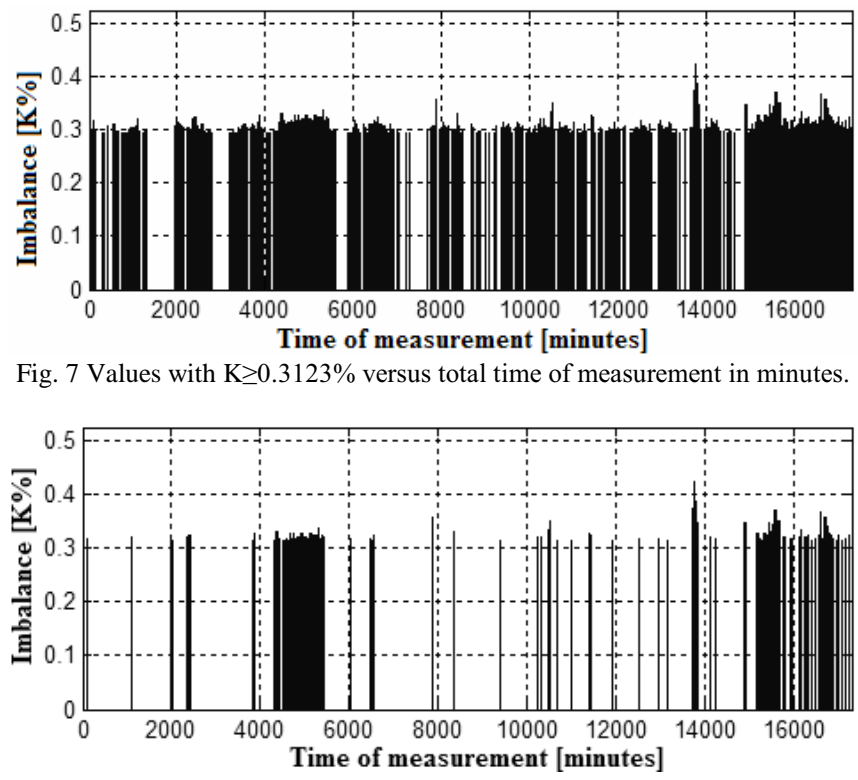

Fig. 8 Values with $\mathrm{K} \geq 0.3123 \%$ versus total time of measurement in minutes. 


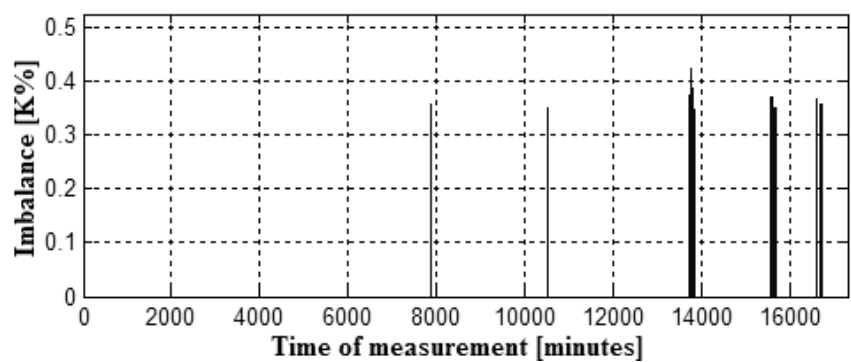

Fig. 9 Values with $\mathrm{K} \geq 0.3462 \%$ versus total time of measurement in minutes.

TABLE II

VOLTAGE IMBALANCE

\begin{tabular}{|c|c|c|c|c|}
\hline & $\begin{array}{c}\text { Square } \\
\text { mean } \\
(\mathbf{0 . 2 9 1 5 \% )}\end{array}$ & $\begin{array}{c}\mathbf{P 9 0 \%} \\
\mathbf{( 0 . 3 1 2 3} \%)\end{array}$ & $\begin{array}{c}\mathbf{P 9 5} \% \\
\mathbf{( 0 . 3 2 0 6 \% )}\end{array}$ & $\begin{array}{c}\mathbf{P 9 9 \%} \\
\mathbf{( 0 . 3 4 6 2 \% )}\end{array}$ \\
\hline $\begin{array}{c}\text { Total minutes } \\
\text { with K } \geq \text { index }\end{array}$ & 8210 & 1710 & 860 & 170 \\
\hline $\begin{array}{c}\text { Maximum } \\
\text { uninterrupted } \\
\text { interval of time } \\
\text { with values of } \\
\mathbf{K} \geq \text { index }\end{array}$ & 820 & 130 & 110 & 90 \\
\hline $\begin{array}{c}\text { Maximum } \\
\text { uninterrupted } \\
\text { interval of time } \\
\text { with values of } \\
\mathbf{K}<\text { index }\end{array}$ & 650 & 1430 & 2290 & 7850 \\
\hline
\end{tabular}

Considering the total time with $\mathrm{K} \geq$ index, it can be observed in table II and figures 2, 7, 8 and 9, a proportional growth, which is expected from its respective definitions, that is, the total period with $\mathrm{K} \geq \mathrm{P} 99 \%$ is approximately 05 times bigger than the one with $\mathrm{K} \geq \mathrm{P} 95 \%$, and successively. In the analysis of the maximum intervals with $\mathrm{K} \geq$ index and $\mathrm{K} \leq$ index, it is noticed variations between the values acquired for each study, indicating that the distribution time is different.

From the analysis with the square mean as reference, we have the biggest uninterrupted interval with $K \geq 0.2915 \%$, about 820 minutes (13.67 hours), and the maximum uninterrupted interval with $\mathrm{K} \leq 0.2915 \%$, approximately 650 minutes (10.83 hours).

The analyses of the occurrence probabilities show that the majority of the uninterrupted intervals of time with values of $\mathrm{K} \geq 0.2915 \%$, about $52 \%$, are concentrated in periods of short duration (10 minutes), spaced between themselves, almost always $(38 \%)$ for periods of 10 minutes. Morever, the existence of uninterrupted bands with $\mathrm{K} \geq 0.2915 \%$ with 450 and 820 minutes have been registered.

Using $\mathrm{P} 90 \%$ as reference, we find 130 uninterrupted minutes with $\mathrm{K} \geq 0.3123 \%$, about 2.17 hours, and 1430 uninterrupted minutes with $\mathrm{K} \leq 0.3123 \%$, approximately 23.83 hours.

From the analyses of the occurrence probabilities it is obtained that the majority of the uninterrupted intervals of time with values of $\mathrm{K} \geq 0.3123 \%$, about $65 \%$, are concentrated in periods of short duration (10 minutes), spaced between themselves, almost always (22\%) for periods of 10 minutes.
Uninterrupted bands with $\mathrm{K} \geq 0.3123 \%$ with 110 and 130 minutes have been detected.

From $\mathrm{P} 95 \%$ as reference, it was observed in item $A$ that 110 uninterrupted minutes ( 1.83 hours) hold $\mathrm{K} \geq 0.3206 \%$ and some 2290 consecutive minutes ( 38.17 hours) present $\mathrm{K} \leq 0.3206 \%$. About $70 \%$ of the uninterrupted intervals of time with $\mathrm{K} \geq 0.3206 \%$ have 10 minutes of duration, and $13 \%$ of the uninterrupted intervals of time with $\mathrm{K} \leq 0.3206 \%$ have up to 10 minutes of duration (Fig.5 and Fig.6). However, it is known the existence of some continuous intervals of time with $\mathrm{K} \leq 0.3206 \%$ between 50 and 500 minutes and another of 2200 minutes of duration.

Finally, when using P99\% as reference, it was registered 90 consecutive minutes with $\mathrm{K} \geq 0.3462 \%$, one hour and a half, and 7850 uninterrupted minutes with $\mathrm{K} \leq 0.3123 \%$, approximately 130.83 hours.

From the analyses of the occurrence probabilities it is obtained that the majority of the uninterrupted intervals of time with values of $\mathrm{K} \geq 0,3264 \%$, about $72 \%$, are concentrated in periods of short duration (10 minutes), spaced between themselves, almost always (12\%), for periods between 70 and 80 minutes, despite there have been detected bands of 90 minutes with $\mathrm{K} \geq 0,3462 \%$.

The highest uninterrupted interval of time with $\mathrm{K} \geq$ (square mean) is $84 \%$ greater than the corresponding period with $\mathrm{K} \geq(\mathrm{P} 90 \%)$. Furthermore, the largest uninterrupted interval with $\mathrm{K} \leq$ (square mean) is $54 \%$ less compared with the respective band with $\mathrm{K} \leq(\mathrm{P} 90 \%)$. Thus, considering the values with $\mathrm{K} \geq$ (square mean), it was observed that they are concentrated in significantly bigger uninterrupted intervals than the corresponding patterns with $\mathrm{K} \geq(\mathrm{P} 90 \%)$, as well as having shorter period of time between these intervals.

\section{Classification of the Values Determined in Analysis}

Figures 6 and 7 present the accumulated distribution of probability and the distribution of occurrences in consideration to the place in the study.

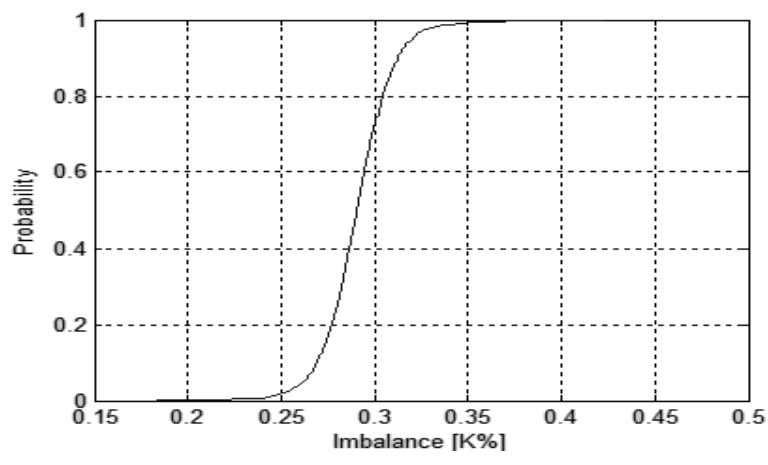

Fig. 7. Accumulated distribution of probability. 


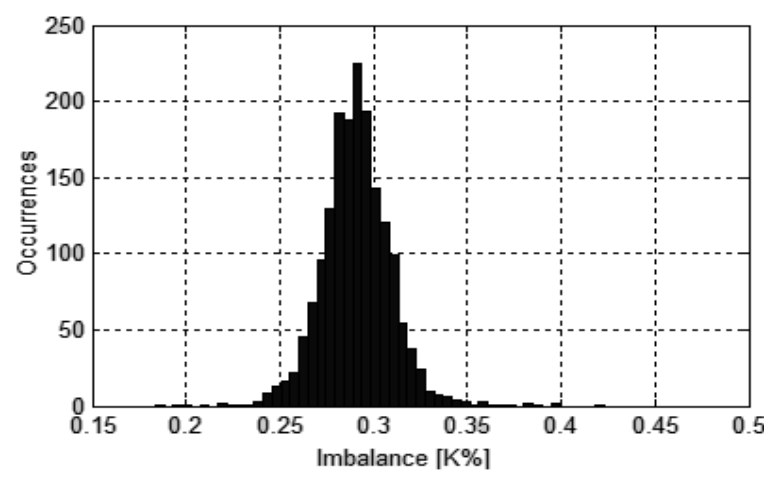

Fig. 8. Distribution of occurrences.

In figures 7 and 8 it has been verified that the great majority of the data is between $0.27 \%$ and $0.33 \%$. The maximum value registered is well below the $2 \%$ established as the limit in the standards. Additionally, it has been verified that, in the period of the measurements, there was not detected occurrences of superior values.

\section{CONCLUSION}

This article presented the results of a study that aims to contribute to the establishment of lines of direction to guide the measurement procedures in voltage imbalance and at contributing to making the most adjusted choice of the index to quantify the voltage imbalance for the Brazilian Resolution. The data measurements were obtained from an industrial consumer, which has been illustrated, over a period of 12 days.

Due to of the time-varying characteristic of the voltage imbalance in the monitored load, the square mean is not an appropriate representative index. It was verified because of the differences between the square mean value and the other indexes, both calculated from the same load in the same period. Therefore, if the square mean is used to classify the samples, divergent results can be determined, owing to the proposed methodology utilized.

From the distribution time analysis, it was emphasized that the highest uninterrupted interval of time with $\mathrm{K} \geq$ (square mean) is $84 \%$ greater than the corresponding period with $\mathrm{K} \geq(\mathrm{P} 90 \%)$. Furthermore, the largest uninterrupted interval with $\mathrm{K} \leq$ (square mean) is $54 \%$ less compared with the respective band with $\mathrm{K} \leq(\mathrm{P} 90 \%)$. Thus, considering the values with $\mathrm{K} \geq$ (square mean), it was observed that they are concentrated in significantly bigger uninterrupted intervals than the corresponding patterns with $\mathrm{K} \geq(\mathrm{P} 90 \%)$, as well as having shorter period of time between these intervals.

The biggest difference among $\mathrm{P} 90 \%, \mathrm{P} 95 \%$ and $\mathrm{P} 99 \%$ reached values of $9.79 \%$. This is a significant value when a comparison is made between one of these indexes with the limits of the standard.

From the comparison among the distribution times of the values with $\mathrm{K} \geq \mathrm{P} 90 \%, \mathrm{~K} \geq \mathrm{P} 95 \%$ and $\mathrm{K} \geq \mathrm{P} 99 \%$ it was observed that the smaller the probability of not being exceeded the bigger the uninterrupted interval having values of $\mathrm{K} \geq$ index. The biggest difference is concentrated in the total number of minutes with $\mathrm{K} \geq$ index, and the spacing between the uninterrupted intervals with $\mathrm{K} \geq$ index.

It will be left to the manufacturers, having the information made available in the analysis concluded here, while also considering the support limits of their equipment in relation to voltage imbalances, to determine if such equipment can support or not the levels presented, and moreover, if the differences determined by the analysis taking into account the values of $\mathrm{P} 90 \%, \mathrm{P} 95 \%$ and $\mathrm{P} 99 \%$ influence aspects such as overheating, reduction of lifespan of the equipment and malfunctioning loads. Thus, it is possible to have an idea of the degree of severity that the measured value has, in reference to the support limits of the equipment.

It is strongly recommended to do the same analysis with data from other locations to prove or not the behavior observed here.

Although the obtained results cannot immediately be generalized for other loads, the presented methodology can be of great utility for both companies and professionals interested in classifying and quantifying voltage imbalances.

\section{REFERENCES}

[1] S. Pinto, Marcos Garcia; F. Filho, Anésio de Leles; Oliveira, Marco A G.; "A Computational Tool to Analyze, Quantify and Classifying the Voltage Imbalance in Electrical Power Systems", VI SBQEE, Belém/PA, Brasil.

[2] R. C. Dugan, M. F. Mcgranaghan and H. W. Beauty, "Electrical Power System Quality", New York: McGraw-Hill, 1996.

[3] Oliveira, José Carlos. Harmônicos e Desequilíbrios, Junho/2000.

[4] David Oliveira, “Análise, Quantificação e Qualificação do Desequilíbrio de Tensão”, Brasília: UnB, 2001.

[5] Marco A. de Oliveira, Anésio de L. F. Filho and G. de H. Oliveira, "Voltage Unbalance Monitoring in CEB Systems", in 10th International Conference on Harmonics, Rio de Janeiro: EFEI, 2002.

[6] W. G. Almeida and F. D. Freitas, "Circuitos Polifásicos", Brasília: Fundação de Empreendimentos Científicos e Tecnológicos, 1995.

\section{BIOGRAPHIES}

Marco De Oliveira (M'91-SM'98) was born in Rio de Janeiro, Brazil, on December 20th, 1958. He has a degree (1982) in Electrical Engineering from UnB (the University of Brasília). He has a Master's Degree (1989) and a PhD (1994) from the University of Paris (France). From 1982 to 1988, he took part in Eletronorte's Operation Division where he was involved in studies of load flux, stability and electromagnetic transients. He joined the University of Brasília in 1994, where he became a professor for the Department of Electrical Engineering, a position he still holds. His line of research includes power electronics and power quality.

Anésio de Leles Ferreira Filho was Born in Patos de Minas, Brazil, on December 26th, 1971. He has a 1994 Electrical Engineering degree from the Federal University of Uberlândia (Brazil), where he also attained his MS in 1997. He joined the University of Brasília in the same year, where he still holds a position as a lecturer in the Electrical Engineering department. His research interests include power electronics and power quality.

Marcos Garcia da Silva Pinto was born in Brasília, Brazil, on January 17th, 1984. He is currently an Electrical Engineering graduation student in the University of Brasília, where he began his studies in 2002. He is currently vice-president of UnB's Electrical Engineering student body. His research interests include power quality, specially the voltage imbalance. 
Marcos Garcia da Silva Pinto - marcos.unb@gmail.com Relatório de Projeto Final de Graduação

Ago/2006 